NUREG/CR-6433

SAND96-2445

\title{
Containment Peformance of Prototypical Reactor Containments Subjected to Severe Accident Conditions
}

Manuscript Completed: November 1996

Date Published: December 1996

Prepared by

E. W. Klamerus, M. P. Bohn, SNL

D. A. Wesley, EQE

C. N. Krishnaswamy, S\&L

Sandia National Laboratories

Albuquerque, NM 87185

Subcontractors

EQE International

Irvine, CA 92715

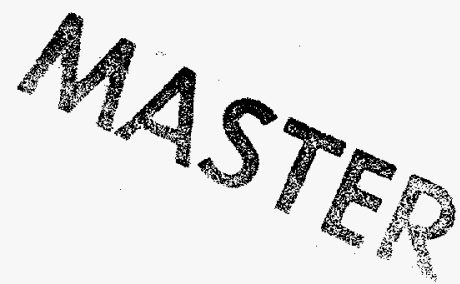

Sargent \& Lundy

Chicago, IL 60603

J. F. Costello, NRC Project Manager

Prepared for

Division of Engineering Technology

Office of Nuclear Regulatory Research

U.S. Nuclear Regulatory Commission

Washington, DC 20555-0001

NRC Job Code L2235 


\section{DISCLAIMER}

Portions of this document may be illegible in electronic image products. Images are produced from the best available original document. 


\section{DISCLAIMER}

This report was prepared as an account of work sponsored by an agency of the United States Government. Neither the United States Government nor any agency thereof, nor any of their employees, make any warranty, express or implied, or assumes any legal liability or responsibility for the accuracy, completeness, or usefulness of any information, apparatus, product, or process disclosed, or represents that its use would not infringe privately owned rights. Reference herein to any specific commercial product, process, or service by trade name, trademark, manufacturer, or otherwise does not necessarily constitute or imply its endorsement, recommendation, or favoring by the United States Government or any agency thereof. The views and opinions of authors expressed herein do not necessarily state or reflect those of the United States Government or any agency thereof. 


\begin{abstract}
In SECY-90-016, the NRC proposed a safety goal of a conditional containment failure probability (CCFP) of 0.1 and the alternative acceptance criteria allowed for steel containments, which specifies that the stresses should not exceed ASME Level $C$ allowables for severe accident pressures and temperatures. In this work, the need for an equivalent criterion for concrete containments was studied.
\end{abstract}

Abstract

Six surrogate containments were designed and analyzed in order to compare the margins between design pressure, pressure resulting in exceedance of Level $\mathrm{C}$ (or yield) stress limits, and ultimate pressure. For comparability, each containment has an identical internal volume and design pressure.
Results from the analysis showed margins to yield are comparable and display a similar margin for both steel and concrete containments. In addition, the margin to failure, although slightly higher in the steel containments, were also comparable.

Finally, a CCFP for code design was determined based on general membrane behavior and imposing an upper bound severe accident curve developed in the $\mathrm{DCH}$ studies. The resulting CCFP's were less then 0.02 (or $2 \%$ ) for all the surrogate containments studied, showing that these containment designs all achieved the NRC safety goal. 


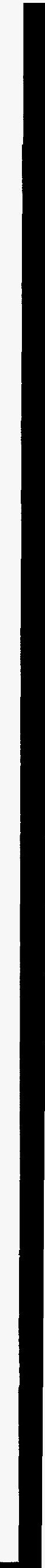




\section{Table of Contents}

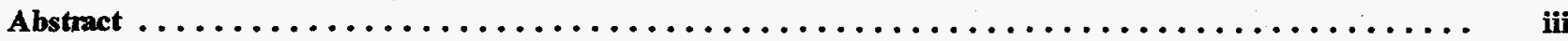

Erecutive Summary $\ldots \ldots \ldots \ldots \ldots \ldots \ldots \ldots \ldots \ldots \ldots \ldots \ldots \ldots \ldots \ldots \ldots \ldots \ldots \ldots \ldots$

Acknowledgements $\ldots \ldots \ldots \ldots \ldots \ldots \ldots \ldots \ldots \ldots \ldots \ldots \ldots \ldots \ldots \ldots \ldots \ldots \ldots \ldots \ldots \ldots \ldots \ldots$ xiii

1. INTRODUCTION $\ldots \ldots \ldots \ldots \ldots \ldots \ldots \ldots \ldots \ldots \ldots \ldots \ldots \ldots \ldots \ldots \ldots \ldots \ldots \ldots \ldots \ldots \ldots$

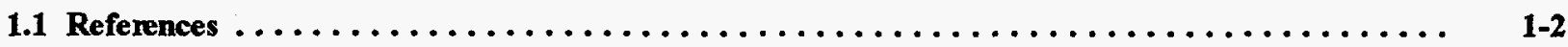

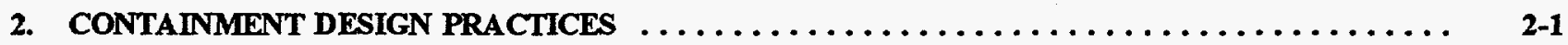

2.1 Design of Steel Containments $\ldots \ldots \ldots \ldots \ldots \ldots \ldots \ldots \ldots \ldots \ldots \ldots \ldots \ldots \ldots \ldots \ldots \ldots, \quad 2-1$

2.1.1 Requirements . . . . . . . . . . .

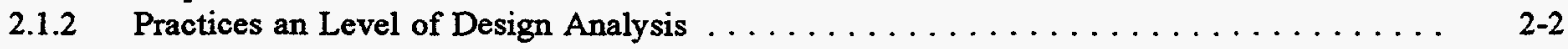

2.2 Design of Reinforced and Prestressed Containments $\ldots \ldots \ldots \ldots \ldots \ldots \ldots \ldots \ldots \ldots \ldots$

$2.2 .1 \quad$ Requirements . . . . . . . . .

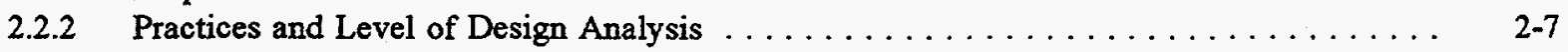

2.3 Comparison Between Steel and Concrete Containment Design $\ldots \ldots \ldots \ldots \ldots \ldots \ldots \ldots \ldots$ 2-9

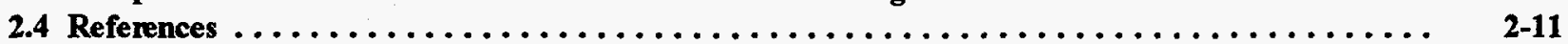

3. CONTAINMENT OVERPRESSURE FAILURE MODES $\ldots \ldots \ldots \ldots \ldots \ldots \ldots \ldots \ldots \ldots \ldots \ldots$

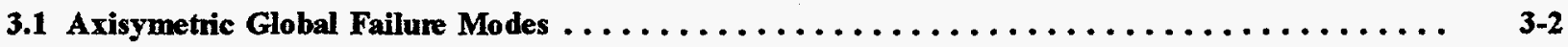

3.1.1 Concrete Containments . . . . . .

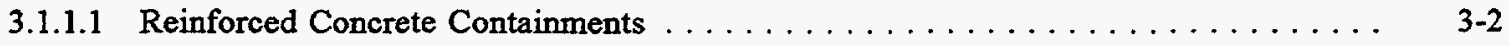

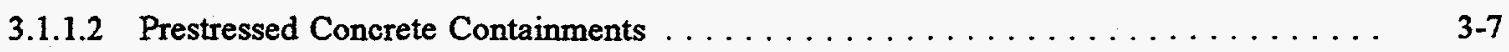

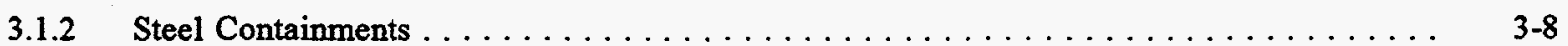

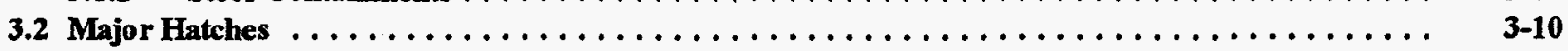

$3.2 .1 \quad$ Equipment Hatches . . . . . . . . . . . . .

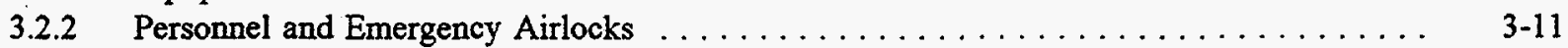

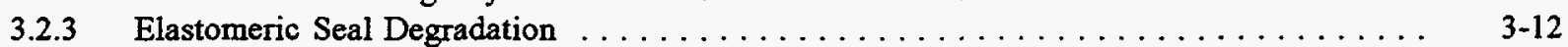

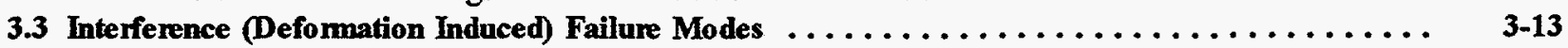

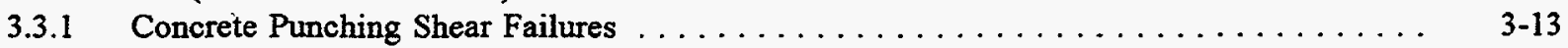

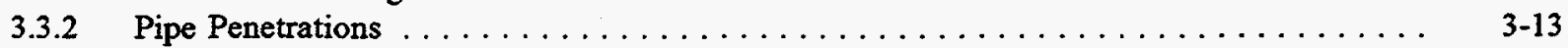

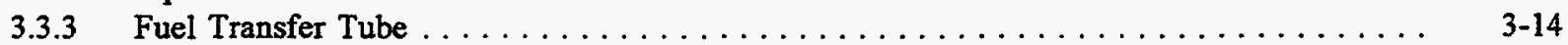

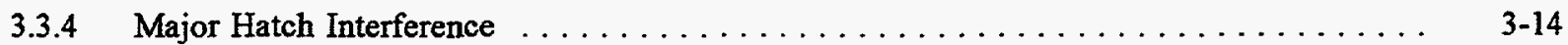

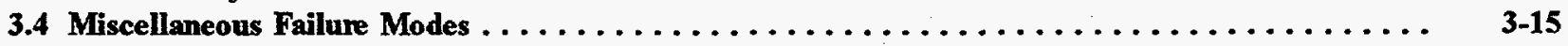

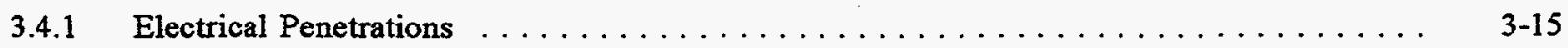

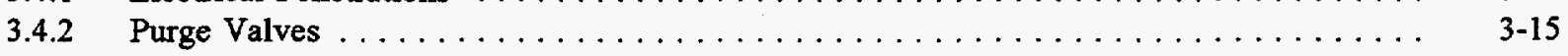

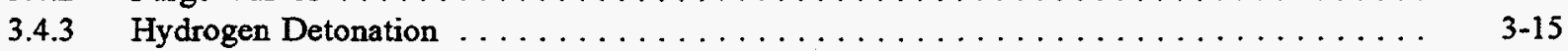

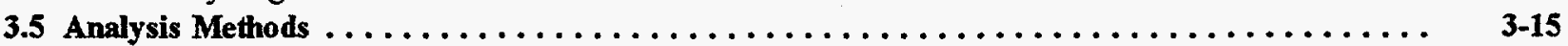

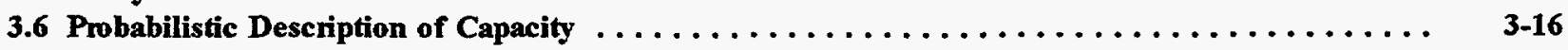

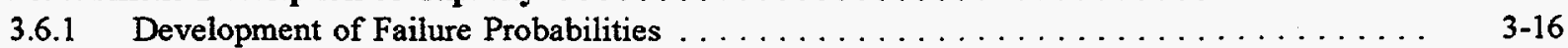

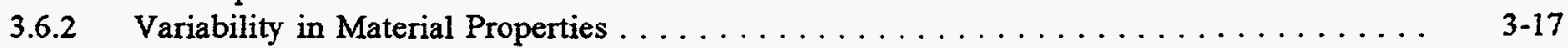

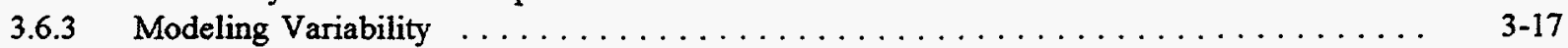

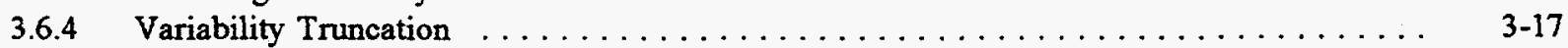

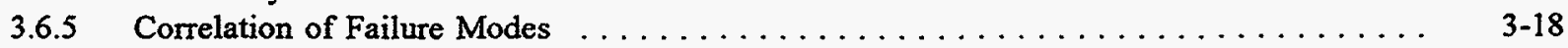

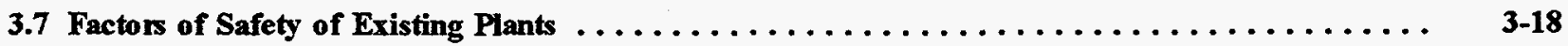

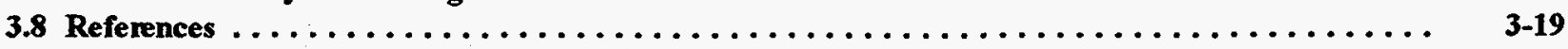


Table of Contents

4. SURROGATE CONTAINMENT DESIGNS $\ldots \ldots \ldots \ldots \ldots \ldots \ldots \ldots \ldots \ldots \ldots \ldots \ldots \ldots$

4.1 Surrogate Containment Design Parameters $\ldots \ldots \ldots \ldots \ldots \ldots \ldots \ldots \ldots \ldots$

4.2 Design Process . . . . . . . . . . . . . . . . . . . . . . . . . . . . . . . . . $4-1$

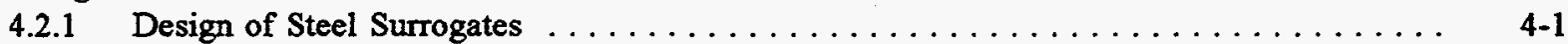

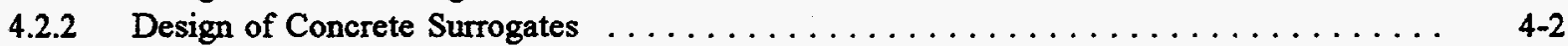

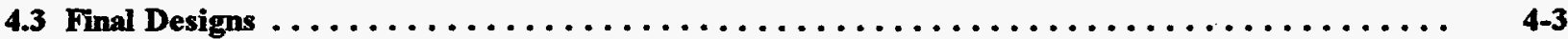

4.4 References . . . . . . . . . . . . . . . . . . . . . . . . . . . . . . . . . .

5. DETERMINISTIC PRESSURE CAPACITIES FOR SURROGATE CONTAINMENTS . . . . . . . 5 1

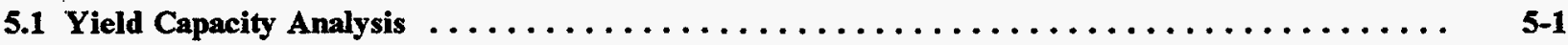

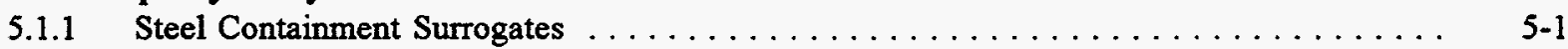

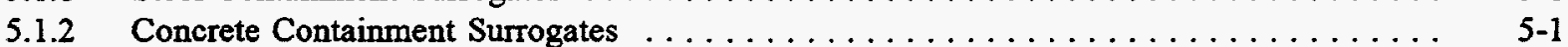

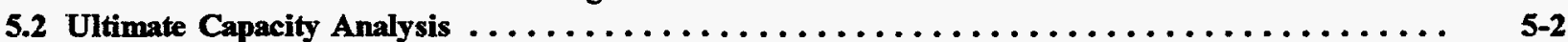

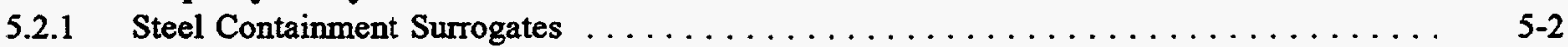

5.2 .2 Concrete Containment Surrogates $\ldots \ldots \ldots \ldots \ldots \ldots \ldots \ldots \ldots$

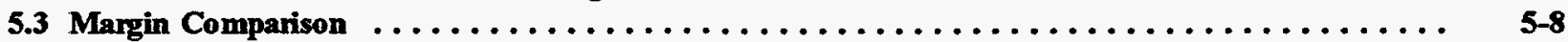

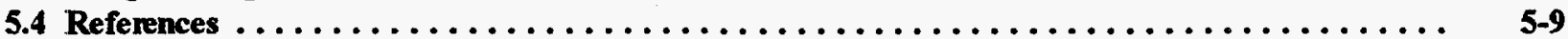

6. PROBABILISTIC FRAGILTIES FOR SURROGATE CONTAINMENTS . . . . . . . . . . . . 6-1

6.1 Monte Cardo Procedure $\ldots \ldots \ldots \ldots \ldots \ldots \ldots \ldots \ldots \ldots \ldots \ldots \ldots \ldots \ldots \ldots$

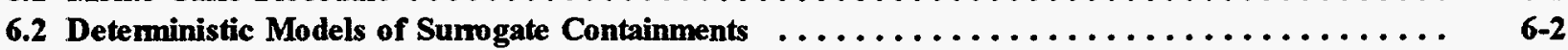

6.2 .1 Concrete Containments $\ldots \ldots \ldots \ldots \ldots \ldots \ldots \ldots \ldots \ldots \ldots \ldots \ldots \ldots$

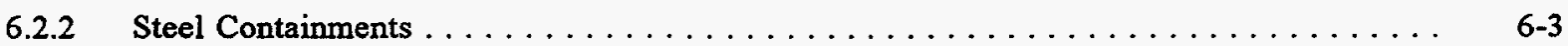

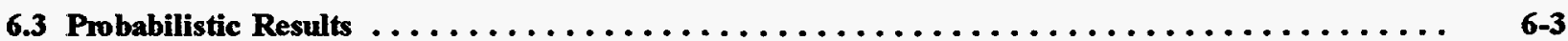

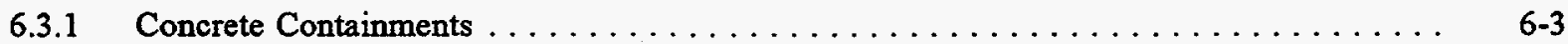

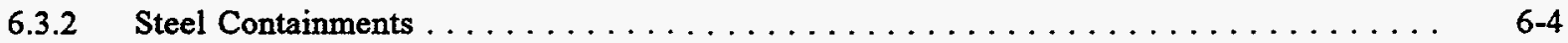

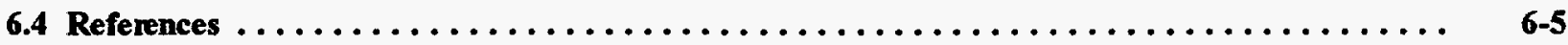

7. CONDITIONAL CONTAINMENT FALURE PROBABILITIES $\ldots \ldots \ldots \ldots \ldots$

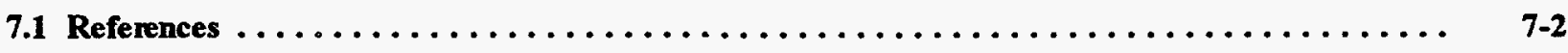

8. CONCLUSIONS $\ldots \ldots \ldots \ldots \ldots \ldots \ldots \ldots \ldots \ldots \ldots \ldots \ldots \ldots \ldots \ldots$ 


\section{List of Figures}

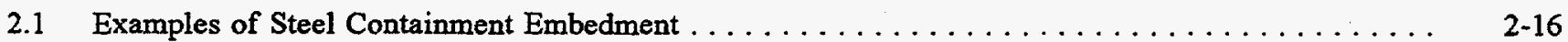

2.2 Variation of LOCA Design Pressure with Containment Volume $\ldots \ldots \ldots \ldots \ldots \ldots \ldots \ldots \ldots .2-16$

3.1 Typical (Prestressed) Wall Section and Possible Crack Spacing $\ldots \ldots \ldots \ldots \ldots \ldots \ldots \ldots \ldots . \ldots \ldots$

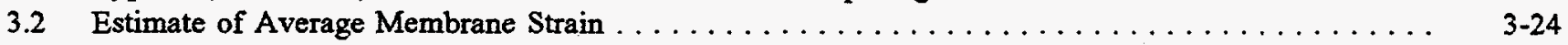

3.3 Example Dome Reinforcing Bar Layout, Rectangular Grid Apex, with Hoop and Radial Bars . . . . 3-25

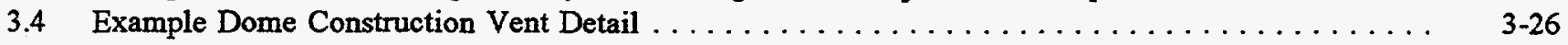

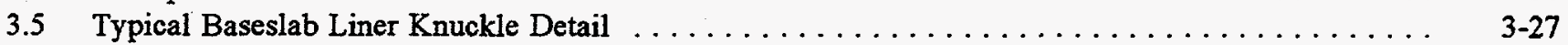

3.6 Possible Baseslab Restraints . . . . . . . . . . . . . . . . . . . . . . . . . . . $3-28$

3.7 Typical Liner Strain Concentration . . . . . . . . . . . . . . . . . . . . . . . . . . 3-29

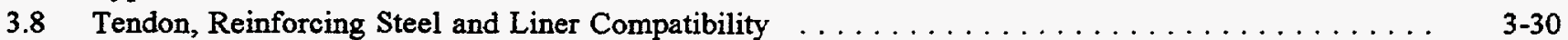

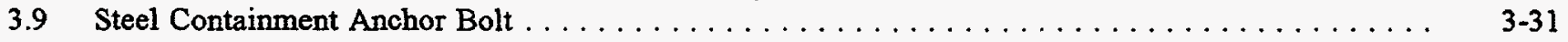

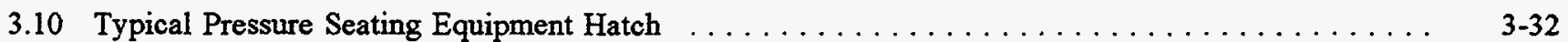

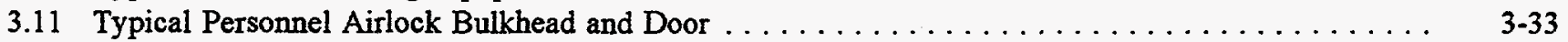

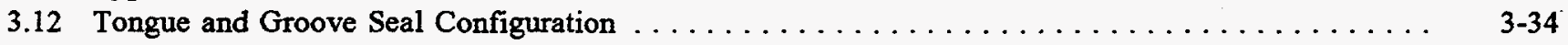

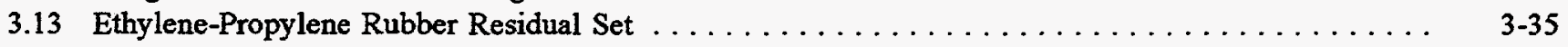

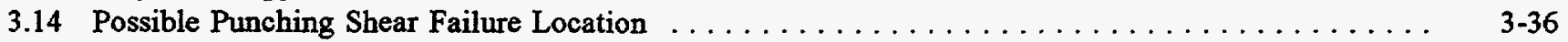

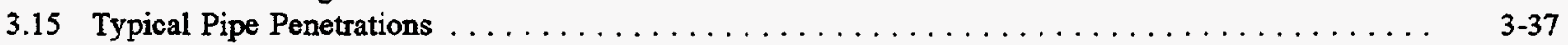

3.16 Personnel Airlock Interference Failure Modes $\ldots \ldots \ldots \ldots \ldots \ldots \ldots \ldots \ldots \ldots \ldots$ 3-38

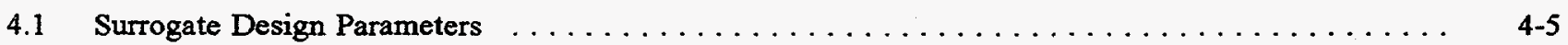

4.2 Comparison of Formulas to Finite Element Model Results at Base of Steel

Cylinder for Hoop Stresses (top) and Meridional Stresses (bottom) $\ldots \ldots \ldots \ldots \ldots \ldots \ldots$

4.3 Cylindrical Steel Containment Stresses (SA-516 Gr. 70)

Hoop Stresses (top) and Meridional Stresses (bottom) $\ldots \ldots \ldots \ldots \ldots \ldots \ldots \ldots \ldots \ldots \ldots \ldots \ldots$

4.4 Cylindrical Steel Containment Stresses (SA-537 Cl. 2)

Hoop Stresses (top) and Meridional Stresses (bottom) $\ldots \ldots \ldots \ldots \ldots \ldots \ldots \ldots \ldots \ldots$

4.5 Spherical Steel Containment Stresses (SA-516 Gr. 70)

Hoop Stresses (top) and Meridional Stresses (bottom) $\ldots \ldots \ldots \ldots \ldots \ldots \ldots \ldots \ldots \ldots$

4.6 Spherical Steel Containment Stresses (SA-537 Cl. 2)

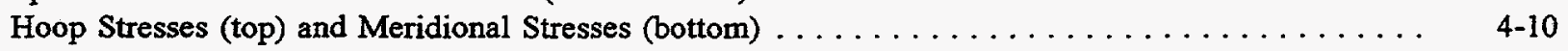

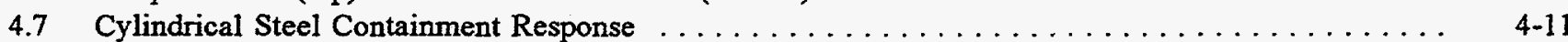

4.8 Overpressure Discontinuity Moments and Shears for Reinforced and

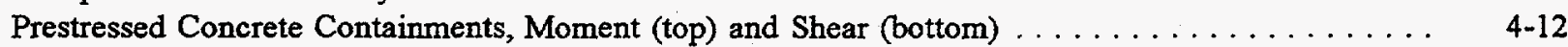

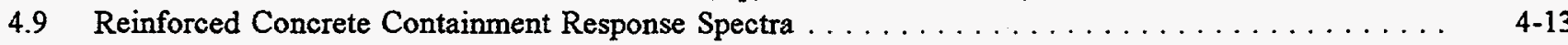

5.1 Typical Stress-Strain Behavior of Surrogate Steel Containment Materials . . . . . . . . $5-15$

5.2 Example of Temperature Effects on the Stress-Strain Behavior of Steel $\ldots \ldots \ldots \ldots \ldots \ldots \ldots .5-15$

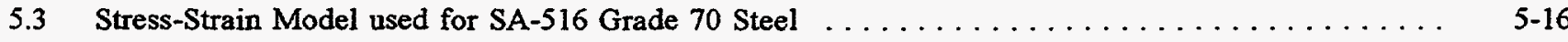

5.4 Stress-Strain Model used for SA-537 Class 2 Steel $\ldots \ldots \ldots \ldots \ldots \ldots \ldots \ldots \ldots \ldots \ldots \ldots . \ldots \ldots$

5.5 Reinforced Concrete Containment Pressure vs. Radial Displacement $\ldots \ldots \ldots \ldots \ldots \ldots \ldots \ldots .5-17$

5.6 Prestressed Concrete Containment Pressure vs. Radial Displacement $\ldots \ldots \ldots \ldots \ldots \ldots \ldots \ldots \ldots .5 .18$

5.7 Reinforced Concrete Containment Finite Element Model . . . . . . . . . . . . . . . . . . . $5-19$

5.8 Prestressed Concrete Containment Finite Element Model $\ldots \ldots \ldots \ldots \ldots \ldots \ldots \ldots \ldots \ldots \ldots . .5 .20$

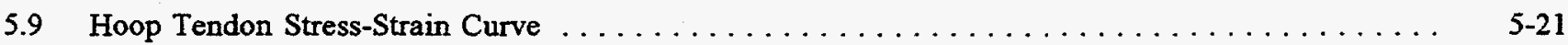

5.10 Maximum Hoop Reinforcement Strain vs. Internal Pressure

Reinforced Concrete Containment @ El. 92'0" ....................... 5-22

5.11 Maximum Hoop Tendon Strain vs. Internal Pressure

Prestressed Concrete Containment @ El. 87' 0" ....................... $5-23$ 
6.1 Flow Chart of Monte Carlo Analysis of Strains $\ldots \ldots \ldots \ldots \ldots \ldots$

6.2 Flow Chart of Containment Failure Probability Analysis . . . . . . . . . . . . . . . . . . . $6-7$

6.3 Predicted Hoop Strain and Actual Strain Response Versus Containment Pressure for the 1:6 Scale

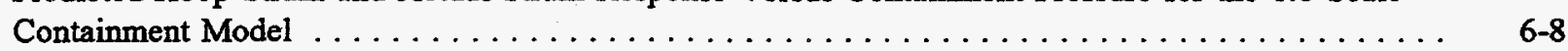

6.4 Reinforced Concrete Surrogate Free-Field Hoop Strain vs. Pressure . . . . . . . . . . . . . . . . $6-9$

6.5 Reinforced Concrete Surrogate Overpressure Fragility Curves . . . . . . . . . . . . . . . . . . 6-9

6.6 Prestressed Concrete Surrogate Free-Field Hoop Strain vs. Pressure . . . . . . . . . . . . . . . 6-10

6.7 Prestressed Concrete Surrogate Overpressure Fragility Curves . . . . . . . . . . . . . . . . 6-10

6.8 Cylindrical Steel Surrogate Free-Field Hoop Strain vs. Pressure SA-516 Grade $70 @ 400^{\circ} \mathrm{F} \ldots . . . .6$ 6-11

6.9 Cylindrical Steel Surrogate Overpressure Fragility Curves SA-516 Grade $70 @ 400^{\circ} \mathrm{F} . . . . . . . .6 .6-11$

6.10 Cylindrical Steel Surrogate Free-Field Hoop Strain vs. Pressure SA-537 Class $2 @ 400^{\circ} \mathrm{F}$........ 6-12

6.11 Cylindrical Steel Surrogate Overpressure Fragility Curves SA-537 Class $2 @ 400^{\circ} \mathrm{F} \ldots . . . . . .66-12$

7.1 DCH Pressure Curves and Bounding Curve using Maximum Median Pressure and Maximum Uncertainty 


\section{List of Tables}

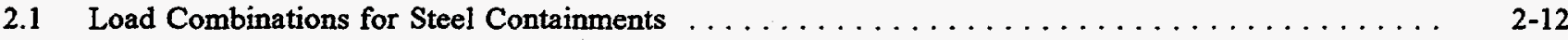

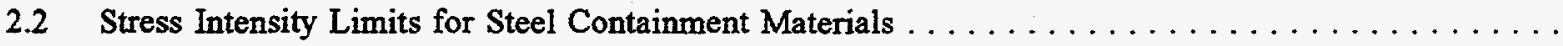

2.3 Typical Stress Values for Commonly Used Steels . . . . . . . . . . . . . . . . . . .

2.4 Load Combinations for Concrete Containments $\ldots \ldots \ldots \ldots \ldots \ldots \ldots \ldots$

2.5 Stress Intensity Limits for Reinforced Concrete Containment Materials . . . . . . . . . . . . . .

2.6 Margins Between Design Pressure and Material Yield Pressure for Steel and Concrete Containments

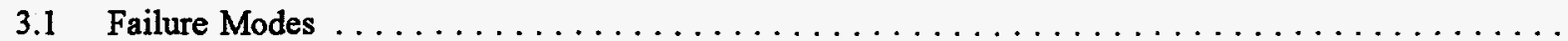

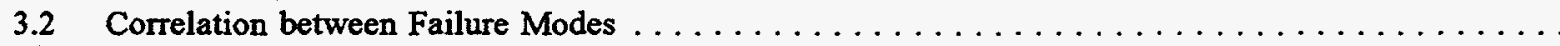

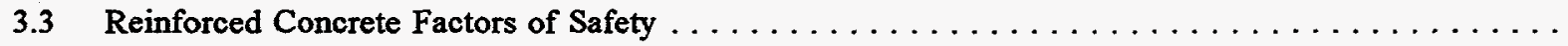

4.1 Minimum Required Thickness For Surrogate Steel Containments . . . . . . . . . . . . . . .

4.2 Thickness Used in Surrogate Steel Containment Designs . . . . . . . . . . . . . . . . . . . . 4.4

5.1 Minimum Review Level Pressures for Surrogate Steel Containments . . . . . . . . . . . . . . . . 5 -11

5.2 Minimum Review Level Pressures for Surrogate Concrete Containments . . . . . . . . . . . . . $5-11$

5.3 Comparison of Typical Steel Material Properties to Code Specified Minimums . . . . . . . . . .

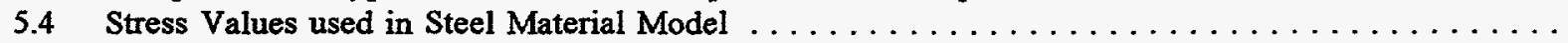

5.5 Material Behavior when Hoop Strain equals $2 \%\left(\varepsilon_{\theta}=0.02\right) \ldots \ldots \ldots \ldots$

5.6 Ultimate Pressures for Steel Surrogate Containments $\ldots \ldots \ldots \ldots \ldots \ldots$

5.7 Surrogate Steel Containment Pressures and Margins $\ldots \ldots \ldots \ldots \ldots \ldots \ldots$

Surrogate Concrete Containment Pressures and Margins

7.1 Conditional Containment Failure Probability for Four Surrogate Containments using a Bounding DCH Severe Accident Load Case

7.2 Median Severe Accident Pressures Yielding a CCFP of $10 \%$ for Four Surrogate Containments ... . 


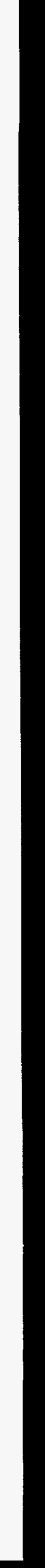




\section{Executive Summary}

SECY-90-016 was the first major policy statement from the NRC to define the manner in which Advanced Light Water Reactor (ALWR) designs should address the issue of severe accident challenges to containment integrity. A guideline recommended for assuring the reliability of the containment structure is stated in the SECY-90-016; "...the probability of failure of the mitigation systems, from the onset of core damage to the loss of containment integrity resulting in an uncontrollable leakage substantially greater than the design basis leakage, should not exceed approximately 0.1." In order to compute a conditional containment failure probability (CCFP) for any containment, both the type and severity of the loads being placed in the structure (along with their uncertainties) and the failure capacity of the actual containment (along with its uncertainties) must be estimated.

Alternatively, the staff recommended a deterministic criterion for steel containments when subjected to a severe accident condition as stated in the safety goals in SECY-90-016; "The containment should maintain its role as a reliable leak tight barrier by ensuring that containment stresses do not exceed ASME Service Level C limits ...." The current ASME Service Level C limits apply only to steel containments and not concrete containments; therefore, it would be useful to develop equivalent criteria for both reinforced and prestressed concrete containments. The goal of the Containment Performance Under Severe Accident Conditions program, and this report, is to evaluate deterministic acceptance criteria applicable to reinforced and prestressed concrete containment designs. These criteria should be consistent with the alternative deterministic criteria proposed for steel containments when subjected to severe accidents.

In order to address these issues on containment performance, a panel of experts (consisting of four individuals) experienced in the area of Nuclear Reactor Containment design and analysis was enlisted to assist Sandia, and the NRC, in scoping out the path of this program and review the results. In order to make some comparisons between the ASME steel and concrete design requirements and inherent margins, the panel recommended examining a set of surrogate containments which would encompass the primary types of containment shapes and construction materials under consideration for 'advanced plant' designs.

The surrogate containments chosen for this study include two concrete, one deformed bar and one prestressed (both cylindrical with hemispherical dome and flat baseslab with identical inside dimensions). In addition, four steel containments were designed. Two of these steel surrogates were cylindrical with hemispherical dome and torispherical embedded base with inside dimensions identical to the concrete containments, one using SA-537 Cl. 2 steel and the other using SA-516 Gr. 70 steel. The other two steel containments are spherical with internal volumes identical to the cylindrical containments, again using the same two materials as the steel cylinder. For direct comparison, each containment had an identical internal volume and design pressure. These containments were sized according to all (current) applicable design code requirements for nuclear reactor containment structures.

After completing the surrogate containments designs, each was deterministically analyzed - both for pressure to first yield and then pressure to failure. In addition, best estimate probabilistic overpressure failure distributions (fragilities) were developed for each design. Based on these analyses, a number of insights and conclusions with regard to the original questions driving the program were reached.

The general membrane stress behavior of the surrogates was the most important because the single major cost of a containment structure is driven by the general thickness and/or the amount of reinforcing. These surrogate containments did not include any penetrations (equipment hatch, airlock, steam line, electrical, etc.) or other local discontinuities (welds, anchors, cranes, etc.). The only discontinuities included in these surrogates are thickness changes at the wall-basemat junction and the springline. Localized discontinuities were also not included in these surrogate analyses because of the limited time and funding available for the program. It was felt that many of the localized failure modes that had been observed in the analysis of existing containments could be avoided by considering them in the design phase. Therefore, the failure analysis of these surrogates were governed by the shell behavior with a strain concentration factor applied to account for local discontinuities.

As to insights gained, it was noted, first and foremost, that the current ASME design practices and requirements for concrete containments are based on yield criteria. Similarly, although the design of steel containments are usually governed by some fraction of 
the ultimate allowable stress $\left[\mathrm{S}_{\mathrm{mc}} \approx 1.1\left(\mathrm{~S}_{\mathrm{u}} / 4\right)\right]$, the ASME Level $C$ allowables are, in fact, based on (code specified) yield. Thus it was found that there is a commonality between the basic concrete design requirements in place today and the alternative Safety Goal criteria based on the Level $\mathrm{C}$ allowables for steel containments. In fact, the margin to yield computed for the surrogate containments is approximately 1.7 times the design pressure for both concrete and steel containments. Therefore, it was found that concrete containments which satisfy all ASME Code design requirements will posses a similar level of margin to yield as that provided by the alternative Level $\mathrm{C}$ allowable criteria currently in place for steel containments.

The margin to failure was also examined both deterministically and probabilistically. For the concrete surrogates it was found that the margin to failure was about 2.9 times the design pressure. Similarly, for the cylindrical SA-516 Grade 70 steel containment, the margin to failure (for accident temperatures between $400^{\circ} \mathrm{F}$ and $600^{\circ} \mathrm{F}$ ) was about 3.0 to 3.1. Thus, again, it is seen that there is a high degree of consistency between the deterministic margins. When a cylindrical containment surrogate was designed with SA-537 Class 2 steel (which has significantly higher strength than the SA-516 Grade 70 steel) a somewhat higher margin to failure results. Note that the definition of failure was based on a global membrane hoop strain of $2 \%$ for the reinforced concrete containments and the steel containments, and a $1 \%$ hoop strain for the prestressed concrete containments. These failure definitions were based on model test failure strains, the presence of typical strain concentrations, and reflect the consensus of the peer review panel

Although a strain failure criteria of $2 \%$ membrane hoop strain was specified (for steel and reinforced concrete containments), in reality, these types of containments might fail in general membrane (assuming no strain concentrations) at about $8 \%$. This would imply that a strain concentration factor of about 4 is appropriate for most localized areas in a containment where strain concentrations might occur. However, in some plant specific cases, it is possible to have higher strain concentration factors which could lower the global membrane failure strain and these would have to be addressed. on a plant specific basis. On the other hand, the ratio between design pressure and median failure pressure determined for most of the surrogates (2.9 to 3.1 ) is comparable to the average median ratio for controlling failure modes computed for several IPE containment fragilities (2.7 to 3.4). In this study of IPE containment fragilities, all plausible failure modes were considered as well as any strain concentration factors which might exist for each specific containment examined.

Finally, the question of the conditional containment failure probability (CCFP) associated with the surrogate containment designs was addressed. In order to do this, a set of severe accident pressure loading distributions had to be identified and these were taken from an ongoing NRC study on direct containment heating (DCH). When these pressure distributions were convolved with the probabilistic overpressure failure distributions, it was found that the CCFP values were at least a factor of 5 under the stated NRC safety goal of 0.1 . This shows that, for the global failure mechanisms assumed and strain concentration factors implicit in the ultimate strain criteria used, containments designed according to current ASME rules for concrete containments and for steel containments would have CCFP values significantly less than the NRC's safety goal. Alternatively, it was found that, for pressure load distributions having a logarithmic standard deviation variation in the 0.1 to 0.3 range (which probably is typical for most severe accident scenarios) the median pressure distribution required to cause a CCFP value of 0.1 is at least twice the design pressure. That is, any pressure distribution (with the stated uncertainty range) having a median value less than twice the design pressure would be expected to have a CCFP value less than 0.1 and hence meet the NRC safety goal. Median pressures to failure (CCFP $=0.50$ ) were about a factor of 3 times the design pressure for containments designed according to the current requirements.

Thus it can be seen that, for the global failure modes and strain concentration factors considered in this study, the current design criteria for concrete containments are consistent with the alternative safety goal criteria for steel containments and both provide probabilistic containment failure probabilities less than 0.1 by a significant margin. Thus it is concluded that no additional criteria need be developed for concrete containments designed according to the current ASME requirements. 


\section{Acknowledgements}

The authors would like to thank our program manager, Dr. James F. Costello, U. S. Nuclear Regulatory

Commission for his continuing support of this work and for providing valuable input necessary to meet the goals of this program. We would also like to thank the four Containment Experts on the Peer Review Panel for this program: Mr. Thomas J. Ahl, Mr. Brian A. Erler, Dr. John D. Stevenson, and Dr. Donald A. Wesley.

Their insights and experience provided helpful guidance during the course of the project. They also provided much valuable information incorporated into this report. 


\section{INTRODUCTION}

The purpose of the containment structure in a nuclear power plant is to prevent the release of radioactivity which may be present as the result of an accident. Containment structures may be constructed from either steel or concrete (reinforced or prestressed). These structures are currently designed and tested in accordance with codes such as the ASME Boiler and Pressure Vessel Code and criteria such as U.S. Nuclear Regulatory Commission (NRC) Standard Review Plans (SRP) and Regulatory Guides. These design criteria assure a high reliability of these structures to withstand Design Basis Accident (DBA) conditions. In addition to DBA internal pressure and temperature, these structures are currently designed to withstand concurrent earthquake, jet impact, and other extreme loads.

Since the Three Mile Island incident, the NRC and Industry has devoted an increased effort to investigating the performance of nuclear power plant containment structures during hypothetical severe accidents. These studies have examined both the plausible loading scenarios caused by a severe accident and the capacity of the containment structure to withstand these various types of loads. There are basically two categories into which these scenarios can be divided, energetic or rapid energy releases (high-pressure core melt injection) and more slowly evolving releases (decay heat and noncondensible gas generation).

SECY-90-016 was the first major policy statement from the NRC to define how Advanced Light Water Reactor (ALWR) designs should address the issue of severe accident challenges to containment integrity. A guideline recommended for assuring the reliability of the containment structure is stated in the SECY-90-016 [1-1]:

In view of the low probability of accidents that would challenge the integrity of the containment, the staff concludes that the probability of failure of the mitigation systems (those systems which can reduce the consequences of a core damage accident), from the onset of core damage to the loss of containment integrity resulting in an uncontrollable leakage substantially greater than the design basis leakage, should not exceed approximately 0.1 . However, the staff intends to ensure that the containment can deal with all credible challenges and does not intend to apply this conditional containment failure probability (CCFP) guideline in a manner that could be interpreted to potentially detract from overall safety.

In order to compute a CCFP for any containment, both the type and severity of the loads being placed in the structure (along with their uncertainties) and the failure capacity of the actual containment (along with its uncertainties) must be determined. Alternatively, the staff recommended a deterministic criteria for steel containments when subjected to a severe accident condition as stated in the safety goals in SECY-90-016 [1-1]:

The containment should maintain its role as a reliable leak tight barrier by ensuring that containment stresses do not exceed ASME Service Level C limits for a minimum period of 24 hours following the onset of core damage and that following this 24 hour period the containment should continue to provide a barrier against the uncontrolled release of fission products.

The current ASME Service Level C limits apply only to steel containments and not concrete containments [1-2]; therefore, it would be useful to develop equivalent criteria for both reinforced and prestressed concrete containments. The goal of the Containment Performance Under Severe Accident Conditions program, and this report, is to develop deterministic acceptance criteria applicable to reinforced and prestressed concrete containment designs. These criteria should be consistent with the alternative deterministic criteria proposed for steel containments when subjected to severe accidents.

This report addresses current containment design practices and compares the two different material types (steel and concrete). Next, the various failure modes evaluated and computed in previous containment designs will be presented. A study to compare margin in steel and concrete containments was then performed by designing and analyzing a set of surrogate containments. The containments chosen encompass the primary types of containment shapes and construction materials. For compatibility, each containment has an identical internal volume and design pressure and temperature. These containments are designed according to all applicable code requirements for nuclear reactor containment structures. For each of the 
1. Introduction

surrogate containments designed, a review level pressure $\left(P_{R I}\right)$ at which the containment material reaches first yield is computed and then a deterministic ultimate pressure capacity $\left(P_{v}\right)$ is determined. From these pressures, various margins can be computed and deterministic criterion for concrete containments proposed. Finally, a conditional containment failure probability (CCFP) for each of the surrogate containment designs (for a typical set of severe accident conditions) will be computed. These computed CCFP values will be compared to the NRC safety goal of a CCFP $<10 \%$ and potential alternative criteria for concrete containments studied.

\subsection{References}

1-1. Taylor, J. M. "Evolutionary Light Water Reactor (LWR) Certification Issues and their Relationship to Current Regulatory Requirements," USNRC Policy Issue Letter to The Commissioners, SECY-90-016, January 12, 11990.

1-2. The American Society of Mechanical Engineers, 1995 ASME Boiler and Pressure Vessel Code, 1995. 


\section{CONTAINMENT DESIGN PRACTICES}

In order to develop an understanding of the performance of containment structures subjected to severe accident conditions, one must first understand how steel containments are designed and how this differs from the way reinforced or prestressed concrete containments are designed. One must also determine the levels of margin that are built into the design. This margin can be either specified in the design requirements or inherent in typical design practices. This chapter will summarize the current status of nuclear reactor containment design requirements (both steel and concrete) and typical design practices and level of analysis which are performed by the designer (typically an Architectural/Engineering firm).

\subsection{Design of Steel Containments}

\subsubsection{Requirements}

The acceptance criteria for the design of steel containments are based on meeting the relevant requirements proposed in $10 \mathrm{CFR} 50.55 \mathrm{a}$ and General Design Criteria (GDC) $1,2,4,16$, and 50. These acceptance criteria are summarized in the U.S. Nuclear Regulatory Commission's (NRC's) Standard Review Plan (SRP), NUREG-0800. Section 3.8.2 (Steel Containment) of the SRP summarizes the design requirements for nuclear power plant steel containments built in the U. S. These Standard Review Plans are primarily for the guidance of the Office of Nuclear Reactor Regulation staff responsible for the review of applications to construct and operate nuclear power plants. Regulatory guides and industry standards which provide information, recommendations, guidance, and describe a basis acceptable to the staff that may be used to implement these requirements are:

Code: ASME Boiler and Pressure Vessel Code, Section III, Division 1, Subsection NE, "Class MC Components"

\section{Regulatory}

Guide 1.57: "Design Limits and Loading Combinations for Metal Primary Reactor Containment System Components"

In general, all steel containment vessels built in the United States are designed, fabricated, erected, and tested in accordance with the rules of Section III of the ASME Code, Subsection NE. This code and other acceptance criteria have undergone an evolution which parallels the advances in the capabilities of numerical stress analysis techniques. These practices started with relatively basic hand calculations using general primary membrane theory and currently use sophisticated finite element numerical solvers.

Steel containments were first recognized as a Code regulated component by the ASME in the 1963 version of the Nuclear Vessel Code [Ref. 2-1]. The steel containment was identified as a Class $B$ vessel. Reactor pressure vessels were classified as Class $A$ vessels and Class $\mathrm{C}$ was reserved for other vessels which made up or supported the nuclear steam supply system. This Code required the design pressure to be only $90 \%$ of the maximum internal containment pressure. In 1971 the steel containment was re-classified as a Class MC (metal containment) component and was covered by the rules of Subsection NE of the Code. Allowable stress intensities $S_{m}$ (Tresca Failure Theory) were limited to the code allowable stresses $($ Limit $=1 / 4$ minimum ultimate strength or $5 / 8$ minimum yield, whichever is smaller).

In the Summer 1972 Addendum, a complete rewrite of Subsection NE of the ASME Code appeared. This rewrite made some significant changes to the 1971 edition. These included increasing the internal design pressure from $90 \%$ to $100 \%$ of the maximum containment internal pressure. The code allowable stress was increased by $10 \%$ over that previously used. And, the containment system was specifically limited to the containment vessel and the penetrations and appurtenances attached to it.

The latest version of Subsection NE of the ASME code (1995) is organized into eight major articles which address the following:

Article NE-1000 Introduction

Article NE-2000 Material

Article NE-3000 Design

Article NE-4000 Fabrication and Installation

Article NE-5000 Examination

Article NE-6000 Testing

Article NE-7000 Overpressure Protection

Article NE-8000 Nameplates, Stamping, and Reports

ASME, Subsection NE, references Subsection NCA, which provides the general requirements for code 
compliance. Article NCA-3000 describes the Responsibilities and Duties of the various organizations involved in the completion of a nuclear power plant. Paragraph NCA-3251 requires that the owner provide a Certified Design Specification which includes a description of the containment vessel physical boundaries. The design input requirements are described in NCA-3252. The design effort should start with a review of the specified material parameters as described in Article NE-2000, including tensile, yield, and impact energy capability [Ref. 2-2]. The material mechanical properties are to be achieved at the Lowest Service Metal Temperature (LSMT) as specified in the Certified Design Specification. Impact energy levels or exemption from performing impact tests are provided in NE-2000. The basic allowable stress levels for all stress categories are based upon the tensile strength or yield strength.

Having established the appropriate materials properties, the vessell geometry, the code boundaries, and loading conditions from the Certified Design Specification, the design effort is organized into the various specified loadings, i.e., dead load, live load, internal pressure, wind, earthquake, thermal, etc. and the applicable load combinations [Ref. 2-3]. Table 2.1 shows the loading combinations required in the design of steel containments as specified in the SRP Section 3.8.2 [Ref. 2-4]. This table separates the loads and loading combinations keyed into the ASME Service Levels, i.e., Testing, Design, and Service Levels A, B, C, and D as are described in NE-3113 [Ref. 2-5]. Normally the controlling load is the design basis accident Loss of Coolant Accident (LOCA) internal Pressure $\left(P_{2}\right)$ and Temperature $\left(T_{2}\right)$ (which corresponds to the load case number 5 in Table 2.1).

After the stresses due to these loads have been calculated using approved methods and collected into the applicable ASME Service Levels, they are compared to the allowable stresses defined as applicable to each service level. These acceptance criteria are presented in NE-3221, Table NE-3221-1 and in Figures NE-3221-1 through NE-3221-4. The allowable stress intensity limits in Table NE-3221 are shown in Table 2.2. Note that the allowable stresses presented in Table 2.2 are different for each service level. Also as shown in this Table, for Service Levels C and D load applications where the structure is not integral and continuous, the next lower Service Levels allowables (B and $C$ respectively) must be satisfied. The term "not integral and continuous" refers to sections in which two metal surfaces are not continuously connected (ie. bolted, partial welds, etc.). Also note that the type of stress determines the allowable level within each Service Level, that is, the allowables for each of the stress types (general primary membrane stress, local primary membrane stress, primary bending stress, secondary surface stress and peak stresses) are different. Table 2.3 shows minimum allowable stresses for steel typically used in containment shells and is taken from ASME Section II, Part D, Subpart 1, Table 1A.

Table NE-3217-1 in the ASME Code describes the classification of stress for many of the geometrical configurations which the designer might expect to see in a containment vessel. For cylindrical or spherical shells all stresses are considered to be primary membrane $\left(P_{m}\right)$, primary local $\left(P_{\mathcal{L}}\right)$, or secondary $(Q)$. However, if the bending moment at the edge of a junction with a head is required to maintain the bending stress in the middle to within acceptable limits, the edge bending is classified as primary bending $\left(P_{b}\right)$, otherwise it is classified as secondary $(Q)$.

The allowable stress criteria used in ASME Section III is based on the shear theory of failure, (sometimes called the Tresca theory). This is defined as the maximum absolute difference between any two of the three principal stresses. In a biaxial stress state, in which two stresses are tensile and the third is essentially zero, the stress intensity is equal to the greater of the two tensile stresses. In a tensile/compressive biaxial state, the stress intensity is equal to the sum of the tensile plus compressive values. This biaxial tensile/compressive stress is often present at discontinuities and in ellipsoidal and torispherical heads. A typical ASME ellipsoidal or torispherical head will be controlled by the general primary membrane stress intensity reaching its allowable in the knuckle region of the head. It is very unlikely that the local primary membrane stress will control the design.

\subsubsection{Practices and Level of Design Analysis}

Design practices for steel containments have undergone an evolution, starting with relatively basic hand calculations using general primary membrane theory and currently arriving at the use of sophisticated finite element numerical solvers which account for local primary membrane stresses, primary bending stresses, secondary surface stresses, and peak surface stresses. The designer normally begins by using the Design by Formula rules described in NE-3300, to establish a base 
line for the containment vessel thickness in the free field areas of the vessel. Special areas in which structural discontinuities exist are then designed by formula when formulas are available, or designed by analysis using the rules of NE-3200.

In the early stages of a steel containment design the free field shell thickness must be determined using some pre-chosen material. First, the diameter is set to the minimum required to fit all the necessary equipment and the height is set to the minimum required to allow crane access to all interior equipment. Second, applying the pressure and temperature resulting from the design basis accident, a minimum allowable thickness can be determined using standard formulas found in NE-3300. A sample of these formulas are:

$$
\begin{array}{ll}
t=\frac{P R}{S-0.6 P} & \text { (for cylinder) } \\
t=\frac{P L}{2 S-0.2 P} & \begin{array}{l}
\text { (for hemispherical } \\
\text { head, or sphere) }
\end{array} \\
t=\frac{P D}{2 S-0.2 P} & \begin{array}{r}
\text { (for ellipsoidal } \\
\text { head, 2:1 ratio) }
\end{array}
\end{array}
$$

where

$$
\begin{aligned}
& t=\begin{array}{l}
\text { minimum required thickness of shell } \\
\text { or head, in., }
\end{array} \\
& P=\text { Design Pressure, psi., } \\
& S=\begin{array}{l}
\text { maximum allowable stress value, psi. } \\
\left(1.10^{*} \mathrm{~S}_{\mathrm{ult}} 4\right),
\end{array} \\
& R=\text { inside radius of the shell, in., } \\
& L=\text { inside spherical radius, in., and } \\
& D=\quad \text { inside length of the major axis of an } \\
& \text { ellipsoidal head, in. }
\end{aligned}
$$

After a minimum required thickness has been determined, the designer must determine if postweld heat treatment (PWHT) is required as described in NE4600 and Table NE-4622.7. For most steels the maximum thickness allowed without having to perform
PWHT is 1.75 inches. If the required thickness anywhere in the containment is greater than 1.75 inches (or thickness found in NE-4600), the designer will usually increase the volume of the containment by increasing the diameter or raising the height. This will result in a lower internal design pressure and thereby reduce the required thickness until it is 1.75 inches or less. The added cost of a larger containment will usually be less expensive than performing PWHT on the entire steel containment, but this is something the designer should determine.

Normally, the thickness of the cylindrical portions of the containment vessel is governed by the LOCA design internal pressure load. The addition of dead load, live load, and attached equipment loads can result in increased meridional stresses. However, since the meridional pressure related tensile stress is one-half the circumferential tensile stress and is opposite the gravity induced compressive stress, the addition of these nonpressure related stresses does not affect the required thickness. The addition of earthquake or wind loads may be additive to the meridional tensile stresses, but will normally not govern since there is a margin of at least one-half of the allowable stress available. Normally, wind load is not considered to apply to the steel containment design, except during construction, due to the protection from the concrete shield building surrounding it. In addition, the code specified allowable for the Service Level in which the wind or earthquake loads are present provides additional capacity margins.

Tall cylindrical steel containments with large diameters may be controlled by the specified external pressure loads $\left(\mathrm{P}_{\mathrm{o}}\right)$ resulting from pressure variation either inside or outside the containment. In addition, applying both seismically induced stresses and external pressure stresses, the axial compressive allowable in the cylinder may become the controlling criteria. Normally, if the cylindrical section is governed by compressive stresses, it is more economical to add circumferential stiffeners, rather than increasing the cylindrical shell thickness throughout the entire height of the cylinder. The finite element code BOSOR-5 [Ref. 2-6] is one program typically used to analyze containment structures for buckling stresses. Allowable buckling stress values are defined in NE-3222 and limit the stress to one-third of the critical buckling stress determined by an approved method, for Service Levels A and B. The allowable stress can be increased by $20 \%$ for Level C, which is the Service Level that includes the Safe Shutdown 
Earthqualke (SSE). It is common for this allowable to be the controller in the lower sections of the containment. To address this case, ASME Section III, Code Case N-284 may be invoked. This code case permits the use of a smaller factor of safety on critical buckling than does the basic code rules. For Service Level C, the code would allow a factor of safety on axial compression of $2.5(3 / 1.2)$ whereas, the Code Case $\mathrm{N}-284$ would allow a factor of safety of 1.67 . In order to take advantage of this Code Case, a more rigorous analysis is required than the basic code using the Service Level $\mathrm{C}$ allowables. Although using this Code Case to determine basic compressive allowable stress values is approved by the ASME, it has yet to be accepted by the NRC.

Spherical containments as well as the hemispherical top head of a cylindrical containment are usually governed by internal pressure. Ellipsoidal and torispherical top heads are also typically governed by internal pressure. Although buckling can occur in ellipsoidal and torispherical heads for large internal pressures, due to the presence of compressive hoop stresses, this rarely influences overall containment capacity because of the high pressure capacity for this mode of failure. Occasionally, the top head may be governed by external pressure, depending on the diameter to thickness ratio and the specified level of design external pressure. Often the top head is used as a construction support during the pouring of the concrete shield building roof. The concrete and formwork imparts loads to the steel head which requires both a local effects and global effects analysis. Although these are not operating condition loads, they are present in the containment during construction and their effects must be considered.

The base of a cylindrical steel containment is typically in one of two configurations: One is a flat concrete base mat covered on the inside of the containment with a liner plate with the cylinder wall securely anchored into the concrete base mat, as shown in Figure 2.1(a). The other configuration sits on a concrete foundation built around the bottom portion of the steel shell, which is an inverted dome (typically ellipsoidal) with the bottom filled with concrete, as shown on Figure 2.1(b). Similarly, spherical containments are continuous steel shells with concrete built around the bottom and concrete poured inside. For each of these base configurations there is a point where the steel meets the concrete base mat. The region near this point of embedment is subject to discontinuity stresses driven by internal pressure as well as by temperature, or both acting simultaneously. These stresses are often reduced by placing an expandable material between the steel and concrete at this embedment point on the outside of the shell, thereby allowing the steel shell to expand.

The Certified Design Specification should identify the most severe axial thermal gradient for the loss of coolant accident. This gradient, along with the internal pressure, may result in surface stresses which exceed the specified allowables for Service Levels A or B. The analysis techniques used for this evaluation may be as simple as a "beam on elastic foundations" formulation, a shell of revolution analysis, or may involve more complex approaches such as finite element analysis. Thermal stresses are considered to be secondary, and hence have a higher allowable than just primary stresses. However, they might require a fatigue analysis if the number of cycles and the range of stress do not meet the exemption criteria of NE-3221.5.

Once the containment dimensions and wall thicknesses have been determined, an analysis is performed by applying all applicable load cases and verifying that none of the allowable stresses are exceeded. This is usually performed by developing an axisymmetric finite element model of the containment and applying each load case and solving for local primary membrane stresses, primary bending stresses, secondary surface stresses, and peak surface stresses. These resulting stresses can then be compared directly to the allowables for the material type chosen using the appropriate Service Level and factors shown in Table 2.2. Local discontinuities or special details of the containment require individual detailed analysis and are usually analyzed by formula or by use of a 3-D finite element model of the particular section in question. The analyst must insure that the boundary conditions of this section of the containment are modeled correctly.

The most common of these special details are the penetrations in the steel containment. Normally, penetration reinforcements are designed to replace the area of shell removed, commonly called "area replacement" technique or rule. The guidelines for penetration reinforcement are contained in NE-3330. These rules require that the total cross-sectional area removed in any given plane be replaced by an area of reinforcement $(A)$ using the following equation:

$$
A=d t_{r} F
$$


where

$$
\begin{aligned}
& d=\text { finished diameter of a circular } \\
& \text { opening, } \\
& t_{r}=\text { the required thickness of the shell } \\
& \text { or head, and } \\
& F=\text { a correction factor which } \\
& \text { compensates for the variation in } \\
& \text { pressure stresses (a value of } 1.0 \text { is } \\
& \text { assigned for most configurations). }
\end{aligned}
$$

The entire amount of reinforcement is to be replaced within a parallel limit equal to the radius of the finished opening and a normal limit, for most nozzle configurations, of;

where

$$
\text { limit }=0.5 \sqrt{r_{m} t_{n}}
$$

$$
\begin{aligned}
& r_{m}=\text { mean radius of opening, and } \\
& t_{n}=\text { nominal nozzle thickness. }
\end{aligned}
$$

In addition, two thirds of the area removed must be replaced with reinforcement within a parallel limit of $0.5 \sqrt{R t}$, where $R$ is the mean radius of shell or head, and $t$ is the nominal vessel wall thickness. It is very unlikely that the reinforcement of penetrations will control the design of the containment vessel. These penetrations are commonly subjected to external loadings introduced by the piping systems. Displacement of the containment shell relative to the piping penetration results in shear and radial loads, which are accompanied by three moment vector loads to generate a simultaneous six load system. These loading systems are normally analyzed by use of Welding Research Council Bulletin 107 and the stresses compared to the allowables specified in Table 2.2. These stresses are assessed at the neck shell junction, at $0.5 \sqrt{R t}$, and at the edge of reinforcing. Loads are specified for each of the Service Levels and are normally available after completion of the piping system design and analysis.

Other special local details include the crane girder system, the pipe whip/support systems, the spray header support systems, the personnel airlock drive and locking systems, the external pressure stiffeners, the ladders and platforms and other miscellaneous components. Each of these require special analysis which is unique to the configuration used. Of these, the effect of the crane girder is often the most significant loading to be considered. The allowable stress criteria is as previously stated for each of the Service Levels.

After the preliminary design has been determined, a final design analysis of the entire containment structure must be performed. This is accomplished by using the stresses found in the individual solutions and combining them according to the specified load combinations as stated in Section III of the ASME Code or Standard Review Plan 3.8.2. All critical stresses must be investigated at each section. Finally, a verification analysis is performed for all applicable load combinations and a check of all calculated stresses is made to certify that the design satisfies all the requirements of the ASME Boiler and Pressure Vessel Code, Section III.

\subsection{Design of Reinforced and Prestressed Concrete Containments}

\subsubsection{Requirements}

The acceptance criteria for the design of reinforced and prestressed concrete containments are again based on meeting the relevant requirements proposed in $10 \mathrm{CFR}$ 50.55a and the same General Design Criteria (GDC) 1 , $2,4,16$, and 50 . These acceptance criteria are summarized in the U. S. NRC's Standard Review Plan, Section 3.8.1 (Concrete Containment). Regulatory guides and industry standards which provide information, recommendations, guidance, and describe a basis acceptable to the staff that may be used to implement these requirements are:
ASME Boiler and Pressure Vessel Code, Section III, Division 2, Code for Concrete Reactor Vessels and Containments, for parts of pressure boundary that are backed by concrete.
ASME Boiler and Pressure Vessel Code, Section III, Division 1, Subsection NE, for parts of pressure boundary that are not backed by concrete.

Both sections of the code are listed here because both are necessary in the design of a reinforced or prestressed concrete containment structure. In every nuclear reactor containment structure, the first barrier of any pressure resisting boundary is usually metal (ie. steel liner, steel penetrations, steel hatches, etc.) because concrete alone (either prestressed or reinforced) is not adequate to prevent small leaks from developing. 
However, in concrete containments the reinforcement and/or prestressing tendons provide the strength to prevent the metal pressure boundary from expanding or yielding beyond code allowables. Therefore, the reinforcement and/or prestressing tendons become the primary pressure resisting elements. Since not all metal sections of the containment are backed by concrete (ie. equipment hatch door, airlocks, portions of a steel pipe penetrations, etc.) it is necessary to refer to Division 1, Subsection NE of the ASME Code for the design requirements of these sections of the containment system. In addition, there are several USNRC Regulatory Guides applicable to concrete containments. However, most of them apply only to material testing, inspection, and quality assurance and do not specifically cover the design.

In general, all concrete containment vessels built in the United States are designed, fabricated, erected, and tested in accordance with the rules of Section III of the ASME Code, Division 2, Subsection CC, Concrete Containnaents. Similar to Division 1, Subsection NE, the requirements for prestressed or reinforced concrete containments have evolved with the ever increasing design experience and increased knowledge about the behavior of concrete containments. Requirements for the design of concrete containments had their beginnings in 1966 as a result of meeting between American Concrete Institute (ACD) and ASME where it was decided that each group would prepare separate reports. The ACI would concentrate on developing a concrete containment code and the ASME would prepare a prestressed concrete reactor vessel code. In 1971 it was decided to combine the two reports, due to the basic differences in philosophy between $\mathrm{ACI}$ which considered the containment as a structure and ASME which considered it a pressure vessel.

This new joint Concrete Containment Code, Subsection $\mathrm{CC}$, is similar to that developed by the $\mathrm{ACI}$ and contains much of the design philosophy of the $\mathrm{ACI}$ Building Code 318-71. The organization and format of the new Code and much of its procedures, inspections and reporting requirements follow more closely the other ASME Section III Code requirements. This joint standard is different from earlier versions of either ACI or ASME due to the different design approaches taken by the two societies, which can be summarized as 1) allowable stress versus load factor design, and 2) working stress versus strength design. components uses the allowable stress concept where stresses are limited to some fraction of limiting behavior stresses. These stresses are increased if consequence permits a reduced margin of safety. In some instances fictitious stress limits are used where stress levels extend into the inelastic range when elastic methods are used. Even in the case where inelastic or plastic analysis is permitted, design adequacy is defined in terms of allowable stress. With this method, a working stress can be determined for any loading condition.

The ACI approach, on the other hand, uses load factors to develop various safety margins by increasing the applicable loads by some percentage as a function of their individual importance to safety [Ref. 2-7]. Due to the nonlinear behavior of reinforced concrete, the ACI design codes permit the development of limiting internal forces and moments based on nonlinear analysis. These limiting forces and moments in conjunction with applied load factors (rather than some allowable stress) are then used to define design adequacy. Using this ultimate strength procedure in design makes it difficult to determine the level of stress or working stress for an actual loading condition.

The joint ACI-ASME Code completed in 1973 employs the ACI concept of defining the loading combinations and in some cases employs factored loads to increase the margin of safety. However, it follows the ASME approach of defining behavior limits in terms of allowable stresses rather than determining ultimate strength. In this regard the Containment Code, Subsection $\mathrm{CC}$ is unique in that it combines a factored load approach with an allowable stress criteria.

The latest version of Subsection CC of Section III, Division 2 of the ASME code (1992) is organized into eight major articles which address the following:

Article CC-1000 Introduction

Article CC-2000 Material

Article CC-3000 Design

Article CC-4000 Fabrication and Construction

Article CC-5000 Construction Testing and Examination

Article CC-6000 Structural Integrity Test of Concrete Containments

Article CC-7000 Overpressure Protection Article CC-8000 Nameplates, Stamping, and Reports

The ASME approach for steel pressure retaining 
The required procedures which the designer must follow prior to starting the design are similar to those for steel containments shown in Section 2.1.1 of this report. The design effort should start with a review of the specified material parameters as described in Article CC-2000, including tensile, yield, and impact energy capability. The basic allowable stress levels for all stress categories are based upon the tensile strength or yield strength for reinforcement, yield strength and ultimate strength of prestressing tendons, and compressive strength for concrete.

Having established the appropriate materials properties, vessel geometry, code boundaries, and loading conditions from the Certified Design Specification, the design effort is organized into the various specified loadings, i.e., dead load, live load, internal pressure, wind, earthquake, thermal, etc. and the applicable load combinations. Table 2.4 shows the loading combinations required in the design of concrete containments as taken from Table CC-3230-1. This table separates the loads and loading combinations into two categories; Service Loads and Factored Loads. The Service Loads as defined in CC-3221 represent loads that are normally expected to occur during construction, testing and normal operating conditions. The behavior under these loads is limited to the equivalent of ACI318 - Working Stress. The Factored Loads, as defined in CC-3222, represent loading conditions that are conceivable, but are extremely unlikely or have a very low probability of occurrence during the life of the plant. Notice that the load combinations under Service Load have load factors of one and for the Factored Load category have load factors ranging for 1.0 to 1.5. These varying load factors are used to emphasize the importance of a particular load in that combination to ensure safe behavior of the containment when subjected to that type of loading. Normally the controlling load combination is the design basis accident or Loss of Coolant Accident (LOCA) internal Pressure $\left(\mathrm{P}_{2}\right)$ at its highest factor (1.5) and accident Temperature $\left(T_{2}\right)$, which corresponds to the load case number 8 in Table 2.4. In areas that are greatly affected by seismic loads (ie., the basemat), load case 11 or 15 might govern because they combine the highest possible accident pressure with the highest earthquake loads. In prestressed concrete containments load case 3 could govern due to the high prestressing loads induced on the containment plus the external pressure load $\left(P_{v}\right)$.

After the stresses have been computed for each of these load combinations, they are compared to the allowable stresses defined as applicable to each loading criteria. These acceptance criteria for the concrete, reinforcing steel and tendon systems are presented in section CC3400. A summary of the most important allowable stress intensity limits described in CC-3400 are shown in Table 2.5. Note that the allowable stresses presented in Table 2.5 are different for each of the two loading categories. Also note that the type of compressive stress in the concrete determines the allowable level. That is, the allowables for each of the stress types, general primary membrane stress, primary membrane plus bending stress, primary plus secondary membrane stress, and primary plus secondary membrane plus bending stress, are different. In addition to the compressive stresses in concrete, all shear, torsion, and bearing stress allowables defined in CC-3400 must be satisfied. Concrete tensile strength shall not be relied upon to resist flexural and membrane tension.

Reinforcing steel and prestressing tendons are only permitted to resist loads uniaxially. However, their presence will have some effect on the allowable shear stresses in concrete.

Inside all reinforced or prestressed concrete containments is a steel liner. This liner is required to act as a bladder against the concrete to prevent leakage from inside the containment during overpressurization. Although no credit can be taken for the additional strength this steel liner provides, it must be designed according to the design rules in Section CC-3700 of the ASME Code. Limits on the liner during construction are in terms of allowable stresses. For all other loading categories (Service and Factored) the limits are specified in terms of strain (in./in.). These strain limits allow the liner plate to exceed its yield strain for both Service and Factored Load categories. In addition, the effect of the steel liner must be included in the design of the concrete containment due to the thermal strains imposed by increased temperatures.

\subsubsection{Practices and Level of Design Analysis}

Preliminary sizing of a concrete containment and its reinforcement is similar to the process used for steel containments and is performed using closed form solutions and simplified models. Loads are estimated from information available from the nuclear steam supply system (NSSS) supplier and previous containments of similar design. After individual loads are applied and stresses are determined, they are superimposed on the containment as required by the applicable design criteria. With these solutions, primary 
and secondary stresses within the structure are established for each load applied. Similar to steel containments, the design criteria for all concrete containment materials are expressed in terms of allowable stresses rather than section moment, force or shear capacity.

Other factors may govern sizing of the containment such as equipment and radiation shielding requirements. The internal diameter is often dictated by the space required to accommodate all necessary equipment in a functional manner (typically 130-150 ft minimum diameter). The minimum height of the cylindrical section to the spring line is often dictated by the required elevation of the crane hook to ensure that major equipment can be erected, moved, or removed. The minimum thicknesses of the concrete cylinder and dome are often governed by the radiation shielding requirements for prestressed concrete containments. In deformed bar reinforced concrete containments, the reinforcing steel requirements often require thicker concrete walls in order to accommodate all required steel.

The LOCA pressure $\left(\mathrm{P}_{2}\right)$ is the most significant load for determining the amount of reinforcing (deformed bars or prestressed tendons) required to resist overpressurization of the containment wall and dome [Ref. 2-8]. This accident pressure $\left(\mathrm{P}_{2}\right)$ depends on the free volume in the containment. Figure 2.2 shows the variation of $\mathrm{P}_{\mathrm{a}}$ with volume for a typical pressurized water reactor (PWR) containment. Economic studies using preliminary designs, material trade-offs, and unit costs are necessary to establish the optimal range for $P_{2}$. A review of existing concrete containments shows that the design pressures for most large dry PWR reinforced concrete containments are between 40 and $50 \mathrm{psig}$ and for prestressed concrete containments the design pressures range from about 50 to 60 psig [Ref. 2-9]. One economic study has shown the optimal pressure for $\mathrm{P}_{\mathrm{a}}$ is 60 psig for a prestressed concrete containment design [Ref. 2-10].

In addition to determining the optimum design pressure, Reference [2-10] also studied (for prestressed concrete containments) different dome shapes, internal diameter, and level of prestressing. Both ellipsoidal and hemispherical dome shapes have been used in PWR prestressed containments. A cost comparison of the two shapes found that the hemispherical dome is more economical. This is because the long inverted- $U$ tendons used in the hemispherical configuration require fewer anchors than using both vertical and dome tendons in the ellipsoidal configuration. Many existing containments have ellipsoidal domes because, until recently, the long inverted- $U$ tendon was not considered economically practical due to anticipated difficulties during its construction. In addition, several internal diameters were studied and this study concluded that the cost of the containment is not sensitive to changes in diameter.

The amount of prestressing in a containment is usually chosen to prevent any tension in concrete which occurs due to the applied internal pressure. Since the load case with the highest accident pressure is the factored load case \#8 in Table 2.4, in which $P_{\mathrm{a}}$ has a factor of 1.5 , one would expect that the amount of prestressing should be determined at $1.5^{*} \mathrm{P}_{\mathrm{a}}$. However, a study [Ref. 2-8] has found that it is more economical to set the design prestress to counteract any membrane tension that occurs due to the $1.25 * \mathrm{P}_{\mathrm{a}}$ in load case \#11, and allow the additional pressure in load case $\# 8$ to be carried by reinforcing steel.

The manner in which concrete containments are designed to resist seismic loads can affect their ultimate overpressure capacity. In non-prestressed concrete containments, the current ASME code does not allow the concrete to carry any tangential shear force, therefore designers usually provide diagonal rebar to resist the seismic shear forces. Although the code does not allow credit for the diagonal steel to resist internal pressure loading, including diagonal steel in a pressure capacity analysis will increase the global hoop and meridional capacity of the containment, typically about $10-15 \%$. In prestressed concrete containments, the concrete (when prestressed) is permitted to provide some tangential shear strength. This strength is usually enough to avoid the need to use any diagonal steel in the cylinder wall. In this case, seismic loads are resisted by the vertical steel tendons and reinforcement as well as the compressed concrete.

Note that the liner is not included when demonstrating that code strength requirements are met, even though the liner increases the internal pressure capacity of both reinforced and prestressed concrete containments. Typically the liner inside the concrete containment is a mild carbon steel usually $1 / 4$ inch thick and sometimes $3 / 8$ or $1 / 2$ inch thick, particularly in the dome which is usually designed to carry the load of the concrete when it is poured. This liner is anchored to the concrete using either continuous rolled shapes or headed studs. 
One advantage to using a continuous shape is that during construction it provides additional strength to the liner. Even though, as stated previously, these liners are not permitted to provide any structural resistance for meeting containment strength code requirements, they have been found to contribute about 7 to $10 \%$ to the internal pressure capacity when an ultimate capacity analysis is performed.

The preliminary design analysis is usually performed using an axisymmetric finite element model for determining global section properties. In the initial stages, sections are modeled as uncracked concrete with linear-elastic tensile and compressive properties (without reinforcement) to get forces and moment loads. These resulting forces and moments are then used to determine the amount of steel required in each section analyzed. For prestressed concrete containments, the effect of prestressing is included by applying an external pressure on the outside of the structure. When all reinforcing has been determined, a more detailed analysis is performed which includes the reinforcement, prestress, and thermal effects of the liner. For non-axisymmetric loading such as earthquake, lumped-mass beam models are normally used for both the preliminary and final analysis, since concrete containments are relatively stiff, which reduces the effect of shell modes of vibration in comparison to beam bending modes.

The final design of the containment is performed by combining the stresses found in each shell or element for the specific load applied. These are combined according to the rules set forth in ASME Boiler and Pressure Vessel Code. All stresses are then checked to assure they meet the required allowables as specified in the Code. The design procedure should include some method for relieving, by cracking of the concrete, the self-limiting loads. An example of this is the cylinder basemat junction, where if cracking of the concrete is allowed to occur, a hinge will form and the hoop reinforcement will pick up the additional load. Allowing this type of behavior in the design correctly reduces the reinforcing required and results in a much more efficient design.

Another aspect where special attention must be given is at areas of local discontinuity. Areas around penetrations, the springline, and concrete supports for prestressing tendon anchors all require special detailed analysis. In some simple cases these can be analyzed using hand calculations, while others may require using 2-D or 3-D finite element modeling of the situation.
When these are completed, a final check of the entire containment system is performed by analysis. A design report is then prepared containing a summary of the design, final calculated stresses, and a statement certifying that the design satisfies all applicable criteria.

\subsection{Comparison Between Steel and Concrete Containment Design}

It is difficult to compare the design requirements and practices of steel and concrete containments for several reasons. The main difference is the result of vastly different behavior of the two materials under various loading conditions. Steel normally acts in a very predictable elastic-plastic manner in tension, compression, and even bending, while reinforced concrete on the other hand, is much stiffer in compression than it is in tension and also exhibits nonlinear behavior from the onset of significant loading.

Historically, the primary design codes ASME Section III, Division 1 (steel) and Division 2 (concrete) were developed by two different groups with different philosophies. Division 1 was developed solely by the ASME and treated the entire steel containment system as a pressure vessel. On the other hand, Division 2 was produced jointly by the ACI and ASME and considered the concrete containment to be a structure. These different approaches resulted in a difference in the design requirements for concrete and steel containments. One of these differences is the loading combinations that must be considered in the design. For concrete containments the applied loads have factors ranging from 1.0 to 1.5, as shown in Section 2.2.1 of this report, whereas the loads applied to a steel containment do not have factors applied to them. This difference is because the design criteria in Division 2 (concrete) are based on the Load Factor concept originally developed by the $\mathrm{ACI}$, which varies the safety margin levels by increasing certain loads by some factor relative to their importance to safety. Division 1 (steel), on the other hand, incorporates the allowable stress concept where stresses are limited to some fraction of material properties and are increased for less probable events that justify a reduced margin of safety.

As a result of using load factors for concrete versus allowable stresses for steel, there is a different number of allowable stress categories in both the steel and concrete containment design requirements. As shown previously in Tables 2.2 and 2.5 there are five stress 
categories for steel and only two for concrete. Direct comparison of the allowable stresses is difficult because they correspond to different loading combinations and in the case of concrete include factored loads. Also, comparison of the loading combinations is difficult for these sanae reasons. In fact, Division 1 does not specify the loading combinations or provide a load combination table for steel containment design. Instead the designer is given certain combinations in the Nuclear Regulatory Commission's SRP Section 3.8.2 that must be considered. Table 2.1 in this report shows all major loading combinations given in the SRP. However, in certain instances there may be loads that arise during the design that are not covered. In these cases it is up to the designers to incorporate those particular loads utilizing the same philosophy that was used to arrive at the general load combinations shown in Table 2.1.

Instead of comparing the loading combinations and allowables, one can compare the margin between common loads such as internal design pressure $\left(P_{d}\right)$ and the pressure which causes a similar material behavior such as the minimum specified yield $\left(f_{y}\right)$. For concrete containments, there are two categories of allowables stresses and most containment cross sections are governed by the factored load category, for which the reinforcement cannot exceed $0.9 f_{y}$ or $90 \%$ of specified minimum yield strength. Also, the internal pressure capacity is usually governed by the $1.5 \mathrm{P}_{d}$ load case using factored allowables. By contrast, for steel containments, even though Division 1 of the code allows stresses to reach minimum specified yield $\left(S_{y}\right)$ for Service Level C, most steel containments sections are governed by Service Levels A or B, for which stresses are limited to $S_{m c}=1.1\left(S_{\mathrm{u}} / 4\right)$ for general primary membrane stress.

In order to show the inherent margin to yield in the design code for both steel and concrete containments the following comparisons were made as shown in Table 2.6.

This margin between design pressure $\left(\mathrm{P}_{\mathrm{a}}\right)$ and minimum specified yield pressure $\left(\mathrm{P}_{\mathrm{y}}\right)$ or $\mathrm{P}_{\mathrm{y}} / \mathrm{P}_{\mathrm{d}}$ applies to primary membrane stresses in both concrete and steel containments. The margin shown for concrete (1.67), applies to both prestressed tendons and deformed bar reinforcement, since both are limited to $0.9 f_{y}$ for the factored load stress category. In steel containments, this margin is affected by the ratio between yield strength and ultimate strength since the pressure capacity of steel containments are usually governed by Levels $A$ or $B$, which are limited to some fraction of ultimate strength $\left(S_{v}\right)$. Therefore, two typical steels were chosen with very different material margins; SA-516 Grade 70 has a specified minimum yield strength of $38 \mathrm{ksi}$ and minimum ultimate strength of $70 \mathrm{ksi}$ at $100^{\circ} \mathrm{F}$ $\left(\mathrm{S}_{\mathrm{u}} / \mathrm{S}_{\mathrm{y}}=1.84\right)$, while $\mathrm{SA}-537$ Class 2 steel has a specified yield strength of $60 \mathrm{ksi}$ and ultimate strength of $80 \mathrm{ksi}$ at $100^{\circ} \mathrm{F}\left(\mathrm{S}_{\mathrm{v}} / \mathrm{S}_{\mathrm{y}}=1.33\right)$. Therefore, these two materials have very different margins to yield above design pressure (1.97 and 2.73), although they are both higher than the margin for concrete containments (1.67).

At the higher temperatures shown in Table 2.6, such as design accident temperatures $\left(\sim 275^{\circ} \mathrm{F}\right)$, margins for these steel materials reduce to 1.76 for SA-516 Gr. 70 and 2.4 for SA-537 Cl. 2 and reduce even more at higher severe accident temperatures $\left(\sim 400^{\circ} \mathrm{F}\right)$. This is because the specified yield minimums $\left(S_{y}\right)$ for these materials are reduced more at higher temperatures than are the limiting design minimum $\left(\mathrm{S}_{\mathrm{mc}}\right)$ according to the allowable stress tables in ASME Section II. Therefore, the margins at the design basis accident are similar for steel and concrete containments due to the fact that concrete containment rebar is not much affected by increased temperatures.

Although it appears that steel containments may have a higher margin built into the design, this may be intentional due to event consequences. In other words, a small failure or tear in a steel containment vessel will probably lead to a catastrophic failure as shown in the Sandia tests of a 1:8 scale model of a steel containment [Ref. 2-11]. On the other hand, a similar test at Sandia of a 1:6 scale model of a reinforced concrete containment [Ref. 2-12] failed when a large tear developed in the steel liner inside the containment and it was no longer capable of sustaining pressure, even though the structural integrity of the containment remained intact. For these reasons, it is desirable for steel containments to have a higher safety margin built into the design in order to avoid a catastrophic failure.

Specific details or local discontinuities in the containment (ie., hatches, penetrations, etc.), typically have more conservatism built into their design. Therefore, the margin to yield in these areas will usually be higher in both steel and concrete containments. However, once the containments goes beyond yield, the margin to failure could be either smaller or larger in these local areas when compared to global membrane failure and must be analyzed on a 
case by case basis. These and other failure modes are discussed in the next chapter of this report.

\subsection{References}

2-1. Stevenson, J. D. et. al., "Historical Development of Containment Design Code Requirements," Proceedings of the Specialty Conference on Code Requirements for Nuclear Containments, December 9 and 10 1974, pp. 36-38.

2-2. Ahl, Thomas J. "Guidelines for Steel Containment Design Methodology," letter to Sandia National Laboratories, dated 7/24/94.

2-3. Stevenson, J. D. et. al., Structural A nalysis and Design of Nuclear Plant Facilities, American Society of Civil Engineers, Manuals and Reports on Engineering Practice - No. 58, 1980.

2-4. U. S. Nuclear Regulatory Commission, "Standard Review Plan," NUREG-0800, Section 3.8.1 Concrete Containment, and Section 3.8.2 Steel Containment, Rev. 1, July 1981.

2-5. The American Society of Mechanical Engineers, 1995 ASME Boiler and Pressure Vessel Code, 1995.

2-6. Bushnell, D., "BOSOR 5 - Program for Buckling of Elastic - Plastic Shells of Revolution Including Range Deflections and Creep," Computers and Structures, Vol. 6, 1976, pp. 221-239.

2-7. Koppe, R. E., "Design Load Combinations and Behavior Limits ACI-359, ASME Section III Division 2, Article CC-3000," Proceedings of the Specialty Conference on Code Requirements for Nuclear Containments, December 9 and 101974 , pp. 41-45.

2-8. Amin, M., et. al., "Design Consideration for Concrete Containments Under Severe Accident Loads," Nuclear Engineering and Design, Volume 145, July 1993, pp. 331-338.
2-9. Lobner, P., et. al., Overview and Comparison of U.S. Commercial Nuclear Power Plants, NUREG/CR-5640, SAIC-89/1541, Science Applications International Corporation, September, 1990.

2-10. Putman, S., et. al., "Containment Structure Optimization," Proceedings American Power Conference, Illinois Institute of Technology, April 1979.

2-11. Koenig, L. N., Experimental Results for a 1:8Scale Model Nuclear Power Plant Containment Pressurized to Failure, NUREG/CR-4216, SAND85-0790, Sandia National Laboratories, December, 1986.

2-12. Weatherby, J. R., Postest A nalysis of a 1:6Scale Reinforced Concrete Reactor Containment Building, NUREG/CR-5476, SAND89-2603, Sandia National Laboratories, February, 1990. 
Table 2.1: Load Combinations for Steel Containments

(Taken from USNRC SRP Section 3.8.2)

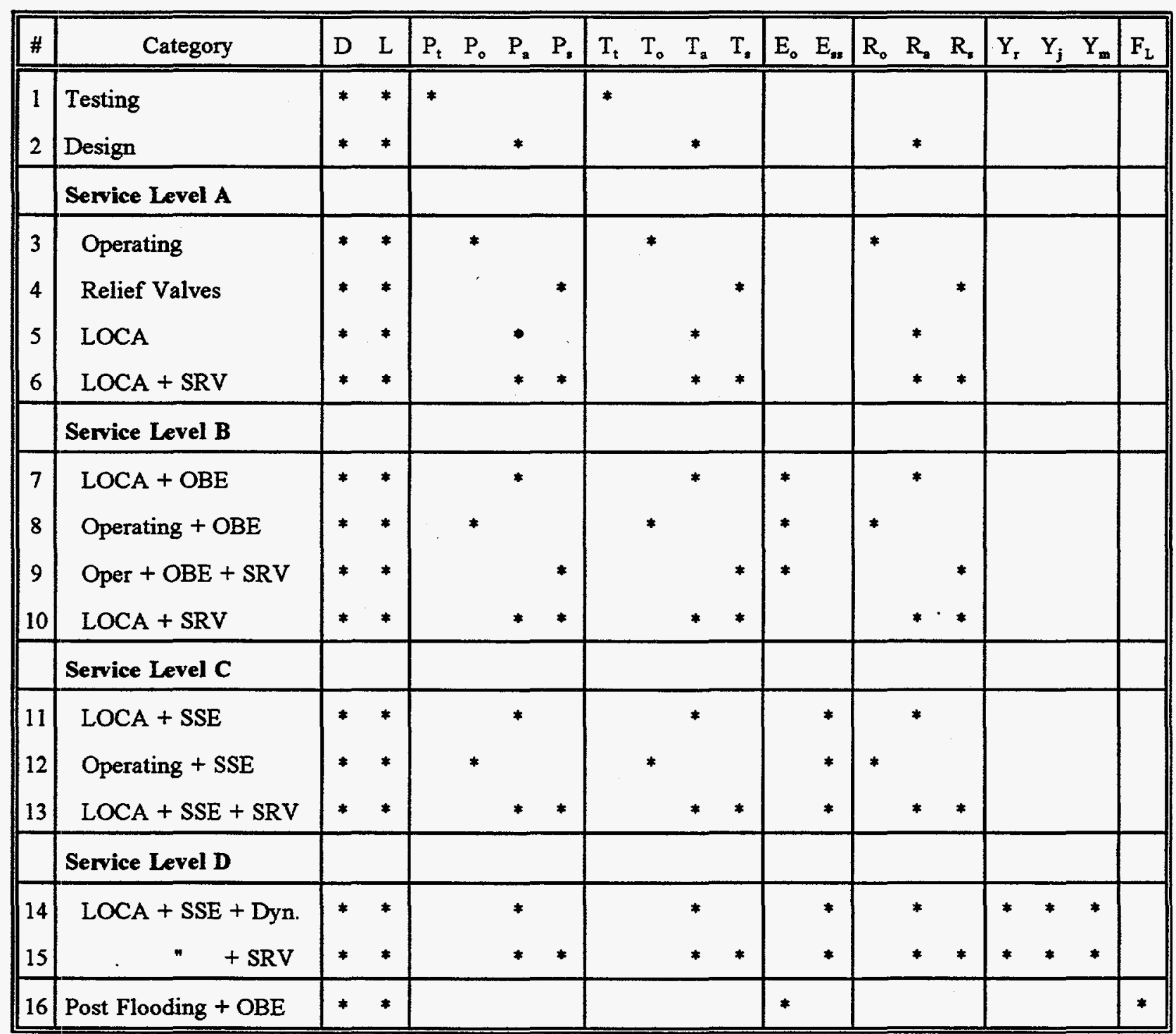

$\mathrm{D}=$ Dead loads

$\mathrm{L}=$ Live loads

$F_{\mathrm{L}}=$ Flooding loads

$P_{t}=$ Test pressure

$P_{\circ}=$ External pressure

$\mathrm{P}_{\mathrm{a}}=$ Accident pressure

$P_{z}=$ Relief valve pressure
$T_{t}=$ Test temperature loads

$\mathrm{T}_{0}=$ Operating temperature loads

$\mathrm{T}_{\mathrm{a}}=$ Accident temperature loads

$\mathrm{T}_{\mathrm{s}}=$ Relief valve temperature loads

$E_{0}=$ OBE loads

$E_{s i}=$ SSE loads
$R_{0}=$ Operating pipe reactions

$R_{\mathbf{a}}=$ Accident pipe reactions

$R_{s}=$ Relief valve pipe reactions

$Y_{s}=$ Reaction pipe design accident

$Y_{j}=$ Jet impingement design accident

$\mathrm{Y}_{\mathrm{m}}=$ Missile impact design accident 
Table 2.2: Stress Intensity Limits for Steel Containment Materials

(Taken from ASME Section III, Table NE-3221-1)

\begin{tabular}{|c|c|c|c|c|c|c|}
\hline Symbol & $\begin{array}{c}\text { Design } \\
\text { Stress }\end{array}$ & $\begin{array}{c}\text { Service } \\
\text { Level A } \\
\text { Stress }\end{array}$ & $\begin{array}{c}\text { Level B } \\
\& \\
\text { Level C } \\
\text { Not } \\
\text { Continuous }\end{array}$ & $\begin{array}{c}\text { Level C } \\
\text { Continuous } \\
\& \\
\text { Level } \mathbf{D} \\
\text { Not } \\
\text { Continuous }\end{array}$ & $\begin{array}{c}\text { Level D } \\
\text { Continuous } \\
\text { (Elastic } \\
\text { Analysis) }\end{array}$ & $\begin{array}{c}\text { Level D } \\
\text { Continuous } \\
\text { (Inelastic } \\
\text { Analysis) }\end{array}$ \\
\hline $\mathrm{P}_{\mathfrak{m}}$ & $1.0 \mathrm{~S}_{\mathrm{me}}$ & $1.0 \mathrm{~S}_{\mathrm{mc}}$ & $1.0 \mathrm{~S}_{\mathrm{mc}}$ & $\begin{array}{c}1.2 \mathrm{~S}_{\mathrm{mc}} \text { or } * \\
1.0 \mathrm{~S}_{\mathrm{y}}\end{array}$ & $S_{f}$ & $S_{\mathrm{f}}$ \\
\hline$P_{L}$ & $1.5 \mathrm{~S}_{\mathrm{mc}}$ & $1.5 \mathrm{~S}_{\mathrm{mc}}$ & $1.5 \mathrm{~S}_{\mathrm{mc}}$ & $\begin{array}{c}1.8 \mathrm{~S}_{\mathrm{mc}} \text { or * } \\
1.5 \mathrm{~S}_{\mathrm{y}}\end{array}$ & $1.5 \mathrm{~S}_{\mathrm{f}}$ & $\mathrm{S}_{\mathrm{f}}$ \\
\hline$P_{L}+P_{b}$ & $1.5 \mathrm{~S}_{\mathrm{mc}}$ & $1.5 \mathrm{~S}_{\mathrm{mc}}$ & $1.5 \mathrm{~S}_{\mathrm{me}}$ & $\begin{array}{c}1.8 \mathrm{~S}_{\mathrm{me}} \text { or }{ }^{*} \\
1.5 \mathrm{~S}_{\mathrm{y}}\end{array}$ & $1.5 \mathrm{~S}_{\mathrm{f}}$ & $S_{f}$ \\
\hline$P_{L}+P_{b}+Q$ & N/A & $3.0 \mathrm{~S}_{\mathrm{m}^{1}}$ & $3.0 \mathrm{~S}_{\mathrm{m}^{1}}$ & N/A & N/A & N/A \\
\hline$P_{L}+P_{b}+Q+F$ & N/A & $\mathrm{S}_{\mathrm{a}}$ & $S_{\mathrm{a}}$ & N/A & $N / A$ & $N / A$ \\
\hline
\end{tabular}

* Use larger of these two limits

$\mathrm{P}_{\mathrm{m}}=$ General primary membrane stresses

$P_{L}=$ Local primary membrane stresses

$\mathrm{P}_{\mathrm{b}}=$ Primary bending stresses

$Q=$ Secondary stresses

$\mathrm{F}=$ Peak stresses
$S_{y}=$ minimum specified yield strength

$\mathrm{S}_{\mathrm{u}}=$ minimum specified ultimate strength

$\mathrm{S}_{\mathrm{mc}}=1.1\left(\mathrm{~S}_{\mathrm{m}}\right) \approx 1.1\left(\mathrm{~S}_{\mathrm{v}} / 4\right)$;

$\mathrm{S}_{\mathrm{m}} 1 \approx \mathrm{S}_{\mathrm{u}} / 3$

$\mathrm{S}_{\mathrm{a}}$ is obtained from fatigue curves in Appendix I

$\mathrm{S}_{\mathrm{f}}=0.85\left(0.7 \mathrm{~S}_{\mathrm{v}}\right)$

Table 2.3: Typical Stress Values for Commonly Used Steels

(Taken from ASME Section II, Part D, Subpart 1, Table 1A)

\begin{tabular}{|c|c|c|c|c|c|c|c|}
\hline \multirow{2}{*}{$\begin{array}{l}\text { Material } \\
\text { Specification }\end{array}$} & \multirow{2}{*}{$@ \begin{array}{c}S_{y} \\
100^{\circ} \mathrm{F} \\
(\mathrm{ksi})\end{array}$} & \multirow{2}{*}{ (a) $\begin{array}{c}\mathrm{S}_{\mathrm{u}} \\
100^{\circ} \mathrm{F} \\
(\mathrm{ksi})\end{array}$} & \multicolumn{5}{|c|}{$\mathrm{S}_{\mathrm{m}}(\mathrm{ksi})$ for Metal Temperature ${ }^{\circ} \mathrm{F}$} \\
\hline & & & 100 & 200 & 400 & 600 & 800 \\
\hline SA-516 Gr.60 & 32 & 60 & 15.0 & 15.0 & 15.0 & 15.0 & 10.8 \\
\hline SA-516 Gr.70 & 38 & 70 & 17.5 & 17.5 & 17.5 & 17.5 & 12.0 \\
\hline SA-299 & 40 & 75 & 18.8 & 18.8 & 18.8 & 18.8 & 12.6 \\
\hline SA-537 Cl.1 & 50 & 70 & 17.5 & 17.5 & 17.2 & 17.2 & -- \\
\hline $\mathrm{SA}-537 \mathrm{Cl} .2$ & 60 & 80 & 20.0 & 20.0 & 19.8 & 19.8 & -- \\
\hline
\end{tabular}

Note: $\mathrm{S}_{\mathrm{mc}}=1.1 * \mathrm{~S}_{\mathrm{m}}$ 
Table 2.4: Load Combinations for Concrete Containments

(Taken from ASME Section III, Table CC-3230-1)

\begin{tabular}{|c|c|c|c|c|c|c|c|c|c|}
\hline$\#$ & Category & D L & F $\quad \mathrm{G}$ & $\begin{array}{lll}P_{t} & P_{a} & P_{v} \\
\end{array}$ & $T_{t} T_{0} T_{2}$ & $E_{0} E_{x s}$ & $\mathrm{~W} \quad \mathrm{~W}_{\mathrm{t}}$ & $\begin{array}{lll}R_{0} & R_{2} & R_{I} \\
\end{array}$ & $\mathrm{H}_{\mathrm{a}}$ \\
\hline & Service & & & & & & & & \\
\hline 1 & Test & 1.01 .0 & 1.0 & 1.0 & 1.0 & & & & \\
\hline 2 & Construction & 1.01 .0 & 1.0 & & 1.0 & & 1.0 & & \\
\hline \multirow[t]{2}{*}{3} & Normal & 1.01 .0 & 1.01 .0 & 1.0 & 1.0 & & & 1.0 & \\
\hline & Factored & & & & & & & & \\
\hline 4 & Severe environmental & 1.01 .3 & 1.01 .0 & 1.0 & 1.0 & 1.5 & & 1.0 & \\
\hline 5 & & 1.01 .3 & 1.01 .0 & 1.0 & 1.0 & & 1.5 & 1.0 & \\
\hline 6 & Extreme environmental & 1.01 .0 & 1.01 .0 & 1.0 & 1.0 & 1.0 & & 1.0 & \\
\hline 7 & & 1.01 .0 & 1.01 .0 & 1.0 & 1.0 & & 1.0 & 1.0 & \\
\hline 8 & Abnormal & 1.01 .0 & 1.01 .0 & 1.5 & 1.0 & & & 1.0 & \\
\hline 9 & & 1.01 .0 & 1.01 .0 & 1.0 & 1.0 & & & 1.25 & \\
\hline 10 & . & 1.01 .0 & 1.01 .25 & 1.25 & 1.0 & & & 1.0 & \\
\hline 11 & Abnormal/severe & 1.01 .0 & 1.01 .0 & 1.25 & 1.0 & 1.25 & & 1.0 & \\
\hline 12 & environmental & 1.01 .0 & 1.01 .0 & 1.25 & 1.0 & & 1.25 & 1.0 & \\
\hline 13 & & 1.01 .0 & 1.01 .0 & & 1.0 & 1.0 & & & 1.0 \\
\hline 14 & & 1.01 .0 & 1.01 .0 & & 1.0 & & 1.0 & & 1.0 \\
\hline 15 & $\begin{array}{c}\text { Abnormal/extreme } \\
\text { environmental }\end{array}$ & 1.01 .0 & 1.01 .0 & 1.0 & 1.0 & 1.0 & & 1.01 .0 & \\
\hline
\end{tabular}

$\mathrm{D}=$ Dead loads

$\mathrm{L}=$ Live loads

$F=$ Prestressing loads

$\mathrm{G}=$ Relief valve loads

$P_{t}=$ Test pressure

$P_{2}=$ Accident pressure

$P_{v}=$ External pressure
$T_{t}=$ Test temperature loads

$T_{0}=$ Operating temperature loads

$\mathrm{T}_{2}=$ Accident temperature loads

$\mathrm{E}_{\mathrm{o}}=\mathrm{OBE}$ loads

$\mathrm{E}_{z z}=$ SSE loads

$\mathrm{W}=$ Wind load

$W_{t}=$ Tornado wind load
$R_{0}=$ Operating pipe reactions

$R_{\mathrm{a}}=$ Thermal accident pipe reactions

$R_{T}=$ Local accident pipe reactions

$\mathrm{H}_{\mathrm{a}}=$ Flooding loads 
Table 2.5: Stress Intensity Limits for Reinforced Concrete Containment Materials

(Taken From ASME Section III, CC-3420 and CC-3430)

\begin{tabular}{||c|c|c|}
\hline $\begin{array}{c}\text { Material \& } \\
\text { Stress Type }\end{array}$ & $\begin{array}{c}\text { Allowable Stresses for } \\
\text { Service Loads }\end{array}$ & $\begin{array}{c}\text { Allowable Stresses for } \\
\text { Factored Loads }\end{array}$ \\
\hline Concrete Compression & & $0.60 f_{c}^{\prime}$ \\
\hline$P_{m}$ & $0.30 f_{c}^{\prime}$ & $0.75 f_{c}^{\prime}$ \\
\hline$P_{m+b}$ & $0.45 f_{c}^{\prime}$ & $0.75 f_{c}^{\prime}$ \\
\hline$\left(P+Q_{m}\right.$ & $0.45 f_{c}^{\prime}$ & $0.85 f_{c}^{\prime}$ \\
\hline$\left(P+Q_{m+b}\right.$ & $0.60 f_{c}^{\prime}$ & \\
\hline \hline Steel Reinforcement & & $0.9 f_{y}$ \\
\hline Compression & $0.5 f_{y}$ & $0.9 f_{y}$ \\
\hline Tension & $0.5 f_{y}$ & \\
\hline Prestress Tendons & & $0.9 f_{p y}$ \\
\hline Tension & $0.70 f_{p u}$ & \\
\hline
\end{tabular}
$\mathrm{P}_{\mathrm{m}} \quad=$ Primary membrane stresses
$P_{m+b} \quad=$ Primary membrane plus bending stresses
$(P+Q)_{m} \quad=$ Primary plus Secondary membrane stresses
$(P+Q)_{m+b}=$ Primary plus Secondary membrane plus bending stresses
$\mathrm{f}_{\mathrm{c}} \quad \quad \quad=$ minimum specified compressive strength of concrete
$\mathrm{f}_{\mathrm{y}} \quad=$ minimum specified steel reinforcement yield strength
$\mathrm{f}_{\mathrm{py}}, \mathrm{f}_{\mathrm{pu}}=$ minimum specified tendon yield and uitimate strengths, respectively

Table 2.6: Margins Between Design Pressure and Material Yield Pressure for Steel and Concrete Containments

\begin{tabular}{|c|c|c|c|c|}
\hline \multirow{2}{*}{$\begin{array}{l}\text { Internal } \\
\text { Temperature }\end{array}$} & \multicolumn{3}{|c|}{$\begin{array}{l}\text { Steel Containments } \\
\sigma\left(\mathrm{P}_{\mathrm{d}}\right) \leq 1.1\left(\mathrm{~S}_{\mathrm{u}} / 4\right)\end{array}$} & \multirow{2}{*}{$\begin{array}{l}\text { Concrete Containments } \\
\sigma\left(1.5 \mathrm{P}_{\mathrm{d}}\right) \leq 0.9 \mathrm{f}_{\mathrm{y}} \\
\mathrm{P}_{\mathrm{y}} / \mathrm{P}_{\mathrm{d}}\end{array}$} \\
\hline & Steel Material & $S_{u} / S_{y}$ & $P_{y} / P_{d}$ & \\
\hline \multirow[t]{2}{*}{$100^{\circ} \mathrm{F}$} & SA-516 Gr. 70 & $70 \mathrm{ksi} / 38 \mathrm{ksi}$ & 1.97 & \multirow[t]{2}{*}{1.67} \\
\hline & SA-537 Cl. 2 & $80 \mathrm{ksi} / 60 \mathrm{ksi}$ & 2.73 & \\
\hline \multirow[t]{2}{*}{$275^{\circ} \mathrm{F}$} & SA-516 Gr. 70 & $70 \mathrm{ksi} / 33.9 \mathrm{ksi}$ & 1.76 & \multirow[t]{2}{*}{1.67} \\
\hline & SA-537 Cl. 2 & $80 \mathrm{ksi} / 52.9 \mathrm{ksi}$ & 2.40 & \\
\hline \multirow[t]{2}{*}{$400^{\circ} \mathrm{F}$} & SA-516 Gr. 70 & $70 \mathrm{ksi} / 32.6 \mathrm{ksi}$ & 1.69 & \multirow[t]{2}{*}{1.67} \\
\hline & SA-537 Cl. 2 & $79.3 \mathrm{ksi} / 50.0 \mathrm{ksi}$ & 2.29 & \\
\hline
\end{tabular}




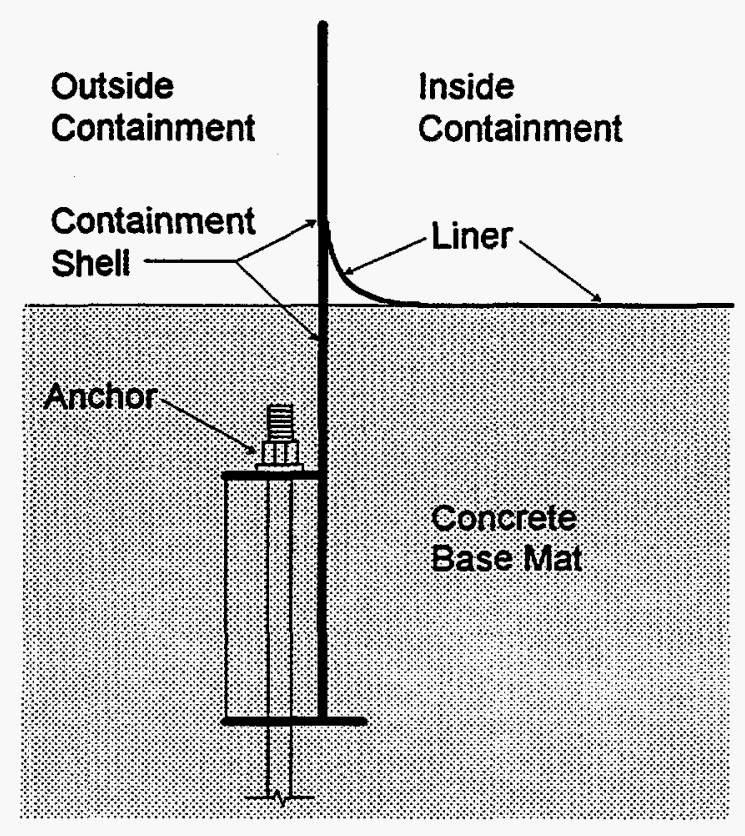

(a)

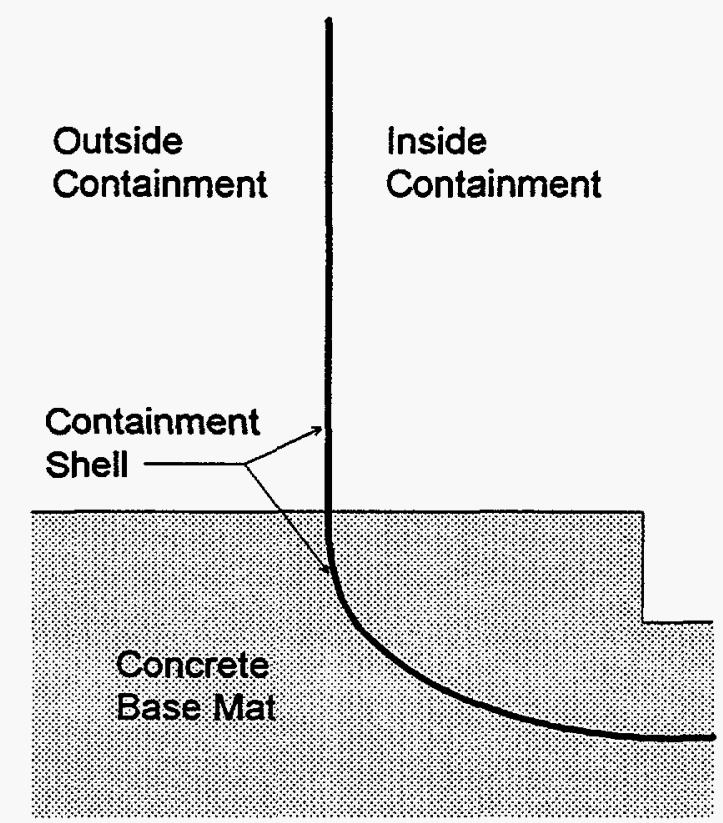

(b)

Figure 2.1: Examples of Steel Containment Embedment.

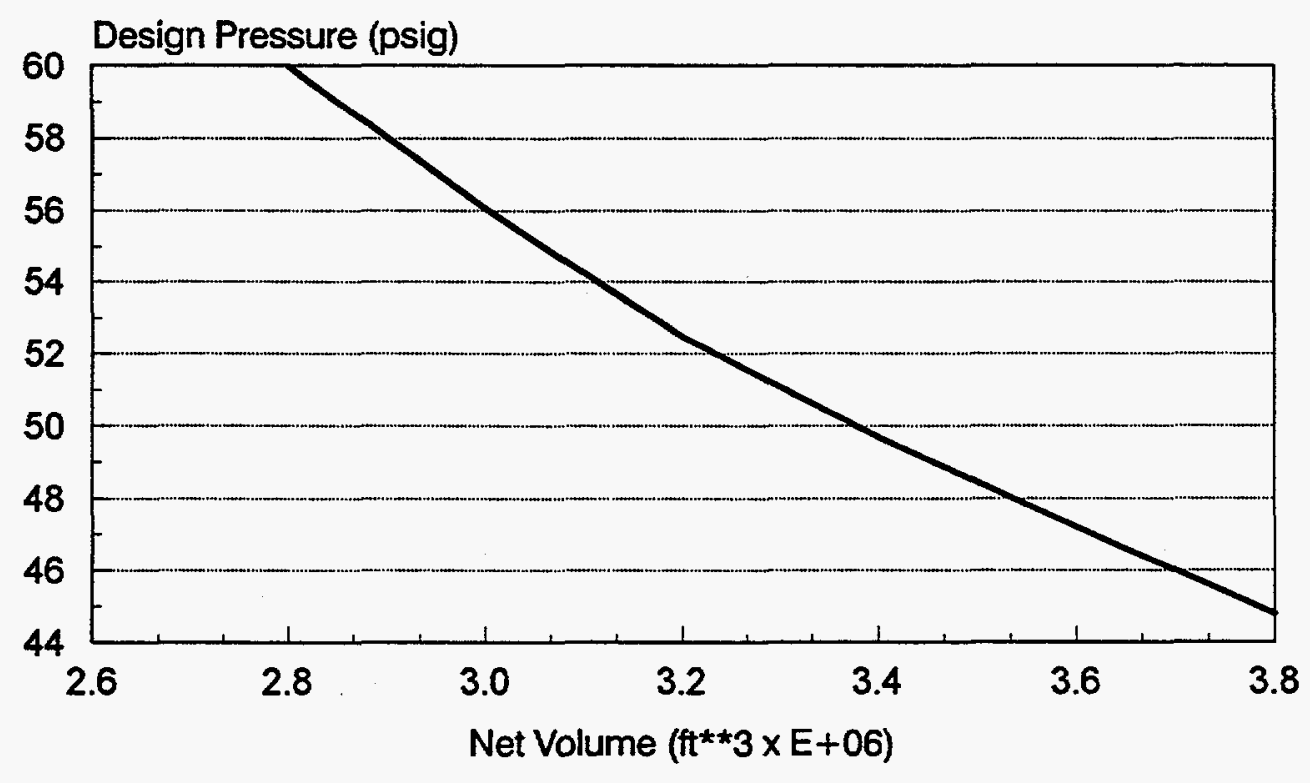

Figure 2.2: Variation of LOCA Design Pressure with Containment Volume (typical for PWR) [Ref. 2-10]. 


\section{CONTAINMENT OVERPRESSURE FAILURE MODES}

Nuclear power plant containment structures may be constructed from either steel or reinforced or prestressed concrete. The baseslabs are typically reinforced concrete. These structures are currently designed and tested in accordance with conservative codes and criteria which assure high reliability of these structures to withstand Design Basis Accident (DBA) conditions. In addition to DBA internal pressure and temperature, these structures are currently designed to withstand concurrent earthquake, jet impingement, and other extreme loads. These structures are also subjected to a proof test of 115 percent of the DBA pressure.

Although the probability of experiencing loads in excess of the DBA conditions is extremely low, such loads are at least theoretically possible and the potential consequences of containment failure are significant. Consequently, a great deal of both test and analysis has recently been devoted to investigating the behavior of containment structures when subjected to above-design basis pressures and temperatures.

Although current design codes and criteria are quite comprehensive and assure a highly reliable structure, one thing they do not currently require is the calculation of a margin of safety for any potential mode of failure. Experience has shown these margins of safety to be highly plant-specific and detail oriented. They vary from plant to plant, even for the same design organization and are a function of overall containment geometry, design pressure and temperature, and, to a lesser extent, the level of other external design load conditions such as seismic criteria.

Ultimate pressure capacity evaluations, regardless of the mode of failure, are normally not exactly quantifiable in terms of pressure, even if a deterministic value of overtemperature is specified. Thus, for above-design basis conditions, a probabilistic description of the failure pressure is normally required, particularly if an estimate of leak area or leak rate is desired. Because the design details as well as the overpressure demand pressure and temperature are site-specific, it is generally impossible to rank the possible modes of failure in terms of relative capacities without at least some preliminary investigation of all modes. Some modes of failure may be expected to exhibit lower pressure capacities than others at a given temperature, whereas other modes may be expected to have lower relative pressure capacities at increased temperatures. An example is the behavior of elastomeric seals which typically exhibit significant degradation at higher accident temperatures and hence may be more likely to control at very high temperatures. In addition, elastomeric seal degradation tends to worsen with time and for some modes of failure involving seals, the pressure capacity may decrease with time, even at an essentially constant accident temperature. Also, the variabilities associated with the individual modes of failure may be highly correlated as is typically the case of membrane failures at various locations in the shell, or may be highly uncorrelated as in the case of a membrane failure mode and an elastomeric seal failure mode. For uncorrelated modes of failure, there may be a higher probability of failure of a mode with a somewhat higher median (or mean) pressure capacity but large variability compared to a mode with a somewhat lower median capacity and only low variability.

The following discussion is a result of the experience gained in the probabilistic pressure capacity evaluations conducted for over 25 U.S. and foreign containment structures, together with discussions with numerous designers, analysts, test engineers, and regulatory personnel. The discussion contained herein is directed towards the most commonly encountered modes of failure identified to date in existing containment structures. In addition, some discussion of analysis techniques as sources of variability is included. However, the discussion should not be considered allinclusive and the evaluation methods have certainly not evolved to a textbook approach. The discussion is generally applicable to both large, dry PWR's and later Mark II and III BWR's. While many of the general principles apply to the earlier BWR Mark I, there are also a number of potential modes of failure specific to this type of containment which are not included here, nor are modes specific to the ice condenser PWRs.

Failure is considered to include breach of the containment pressure boundary and range from leakage above the design basis leak rate up to global failure. Failure may also be considered to involve disruption of essential services into the containment such as failure of a pipe due to excessive deformation of the containment structure. The latter type of failure is normally much less important in view of the fact that these lines will probably be unavailable at a stage of the accident involving potential containment failure conditions. In general, with the exception of such considerations as hydrogen detonation, accident pressure and temperature 
changes are slow in comparison to the dynamic response characteristics of the containment, and most pressure loadings can be considered as quasi-static. In other words, the pressure rise times can be assumed to be of sufficient duration that the dynamic response characteristics can be neglected and the temperatures in the material can be assumed to have reached steadystate.

Both freestanding steel and concrete containments are considered here and the concrete containment discussion includes both reinforced and prestressed designs. Both global and local failure modes are discussed. Leak before break considerations are included, as are potential modes of failure associated with strength controlled (direct pressure) effects as well as failure modes associated with interference effects resulting from large containment deformations at pressures which result in inelastic response.

\subsection{Axisymmetric Global Failure Modes}

\subsubsection{Concrete Containments}

A typical PWR concrete containment consists of a vertical cylinder with either hemispherical or torispherical dome and a flat baseslab, often with a reactor vessel cavity near the center of the slab. Wall thickness in the cylinder is normally 3 to $4 \frac{1}{2}$ feet and often somewhat thinner in the dome. Baseslab thickness in the 9- to 10-foot range is common. The structure is lined with a mild carbon steel plate which is usually $1 / 4$ to $3 / 8$-inch thick, but may be $1 / 2$ inch in the dome and is usually locally thickened around penetrations. The baseslab liner is usually covered by several feet of fireproofing concrete which may be either reinforced or unreinforced. Several major penetrations including an equipment hatch, one or more personnel airlocks, and possibly, one or more emergency airlocks are present. A fuel transfer tube, pipe and electrical penetrations, purge valves and sump drains are also present.

A typical large dry PWR concrete containment may be of the order of 130 feet inside diameter and 140 to 180 feet from the top of the baseslab to the spring line, and may be constructed using either a reinforced or prestressed concrete shell. The structure may be partially embedded to various depths and depending on the local soil conditions, may be founded on either soil or rock Details such as a ring girder at the spring line, embedded polar crane supports (if supported from the containment), liner anchorage, hatch designs, and clearance (rattle space) between adjacent structures are all highly plant specific. BWR details such as wet well, refueling head design, etc., are unique to $B W R$ containments.

\subsubsection{Reinforced Concrete Containments}

Reinforced concrete containment structures are designed in accordance with the ASME Boiler and Pressure Vessel Code, Section III, Division 2 [Ref. 3-1]. One of the provisions of the ASME Code is that no credit for the strength of the liner may be taken in the design. Also, current factored load combinations include a 1.5 factor on accident pressure together with normal loads. Typical global membrane failure modes include hoop failure in the cylinder, axial (meridional) failure in the cylinder, and membrane failure in the dome. For reasons to be discussed later, the cylinder hoop failure mode often has a slightly lower pressure capacity than others, but usually this difference is small for concrete containments.

Hoop failure typically may be expected to occur away from discontinuities such as a ring girder, which may impose some meridional bending, but is often somewhat over-reinforced to compensate for this bending moment. In general, bending stress is more important in the elastic design condition than the inelastic ultimate pressure capacity condition. Depending on the seismic design conditions, more reinforcing may be present in the lower portion of the cylinder to carry the lateral shear and bending moment. The seismic reinforcing steel may be placed at a $45^{\circ}$ angle. However, in the absence of lateral loads, this reinforcing is also effective in resisting both the hoop and meridional pressure loads which the code does not allow the designer to take credit for.

For this type of design, hoop failure can normally be expected to occur in the upper region. This area is normally removed from the majority of hatches and other penetrations and is typically a simple uniform cylindrical region of the containment. Hoop failure in such a region can often be treated as a uniform $\mathrm{pr} / \mathrm{t}$ type condition where

$p \quad$ is the internal pressure

$r \quad$ is the cylinder inside radius at failure, and 
$t \quad$ is an equivalent uniform steel thickness corresponding to the individual hoop reinforcing bars.

This simple approach requires a recognition that the radius at failure is not the initial inside radius, $r_{i}$, but rather $r_{i}(1+\epsilon)$ where $\epsilon$ is the hoop strain at failure. Also, the value of $\epsilon$ in the above expression is not the elongation obtained from reinforcing steel coupon test results. Standard tensile test elongations are normally obtained from either two or eight-inch coupons. Part of the elongation from such tests results from uniform elongation over the specimen gage length and part results from necking after plastic instability is reached. The necking is essentially independent of gage length such that longer gage lengths indicate lower failure elongations. The effective gage length for the in-situ reinforcing steel can be approximated as the distance between major concrete cracks in the cylinder.

Sometimes potential crack initiators such as liner anchor rolled steel members can be used to provide an estimate as shown in Figure 3.1. These members are often used to provide liner stiffness to resist wind loads during erection and form the liner anchor system after the concrete is poured. For other liner anchor systems such as those utilizing headed studs welded to the liner, the crack spacing may be less obvious and require an estimate from empirical relationships [Ref 3-16].

A second effect which reduces the containment failure strain compared to the reinforcing test elongation is the fact that tensile stress and hence strain in the in-situ steel is not constant but varies between cracks. For instance, the assumption of a uniform bond stress and linear tensile stress distribution as shown in Figure 3.2 leads to a nonlinear strain distribution for stresses above yield which results in an average strain at failure well below the uniform elongation.

Both Grade 40 and Grade 60 reinforcing steel are used in current concrete reactor structures but Grade 40 tends to be limited to smaller diameter bar sizes used for crack control. Grade 60 reinforcing steel has minimum specified yield and ultimate strengths of 60 and $90 \mathrm{ksi}$ together with minimum specified elongation from 9 percent for smaller diameter bars to 7 percent in the \#14 and $\# 18$ bars in 8 -inch specimens. Median strengths as well as elongations are typically higher. For instance, Reference 3-2 lists a median yield strength for Grade 60 of 71 ksi with Coefficient of Variation (C.O.V.) of 9.3 percent with a median ultimate strength of about 111 ksi and C.O.V. of about $2.8 \%$. These values are typical of plant specific test results observed for U.S. plants. Median 8-inch specimen elongation data is normally about 8.5 to 9 percent for $\# 14$ and $\# 18$ bars. However, with the reductions in average failure strain noted above, reinforced concrete containment structures can normally be expected to have median failure strains for global membrane failure in the 4 to 5 percent range.

A typical liner material might be ASME SA-285 Grade A plate with code minimum room temperature yield and ultimate strengths of 24 and $45 \mathrm{ksi}$, respectively. A typical median yield strength of about $31 \mathrm{ksi}$ could be expected for this material. Occasionally, a stronger liner material such as ASTM A-36 plate with code minimum yield and ultimate strengths of 36 and $58 \mathrm{ksi}$ is specified. A median yield of about $43 \mathrm{ksi}$ with C.O.V. in the 0.11 range and ultimate of $68 \mathrm{ksi}$ with C.O.V. in the 0.06 range are typical for this material. Even higher strength liner materials such as ASTM A442 Grade 60 plate have been used. Appropriate variations in both reinforcing and liner material strengths and elongations must be considered. The wall thickness permits an assumption of essentially uniform strain at failure. However, due to the existence of the thermal gradient through the wall, the strengths of the individual layers of rebar will vary.

Another possible influence on the strength of containment in a global membrane mode of failure is the presence of mechanical bar splices (Cadwelds). The splices are staggered so that the spacing throughout the structure prevents a possible failure plane through the splices. Cadwelds are designed to develop the full yield strength of the rebar and quality assurance is maintained by cutting out a percentage of in-place splices and testing them to failure. Tests of Cadwelds from in-situ splices indicate the failure in the splice is much more likely to occur in the reinforcing steel than in Cadweld itself. For those failures which do occur in the Cadweld, the strength of the joint has been found to be in the same range as reinforcing steel ultimate. Thus, Cadwelds have not been identified as a controlling detail in U.S. containments evaluated to date.

\section{Global Liner Behavior}

As noted previously, the strength of the liner is not included in the design strength of the containment. Only a check of compatibility is required. However, depending on the liner thickness, percentage of reinforcing steel, etc., the liner may typically be expected to contribute in the range of 7 to 10 percent of 
the total containment strength in the hoop direction.

Welded, low carbon mild steel plate with a minimum thickness of 1/4 inch is typically used for the liner. Plate to a number of material specifications has been used as noted above. As a typical example, A36 has a specified minimum yield strength of $36 \mathrm{ksi}$ with a typical median yield strength of about 42 to $44 \mathrm{ksi}$. Minimum uniaxial elongation of 23 percent for 2 -inch specimens and 20 percent for 8 -inch specimens with a reduction for plate thickness less than $5 / 16$ inch is specified. The biaxial yield stress in the liner may be estimated from the von Mises stress (an equivalent uniaxial stress) which is given by:

$$
\sigma_{e}=\frac{1}{\sqrt{2}}\left[\left(\sigma_{r}-\sigma_{\theta}\right)^{2}+\left(\sigma_{\theta}-\sigma_{z}\right)^{2}+\left(\sigma_{z}-\sigma_{r}\right)^{2}\right]^{1 / 2}
$$

where $\sigma_{r}$ is the normal pressure and $\sigma_{r} \ll \sigma_{z}<\sigma_{\theta}$.

For $\sigma_{z}=1 / 2 \sigma_{\theta} ; \sigma_{\theta} \approx 1.155 \sigma_{e}$ and for $\sigma_{z} \approx \sigma_{\theta}$; $\sigma_{\theta} \approx \sigma_{e}$. A biaxial stress state further results in a substantial reduction in failure elongation.

A number of factors will reduce the above failure elongation in the containment. A gage length effect exists as discussed above for reinforcing steel. Also the liner is in a biaxial stress state. A simple method to estimate this reduction in failure strain can be made where the elongation at failure is reduced by the use of a triaxiality factor:

$$
e_{f}=e^{*(1-T S)}
$$

where $e_{\mathrm{f}}$ is the elongation at failure, $\mathrm{e}$ is the uniaxial elongation, and using Manjoines' approach [Reference 3-3] the triaxiality factor is:

$$
T F=\frac{\sqrt{2}\left(\sigma_{1}+\sigma_{2}+\sigma_{3}\right)}{\left[\left(\sigma_{1}-\sigma_{2}\right)^{2}+\left(\sigma_{2}-\sigma_{3}\right)^{2}+\left(\sigma_{3}-\sigma_{1}\right)^{2}\right]^{1 / 2}}
$$

For a thin plate with a normal pressure much less than the in-plane stress $\left(\sigma_{3}<\sigma_{1} \leq \sigma_{2}\right)$ a reduction in ductility of from about 0.6 for $\sigma_{1}=2 \sigma_{2}$ (homogeneous cylinder) to 0.5 for $\sigma_{1}=\sigma_{2}$ (sphere) is predicted. Depending on the hoop to meridional strength of the concrete cylinder, the liner biaxiality ductility reduction in the cylinder is normally somewhere between these two values. In addition, some strain concentration across a major crack may exist. A third effect is the reduction in failure elongation for low carbon steel at increased temperatures. A median reduction of about 30 percent at $250^{\circ} \mathrm{F}$ and over 40 percent at $400^{\circ} \mathrm{F}$ is typical for liner materials. Some reduction in reinforcing bar failure elongation will also occur with temperature although the liner will see higher temperatures throughout the accident cycle. However, unless significant strain concentration such as is present in areas where liner thickness variations or other discontinuities exist, rebar fracture may occur prior to liner tearing.

If a single bar fractures for some reason at a relatively low stress, the adjacent bars will probably be able to pick up the increased load without fracture. However, if all bars are very close to failure, fracture of a single bar may lead to failure of a number of bars with a very large leak path. Similarly, if a local liner tear occurs, it is likely that the reinforcing steel can pick up the increased load unless the liner tear is very long and the bars are very close to fracture. Some additional aspects of liner tear are discussed in subsequent sections for examples of liner strain concentrations.

A high temperature spike in conjunction with relatively low internal pressure has the potential of causing local liner buckling. However, liner buckling does not necessarily lead to leakage. Thermally induced liner buckling is a deformation controlled condition such that stress is relieved as soon as buckling occurs. The postbuckled state is a relatively low membrane compression with low bending strains. Thus, the probability of crack formation is low and a high temperature spike with liner buckling is unlikely to result in a breach of the pressure boundary.

\section{Cylinder Meridional Failure}

Many aspects of global hoop failure modes discussed in the previous section are also applicable to cylindrical meridional global failure. For instance, the presence of additional seismic reinforcing near the base makes the probability of meridional failure in the higher portion of the structure more likely than near the base. The dead weight of the structure further biases the probable failure location slightly towards the upper portion of the cylinder.

For a cylinder of homogeneous material where the meridional stress $(p r / 2 t)$ is only one-half the hoop stress, 
the probability of meridional failure would be quite small with the possible exception of a large flaw. However, the concrete containment designer reduces the amount of vertical reinforcing steel to compensate for this geometrical effect and thus produces a more balanced design. Note that for large containment strains, the axial load must also include the global hoop strain (i.e. $\left.\mathrm{pr}_{\mathrm{i}}(1+\varepsilon) / 2 \mathrm{t}\right)$.

Since the liner is a homogeneous cylinder, the contribution of the liner strength in the meridional direction is twice that of its contribution in the hoop direction. Therefore, since the strength of the liner is not allowed in the design, it's contribution to the overall strength means the meridional global pressure capacity is typically slightly greater than the hoop capacity for a given concrete containment. If a ring girder is present, some local meridional bending moment and hoop constraint is likely to exist. The bending moment tends to damp out more rapidly for strains above yield and additional reinforcing is normally present in this region to compensate for the elastic design discontinuity stresses. Global failure resulting from the presence of a ring girder has not been observed in existing concrete containment structures.

\section{Dome}

Reinforced concrete containment structures may have either semi-ellipsoidal, torispherical or hemispherical shaped domes. Often the liner thickness in the dome is greater than that in the cylinder region. This is necessary since the liner is used as the inside form for the concrete for both the cylinder and dome, but the concrete form deformations tend to be higher in the dome. Since the global stress in the dome is a nominal $(p r / 2 t)$ or similar stress, many of the comments on the meridional cylinder failure are appropriate for the dome as well. For instance, due to the essentially uniform liner biaxial stress distribution in the dome, the dome may be expected to have a slightly greater capacity compared to cylinder hoop failure. This is particularly true if the liner thickness in the dome is greater than that of the cylinder together with similar reinforcing steel capacity. In some cases, depending on the designs, both the cylinder meridional membrane and dome membrane capacities may be substantially higher than the hoop capacity.

Some aspects of the dome reinforcing pattern present some unique aspects to dome pressure capacity. For instance, if a uniform hoop bar spacing together with a radial meridional bar pattern is used, the strength in the meridional direction is not constant but varies as additional or fewer bars exist. Figure 3.3 indicates how the meridian spacing and hence, strength, may vary. Also, some designs incorporate a rectangular grid near the apex and the strength of this region may be somewhat different than that of the hoop and radial bar pattern.

Occasionally, some of the meridional bars are continued up until they are welded to circular plates at the apex. Sometimes this is the result of a construction vent which is closed late in the construction sequence. Figure 3.4 illustrates such a detail. The behavior of this type of construction after yield involves the ductility of the flat plates and vent sleeve including possibly high tangential strains at the inside plate diameters and sleeve weld at stresses above yield, consideration of the rebar to plate welds, the relative spacing of the hoop and meridional bars at the apex, and the liner behavior, particularly if a thickened closure plate is used.

\section{Cvlinder Wall/Baseslab Hinge}

Meridional flexural failure or radial shear failure at the base of the cylindrical wall are well-recognized potential failure mode of concrete containment structures. Since a reinforced concrete containment wall is normally in a state of net tension across the wall thickness at pressures approaching failure (or even at the design basis accident pressure), most containments have substantial additional vertical reinforcing steel at this junction. Nevertheless, a meridional hinge or radial shear failure is possible. If a hinge forms, it will tend to be deformation limited as the hoop reinforcing near the baseslab picks up the load until the maximum radial deformation is controlled by the hoop strain in the reinforcing steel. Deeply embedded containment structures may develop sufficient soil pressure to help resist this type of failure provided the embedment is uniform around the circumference. Normally, but not always, the additional vertical reinforcing steel is capable of carrying the radial shear to well above hoop failure pressure. In a few plants, embedded vertical wide flange sections are added to resist the radial shear. Since the section is in net tension, shear friction in the concrete is reduced, although some aggregate interlock is still likely.

Whether a breach of the liner is likely to occur prior to radial shear failure depends on the detail design in the region of the liner knuckle. Some designs utilize 
crushable foam around the knuckle. Such a detail provides considerable flexibility with the ability of the knuckle to "unroll" to accommodate the rotation and vertical uplift caused by the hinge, together with any radial deflection. However, if the knuckle is concrete backed on both sides and if a liner anchor or thickened liner exists for the lower wall liner as is sometimes the case, the fireproofing concrete (normally two feet thick) above the baseslab liner may develop enough downward force in the knuckle to fail the knuckle-to-cylinder liner weld. Alternatively, a liner anchor in the baseslab near the knuckle may provide the same downward restraint as the fireproofing concrete above the liner or a combination of the two may occur. Some of these concepts are shown schematically in Figure 3.5. If a liner tear or weld crack occurs in the knuckle region, the result is likely to be a controlled leak rather than a reinforcing steel fracture with large uncontrolled leak areas.

\section{Baseslab Failure}

Potential baseslab failures include both flexure and shear failure of the slab at high pressures. At pressures above the DBA conditions, the outer edge tends to uplift from the supporting foundation media, particularly for rock sites. This uplift will often change the location of maxinum moment or shear to where the reinforcing is reduced compared to the design conditions.

Some baseslabs are essentially flat while others have a recessed reactor pressure vessel cavity located near the center. Additional moment restraint is often provided by the cavity although if the cavity is nonsymmetric, local regions of high stresses may be introduced.

Due to the presence of the concrete fill above the baseslab liner, the mass of the 8- to 10-foot-thick base mat itself, and the contact with the supporting soil or rock, accident temperatures in the baseslab are usually considerably lower than in the concrete shell.

Depending on the embedment depth and design detail, the surrounding soil or rock can also provide substantial restraint against both shear and flexural failures. Normally, the outside diameter of the baseslab is several feet larger than the cylinder. The dead weight and shear resistance of the uplifted soil is in opposition to the uplift generated by the cylinder wall due to internal pressure. In some cases for rock sites, the outside circumference of the baseslab is poured directly against the essentially vertical excavated rock face which, depending on the strength of the rock, may provide a large shear restraint against uplift. However, if a layer of rigid foam insulation is introduced at the rock-concrete interface, this restraint is negligible. As the baseslab flexes, some horizontal shear is also developed along the bottom surface (provided it remains in contact with the foundation) which again resists the bending moment in the slab. Some of these effects are illustrated in Figure 3.6.

As in the case of the containment dome, the reinforcing steel grid pattern may vary from plant to plant. A pattern of radial and circumferential bars is common which again introduces regions of relatively higher or lower radial bending moment and shear capacity. The shear is normally carried by a combination of the stirnups as well as shear friction provided by the main reinforcing steel. Critical sections for shear and flexure may be different, but often occur near junctions with the cylinder wall. The effectivity of the fireproofing concrete above the liner is also variable from plant to plant. If the fireproofing concrete is unreinforced and a layer of insulation is placed between the vertical liner and outer diameter of the fireproofing concrete as is often the case, its ability to resist baseslab loads is negligible. Note that the curvature of the baseslab at high containment internal pressures tends to result in liner compression. Thus, the probability of local liner tears developing in the baseslab liner (away from the knuckle) prior to failure of the baseslab reinforcing steel is low.

\section{Liner Strain Concentration and Tearing}

The phenomenon of local liner strain concentration and liner tearing is currently well recognized, particularly after the Sandia 1/6 scale model test. Duplication of these results using local biaxial tests has not proven to be easily repeatable, however. The most common example of liner strain concentration typically involves a locally thickened liner plate together with a concrete anchor attached to the standard liner in close proximity to the thickened plate. This condition is shown schematically in Figure 3.7 .

If the stress in the thickened liner plate is assumed proportional to the standard liner plate and the concrete anchor essentially rigid, then at global strains above yield, the strain in the region " $\mathrm{d}$ " in Figure 3.7 may be very high since almost the entire global deformation which would normally be distributed between the anchors, " $s$ ", must now be accommodated in the region "d". As an example, assume the ratio of liner plate 
thickness is in the range of $2: 1$ such that the thickened plate is likely to be less than yield at the standard liner plate ultimate stress condition. Further assume " $\mathrm{d}^{n}$ is of the order of three inches and " $\mathrm{s}$ " of the order of 36 inches. For this elementary example, a strain concentration of about 12 results. Or for a global strain of about 4 percent in the reinforcing steel, liner elongation of 48 percent would be required to prevent liner tearing prior to rebar fracture.

When attempting to analytically predict liner strain concentration and tearing, several conditions must normally be assessed. First, the spacing " $d$ " is usually unknown. Sometimes a minimum distance of " $d$ " such as 3 inches is specified while for other plants, no dimension is specified and so could be less depending on weld access. In virtually all plants, the angular orientation in plan of the liner supports or headed stud grid is not specified. Thus the value of " $\mathrm{d}$ " is a random variable with essentially a uniform distribution from either the minimum specified (or estimated) value of "d" to "s".

In attempting to evaluate the expected failure elongation in the region "d", it should be noted that both the gage length and ratio of biaxial strains are both functions of " $\mathrm{d}$ " and are not constant as in the case of global strain in the liner. Also, the rigidity of the liner anchor in the vicinity of the strain concentration is dependent on crack location which can never be known exactly.

As noted previously, if the liner tear is not long, it is likely that the reinforcing steel will pick up the additional load without fracture. However, in some plants, the thickened liner may exceed 10 or more vertical feet. Such details often exist where a bank of small pipes or electrical penetrations are located. If the liner strain concentration for such configuration is not high such that liner tear does not occur until near the rebar ultimate capacity, the reinforcing steel may not be able to withstand the increased load from a long tear and global rupture may occur at this location, even though it is initiated by a liner tear.

Thus, while local liner tears are a likely expected mode of failure for concrete containment structures, it should be recognized that considerable variability is associated with this type of failure. To an even greater degree, the resulting leak areas or leak rates resulting from such failure modes are highly uncertain

\subsubsection{Prestressed Concrete Containments}

Much of the foregoing discussion has been directed towards reinforced concrete containment structures. However, topics such as baseslab failure, liner behavior, local liner tearing, etc. are applicable to prestressed concrete containments as well.

Prestressed concrete containment structures differ from reinforced containments due to the presence of highstrength steel tendons which are prestressed to provide an initial compression in the concrete shell (and liner). Normally the cylinder and dome thicknesses are somewhat less than corresponding reinforced containments. Reinforcing steel percentages are lower and are provided for crack control and to resist increased stresses resulting from local bending moments such as around a ring girder, at the baseslab/wall junction, stress concentrations around major hatches, or other loads including seismic.

Tendons are usually located in both the hoop and vertical directions in the cylinder. Hoop tendons typically are anchored in vertical exterior buttresses (usually three in number in the U.S., but sometimes four) with the tendons spanning $240^{\circ}$ (or $270^{\circ}$ for the four-buttress configuration). Vertical tendons are typically anchored at the bottom of the baseslab with access for inspection provided by an annular tendon gallery beneath the slab. In a few instances, tendons are anchored at the bottom by means of grouted rock anchors. The upper ends of the vertical tendons may be anchored in a ring girder near the spring line or may extend over a portion of the dome and return to the tendon gallery at the baseslab. If the vertical tendons are anchored in the ring girder, a separate set of tendons, also anchored in the ring girder, are provided for the dome. The pattern for these tendons may vary, but typically cross at about $60^{\circ}$ angles.

The material used for tendons by different vendors varies as does the number of wires per strand, number of strands per tendon, and tendon anchor cap details. For instance, consider a typical tendon fabricated from stress relieved ASTM A 421, Type BA, a common material, with code minimum yield and ultimate strengths of 192 and $240 \mathrm{ksi}$, respectively. From sitespecific test data for a particular site, a median ultimate strength of $279 \mathrm{ksi}$ and median failure strain of about 5.4 percent were found together with a C.O.V. of about 0.02 on strength. These wires were fabricated into seven-wire, 1/2-inch nominal diameter strands and 55- 
strand teadons. For the same material at a different plant, a typical tendon may consist of ninety (90) 1/4inch-diarneter wires.

Most tendons in the U.S. are grease packed, although many european tendons are grouted. However, friction (particularly in regions of sharper radii such as around major hatches) and the fact that strands fail at somewhat reduced strains compared to individual wires indicate global failure strains in the 3 to 4 percent range are more realistic for tendons of this material compared to the 5.4 percent discussed above; or somewhat less than the median range of reinforced concrete containments. Other strand materials may exhibit lower elongations.

Since the concrete and hence the reinforcing steel and liner are initially in a state of compression, slightly less strain hardening can be utilized for these components compared to a reinforced concrete containment at the tendon failure strain. As in the case of a reinforced concrete containment, the ultimate strengths of all components (tendons, reinforcing steel, and liner) are not all developed at the same strain. Compatibility requires that only a fraction of the ultimate reinforcing and liner strengths are developed if the tendons fail at a lower global strain, particularly if the liner and some of the reinforcing steel are at a higher temperature. Figure 3.8 illustrates this behavior. Also, since the median prestressed concrete containment global failure strain is likely to be somewhat less than a reinforced containment global strain, there is a slightly reduced chance of local liner tear occurring prior to global rupture for a given liner strain concentration. Nevertheless, since the two types of containment are designed to similar criteria, similar margins of safety have been calculated for both types, as will be discussed in a subsequent section.

\subsubsection{Steel Containments}

Freestanding steel containments also normally consist of a verticall circular cylinder with hemispherical dome although some early U.S. steel containments were spherical and spherical containments are also used in Europe, particulariy for KVU plants. Cylindrical containments may include stiffening rings and vertical stringers and may include different thickness steel plate with thicker panels near the base to withstand lateral seismic loads. The simplest configuration is probably a uniform thickness cylinder without rings or stringers together with a uniform thickness hemispherical dome which would normally be one half the cylinder thickness.

The attachment of the cylinder to the baseslab may consist of either a system of cast in place anchor bolts and bolt chairs welded to the cylinder, or an embedded steel head in the baseslab concrete. If anchor bolts are used, a 1/4 inch thick liner on the baseslab is normally used in the same manner as concrete containments. With this configuration, although the liner is the pressure boundary, the pressure loads are resisted by the reinforced concrete baseslab. If an embedded head configuration is used, no anchor bolts are required and the pressure loads are resisted by the (normally torispherical) head itself. For spherical containment structures, the lower portion of the sphere is also normally embedded in the concrete baseslab and carries the pressure load in the same manner.

\section{Steel Containment Membrane Failure Modes}

Freestanding steel containments are designed and constructed in accordance with criteria defined in the ASME Boiler and Pressure Vessel Code, Section III, Division 1. While obviously not identical with concrete criteria (Division 2) many similarities exist including overall conservative philosophy, 115 percent overpressure proof test, etc.

Consider first a uniform thickness cylinder with hemispherical dome of one half the cylinder thickness. Away from any baseslab or hatch effects, the cylinder and dome are in a pure membrane stress state. No discontinuity stresses initially exist at the spring line and the hoop stress in the cylinder is equal to $p r / t$ with the membrane stress in the dome and the meridional stress in the cylinder equal to $\mathrm{pr} / 2 \mathrm{t}$. Again, as discussed for the liner, the shell is in a biaxial stress state with stress in the cylinder estimated at about $\sigma_{\theta}=$ $1.155 \sigma_{e}$ based on von Mises criteria and stress in the dome at about $\sigma_{\theta}=\sigma_{\phi}=\sigma_{\mathrm{e}}$.

Plastic failure strain can again be estimated from the uniaxial failure elongation using Manjoines method as was done for the reinforced concrete containment liner. For instance, for A36 plate gage length effects can be expected to result in a reduction of about 17 percent for 2-inch gage length specimen data to about 5 percent for 8 -inch specimen data. Biaxial effects result in a reduction of about 50 percent in the dome and 42 percent in the cylinder hoop direction. Thus for an A36 plate cylinder which has code minimum room temperature failure elongations of 23 and 20 percent, 
respectively for 2- and 8-inch gage length specimens, and assuming median elongation properties for 8-inch specimens of about 24 percent, global failure at $400^{\circ} \mathrm{F}$ strain can be estimated in the range

$$
\varepsilon \approx 0.24(1-0.05)(1-0.42)(1-0.40)=0.079
$$

Any local stress concentration effects, poor welds, etc., will obviously result in earlier failure. Small leak type failures analogous to liner tears are extremely unlikely in steel containment membrane failures. Once a through wall crack develops in a vessel in a general membrane yield condition, it is likely to run with catastrophic consequences. Even if rings and stringers are present, if they are above yield as is usually the case for this type of pressure vessel, the crack will not be arrested at the stiffener.

As previously noted, rings and stringers are occasionally used for free standing steel containment vessels. They are normally small enough that they can be expected to be well above yield prior to vessel fracture and thus the global increase in radius of the ring is normally only slightly less than the enclosed panel. As such, the bending and shear stresses in the panel at the ring or stringer are usually relatively small compared to the membrane stresses. Also, at stresses above yield these local stresses dampen out much more rapidly than equivalent elastic stresses. Nevertheless, some additional reduction in global membrane strain at failure should be expected if rings or stringers are present.

\section{Shell Buckling}

If either a semi-ellipsoidal or torispherical upper dome is used in place of a hemispherical configuration, buckling due to internal pressure is an additional potential mode of failure. Two modes of buckling have been identified for pressure vessels. The first is asymmetric buckling denoted by $\boldsymbol{P}_{\mathrm{c}}$ and the second is plastic collapse denoted by $\boldsymbol{P}_{\boldsymbol{O}}$. In all cases, $\boldsymbol{P}_{\boldsymbol{O}}$ controls for steel heads. Buckling pressure capacities for $P_{o}$ (as well as $\boldsymbol{P}_{\boldsymbol{e}}$ ) were developed by Galletly and his coworkers [References 3-4 through 3-7] using the BOSOR-5 computer program [Reference 3-8]. The analytical results obtained are sensitive to modeling assumptions. Based on very limited tests of steel head pressure buckling, median expected plastic collapse pressures have been estimated in References 3-9 and 3-10 as follows:

$$
P_{o}=1.78 \sigma_{y} \frac{t\left(1+50 \varepsilon_{y}\right)}{r}
$$

for 2:1 semi-ellipsoidal heads and

$$
P_{0}=22.4 \frac{\sigma_{y}\left(1+240 \varepsilon_{y}\right)\left(r_{s} / 2 r\right)^{1.04}}{(2 r / t)^{1.09}\left(R_{s} / 2 r\right)^{0.79}}
$$

for torispherical heads, where

$$
\begin{aligned}
& \sigma_{y}=\text { yield stress } \\
& \boldsymbol{t}=\text { head thickness } \\
& r=\text { radius of the attached cylinder } \\
& \varepsilon_{y}=\text { yield point strain } \\
& \boldsymbol{r}_{t}=\text { toroidal (knuckle) radius, and } \\
& R_{s}=\text { radius of the spherical portion. }
\end{aligned}
$$

The range of parameters for semi-ellipsoidal heads is:

$$
\begin{aligned}
& 200<\boldsymbol{w} / \mathrm{t}<750 \\
& 20 \mathrm{ksi}<\sigma_{y}<60 \mathrm{ksi}
\end{aligned}
$$

and

$$
\begin{aligned}
& 250<\pi / t<750 \\
& 1.5<R_{s} / r<3 \\
& 0.12<r_{t} / r<0.36 \\
& 20 \mathrm{ksi}<\sigma_{y}<75 \mathrm{ksi}
\end{aligned}
$$

for torispherical heads. Assuming a lognormal distribution, lognormal standard deviations ranging from 0.22 at room temperature to 0.25 at $400^{\circ} \mathrm{F}$ were recommended. Given that buckling has occurred there is no assurance of a crack formation. Again based on very limited test data it is estimated that the conditional probability of crack formation given buckling is about 0.2 for laboratory specimens. For welded structures such as a steel containment dome, the conditional probability of crack formation is likely higher. Note that in the case of a torispherical head used on the bottom of the containment vessel and backed on both sides by concrete, the probability of buckling is negligible. A temperature spike may induce compressive stresses in the steel shell near the baseslab which can result in buckling. This is a deformation controlled buckling mode which is in many regards similar to that of liner buckling previously discussed, and crack formation is not likely given buckling has occurred. 


\section{Baseslab Failure}

For freestanding steel containment structures which utilize an anchor bolt system without an embedded lower head, the behavior of the slab is essentially the same as previously discussed for concrete containment structures. An additional potential mode of failure is the anchor bolts themselves. These bolts are normally high strength steel of the order of 8 feet long. Bolt fractures (normally through the threaded section), concrete cone pullout, failure of the bottom bolt plate, flexure of the bolt chair plate, bolt chair to cylinder welds, etc., are all possible controlling modes of bolt failure. Reduction of bolt pullout strength due to edge distance to the outside diameter of the baseslab or closely spaced bolts may also be of concern. For designs with little flexibility around the baseslab liner knuckle as shown in Figure 3.9, actual fracture of the bolt is not required to develop a liner tear in a location such as shown by the knuckle to wall fillet weld. Inelastic bolt stretch or even elastic stretch may result in sufficient deformation to fail the weld. Note that the leak area for such a failure involves the path down the inside of the cylindrical plate and up the other side (although the weld failure may extend around a large portion of the wall circumference).

\subsection{Major Hatches}

Major hatches normally include an equipment hatch, one or more personnel airlocks, and possibly one or more emergency airlocks. Sometimes a personnel airlock is integrated with the equipment hatch. Elastomeric seals are provided to insure leak tightness, and the hatches are fabricated from welded mild steel plate such as SA 516 Grade 60 or Grade 70 . Personnel airlock and emergency airlock doors are normally pressure seating (inward opening) and double doors are usually provided such that both doors must be bypassed for leakage to occur. The equipment hatch is usually a single pressure boundary and may be either pressure seating or pressure unseating (outward opening). The refueling tube in a PWR may also be considered as a major penetration. Failure of the refueling tube penetration as well as pipe penetrations is discussed in the section on interference or deformation induced modes of failure.

\subsubsection{Equipment Hatches}

The main components of a typical equipment hatch are shown in Figure 3.10. Equipment hatches are typically on the order of 20 feet in diameter. In this case a hemispherical pressure seating cap is shown but the cap could also be pressure unseating and located outside the containment wall. Included in the potential failure modes of an equipment hatch are (a) buckling of the spherical cap, (b) formation of a plastic hinge in the cap, (c) rotation of the seal ring, (d) buckling of the sleeve, (e) uncovering of the seal rings due to global containment deformation by either ovalling (inextensional deformation) or axisymmetric (extensional) deformation, (h) loss of the sleeve concrete shear anchor, or $(\mathrm{g})$ liner tear between the thickened collar and the nearest liner anchor.

Deterioration of the elastomeric seals is discussed in a subsequent section. If the hatch is pressure unseating, stretch of the bolts is a common mode of failure.

Buckling of the spherical cap has a high factor of safety at design pressure imposed by the ASME Code. Test results of spherical caps usually indicates median pressure capacities in the range of 35 percent of theoretical values $\left(\hat{p}_{\text {fal }} \approx 0.35 p_{\text {gheor }}\right)$, but with substantial variability [c.f. Ref. 3-11]. Available test results from laboratory specimens may over-estimate the capacity for some equipment hatches since some plants have observable geometric eccentricities in the welded plate configurations used for large caps. Distributed bending moments are developed at the seal ring intersection which may produce high plate bending at the ring plate intersection. Depending on the design detail and possible load eccentricity, the seal ring may be subject to a twisting moment which tends to rotate it in its plane with the possibility of uncovering the seals.

If the sleeve is relatively thin and particularly if it extends a significant length inside the containment, it may be susceptible to buckling from the combined axial load and radial pressure. Loss of concrete shear anchorage may occur by a combination of failure of the liner to sleeve and shear anchor (studs or circular plate) welds due to the outward acting axial sleeve load.

Depending on the design details of the concrete structure around the hatch, the sleeve and collar thickness and the type of sleeve anchor system, several possible failure modes may exist resulting from relative deformation between the concrete and the sleeve and liner system. For plants with a heavily overreinforced concrete boss around the hatch, essentially a "hard spot" is created in the containment wall around the hatch with little concrete deformation occurring immediately 
around the sleeve and little chance of liner tear in the region between the thickened liner collar and the nearest liner anchor. If liner tearing does occur, it is more likely in a region towards the outer edge of the boss where strain concentrations may occur. On the other hand, if the concrete around the hatch is only moderately reinforced (likely especially with prestressed containments) the concrete will tend to deform approximately as the structure remote from the hatch. This may involve essentially equal vertical and hoop concrete strain or hoop strains significantly greater than the vertical. The behavior of the sleeve and thickened liner collar depend on a number of design details. If the collar is thick with a large O.D. (and especially if the sleeve anchor system does not involve headed studs or the equivalent which tend to force the sleeve to follow the concrete deformation) the concrete may simply pull away from the collar and sleeve.

Depending on the liner anchor system and spacing, large liner strain concentrations may occur in the standard thickness liner at the O.D. of the collar. If the collar is relatively weak and if sufficient capacity exists in the sleeve anchor system, the sleeve and collar may deform with the concrete. This radial deformation of the sleeve and collar tends to produce an offset between the seal flange rings which may uncover the seals. This offset may be essentially axisymmetric or may include considerable ovalling. The shorter the sleeve extending inside the containment from the liner the less length the sleeve has to damp out the distortion at the collar and the more likely the seals will be uncovered. There is also no assurance that the hatch will remain concentric with the sleeve once relative motion occurs at the flange face. The weight of the hatch will tend to cause the top of the seals to uncover before the bottom and slight differences in bolt preload or seal ring shear strength may mean that essentially all the relative motion is accumulated at one location. Even if the seal rings are not uncovered, sufficient relative motion may occur to shear the seal indenter rings. This may still result in essentially metal to metal contact but bypass the elastomeric seals.

If the hatch is outward opening (pressure unseating) normally more and larger bolts are used to provide the required clamping force to withstand the DBA internal pressure. Although buckling of the hatch or sleeve are not of concern for this configuration, membrane tensile stress in the sleeve or hatch may be important. Of more concern is the strength and elongation of the bolts. Bolt fracture in the threaded section or shear of the lug, shear or bending failure of the bolt pin or weld failure in the bolt chair gusset plates are all obvious potential modes of failure. The length of these swing head bolts is often of the order of 2 feet. Tensile strains in these bolts may provide sufficient elongation for metal to metal separation to result in elastomeric seal deterioration and a significant leak area, even if the bolts remain elastic.

Equipment hatches in freestanding steel containment structures are subject to some of the above modes of failures such as spherical cap buckling, seal flange ovalling or pressure unseating leakage, but modes such as liner tear, loss of concrete shear anchors, etc., are clearly limited to concrete containments. For pressure seating hatches in steel containments, ovalling of the seal flange with shear failure of the indenter rings or uncovering of the rings is probably one of the more common modes of failure due to the 2:1 hoop to meridional stress ratio and much larger hoop to meridional strain ratio after global yield.

BWR refueling heads are pressure unseating and behave similar to pressure unseating equipment hatches except that liner tear, etc. is not a concern. Often the refueling head bolts are relatively long and even elastic strain may be enough to result in leakage depending on the seal behavior. Bolts embedded in concrete have a bolt pullout mode of failure which also may be important.

\subsubsection{Personnel and Emergency Airlocks}

Personnel and emergency airlocks (if used) are provided for use at periods other than refueling, etc., when the equipment hatch is sealed. Most personnel and emergency airlocks are similar in principle with two pressure seating doors provided in series. These doors are supported from flat (often stiffener reinforced) bulkheads which are in turn welded to a circular sleeve which is either embedded in the concrete or welded to the shell for steel containments. Occasionally a personnel airlock is integral with the equipment hatch with the personnel airlock sleeve concentric with the equipment hatch spherical cap. Figure 3.11 shows schematically a typical personnel airlock. The access door is usually of the order of $3^{\prime}-6^{\prime \prime}$ by $6^{\prime}-8^{\prime \prime}$ and is reinforced to form a one-way horizontal span. The bulkhead is usually a flat plate, reinforced with stiffener ribs as required, with the door jambs fabricated from welded flat plate. A double tongue and groove configuration with recessed rectangular elastomeric seals is common. Alternatively, double circular cross section seals partially exposed may be used with a flat mating 
flange. For leakage to occur, both doors must be bypassed. In an accident condition, the exterior door may be expected to remain substantially cooler.

If one or more emergency airlocks are used they are usually significantly smaller. Doors may be of the order of a 2-foot diameter plate with correspondingly smaller diameter sleeves. Sight glasses are sometimes installed in either the personnel airlock doors or emergency airlock doors or both.

Many personnel airlock failure modes such as sleeve concrete anchor failure, liner tearing around the collar, elastomeric seal degradation, etc., are similar to those previously described for the equipment hatch. Because of the smaller dimensions of the personnel airlock, somewhat higher pressure capacities usually result for similar modes compared to the corresponding equipment hatch failures. For instance, if the liner strain concentration annulus is 3 inches from the thickened collar to the liner anchor for both hatches, a 20 foot diameter equipment hatch will develop about twice the strain concentration as a 10 foot diameter personnel airlock, assuming similar strains in the collars, etc.

Other failure modes include (a) shear failure of the bulkhead or bulkhead to sleeve weld, (b) flexural failure of the bulkhead (particularly the vertical or horizontal doorjamb sections, (c) flexural failure of the door, (d) sight glass fracture, or (e) seal deterioration. Bulkhead shear and weld failures are normally above the range of interest. Flexural failure of either a bulkhead member or door may have lower capacities but are not usually a controlling failure mode unless accompanied by temperatures high enough for seal degradation. Initiation of yield in a flexural member usually results in insufficient deformation to cause leakage provided the seal still has reasonable performance, and formation of a plastic hinge is usually required. Depending on the relative flexibilities of the door and door jambs, the door may deflect to follow the doorjamb and thus maintain metal to metal contact, even above elastic limits. Room temperature pressure capacity test verification of a typical personnel airlock bulkhead and door has shown high capacity.

Sight glasses are installed in some hatches. The glass is normally a thick, circular disk of Pyrex supported by an elastomeric seal. The glass itself usually has a high pressure and temperature capacity although actual engineering strength parameters are usually difficult to obtain from the vendor. Scratches in glass result in reduced fracture toughness, however, and a severely scratched glass may be reduced in capacity enough to be of concern.

\subsubsection{Elastomeric Seal Degradation}

Elastomeric seals used in nuclear power plants are usually either a silicone rubber or EPDM compound. Deterioration of these materials is a function of both time and temperature. Elastomeric seals are normally used in equipment and personnel hatches as previously noted, and sometimes in the form of ' $O$ ' rings in some electrical penetration assemblies (EPA) or as seal rings for butterfly type purge valves, etc.

Equipment and personnel hatch seals normally utilize double recessed continuous rectangular cross section seals with a tongue indenter as shown in Figure 3.12 or with recessed circular cross section seals with the elastomer extending beyond the metal surface.

Provision is normally made to pressurize the annulus between the seals as a leak test procedure. These seals are also periodically replaced. Provided metal to metal contact between the flange surfaces is maintained, the seals can withstand significant deterioration and still retain pressure. At high temperatures, however, if flange separation occurs the seal can be extruded as a ribbon between the flanges. Pressure unseating flanges are clearly more susceptible to seal extrusion than pressure seating flanges. A rough approximation [Reference 3-12] of the time for silicone rubber seal deterioration at various seal temperature is shown below:

\begin{tabular}{cc} 
Temperature & Time (hours) \\
\cline { 2 - 2 } 450 & 1000 \\
500 & 20 \\
550 & 3 \\
600 & 1 \\
650 & 0.6
\end{tabular}

EPDM compounds show a similar trend.

A second type of deterioration involves temperature and time induced loss of rebound or "set", and can occur at much lower temperatures. For instance, EPDM seal rings in a typical PWR equipment hatch show a permanent set in the range of 12 to 15 percent due to normal operating temperature over a refueling period. For the elastomers used in nuclear power plants significant rapid set begins to occur in the range of 
$300^{\circ} \mathrm{F}$ with virtual total loss of rebound capability by about $400^{\circ} \mathrm{F}$. Figure 3.13 shows typical 70 hour residual set test data for several common EPDM compounds. Silicone rubber exhibits similar behavior. Thus, if a pressure unseating flange such as equipment hatch or BWR refueling head is subjected to a soak temperature in this range and then a further increase in pressure, the seal may not have sufficient rebound capacity to follow a slight increase in the flange gap, and a leak may develop. Once a leak is initiated, high velocity, high temperature gas flow can quickly erode the seal with the leak area subsequently controlled by the metal to metal gap only.

\subsection{Interference (Deformation Induced) Failure Modes}

Both concrete and freestanding steel containment structures are designed to remain elastic under DBA conditions. Prior to failure, most potential modes of failure involve some inelastic response of the structure with correspondly increased strains and deformations. This section discusses several potential modes of failure which result from interference effects rather than from direct pressure induced stress conditions. Included in this category are punching shear failures in concrete structures, point or line load conditions in steel containments, interference induced loads on pipe penetrations, deformation induced failures of bellows including PWR refueling tubes and bellowed pipe penetrations, and interference induced failure of major hatches.

\subsubsection{Concrete Punching Shear Failures}

Concrete containment structures are separated by gaps between the containment and adjacent structures. These gaps are provided to allow thermal and pressure growth of the containment under normal and DBA conditions as well as to provide seismic "rattle space" to avoid seismic impact between adjacent structures. Higher gaps usually exist for soil sites with high SSE acceleration levels.

If the adjacent structure is relatively weak compared to the containment it may simply be pushed away by the expanding containment wall. However, if the structure is strong as may be the case where the massive walls of a fuel transfer canal are loaded in in-plane shear, punching shear failure of the containment may be an important mode of failure. Such a condition is shown schematically in Figure 3.14. Once the gap between structures is closed, additional radial containment deformation is resisted by high shear loads developed by the fuel transfer canal walls. The containment is likely to be severely cracked by this time so that the concrete shear strength is degraded and the reinforcing steel is in a state of combined shear and tension. Since this is not a design condition, no additional stirrups will be present in the containment to help resist these loads. Local bending curvature of the containment at this location may also introduce additional tensile strain in the liner.

Interference loads of this type in a freestanding steel containment are normally of less concern. The shear can usually easily be carried with combined tensile and bending stress and the effect is simply to add additional restraint to the shell. A possible exception is the existence of a hard, sharp point at the contact location.

\subsubsection{Pipe Penetrations}

Pipe penetrations may be either rigidly attached to the containment or bellows may be provided as the pressure boundary with the pipe essentially free to move relative to the containment at the penetration. Rigid penetrations typically include a cylindrical sleeve with a concrete shear anchor for concrete containments or with the sleeve welded to the (often locally thickened) steel containment vessel. The closure plate may be either a forged (flued) head or a flat plate welded to the sleeve and process pipe spool. As the containment deforms inelastically at high internal pressures, large loads may be developed at the penetration. If the inner and outer pipe supports nearest to the penetration are relatively weak, the supports may fail. Alternatively, the pipe may hinge or buckle, particularly for thin wall pipe with one or more elbows between the penetration and the support. This may result in a cracked or crimped pipe with reduced flow. However, at this stage of an accident it is likely no flow exists.

If the pipe is heavy-walled with a straight run to a strong support, sufficient load may be developed to fail the penetration. Failure may occur in the concrete sleeve anchor, in the sleeve to closure plate weld or in the closure plate to process pipe weld, or in excessive shear and bending of the closure plate. Figure 3.15 shows typical flat plate and forged head penetrations. Forged head penetrations are usually stronger than flat plate types with failure of such penetrations usually limited to loss of the concrete anchor. While conditions 
leading to failure of a non-bellows-type pipe penetration are not a common occurrence, it has been identified as the controlling mode of failure for at least one U.S. containment.

Also shown is Figure 3.15 is a typical bellowed penetration. Although bellows are more commonly found on steel containments, they have been used on concrete containment pipe penetrations as well. They are also commonly used on refueling tube penetrations to accommodate relative thermal motion between the fuel storage building and concrete internal structure and the containment. For the fuel transfer tube bellows, some configurations result in a breach the pressure boundary if the bellows fail while others do not. For those which do, the bellows behave in a similar manner to those shown for a pipe penetration in Figure 3.15. Bellows are typically formed from austenitic stainless steel and are usually designed with more than a single ply in order to limit the bending strain introduced during forming. Multi-ply bellows often have layers of wire mesh between the plies and are often designed with a limiting number of cycles as one of the controlling design parameters. The number and geometry of the convolutions vary with the bellows size and design conditions, with more convolutions often used for hot lines in order to accommodate the increased thermal movements of these lines.

As the containment wall deforms radially outward (and possibly vertically upward) the inner bellows is stretched and the convolutions are flattened. If a single convolution is thought of as a ring, as the bellows is axially stretched, the section modulus is decreased and the equivalent area subjected to the radially inward pressure is increased. In the limit, the bellows approaches a constant radius, multi-ply cylinder, and is subject to buckling. Buckling of the inner bellows, even with subsequent crack formation, does not automatically lead to breach of the pressure boundary since the: outer bellows must also be bypassed.

The outer bellows will be compressed axially, and assuming a failed inner bellows, will be pressurized from the inside. Axial compression will not greatly change the section modulus of a convolution, but will reduce the area which is pressurized, thus reducing the hoop stress compared to the case where the bellows is not axially compressed. In this condition, the outer bellows normally has a high pressure capacity. Further radial growth of the containment will eventually close the bellows convolutions. As in the case of the axially stretched bellows, the meridional bending strains in the convolutions are not normally excessive so that formation of a crack due to the meridional bending strain is unlikely prior to closure of the convolutions. However, additional radial deformation of the containment after the convolutions have been closed does result in a rapid increase in strain with at least a possibility of formation of a crack. Testing has shown that crack formation is unlikely up to closure of the convolutions, but it is probably prudent to assume breach of the pressure boundary at containment deformations above those required to compress the outer bellows convolutions. The load-deformation curve of the containment at strains resulting in bellows compression is normally fairly flat so that a small increase in containment pressure results in a relatively large increase in containment radial deformation. Bellows are often a controlling mode of failure for those plants where they are used.

\subsubsection{Fuel Transfer Tube}

As previously noted the bellows used for the fuel transfer tube may or may not form the containment pressure boundary. For those that form the pressure boundary, their behavior is similar to that described above for pipe penetration bellows. Since fuel transfer tube penetrations are often located at relatively low elevations of the containment, the restraint provided by the baseslab may result in reduced containment deformation compared to pipe penetration locations. Also, the presence of fuel transfer canal shear walls may prevent further containment deformation after the closure of the structure to structure gap in this location.

\subsubsection{Major Hatch Interference Failure}

Interference type failure modes can also occur at major hatches. Consider for instance a personnel airlock and adjacent concrete structure with a reinforced concrete floorslab as shown in Figure 3.16. For some configurations, the airlock sleeve extends over the adjacent structure floor slab and a moveable or semipermanent ramp is used to provide the transition from the floor slab to the airlock floor level as shown in Figure 3.16. The gap between the ramp may close before that between the containment and adjacent structure but the ramp simply slides and, in this case essentially no interference loads are developed on the hatch.

However, if the floor slab and airlock floor elevations 
are about the same elevation and the gap between the floor slab and airlock sleeve closes prior to the gap between the remainder of the adjacent structure and the containment, then large interference forces are developed on the airlock sleeve. These can either crush the sleeve or, more likely, fail the sleeve concrete anchor. If the sleeve concrete anchor fails, failure of the liner to sleeve weld with breach of the pressure boundary may occur.

\subsection{Miscellaneous Failure Modes}

Several additional potential failure modes exist which have not been previously discussed. These include failure of the pressure boundary at an electrical penetration or purge valve, and hydrogen detonations.

\subsubsection{Electrical Penetration Assemblies (EPA)}

Electrical penetration failure is often more temperature sensitive than directly pressure related. This is due to the presence of potting compounds and sometimes elastomeric ' $O$ ' rings. Many types of EPAs exist in current plants although a number of these are no longer supplied. EPAs are normally qualified by test for the plant DBA conditions and many designs are not particularly amenable to analysis at above DBA conditions. Reports such as Reference 3-13 provide a good summary of available knowledge of many U.S. vendor EPAs. In general, EPAs have not been found to be a controlling failure mode for most containment evaluations conducted to date.

\subsubsection{Purge Valves}

Purge valves used for containment typically are 36 inch or larger motor operated butterfly valves. Potential failure modes include loss of the sleeve concrete anchorage, failure of the butterfly disk or pivot, or leakage past the valve seat. Loss of concrete anchorage and failure of the valve disk or pivot have typically been shown to have very high pressure capacities. Often the valve seat contains an elastomeric seal rather than metal to metal seat and is hence subject to high temperature deterioration and leakage. If leakage is predicted, it is controlled by the metal annulus area after loss of the elastomer.

\subsubsection{Hydrogen Detonation}

Some types of plants including BWR Mark III and ice condenser plants may have the potential for generating hydrogen in detonatable mixtures. Predicted pulse shapes and periods have indicated the potential to excite the containment dynamically rather than as a quasistatic loading as previously discussed. Evaluation of hydrogen detonation not only requires a consideration of the containment strength and ductility characteristics as previously discussed, but also the dynamic characteristics such as damping, modal characteristics, and strain rate effects. In general considerable uncertainty is associated with the dynamic pulse rise time, shape and period as well as the peak dynamic pressure.

In the case of hydrogen detonation, the pulse may be distributed essentially axisymmetrically within the containment or may be unsymmetric and highly localized. The concrete internal structure and equipment may introduce a great deal of scattering in the wave front as well. In evaluation of the dynamic response of the containment, both the reflected wave and the incident wave must be considered. Also strain rate effects in both concrete and steel containments typically can result in the order of a 20 percent increase in strength for commonly encountered hydrogen pulse rise times compared to static values.

\subsection{Analysis Methods}

Both finite element methods (FEM) and simple hand analysis techniques are used for analysis of containment structures and both have individual strengths and weakness. FEM methods have the capability of modeling complex geometric shapes and are used for such components as personnel hatch bulkheads, etc., when tributary areas and redundant load paths may make hand calculations uncertain. To be useful in this type of evaluation, a FEM computer program must have both large deformation and large strain capability. Most FEM axisymmetric models do not have the level of detail to model liner anchor stiffness and tearing effects, liner knuckle behavior and similar type of failures in a single axisymmetric model. In addition, some codes suffer from numerical instability for some types of behavior such as formation of a hinge at the cylinder wallbaseslab junction. In such instances it is difficult to judge whether a physical failure is likely or merely a numerical instability caused by large deformation with little or no pressure increase until sufficient deformation is reached that the hoop reinforcing steel carries the load. FEM in themselves do not eliminate the sources 
of the majority of the uncertainty associated with analysis of the type of failures previously described. Uncertainties in material strengths and inelastic behavior, thermal gradients, crack spacing, liner anchorage locations, and many other parameters still require considerable judgment by the analyst.

Simple hand calculations probably form an economical and adequate means of evaluating the majority of the failure modes discussed here. At least the initial screening and ranking of capacities for different modes of failure together with bounding calculations as required can usually most economically be done using hand calculations. If additional refinement of one or more of the controlling modes is desirable FEM can sometimes be used to reduce the range of uncertainty.

\subsection{Probabilistic Description of Capacity}

In view of the inherent variability associated with ultimate pressure capacity of virtually all of the potential modes of failure, a probabilistic description of containment pressure capacity is normally required. Since the pressure capacity is treated as a random variable, it is possible for more than one mode of failure to significantly contribute to the overall risk. This section discusses some aspects of how the capacities may be described in a probabilistic form.

\subsubsection{Development of Failure Probabilities}

The pressure capacities are normally evaluated using limit state analyses for the various failure modes considered. In most investigations, failure is interpreted as incipient leakage, which may be a small controlled leak or a large catastrophic rupture. The calculated capacities are dependent on several factors, including the material properties, modeling assumptions, and the postulated failure criteria. For concrete containments, in addition to material strengths, a major source of uncertainty in the failure criteria is the expected liner strain resulting in failure. Biaxial strains, gage length effects, and strain concentrations can greatly reduce the expected global strain at failure when compared to the elongation data developed from standard specimen ultimate tests. Considerable variability is introduced, not only in the failure criteria but in analytical modeling and other assumptions as well. In view of the expected variability in the basic parameters and the analytical methods, the pressure capacity for any failure mode is considered to be a random variable. It is often assumed that the pressure capacities are characterized by a lognormal probability distribution. The lognormal distribution is a mathematically tractable distribution and has been shown to be a valid description for the variability in most material strengths. In addition, for a random variable that can be expressed as the product or quotient of several random variables, the distribution of the dependent variable tends to be lognormal regardless of the distributions of the independent base variables. However, other assumed distributions may be equally valid. Fortunately, the overall risk is not particularly sensitive to the particular type of mathematical distribution assumed.

With the pressure capacity for a given failure mode assumed to be a lognormal random variable and denoting it as $P$, the probability of failure occurring at a pressure equal to or less than a specific value $p$ is expressed as:

$$
P_{f}=\operatorname{Prob}(P \leq p)=\Phi\left[\frac{\ln (p \mid \hat{P})}{\beta}\right]
$$

where:

$$
\begin{aligned}
\boldsymbol{P}_{\boldsymbol{f}}= & \text { probability that failure occurs at a pressure } \\
\boldsymbol{P} \leq \boldsymbol{p} & \text { random internal pressure capacity } \\
\boldsymbol{P}= & \text { logarithmic standard deviation of } \boldsymbol{P} \\
\hat{\boldsymbol{P}}= & \text { Median (50th percentile) pressure capacity } \\
\Phi[]= & \text { cumulative distribution function for a } \\
& \text { standard normal random variable }
\end{aligned}
$$

In Equation (3-5), the pressure capacity for a given failure mode is probabilistically described by the following expression:

$$
P=\hat{P} \cdot M \cdot S
$$

In the above equation, $\hat{P}$, the median pressure capacity, represents the internal pressure level for which there is a $50 \%$ probability of failure, or equivalently, the best estimate of the pressure capacity. $M$ is a lognormally distributed random variable having a unit median value and a logarithmic standard deviation, $\beta_{M}$, which represents the uncertainty due to analytical modeling. $S$ is also a lognormally distributed random variable having a unit median value and the logarithmic standard deviation, $\beta_{S}$, representing the uncertainty associated with the material properties. The overall uncertainty in the 
pressure capacity is obtained by taking the square root of the sum of the squares of $\beta_{M}$ and $\beta_{S}$.

$$
\beta=\sqrt{\beta_{M}^{2}+\beta_{S}^{2}}
$$

As a result, the probabilistic pressure capacity is described by three parameters: the median pressure, $\hat{\boldsymbol{P}}$, the modeling uncertainty, $\beta_{M}$, and the material strength uncertainty, $\beta_{S}$.

The logarithmic standard deviations, $\boldsymbol{\beta}_{M}$ and $\boldsymbol{\beta}_{S}$, quantify the variability due to a lack of knowledge resulting from differences between the analytical model and the real structure. Modeling uncertainties are introduced by assumptions used to develop analytical models and their ability to adequately represent the failure condition. The strength uncertainties correspond to variabilities related to material resistance. Examples of the sources of such uncertainties include: variability in material yield and ultimate strengths, stress-strain relationships, and the influence of temperature on material strength.

\subsubsection{Variability in Material Properties}

The materials for most containment structures are typically characterized in terms of minimum specified strengths. For example, the tendons, reinforcing bars and the liner plate are specified in terms of a standard material grade having minimum yield and ultimate strengths. However, since these are minimum values, the median (50th percentile) strengths are expected to be higher. Site specific test results are always preferable. In the absence of a site-specific test results for the different materials, the median material strengths and variabilities can be estimated from generic data in the literature. In some cases, these estimates may be conservative. However, for those materials for which site-specific test data are available, the median strengths and variabilities can usually be obtained from the sample statistics. The median values and logarithmic standard deviations are usually evaluated with the assumption that all of the material strengths can be characterized by a lognormal distribution.

Since elevated temperatures are considered in most accident investigations, it is usually necessary to estimate the influence of those temperatures on the material strengths. Normally the analyst does not have the luxury of detailed thermal gradients, etc., for the possible above DBA accident conditions. Due to this lack of preciseness in thermal gradients, it is usually acceptable to estimate temperature dependent strength reduction factors from available data on the same or similar materials. This approach is taken because in much of the test data used to evaluate the temperature effects [c.f. References 3-14 and 3-15] the material strengths at elevated temperatures are referenced to the strengths at room temperature. Given a median characteristic material strength at room temperature, $\hat{S}_{R M . T}$, the median material strength at a higher temperature can be estimated by:

$$
\ddot{S}_{T}=\ddot{R}_{T} \cdot \ddot{S}_{R M T}
$$

where $\hat{R}_{T}$ is the median temperature strength reduction factor. Noting that there is uncertainty in both the material strength at room temperature and in the reduction factor, the overall logarithmic standard deviation of the material strength at the elevated temperatures is estimated as:

$$
\beta_{S}=\sqrt{\beta_{R T}^{2}+\beta_{R M T}^{2}}
$$

in which $\beta_{R T}$ is the logarithmic standard deviation associated with the temperature strength reduction factor and $\beta_{R M . T}$ is the logarithmic standard deviation of the material strength at room temperature.

\subsubsection{Modeling Variability}

Uncertainties will also exist in the estimated pressure capacities due to differences between the analytical idealization of the structure and the real conditions. There are numerous possible sources of modeling uncertainties. Examples of the possible sources include: assumptions used to develop internal force distributions, failure criteria, and use of empirical formulae or a single FEM code. Moreover, since they are dependent on the particular failure mode under consideration, they must be evaluated on a case-by-case basis. However, in many instances, the evaluation of these uncertainties would require very detailed analysis and/or extensive data which may not be available. As a result, it is usually necessary to use subjective evaluation and engineering judgment to estimate these uncertainties.

\subsubsection{Variability Truncation}

Truncation in the variability can be expected in several of the parameters influencing the capacities described 
by a lognormal distribution. For instance, typical material ultimate strength test data normally show some lower bound cut-off, below which there is essentially no probability of failure. This cut-off is often above the value which would be indicated for the extreme "tail" (say, minus three standard deviations) of a lognormal distribution. As such, the probability of failure predicted by use of a lognormal distribution may be overconservative in the strength range governed by the tail of the distribution. Based on the available material data some value (or range of values) may be assigned as a lower bound. Alternatively, at least initially, truncation may not be incorporated in the risk analysis, recognizing that some conservatism is introduced into the results. Also, there are normally insufficient data upon which to determine a cut-off in the modeling variability without performing numerous bounding calculations.

\subsubsection{Correlation of Failure Modes}

For many of the failure modes described here, the failure pressure variabilities may not be completely independent. For the purpose of estimating the correlation between structural failure modes, the uncertainty is often subdivided into two independent components:

1. Uncertainty in modeling

2. Uncertainty in strength

These uncertainties may be represented by two independent random factors with logarithmic standard deviations, $\beta_{M}$ and $\beta_{S}$, respectively. The combined coefficient of variation is then given by:

$$
\beta=\sqrt{\beta_{M}^{2}+\beta_{S}^{2}}
$$

The advantage of splitting the uncertainty into these two components is that for a given pair of failure modes the uncertainty factor for one of the components may be correlated for both modes, while the other is independent. However, for other plants it may be found in all cases that if the uncertainty in modeling for a given failure mode is expected to be correlated with the uncertainty in modeling for a different mode, the uncertainty in the strengths of the same two modes may also be expected to be highly correlated. For example, for a prestressed concrete containment the strengths of the various shell membrane capacities are usually governed largely by the tendon capacities for which common strength values are usually used and hence a high degree of correlation in the uncertainty of the strength parameters is expected. Similarly, for these same failure modes, similar modeling assumptions are used including failure strain criteria, similar load redistribution due to tendon friction, etc. Likewise, while the strength and modeling assumptions used to evaluate a personnel airlock and emergency airlock doors are correlated, these assumptions are completely different from those used for the membrane capacities. Similar considerations for every pair of typical failure modes as shown in Table 3.1 lead to the simplified example correlation matrix shown in Table 3.2. In this table, the uncertainty factors are assumed to be either perfectly correlated, in which case, a cross is placed in the appropriate box, or perfectly uncorrelated. Perfect correlation is assumed whenever the degree of correlation is estimated to be more than one-half. A more refined approach may require a percentage correlation between modes but usually this degree of effort is unwarranted.

\subsection{Factors of Safety of Existing Plants}

As noted previously, the current codes and standards provide a high degree of reliability for the containment to withstand the DBA conditions without failure. Many of the potential modes of failure described here are only credible at beyond design conditions and are hence not directly addressed by the codes. As an example, punching shear failures are not treated in the codes since the design requirements prevent interference at the DBA conditions. Most potential modes of failure involve at least some degree of inelastic response, and the codes do not require the calculation of a margin of safety even for such failure modes as shell membrane failures or baseslab shear or flexure failures for which code imposed criteria exist.

Factors of safety are defined in this section as the failure pressure divided by the design basis accident pressure. The factors of safety shown here correspond essentially to the DBA temperature, or in some cases the DBA temperature rounded up to an even hundred degrees Fahrenheit (i.e. from the DBA temperature $280^{\circ} \mathrm{F}$ to $300^{\circ} \mathrm{F}$ ). At higher accident temperatures reduced factors of safety corresponding to lower material strength values occur although higher temperature factors are not included here. Also, different failure modes may control at higher 
temperature as is likely for elastomeric seal failures at high temperatures well above the design basis. The lowest (controlling) factor of safety is shown as well as the factor of safety for hoop, dome, and baseslab failure. The latter three modes are shown since they are all controlled by existing code requirements. The controlling mode of failure may also be a hoop or baseslab failure or may be a liner tear or interference type of failure which are not directly addressed by current codes.

Factors of safety are shown for reinforced concrete, prestressed concrete, and free standing steel PWR containments in Tables 3.3, 3.4, and 3.5 respectively. BWR Mark II and Mark III containments show similar trends. The factors of safety shown here are all the results of probabilistic evaluations. Consequently both median factors of safety and some measure of a lower bound factor of safety are available. In this case the 95 percent non-exceedance factor of safety (95\% NEP) is shown. The 95\% NEP can be considered to represent a factor of safety comparable to a conservative deterministic factor of safety. Shown here are the average (numerical mean) of the medians and $95 \%$ NEP as well as the range of values for about six plants in each groups.

With this small sample, conclusions should not be drawn concerning the relative capacities of various types of plants, nor should any statistical robustness be implied. Rather the conclusions that can be drawn are that the current codes and standards result in median factors of safety between 3 and 4 and 95\% NEP in the range of 2.5. Median controlling factors of safety which may or may not be directly addressed by the codes are likely to be in the 2.5 range.

\subsection{References}

3-1. ASME Boiler and Pressure Vessel Code, Section III Divisions 1 and 2, 1995.

3-2. Mirza, S.A., and J.G. MacGregor, "Variability of Mechanical Properties of Reinforcing Bars", Journal of the Structural Division, ASCE, Vol. 105 No. ST5, May 1979.

3-3. Manjoine, M., "Ductility Indices at Elevated Temperatures", Journal of Engineering Materials and Technology, Transactions, ASME, Vol. 97, Series H, No.2, 1975.
3-4. Galletly, G.D., "Elastic and Elastic - Plastic Buckling of Internally Pressurized 2:1 Ellipsoidal Shells", Trans. of the ASME, Journal of Pressure Vessel Technology, Vol. 100 , Nov. 1978, pp 335-343.

3-5. Galletly, G.D. and R.W. Aylward, "Plastic Collapse and Controlling Failure Pressures of Thin 2:1 Ellipsoidal Shells Subjected to Internal Pressure", Trans. of the ASME, Journal of Pressure Vessel Technology Vol. 101, Feb. 1979, pp 64-71.

3-6. Galletly, G.D. and S.K. Radhamohan, "Elastic Plastic Buckling of Internally Pressurized Thin Torispherical Shells", Trans. of the ASME, Journal of Pressure Vessel Technology, Vol. 101, Aug. 1979, pp 216-225.

3-7. Radhamohan, S.K. and G.D. Galletly, "Plastic Collapse of Thin Internally Pressurized Torispherical Shells", Trans. of the ASME, Journal of Pressure Vessel Technology, Vol. 101, Nov. 1979, pp 311-320.

3-8. Bushnell, D., "BOSOR 5 - Program for Buckling of Elastic - Plastic Shells of Revolution Including Range Deflections and Creep", Computers and Structures, Vol. 6, 1976, pp 221-239.

3-9. Wesley, D.A., et al. "Pressure - Dependent Fragilities for Piping Components Pilot Study on Davis-Besse Nuclear Power Station" NUREG/CR - 5603, EGG - 2607, Oct. 1990.

3-10. Wesley, D.A., "Screening Methods for Developing Internal Pressure Capacities for Components in Systems Interfacing with Nuclear Power Plant Reactor Coolant Systems", NUREG/CR-5862, EGG-2673, May 1992.

3-11 Kaplan, A., "Buckling of Spherical Shells", from Thin Shell Structures, Y.C. Fung and E.E. Sechler, Editors, Prentice Hall, N.J. 1974.

3-12 "Parker O-Ring Handbook," Prepared by Parker Seal Group, 1982. 
3-13 Sebrell, W.A., "The Potential for Containment Leak Paths through Electrical Penetration Assemblies Under Severe Accident Conditions," NUREG/CR-3234, SAND83-0538, Sandia National Laboratories, Albuquerque, New Mexico, July 1983.

3-14 Holmes, M., et al, "The Effects of Elevated Temperatures on the Strength Properties of Reinforcing and Prestressing Steels," The Structural Engineer, Vol. 60B, No.1, March, 1982.,

3-15 Abrams, M.S., "Compressive Strength of Concrete at Temperatures to 1600F," Temperature and Concrete, ACI Special Publication SP25, American Concrete Institute.

3-16 Park, P. and T. Paulay, "Reinforced Concrete Structures", J. Wiley \& Sons, N.Y. 1975. 
Table 3.1 Failure Modes

\begin{tabular}{|c|l|}
\hline \multicolumn{1}{|c|}{ Failure Mode Number } & \multicolumn{1}{|c|}{ Failure Mode } \\
\hline \hline 1 & Wall-Basemat Junction Flexure \\
\hline 2 & Wall-Basemat Junction Shear \\
\hline 3 & Basemat Flexure \\
\hline 4 & Basemat Shear \\
\hline 5 & Cylinder Hoop Membrane \\
\hline 6 & Dome Meridional Membrane \\
\hline 7 & Cylinder Meridional Membrane \\
\hline 8 & Personnel Airlock Door \\
\hline 9 & Emergency Airlock Door \\
\hline
\end{tabular}

Table 3.2 Correlation between Failure Modes (Strength and Modeling Uncertainty)

$\begin{array}{rrrrrrrrrr} & 1 & 2 & 3 & 4 & 5 & 6 & 7 & 8 & 9 \\ 1 & \mathrm{x} & \mathrm{x} & & & & & & & \\ 2 & & \mathrm{x} & & & & & & & \\ 3 & & & \mathrm{x} & \mathrm{x} & & & & & \\ 4 & & & & \mathrm{x} & & & & & \\ 5 & & & & \mathrm{x} & \mathrm{x} & \mathrm{x} & & \\ 6 & & \text { Symmetric } & & & \mathrm{x} & \mathrm{x} & & \\ 7 & & & & & & \mathrm{x} & & \\ 8 & & & & & & & \mathrm{x} & \mathrm{x} \\ 9 & & & & & & & & & \mathrm{x}\end{array}$


3. Containment Overpressure Failure Modes

Table 3.3 Reinforced Concrete Factors of Safety (Typical Existing Plants)

\begin{tabular}{||l|c|c|}
\hline \multicolumn{1}{|c|}{ Failure Mode } & \multicolumn{2}{c|}{ Factor of Safety } \\
\hline \hline & Avg. Median (Range) & Avg. 95\% (Range) \\
\hline Controlling & $3.0(2.4-3.4)$ & $2.2(1.5-2.5)$ \\
\hline Hoop & $4.0(3.3-4.7)$ & $2.9(2.3-3.4)$ \\
\hline Dome & $4.7(3.6-6.3)$ & $3.4(2.5-4.3)$ \\
\hline Baseslab & $3.8(2.4-6.2)$ & $2.8(1.5-4.6)$ \\
\hline
\end{tabular}

Table 3.4 Prestressed Concrete Factors of Safety (Typical Existing Plants)

\begin{tabular}{||l|c|c|}
\hline \multicolumn{1}{|c|}{ Failure Mode } & \multicolumn{2}{c|}{ Factor of Safety } \\
\hline \hline & Avg. Median (Range) & Avg. 95\% (Range) \\
\hline Controlling & $2.7(2.4-3.0)$ & $1.9(1.7-2.1)$ \\
\hline Hoop & $3.1(2.6-3.6)$ & $2.4(2.1-2.6)$ \\
\hline Dome & $3.7(2.9-5.2)$ & $3.0(2.3-4.1)$ \\
\hline Baseslab & $3.0(2.6-3.4)$ & $2.1(1.7-2.4)$ \\
\hline
\end{tabular}

Table 3.5 Freestanding Steel Factors of Safety (Typical Existing Plants)

\begin{tabular}{||l|c|c||}
\hline \multicolumn{1}{|c|}{ Failure Mode } & \multicolumn{2}{c|}{ Factor of Safety } \\
\hline \hline & Avg. Median (Range) & Avg. 95\% (Range) \\
\hline Controlling & $3.4(2.2-6.4)$ & $2.8(1.8-5.5)$ \\
\hline Hoop & $3.5(2.3-6.4)$ & $2.9(1.8-5.5)$ \\
\hline Dome & $3.5(2.3-6.7)$ & $2.9(1.8-5.7)$ \\
\hline Baseslab & & \\
\hline
\end{tabular}


3. Containment Overpressure Failure Modes
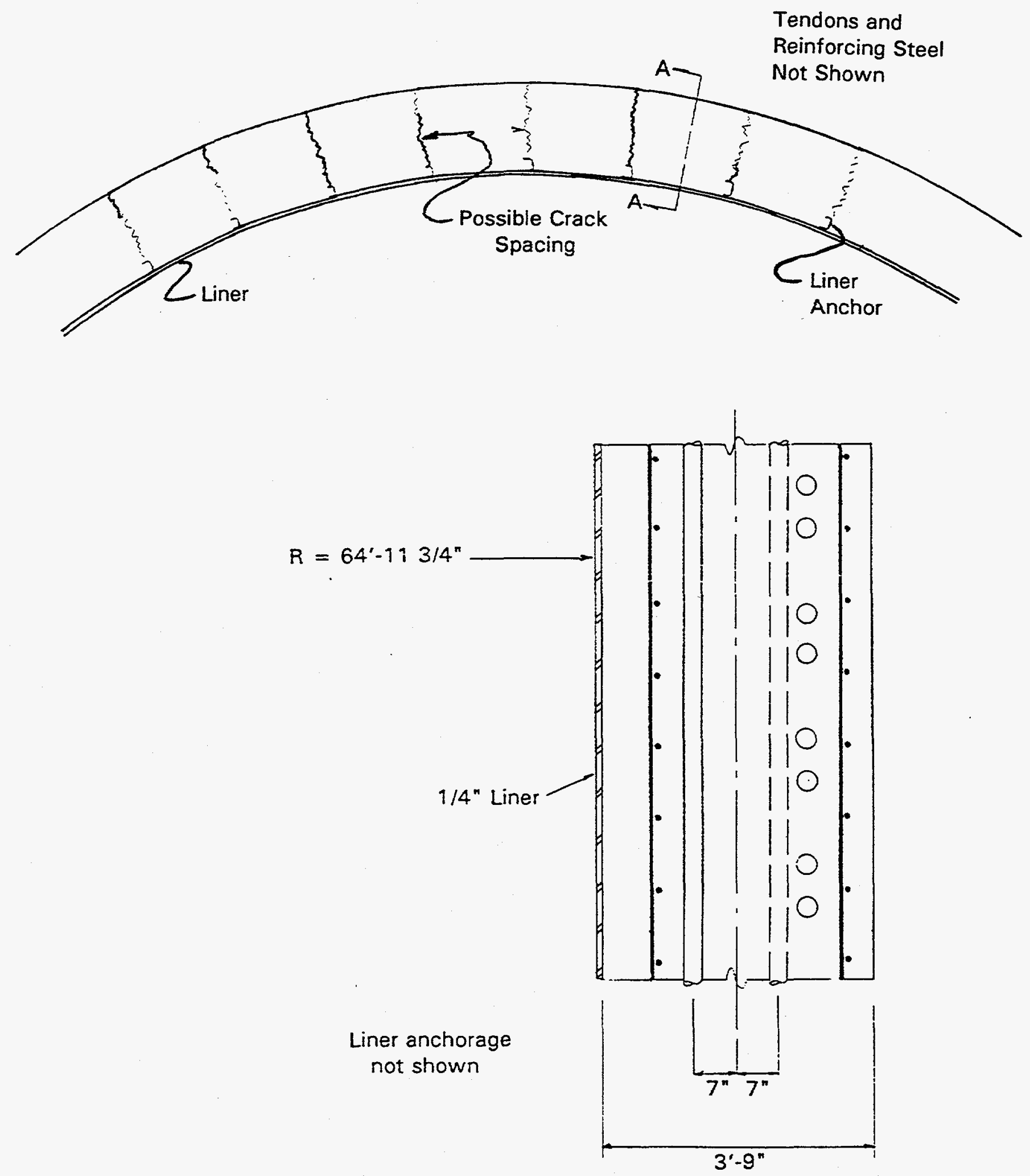

Section A-A

Figure 3.1 Typical (Prestressed) Wall Section and Possible Crack Spacing 
3. Containment Overpressure Failure Modes

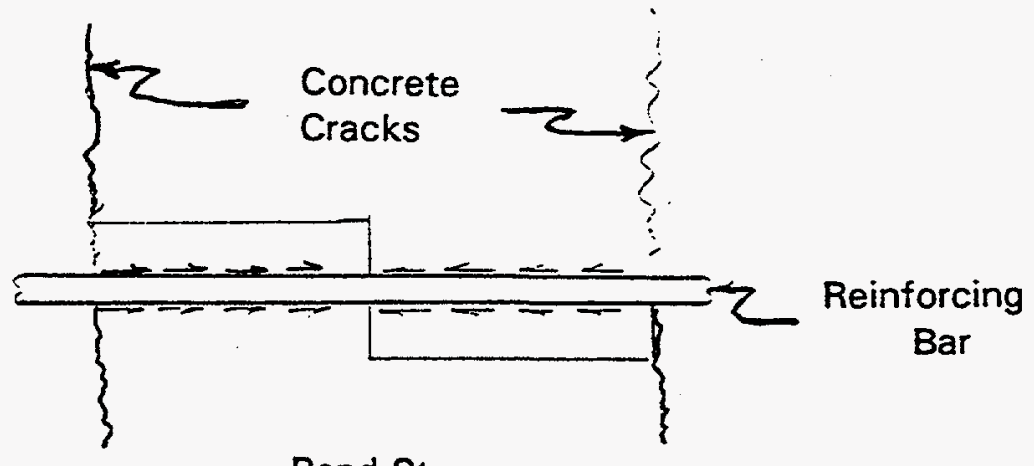

Bond Stress
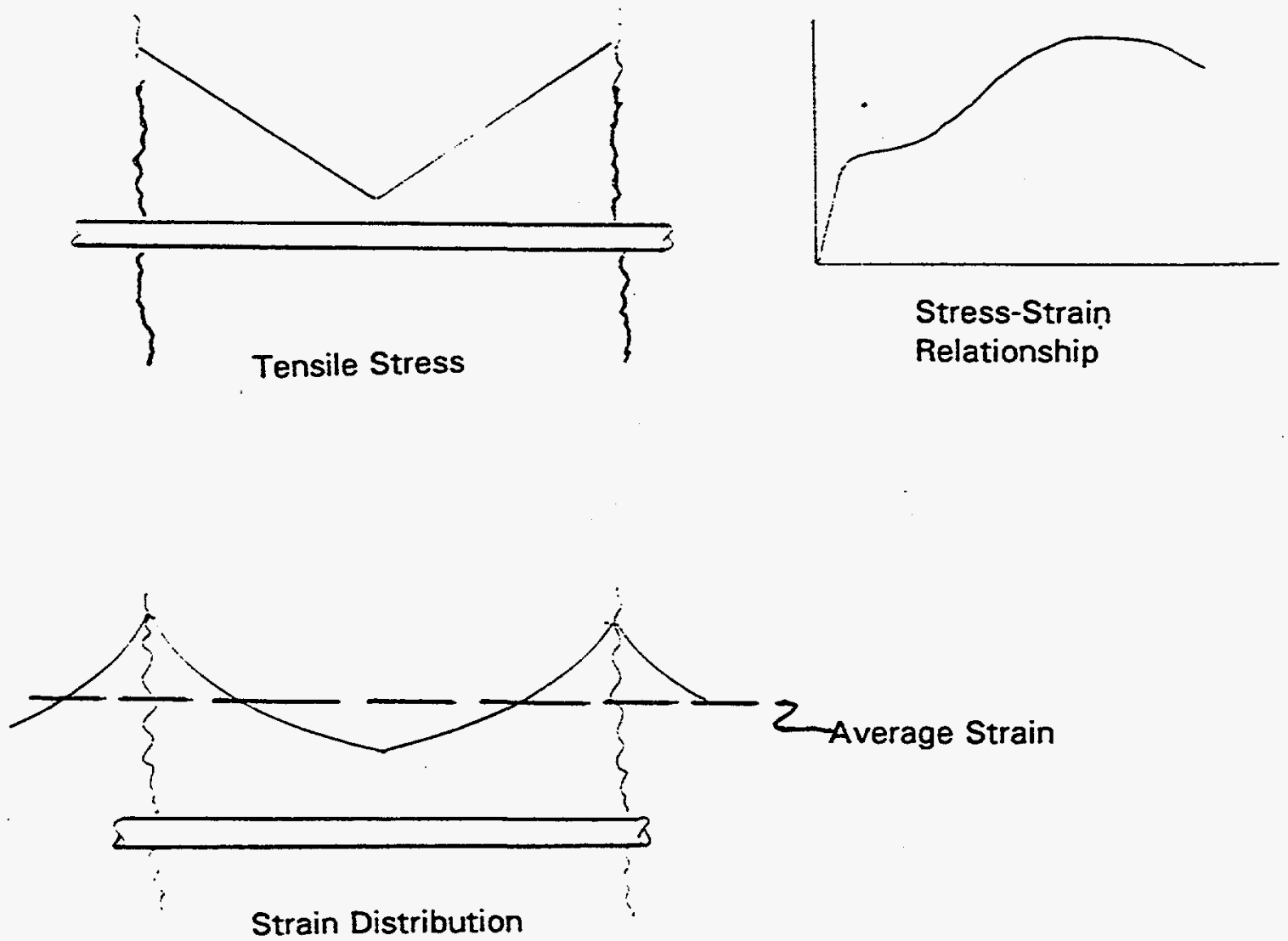

Figure 3.2 Estimate of Average Membrane Strain 


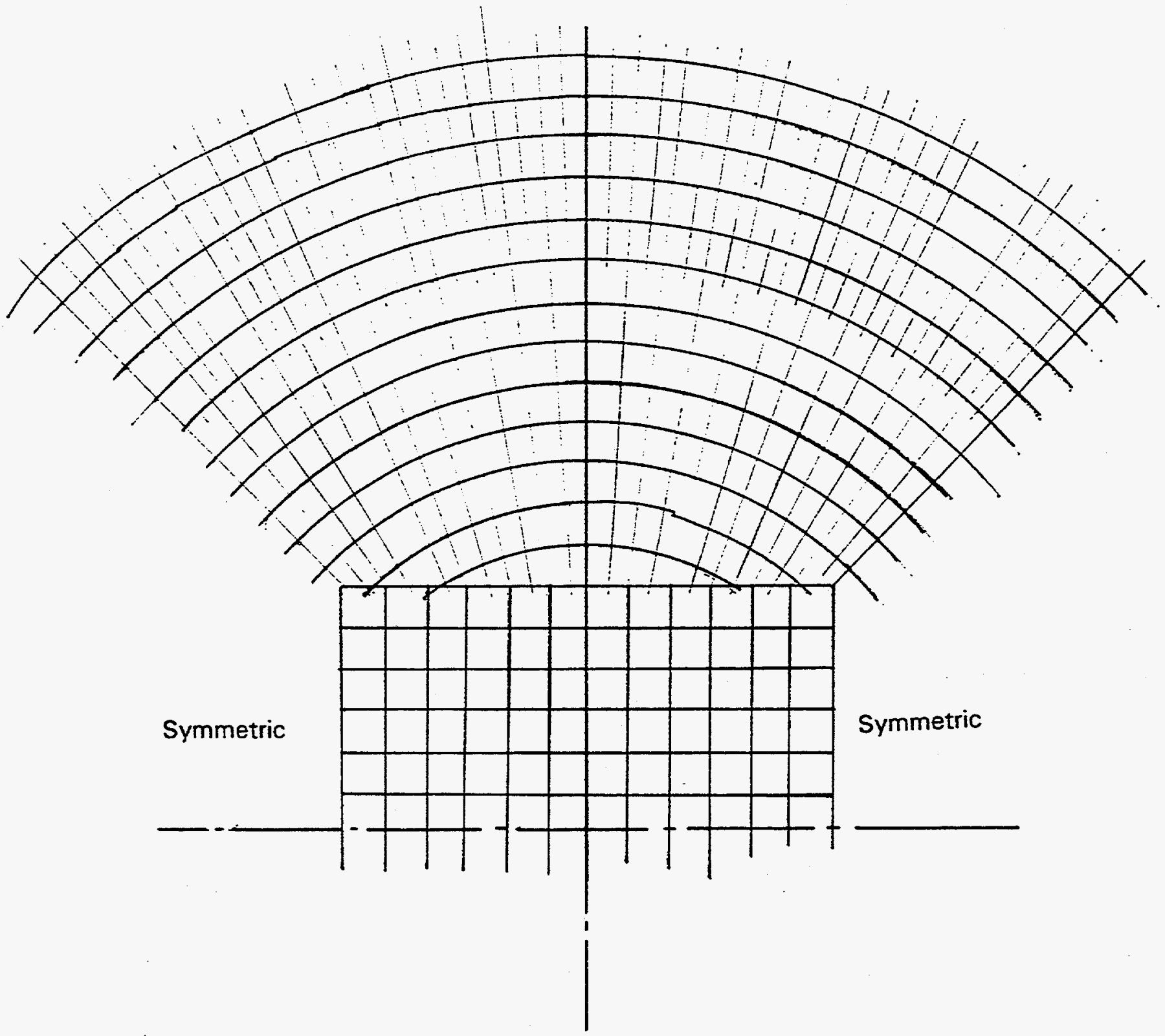

Figure 3.3 Example Dome Reinforcing Bar Layout; Rectangular Grid Apex, with Hoop and Radial Bars 
3. Containment Overpressure Failure Modes
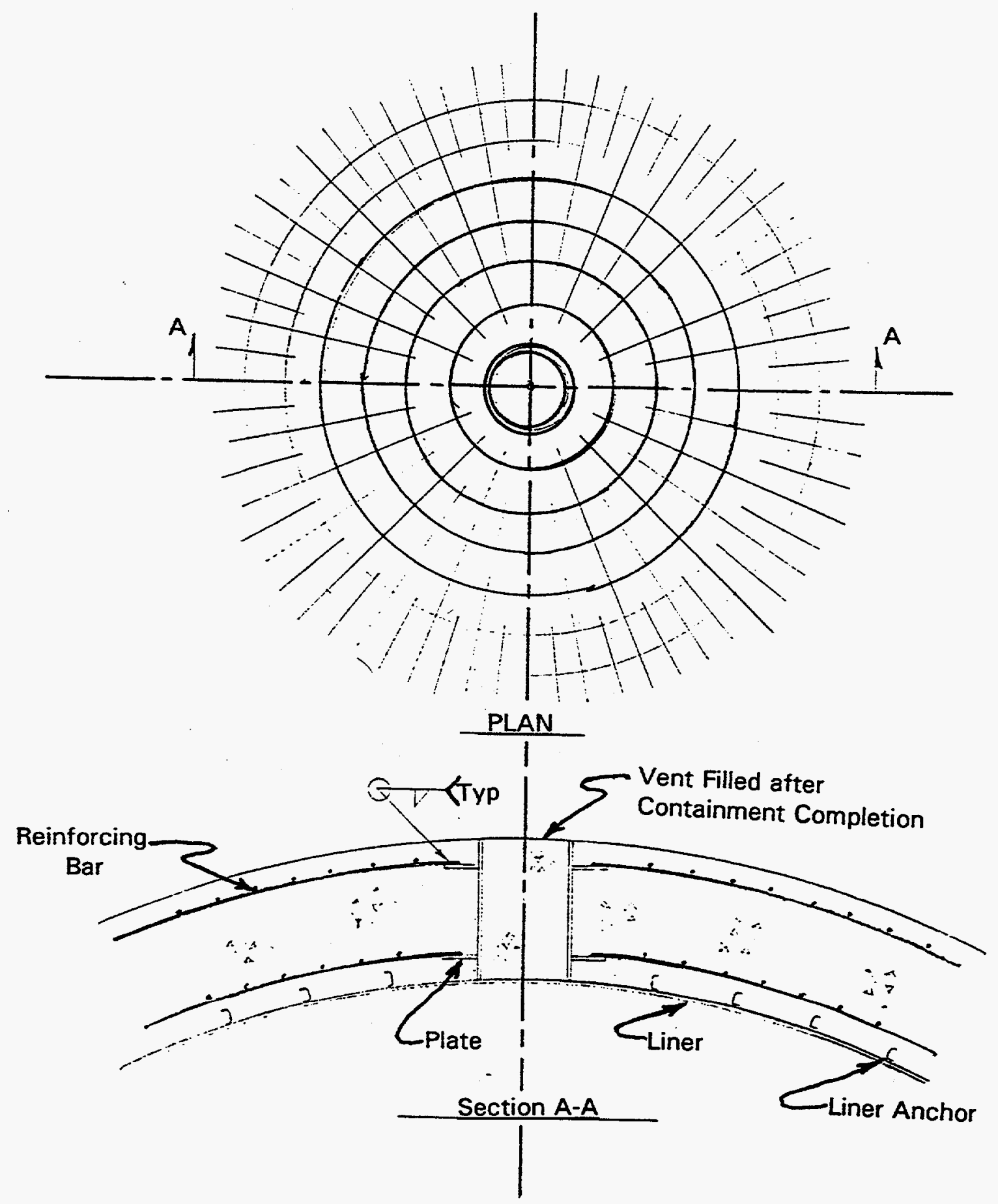

Figure 3.4 Example Dome Construction Vent Detail 
3. Containment Overpressure Failure Modes

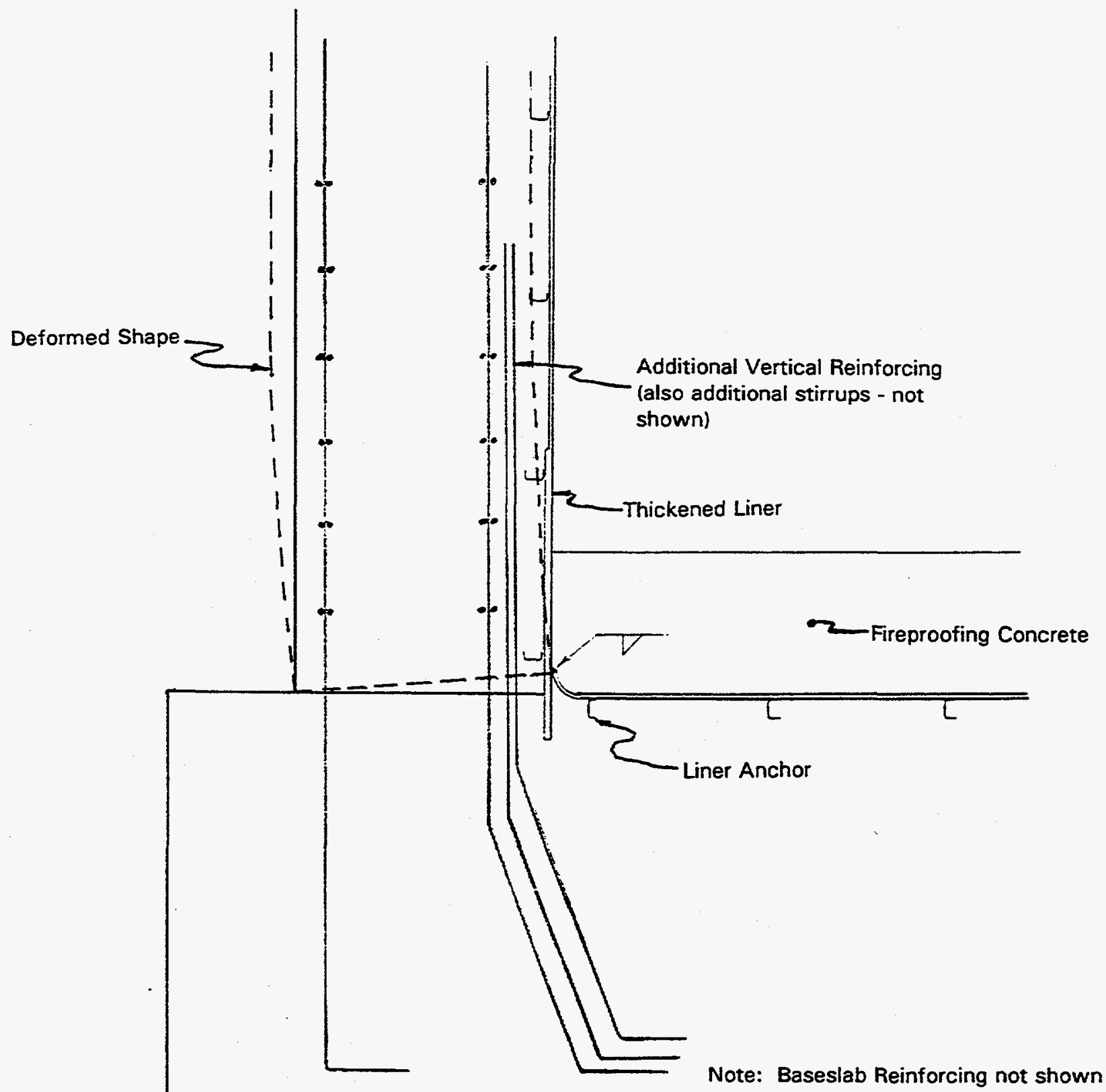

Figure 3.5 Typical Baseslab Liner Knuckle Detail 
3. Containment Overpressure Failure Modes

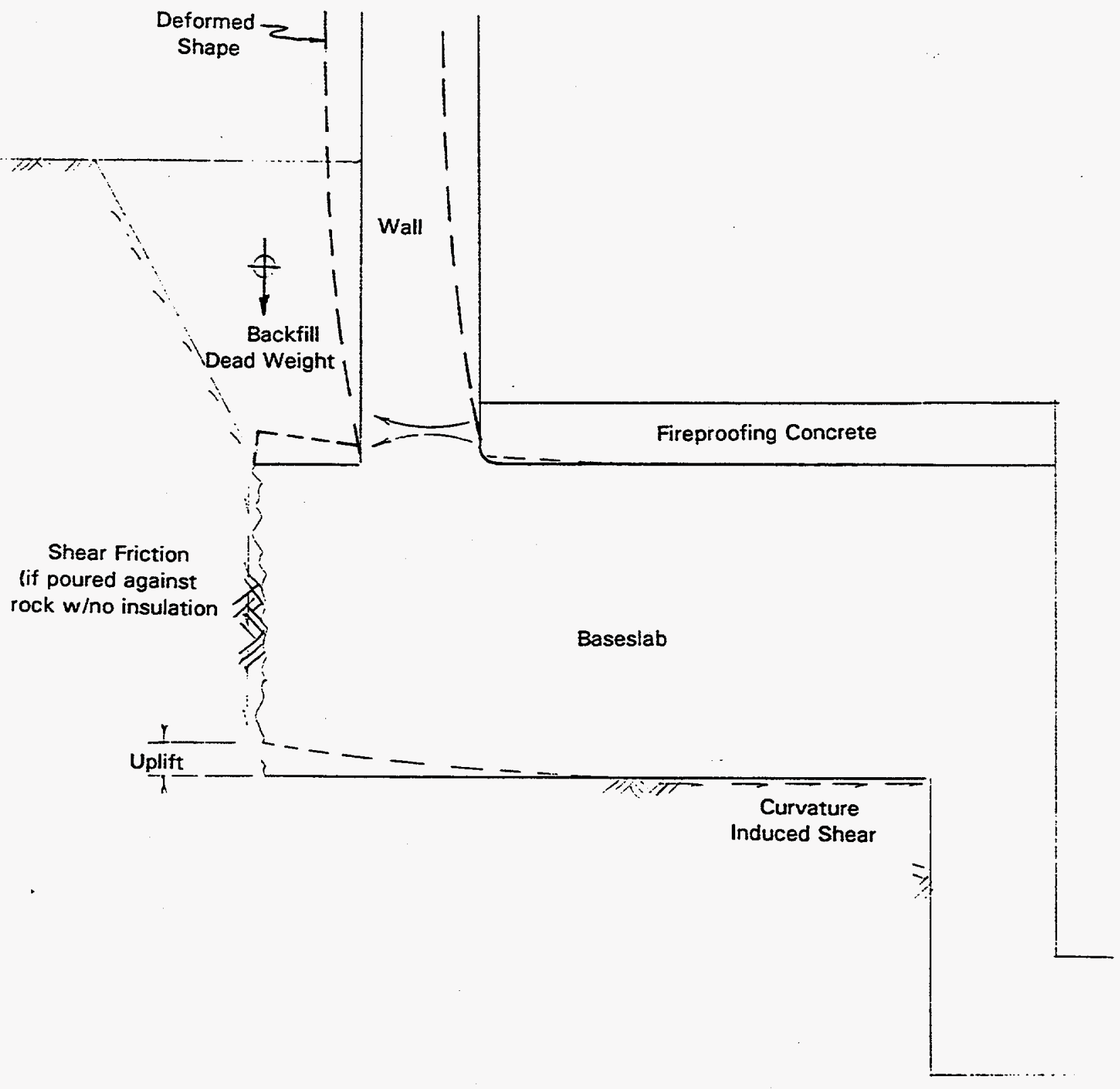

Figure 3.6 Possible Baseslab Restraints 
3. Containment Overpressure Failure Modes

Note: Reinforcing not shown

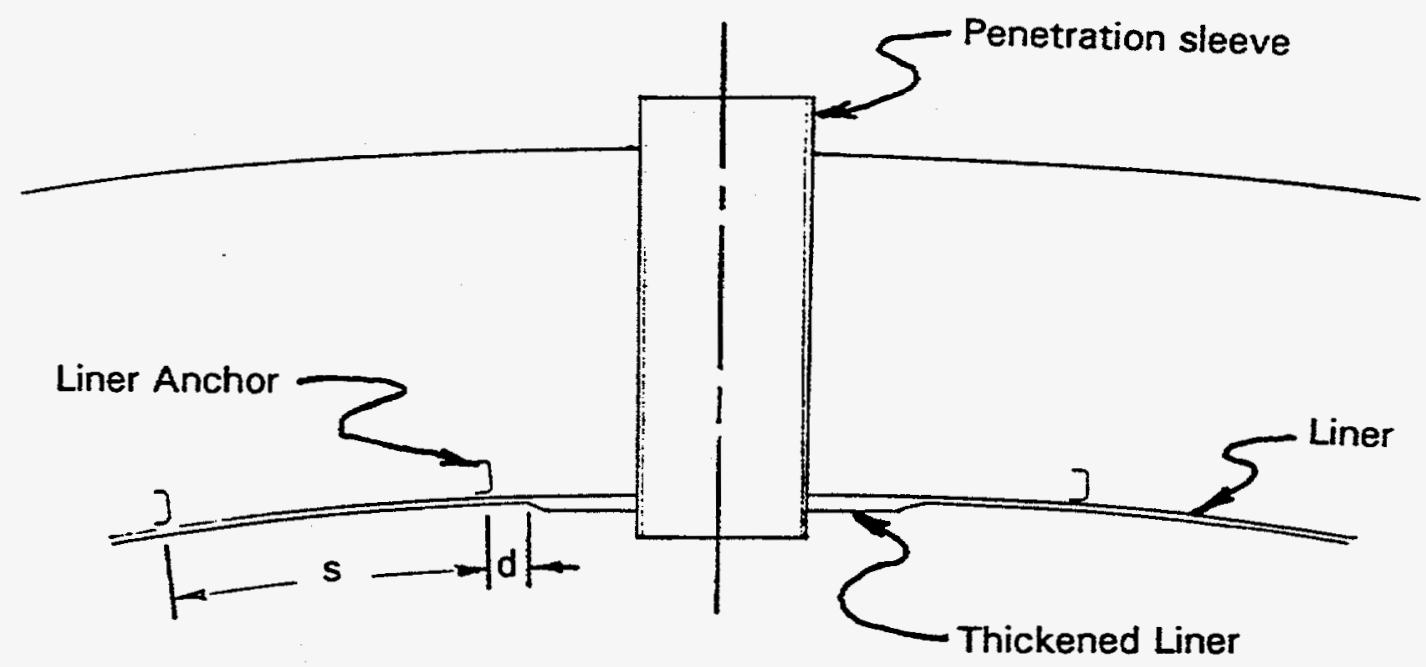

Figure 3.7 Typical Liner Strain Concentration 
3. Containment Overpressure Failure Modes

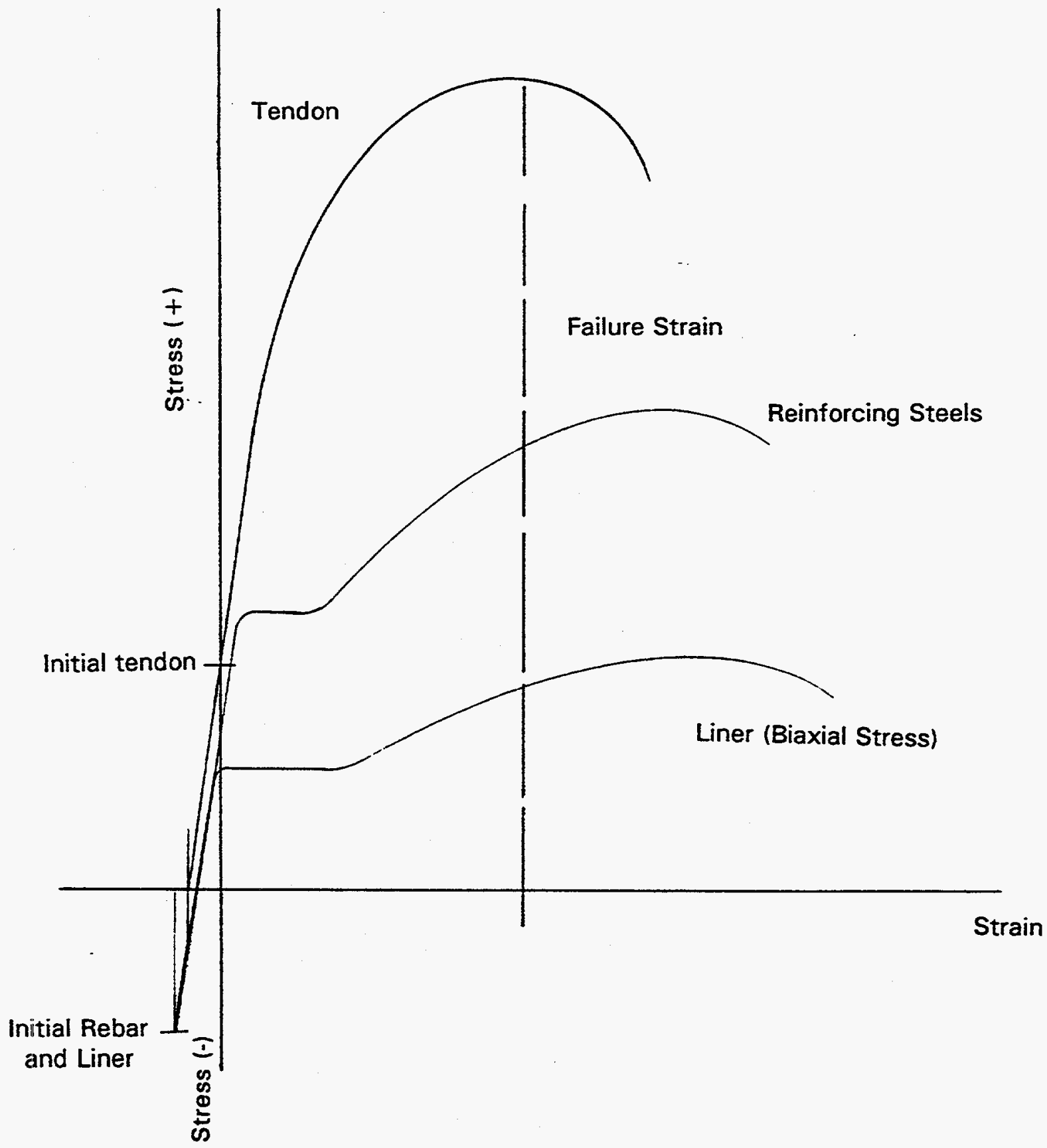

Figure 3.8 Tendon, Reinforcing Steel and Liner Compatibility 


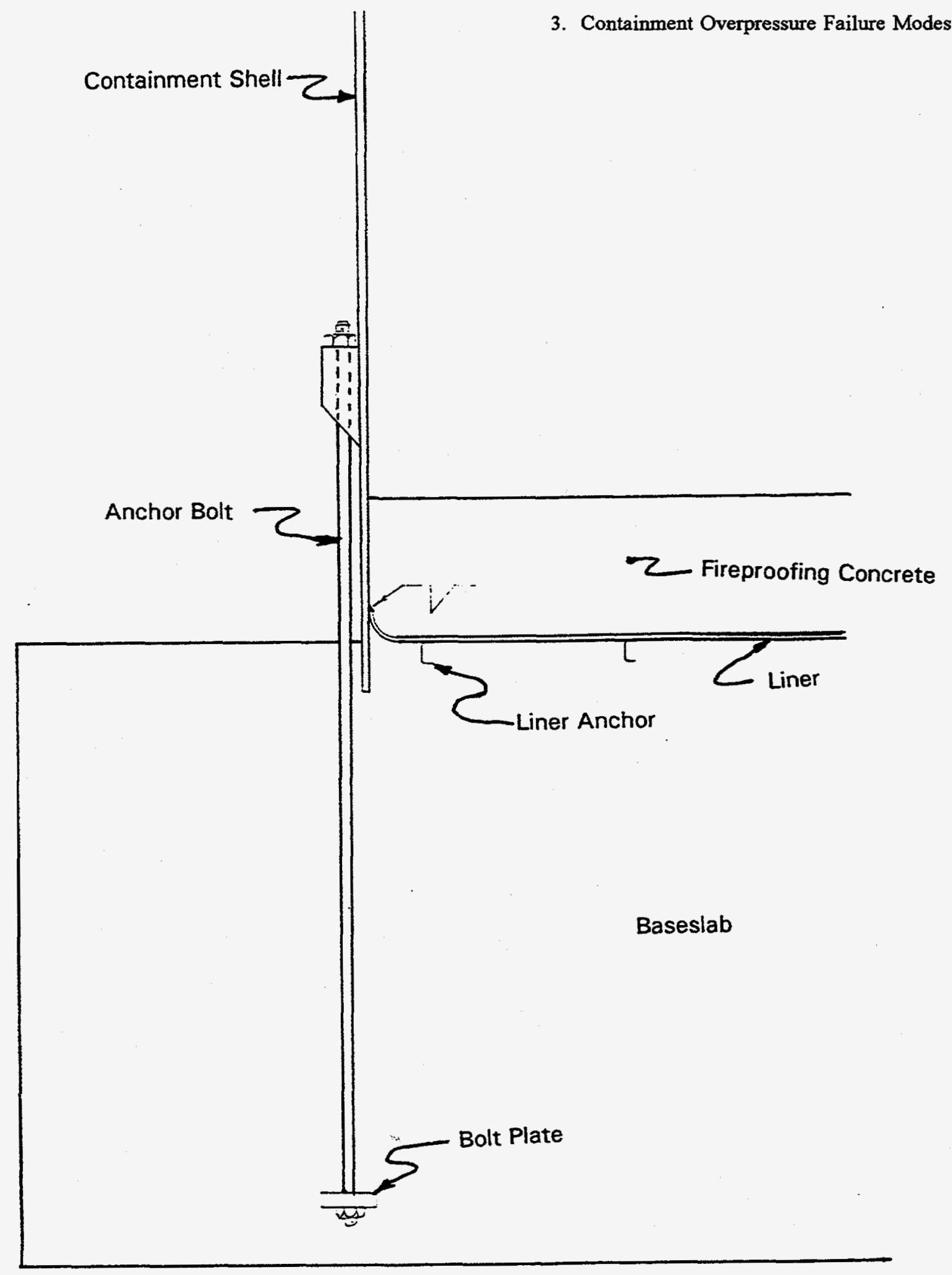

Figure 3.9 Steel Containment Anchor Bolt 
3. Containment Overpressure Failure Modes

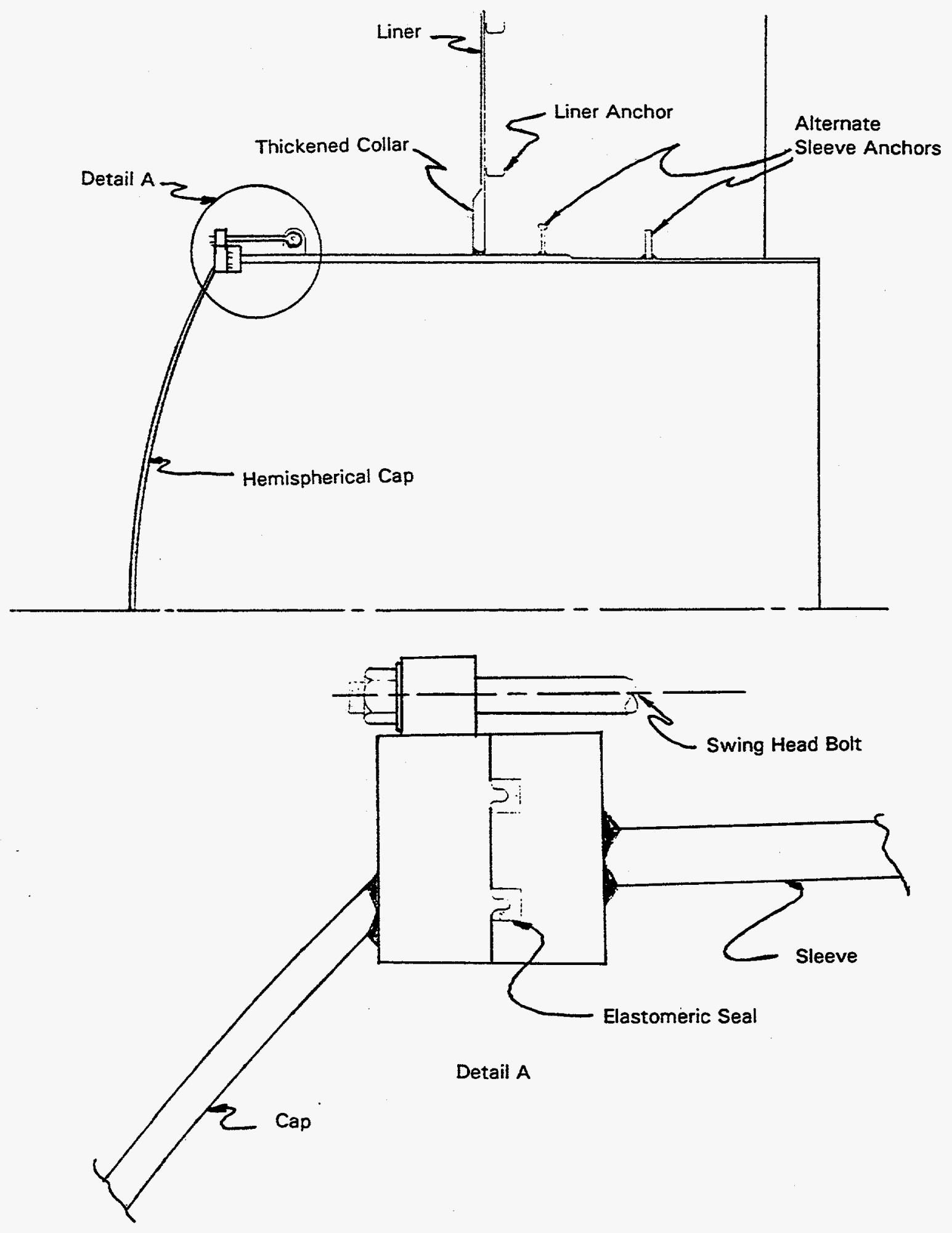

Figure 3.10 Typical Pressure Seating Equipment Hatch 

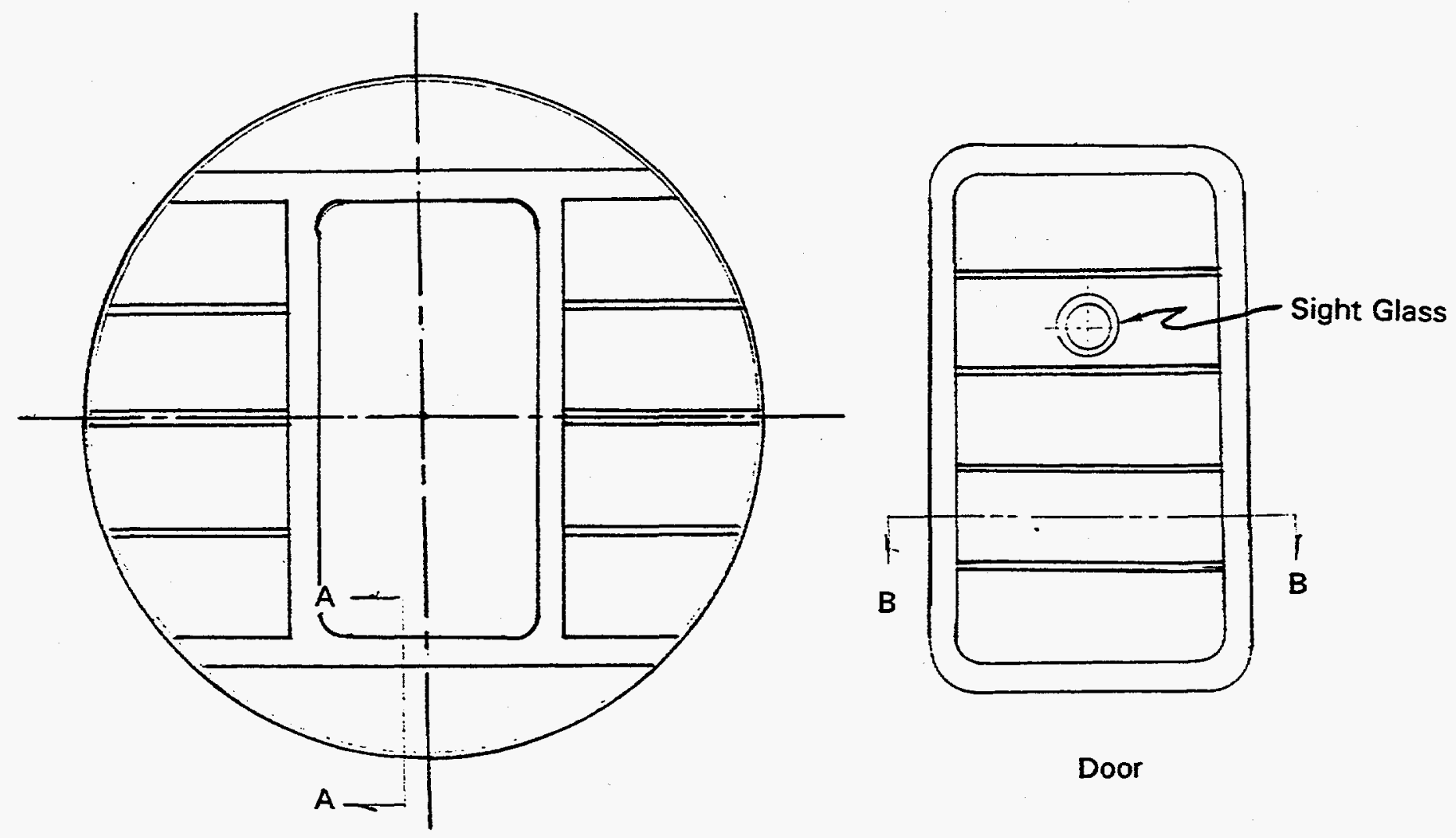

Bulkhead

Elastomeric

Seal Rings

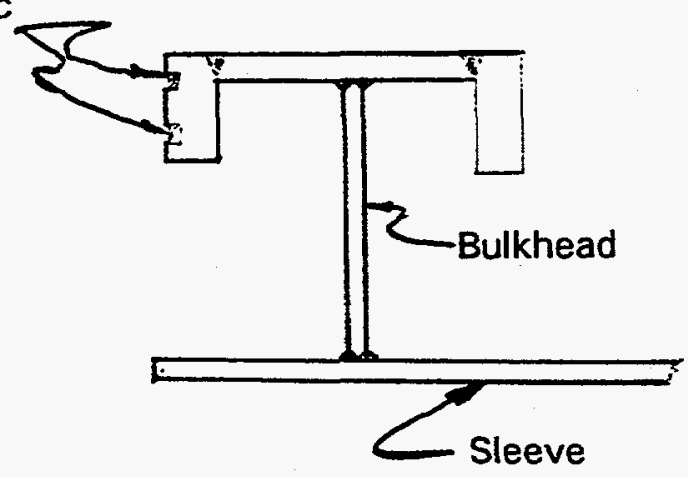

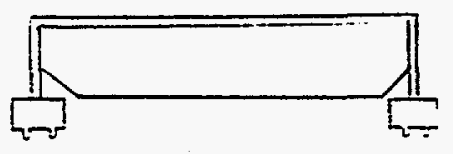

Section B-B

Section A-A

Figure 3.11 Typical Personnel Airlock Bulkhead and Door 
3. Containment Overpressure Failure Modes

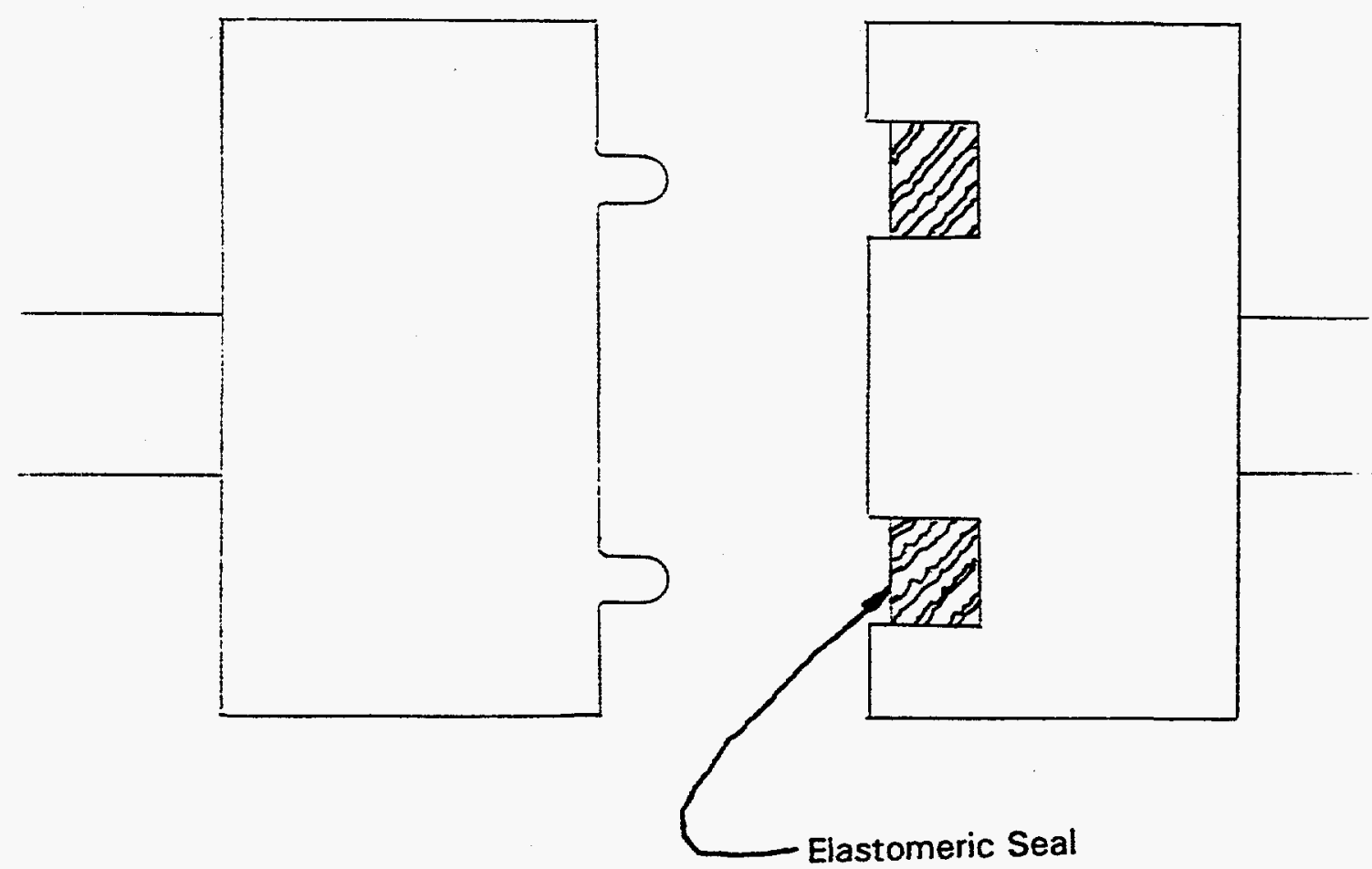

Figure 3.12 Tongue and Groove Seal Configuration 
3. Containment Overpressure Failure Modes

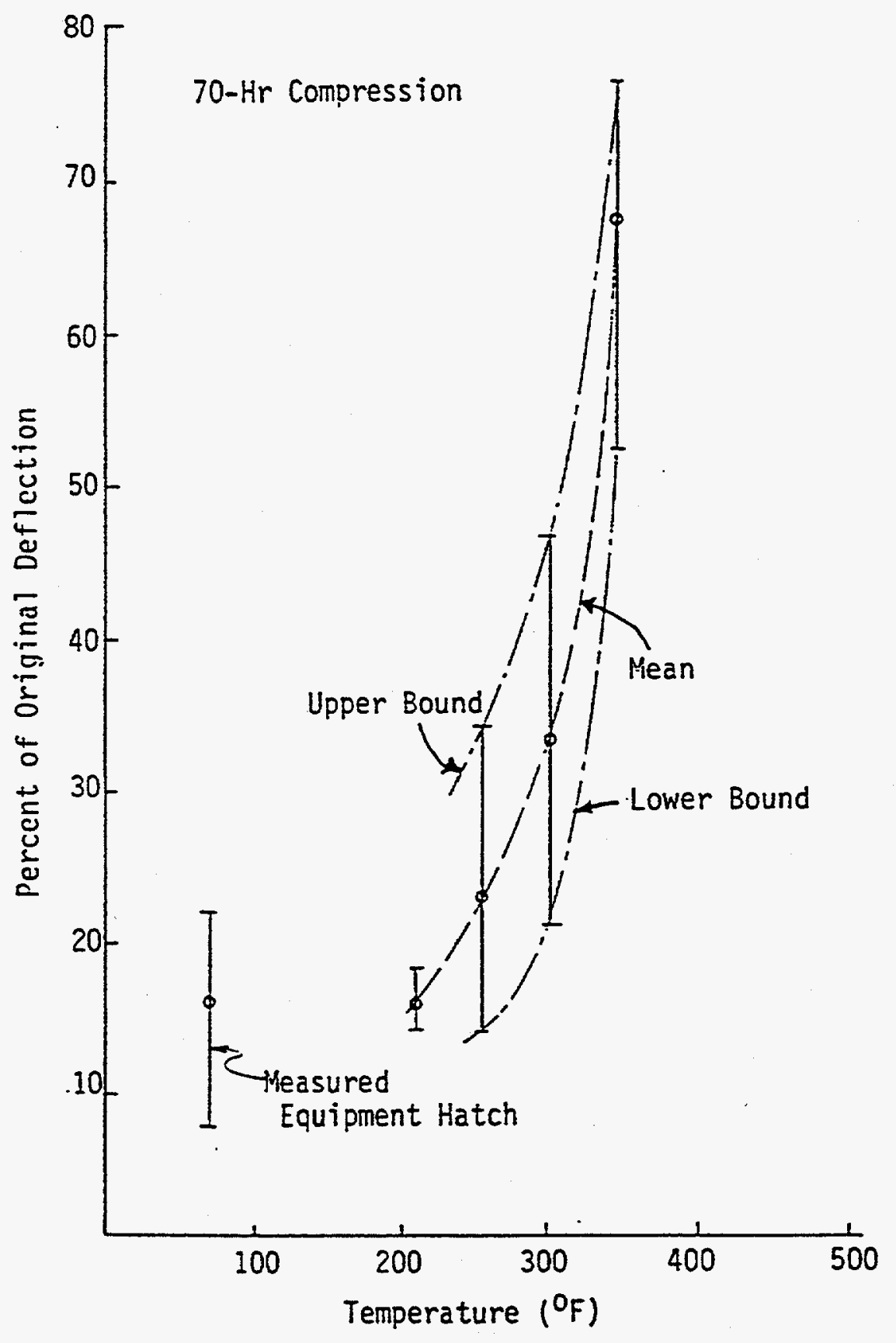

Figure 3.13 Ethylene-Propylene Rubber Residual Set 
3. Containment Overpressure Failure Modes

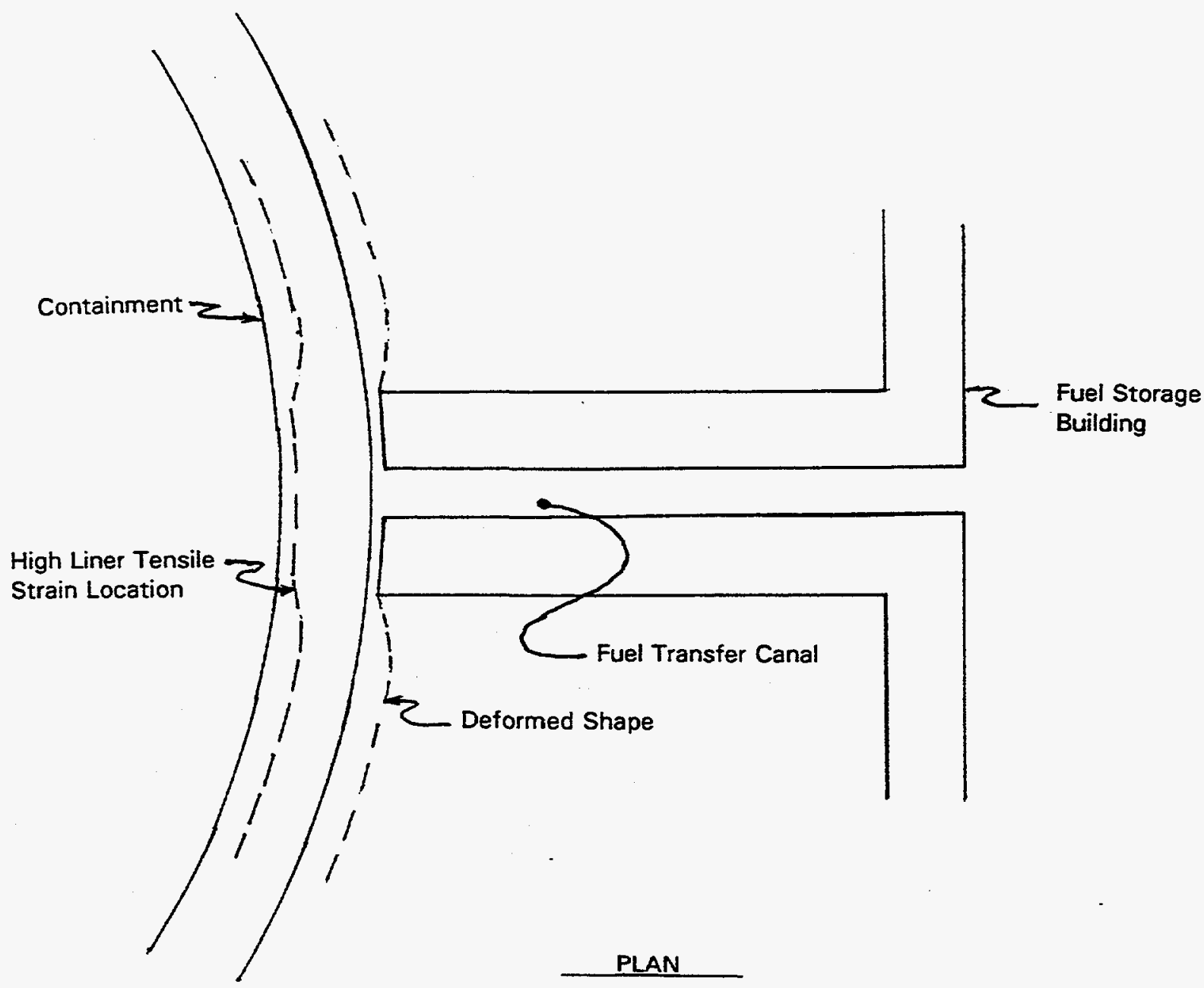

Figure 3.14 Possible Punching Shear Failure Location 
3. Containment Overpressure Failure Modes

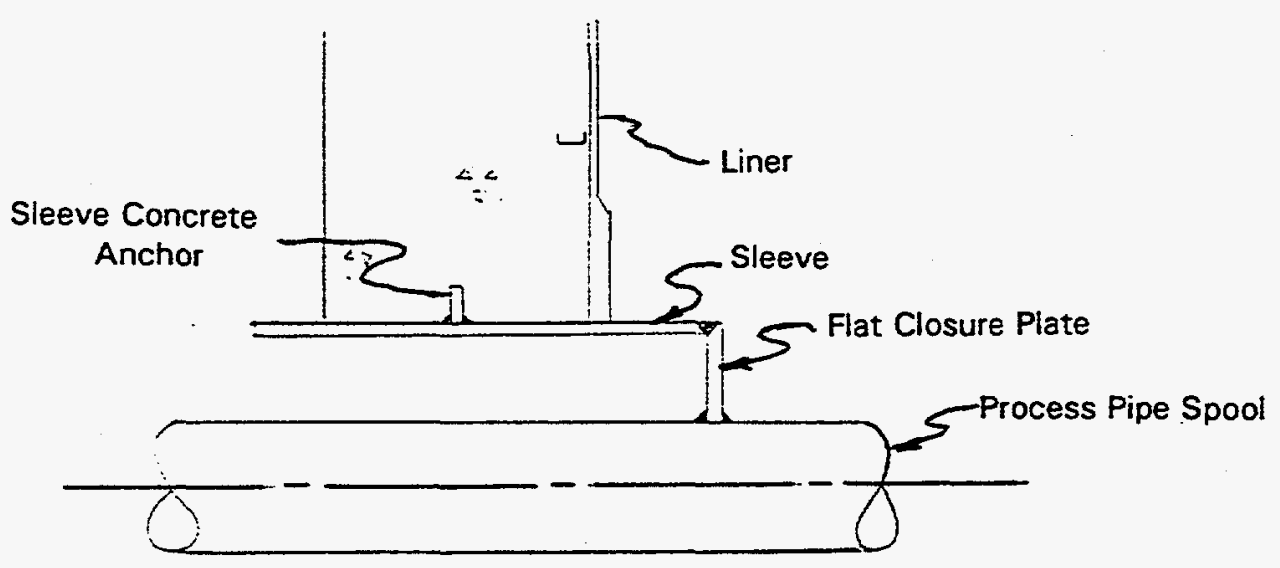

Flat Closure Plate Penetration

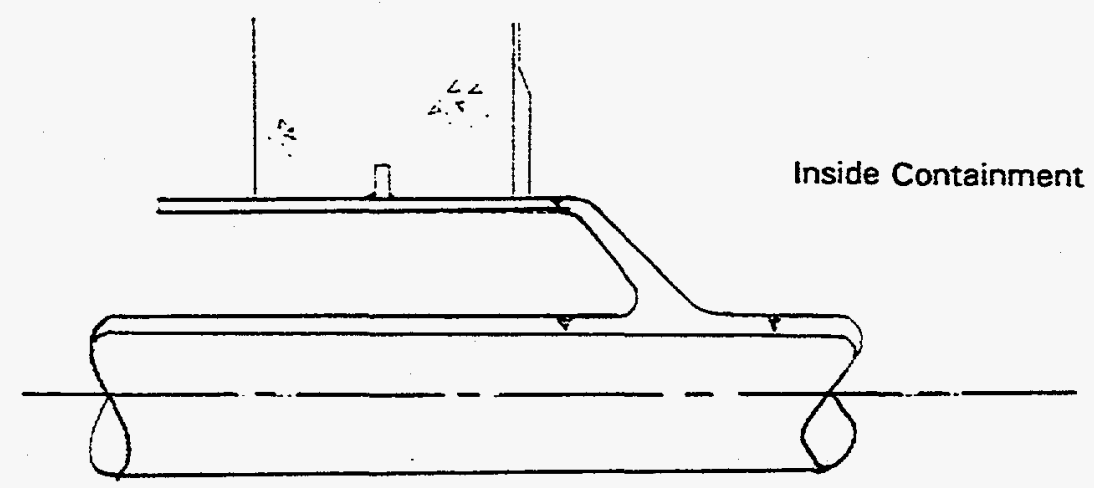

Forged (Flued) Head Penetration

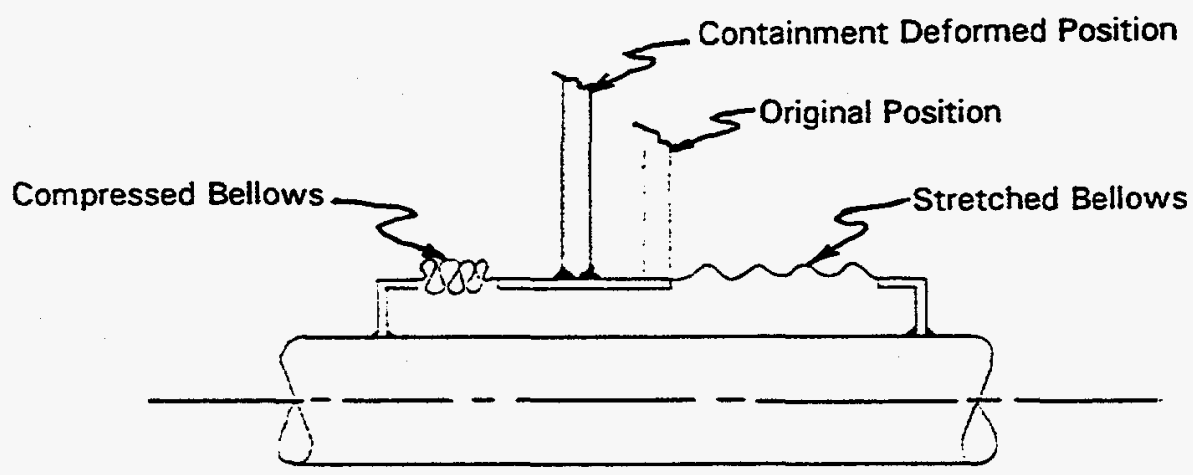

Bellows Penetration

Figure 3.15 Typical Pipe Penetrations 
3. Containment Overpressure Failure Modes

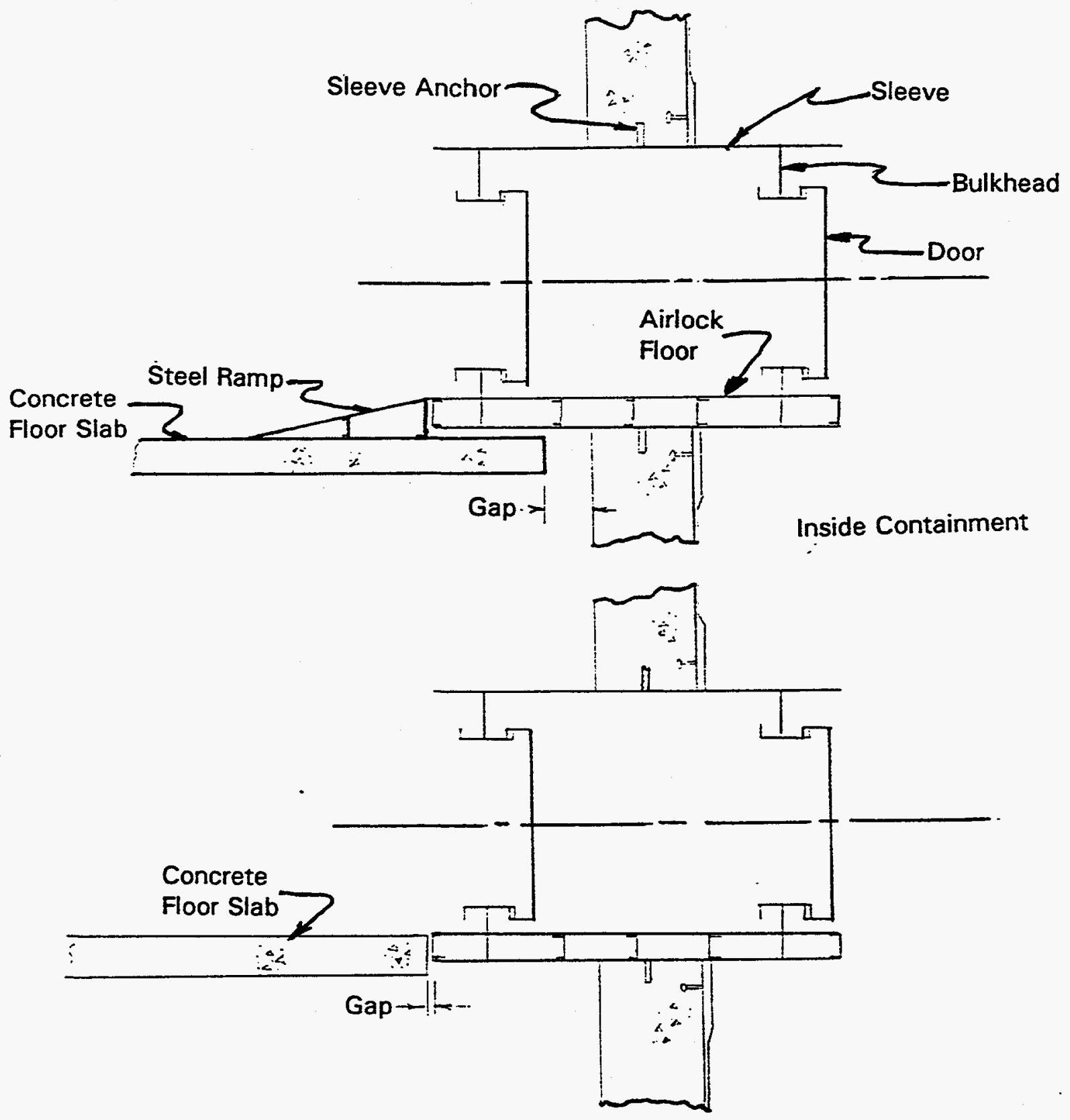

Figure 3.16 Personnel Airlock Interference Failure Mode 


\section{SURROGATE CONTAINMENT DESIGNS}

Early in this containment performance program, a panel of experts (consisting of four individuals) experienced in the area of Nuclear Reactor Containment design and analysis was enlisted to assist Sandia, and the NRC, in scoping out the path of this program and review the results. In order to make some comparisons between the ASME steel and concrete design requirements and inherent margins, the panel recommended designing and analyzing a set of surrogate containments which would encompass the primary types of containment shapes and construction materials. For direct comparison, each containment has an identical internal volume and design pressure. These containments are to be designed according to all applicable code requirements for nuclear reactor containment structures.

\subsection{Surrogate Containment Design Parameters}

The surrogate containments chosen for this study include two concrete, one deformed bar and one prestressed (both cylindrical with hemispherical dome and flat baseslab with identical inside dimensions). In addition, four steel containments were designed. Two of these steel surrogates were cylindrical with hemispherical dome and torispherical embedded base with inside dimensions identical to the concrete containments, one using SA-537 Cl. 2 steel and the other using SA-516 Gr. 70 steel. The other two steel containments are spherical with identical internal volume to the cylindrical containments, again using the same two materials as the steel cylinder. The typical design conditions applicable to all containments were chosen to be a design pressure $\left(P_{d}\right)=45$ psig, design temperature $\left(T_{\partial}\right)=275^{\circ} \mathrm{F}$, and a safe shutdown earthquake $(\mathrm{SSE})=0.3 \mathrm{~g}$

Next, the basic geometries of the surrogate containments were determined by the Review Panel. All cylindrical containments were to have a height from top of base slab to springline of 145 feet and internal diameter of 124 feet. These were considered typical and maintained the thickness of the steel containments below 1.75 inches, in order to avoid heat treatment requirements. Thicknesses of each of the surrogate steel containments were determined by analysis. However, thickness of the hemispherical dome was governed by the normal loading conditions and was not increased to provide additional support for other loads such as supporting the construction of the secondary shield building. Therefore, if the thickness of the cylinder and dome is governed by internal pressure, which is typical, the thickness of the dome is exactly $1 / 2$ the thickness of the cylinder. The spherical steel containment has one uniform thickness throughout and was not thickened in certain regions of high stress, such as near the point of embedment. The internal diameter of the steel sphere was determined to be 162.5 feet in order to provide the same internal volume as the cylindrical containments.

The thickness of the concrete containments was also specified and was based on typical design practices. The base slab was chosen to be 10 feet for both concrete containments. The cylinder wall thickness are 3.5 feet in the prestressed concrete and 4.5 feet in the reinforced concrete containments. The dome thicknesses were specified as 3.0 feet in the prestressed and 3.5 feet in the reinforced concrete containments. In addition, a $1 / 4$ inch steel liner was specified for inside the cylinder walls and $1 / 2$ inch liner was used in the dome. A summary of all these initial design parameters for the six surrogate containment designs is shown in Figure 4.1.

No penetrations or hatches were included in these surrogate containment designs. This was decided upon because in most cases these areas have a higher design margin built into them and are not controlling the design of the containment. Each of the surrogate containments would also need to meet all applicable code requirements (ASME Boiler and Pressure Vessel Code, USNRC Standard Review Plans, etc.).

\subsection{Design Process}

The six surrogate containments, described in the previous section, were designed to all applicable containment design requirements using each of the design conditions specified. Design details of both the steel and concrete surrogate containments are discussed below.

\subsubsection{Design of Steel Surrogates}

Preliminary designs of the surrogate steel containments were determined by using the design by formula rules given in the ASME Code Section NE-3300 [4-1] and also shown in section 2.1.2 of this report. These formulas were used to determine the minimum required shell thickness in the cylinder, dome, or sphere using design accident internal pressures. The minimum 
required thickness for each of the steel surrogates is shown in Table 4.1.

An axisymmetric finite element model (FEM) code called AXISYM was then used to analyze the stresses in all the steel containment surrogates. Initially, small sections near discontinuities (point of embedment and springline) were analyzed and compared to results found using Roark's [4-2] equations for stresses in pressure vessels and these compared very favorably. Figure 4.2 shows this comparison for one of the steel cylinder containments at the point of embedment when applying the design accident internal pressure $\left(P_{2}\right)$. Each of the entire steel containments was then modeled axisymmetrically in order to determine general membrane stresses, local membrane stresses, and bending stresses. The resulting stress curves for meridional and hoop stresses for all four surrogate steel containments are shown in Figures 4.3 through 4.6.

The stress intensity $\left(\mathrm{S}_{\mathrm{m}}\right)$ is defined in Section NE-3215 of the ASME Code as the largest absolute value of the stress differences (or Tresca):

$$
\begin{aligned}
& S_{12}=\sigma_{1}-\sigma_{2}=\sigma_{\mathrm{h}}-\sigma_{\mathrm{m}} \\
& \mathrm{S}_{23}=\sigma_{2}-\sigma_{3}=\sigma_{\mathrm{m}}-\sigma_{\mathrm{r}} \\
& \mathrm{S}_{31}=\sigma_{3}-\sigma_{1}=\sigma_{\mathrm{r}}-\sigma_{\mathrm{h}}
\end{aligned}
$$

where,

$$
\begin{aligned}
& \sigma_{\mathrm{h}}=\text { hoop stress, } \\
& \sigma_{\mathrm{m}}=\text { meridional stress, and } \\
& \sigma_{\mathrm{r}}=\text { radial stress }
\end{aligned}
$$

All general primary membrane stress intensities $\left(\mathrm{P}_{\mathrm{m}}\right)$ were found to be below the allowable stress $1.0^{*} \mathrm{~S}_{\mathrm{mc}}$ for all four surrogate containments. Membrane stresses that exceed $S_{m c}$ are considered local since they do not extend more then $1.0^{*} \sqrt{R T}$, in the meridional direction. These local primary membrane stresses $\left(P_{L}\right)$ do not exceed the allowable $1.5 * \mathrm{~S}_{\mathrm{mc}}$ for all four surrogates. The stresses at the inside and outside surface of these containments walls are considered secondary $(Q)$ and not primary bending $\left(P_{b}\right)$ because the bending moment is not required to maintain the bending stress at the middle to within acceptable limits, such as a flat head. These secondary surface stresses are all well below the allowable $3.0^{*} S_{\mathrm{m} 1}$ for all four steel surrogates.

The next step was to analyze the steel containments for seismic loading. Lumped mass stick models of the steel containments were developed and analyzed using
DYBEAM, a dynamic beam analysis FEM code. An eigenvalue analysis determined fixed-base fundamental frequencies of about $6 \mathrm{~Hz}$ horizontal and $20 \mathrm{~Hz}$ vertical for the cylindrical containments and $8 \mathrm{~Hz}$ horizontal and $15 \mathrm{~Hz}$ vertical for the spherical containments. The lumped mass stick models were then excited at the base using an artificial time history scaled to the SSE of $0.3 \mathrm{~g}$. Response spectra were generated, as shown in Figure 4.7, and maximum forces and moments output.

Using these maximum forces and moments, peak tensile and compressive stresses were determined. Peak meridional stresses in each of the surrogates, at the point of embedment, were in the range of about $1 \mathrm{ksi}$. This will have no effect on the cylindrical containments when the design internal pressure is applied because meridional stresses are at $1 / 2$ the allowable with a margin of about $10 \mathrm{ksi}$. The spherical containments, on the other hand, do not have this extra margin in the meridional direction and the thickness must be increased to account for this additional loading. Checks were also made to assure that compressive buckling stresses were not exceeded in each of the steel surrogate designs.

\subsubsection{Design of Concrete Surnogates}

Design of the surrogate concrete containments consisted of determining the amount and placement of all reinforcement. Using the initial design parameters defined in Section 4.1, all applicable loading combinations were applied in order to determine the maximum loads in each direction and thereby determine the amount of reinforcement required. Hoop reinforcement and dome reinforcement were both governed by the $1.5^{*} \mathrm{P}_{\mathrm{a}}$ load case, as well as the meridional reinforcement in the upper portion of the cylinder. The amount of prestressing was chosen to resist $1.2 * \mathrm{P}_{\mathrm{z}}$, leaving the remaining $0.3^{*} \mathrm{P}_{\mathrm{z}}$ to be resisted by deformed bar reinforcement necessary to control cracking. At the base of the cylinder, the meridional reinforcement must resist membrane loads caused by internal pressure, seismic, and dead loads as well as bending stresses resulting from the overpressure discontinuity moments. This discontinuity moment was determined using Roark's [4-2] formulas for pressure vessels and is shown in Figure 4.8. Also shown in Figure 4.8 is the overpressure discontinuity shear in the containment as determined using Roark's formulas. This discontinuity shear determined the amount of radial shear reinforcement required near the base of the cylinder. 
The other reinforcement to be determined was the required amount of inclined steel to resist the tangential shear forces caused by the SSE. As was done for the steel surrogates, a lumped mass stick model of each containment was developed and analyzed using DYBEAM. Fundamental frequencies were $5.5 \mathrm{~Hz}$ horizontal and $14.3 \mathrm{~Hz}$ vertical for the reinforced concrete and $5.3 \mathrm{~Hz}$ horizontal and $14.0 \mathrm{~Hz}$ vertical for the prestressed concrete surrogate. A sample response spectra using an artificial time history is shown for the reinforced concrete containment in Figure 4.9.

In order to determine the stresses in the inclined bars, a fortran code was developed using equations developed by Duchon [4-3]. These equations are used to predict stresses and deformations in reinforced or pre-stressed concrete sections subjected to membrane forces, and reinforced by a combination of orthogonal and inclined bars. Employing these formulas on the preliminary reinforced concrete design and applying internal pressure loads, dead loads, and vertical and horizontal earthquake loads for various load combinations, the resulting stresses in all the steel reinforcement were found. It was determined that inclined bars were not necessary in the prestressed containment.

Reinforcing of the base slab was not determined for the two surrogate concrete containments. This was based on the Review Panel judgement that this area usually does not control the ultimate containment capacity.

\subsection{Final Designs}

After the preliminary surrogate containment designs were analyzed, they were reviewed by the Peer Review Panel, and then finalized. The geometries of the four steel surrogate containments were set in the initial parameters as discussed in Section 4.1. The only unknown was to determine the thicknesses of the cylinder wall and spherical shell wall. Thickness of the dome was assumed to be exactly $1 / 2$ the cylinder wall thickness and all wall thicknesses were to be uniform (no thickening in certain regions of high stress). The resulting steel plate thicknesses for the containments are shown in Table 4.2.

The surrogate concrete containments were also designed according to the parameters given in Section 4.1 and described in Section 4.2. After completing the preliminary designs, the designs were reviewed by Sargent \& Lundy, who is also performing the analysis of the concrete containments. After some minor modifications were made the following reinforcing steel requirements were specified:

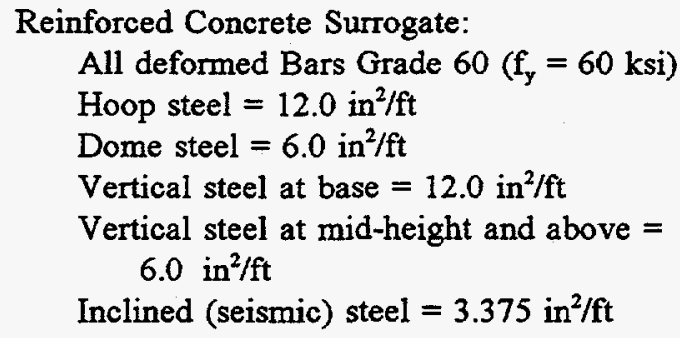

Prestressed Concrete Surrogate:

Each tendon is 170 wires with O.D. of $1 / 4$ " $\left(\mathrm{f}_{\mathrm{pu}}=240 \mathrm{ksi}\right)$

Hoop tendons $=96$ total at 17.2 inch spacing

Vertical and dome $n$ tendons $=106$ total at 45.4 inch spacing.

Additional deformed bar reinforcement (fy $=60 \mathrm{ksi}$ )

Hoop steel $=2.54 \mathrm{in}^{2} / \mathrm{ft}$

Dome and upper vertical steel $=2.54 \mathrm{in}^{2} / \mathrm{ft}$

Vertical steel at base $=5.1 \mathrm{in}^{2} / \mathrm{ft}$

These six surrogate containment designs were then used to calculate the deterministic yield and ultimate capacities and probabilistic ultimate capacities shown in Chapters 5 and 6 of this report.

\subsection{References}

4-1. The American Society of Mechanical Engineers, 1995 ASME Boiler and Pressure Vessel Code, 1995.

4-2. Roark, R. J., Formulas for Stress and Strain, McGraw-Hill Book Co., New York, NY, 1965.

4-3. Duchon, N. B., "Analysis of Reinforced Concrete Membrane Subject to Tension and Shear," ACI Journal, September, 1972. 
Table 4.1 Minimum Required Thickness For Surrogate Steel Containments

\begin{tabular}{||l||c|c|c|}
\hline \multirow{2}{*}{ Material } & \multicolumn{3}{|c|}{ Thickness (inches) } \\
\cline { 2 - 4 } & $\begin{array}{c}\text { Cylinder } \\
\text { Wall }\end{array}$ & $\begin{array}{c}\text { Cylinder } \\
\text { Dome }\end{array}$ & Sphere \\
\hline \hline $\begin{array}{l}\text { SA-516 } \\
\text { Grade 70 }\end{array}$ & 1.742 & 0.871 & 1.139 \\
\hline $\begin{array}{l}\text { SA-537 } \\
\text { Class 2 }\end{array}$ & 1.524 & 0.762 & 0.997 \\
\hline
\end{tabular}

Table 4.2 Thicknesses Used in Surrogate Steel Containment Designs

\begin{tabular}{||l||c|c||}
\hline \multirow{2}{*}{ Material } & \multicolumn{2}{c|}{ Thickness (inches) } \\
\cline { 2 - 3 } & $\begin{array}{l}\text { Cylinder } \\
\text { Wall }\end{array}$ & Sphere \\
\hline \hline $\begin{array}{l}\text { SA-516 } \\
\text { Grade 70 }\end{array}$ & $1-3 / 4$ & $1-1 / 4$ \\
\hline $\begin{array}{l}\text { SA-537 } \\
\text { Class 2 }\end{array}$ & $1-9 / 16$ & $1-3 / 16$ \\
\hline
\end{tabular}




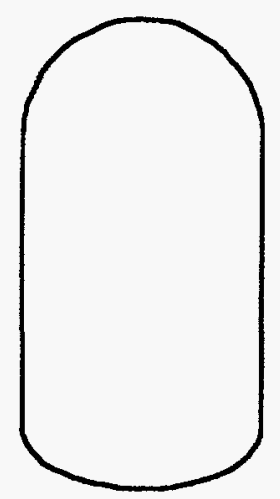

Steel Cylinder (2 Materials)
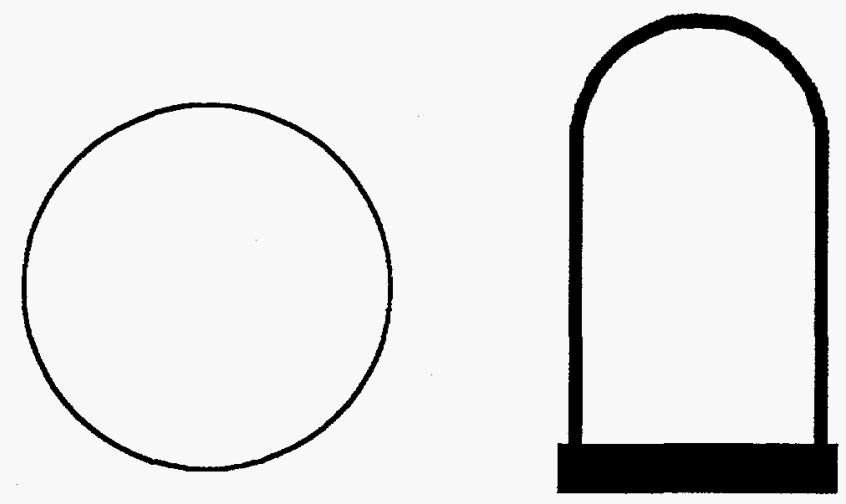

Reinforced Concrete

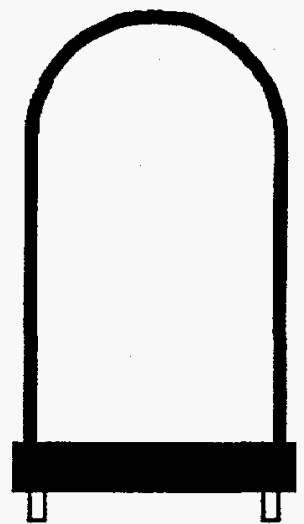

Prestressed Concrete

Surrogate Design Conditions:

Design Pressure $=45 \mathrm{psig}$

Design Temperature $=275^{\circ} \mathrm{F}$

Safe Shutdown Earthquake $=0.3 \mathrm{~g}$

All Cylindrical Containments:

Internal Diameter $=124$ feet

Height to Springline $=145$ feet

Hemispherical Dome

Steel Spherical Containments:

Same Internal Volume as Cylinder

Internal Diameter $=162.5$ feet

Steel Containment Materials:

SA - 516 Grade 70 Steel

(one cylinder, one sphere)

SA - 537 Class 2 Steel

(one cylinder, one sphere)
Reinforced Concrete Containments:

Cylinder Concrete Thickness $=4.5$ feet

Dome Concrete Thickness $=3.5$ feet

Base Slab Thickness $=10.0$ feet

Cylinder Liner Thickness $=1 / 4$ inch

Dome Liner Thickness $=1 / 2$ inch

$\mathrm{f}_{\mathrm{c}}^{\prime}=4,000$ psi $\mathrm{f}_{\mathrm{y}}=60,000 \mathrm{psi}$

Prestressed Concrete Containments:

Cylinder Concrete Thickness $=3.5$ feet

Dome Concrete Thickness $=3.0$ feet

Base Slab Thickness $=10.0$ feet

Cylinder Liner Thickness $=1 / 4$ inch

Dome Liner Thickness $=1 / 2$ inch

Hoop Tendons - 3 buttresses

Vertical \& Dome Tendons - Hairpin

$f_{c}^{\prime}=5,500$ psi $f_{p w}=240,000$ psi

Figure 4.1 Surrogate Design Parameters 

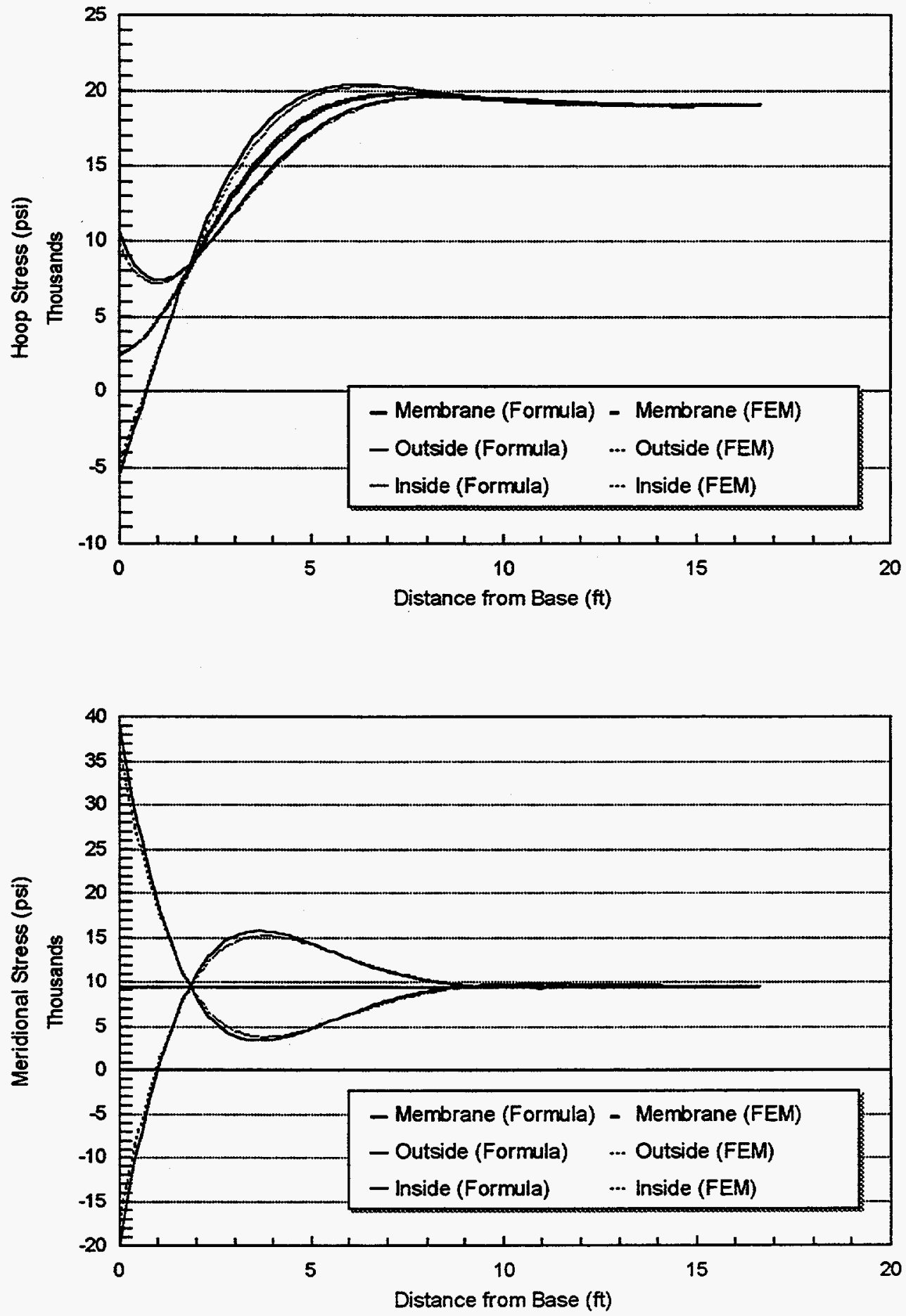

Figure 4.2 Comparison of Formulas to Finite Element Model Results at Base of Steel Cylinder for Hoop Stresses (top) and Meridional Stresses (bottom). 


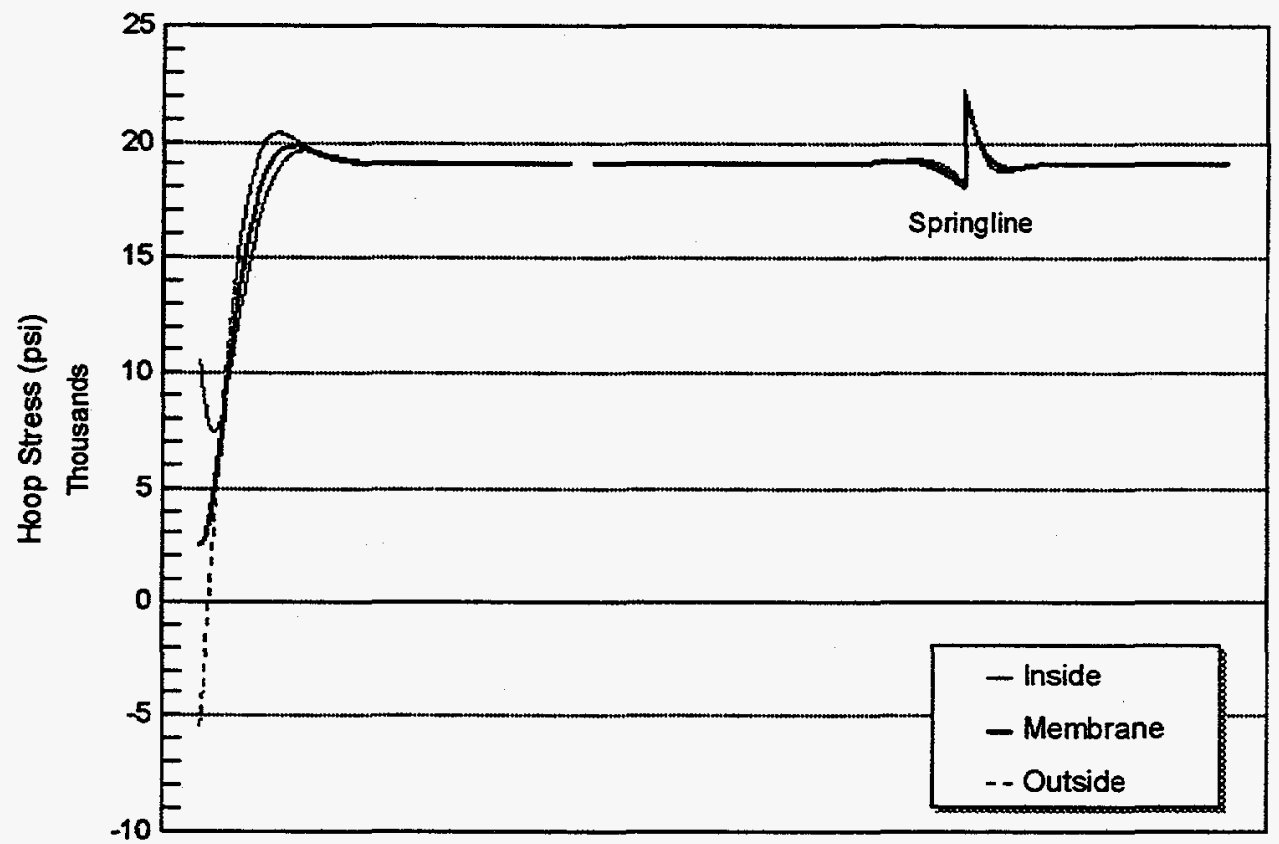

Height of Containment

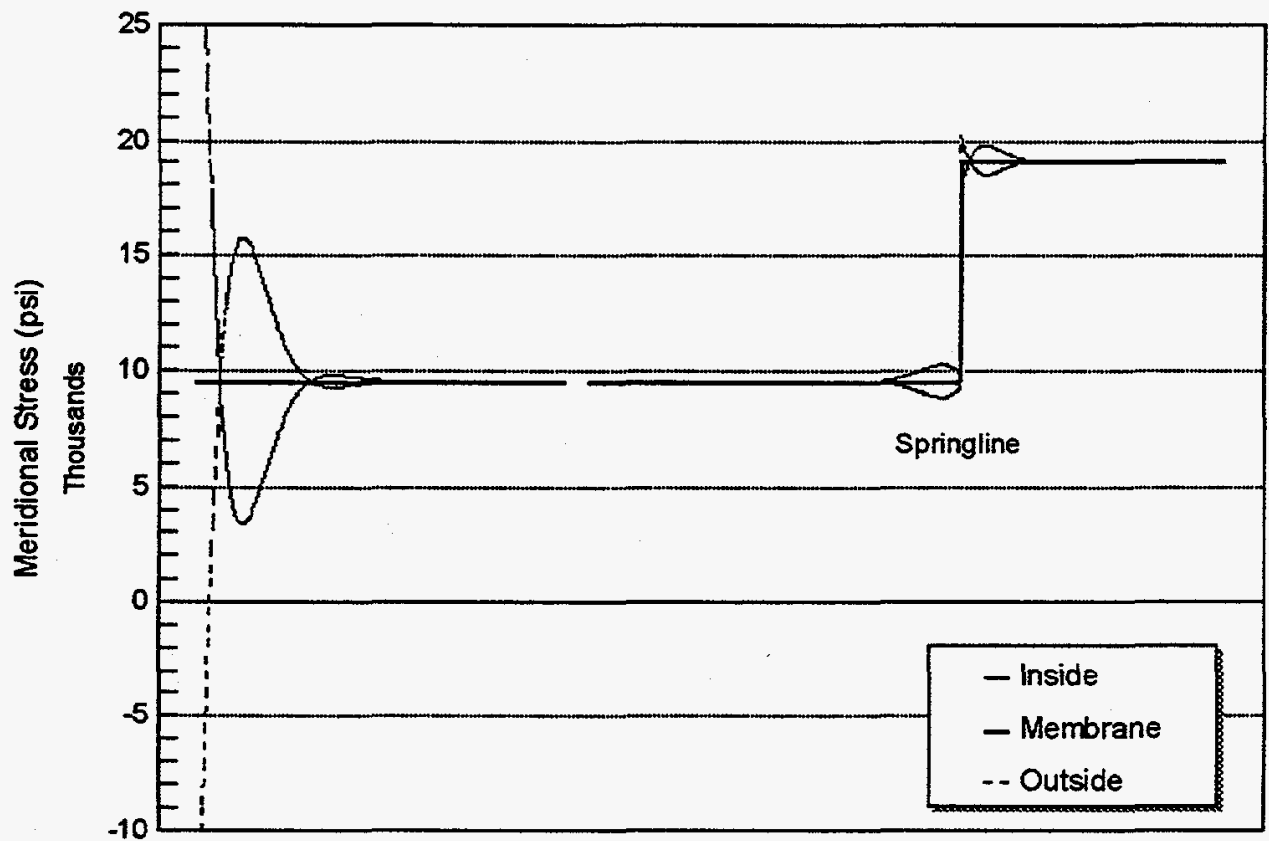

Height of Containment

Figure 4.3 Cylindrical Steel Containment Stresses (SA-516 Gr. 70) Hoop Stresses (top) and Meridional Stresses (bottom). 


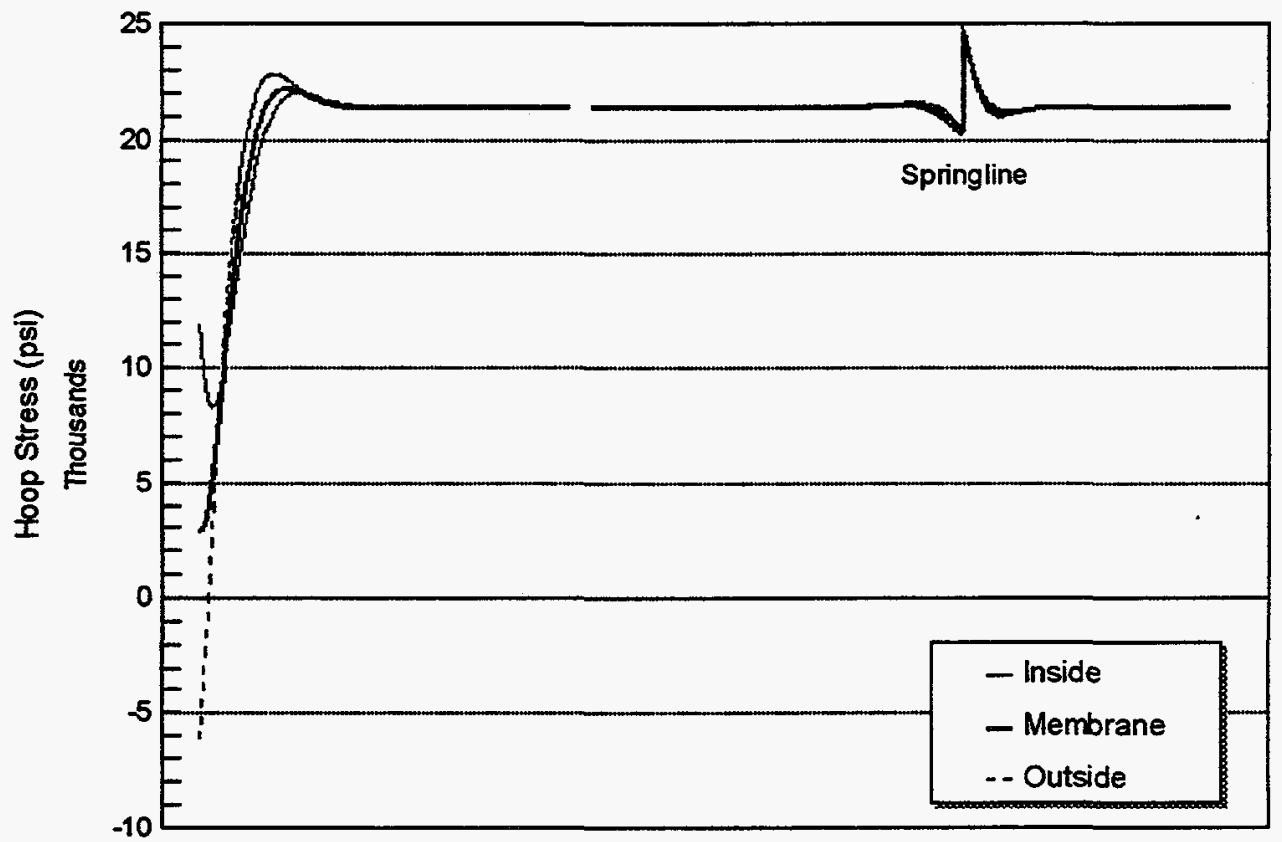

Height of Containment

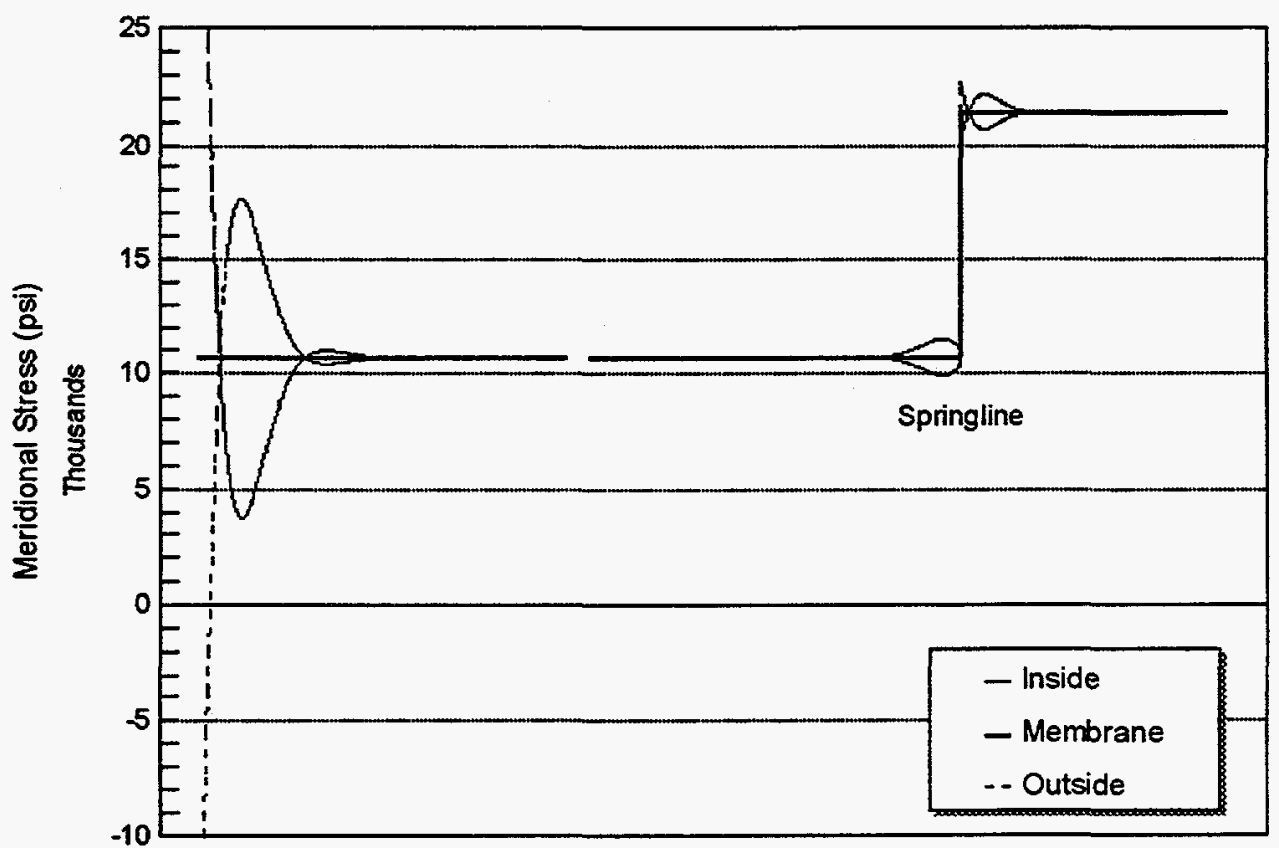

Height of Containment

Figure 4.4 Cylindrical Steel Containment Stresses (SA-537 Cl. 2) Hoop Stresses (top) and Meridional Stresses (bottom). 

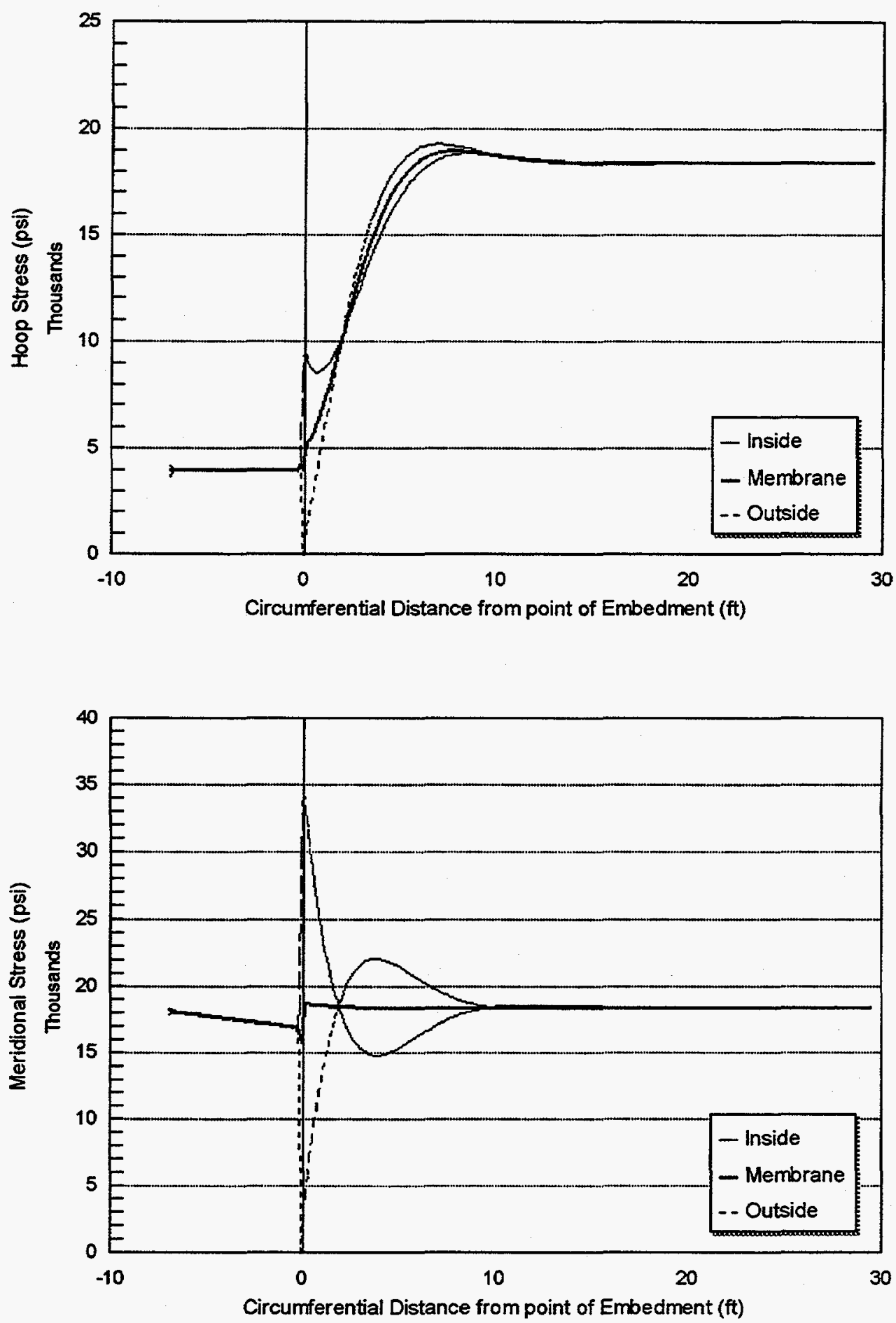

Figure 4.5 Spherical Steel Containment Stresses (SA-516 Gr. 70) Hoop Stresses (top) and Meridional Stresses (bottom). 

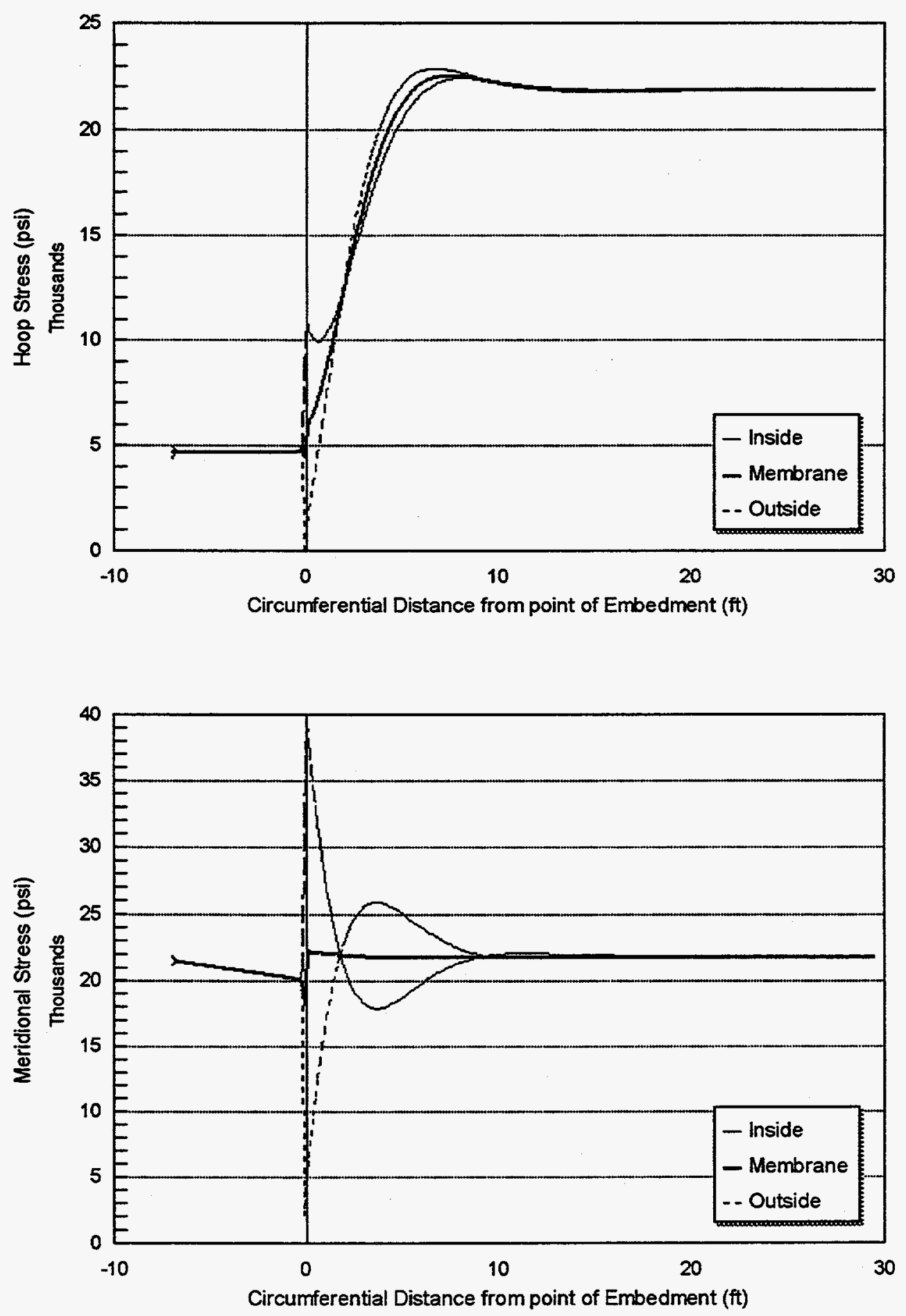

Figure 4.6 Spherical Steel Containment Stresses (SA-537 Cl. 2) Hoop Stresses (top) and Meridional Stresses (bottom). 
4. Surrogate Containment Designs

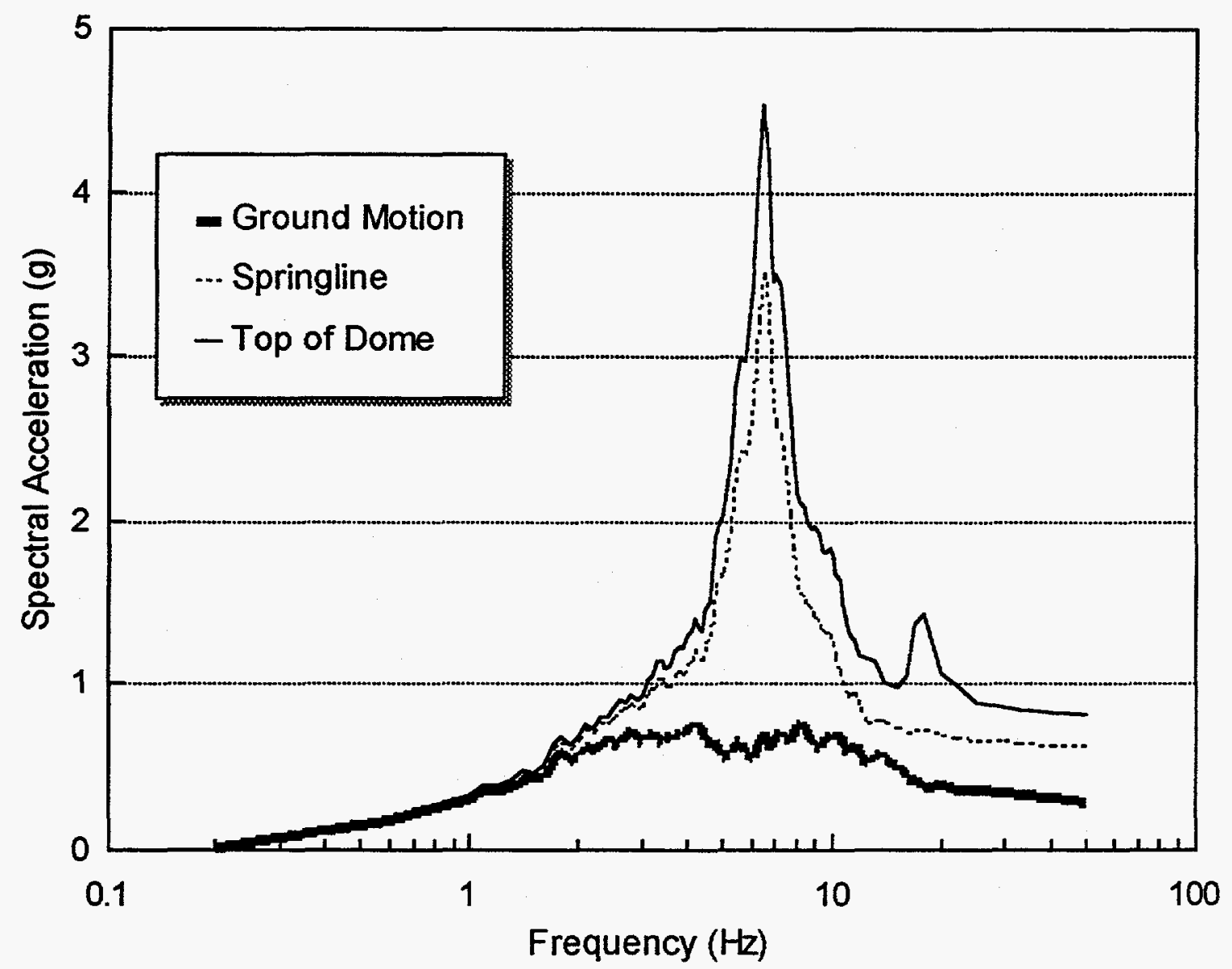

Figure 4.7 Cylindrical Steel Containment Response Spectra 

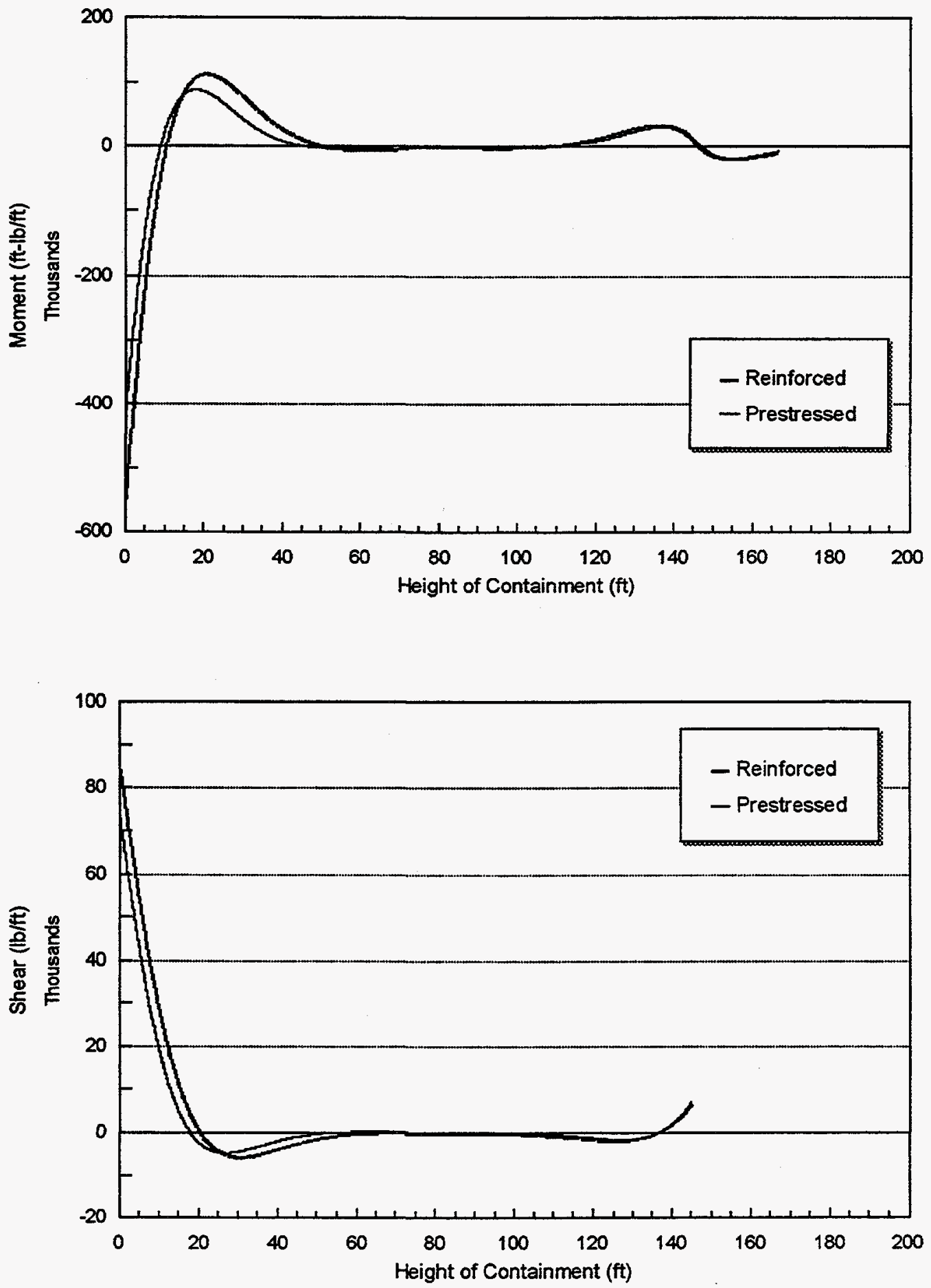

Figure 4.8 Overpressure Discontinuity Moments and Shears for Reinforced and Prestressed Concrete Containments, Moment (top) and Shear (bottom). 
4. Surrogate Containment Designs

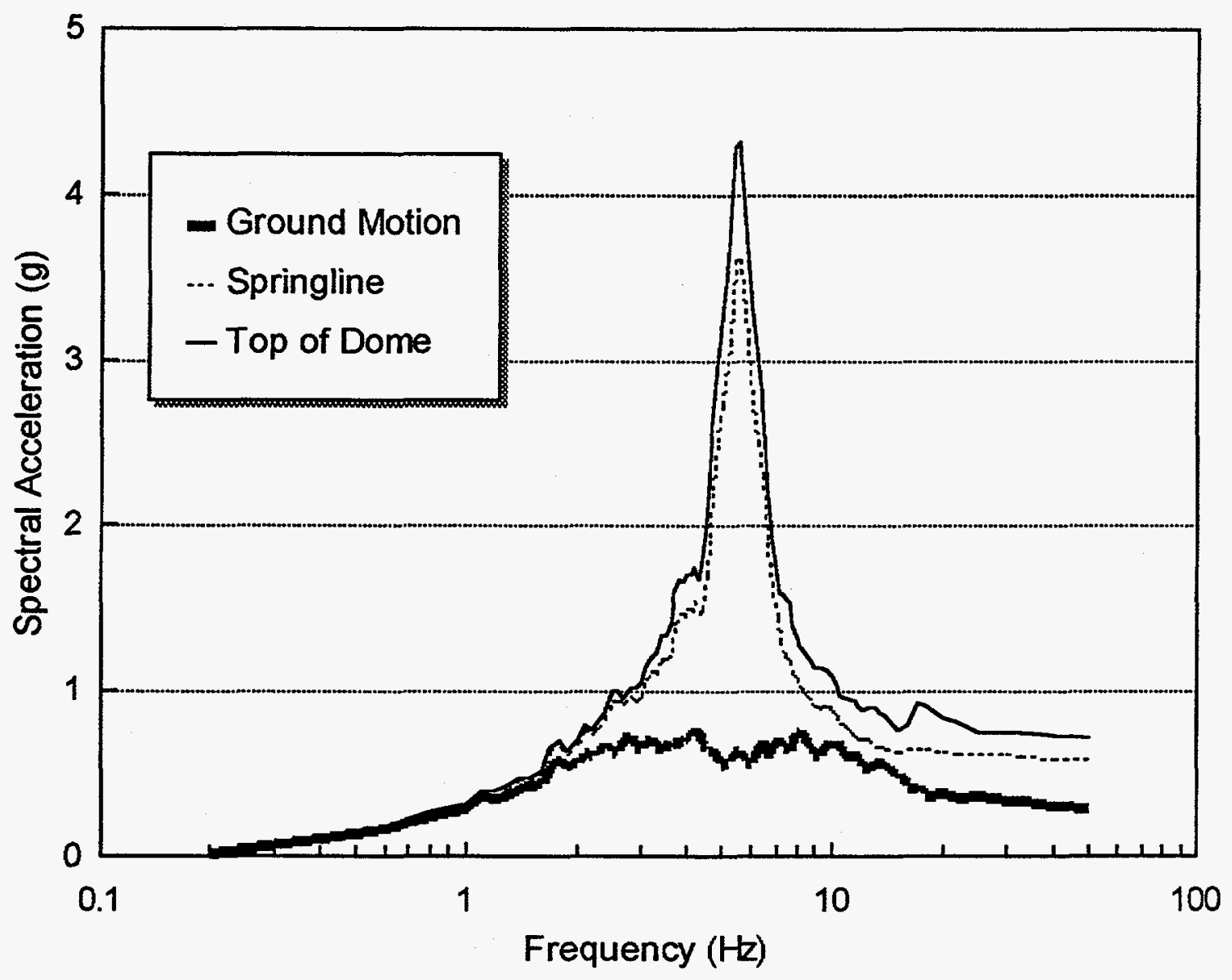

Figure 4.9 Reinforced Concrete Containment Response Spectra 


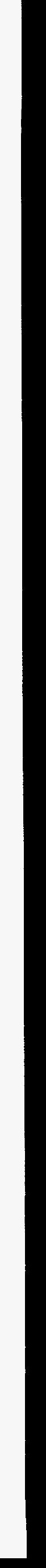




\section{DETERMINISTIC PRESSURE CAPACITIES FOR SURROGATE CONTAINMENTS}

This chapter will determine, for each of the six surrogate containments designed in the previous chapter, a review level pressure $\left(\mathrm{P}_{\mathrm{RL}}\right)$ at which the containment material first reaches yield and then calculate a deterministic ultimate pressure capacity $\left(P_{u}\right)$. For the steel surrogates, this review level pressure is also equivalent to using the ASME Service Level C stress limits for primary general membrane stresses for pressure only. Similarly, for the concrete containments, the pressure required to reach minimum factored load allowable stresses, with no capacity reduction factor $(\Phi=1.0)$, is equivalent to using minimum required yield stresses. Next, an ultimate pressure capacity for the surrogates will be determined based on deterministic failure criteria. These review level pressures and ultimate pressures can then be compared to the design pressure and margins computed for each of the containment types and severe accident temperatures.

\subsection{Yield Capacity Analysis}

\subsubsection{Steel Containment Surrogates}

After completing the preliminary designs of the steel surrogate containments, an analysis of their pressure capacity was performed. Initially, the pressure which causes the minimum specified yield stress to be reached (based on Tresca yield criteria and code specified minimum yield), was determined. This level was chosen because minimum yield stresses are a specified value which can be used to deterministically compute a resulting pressure. Yield stresses can also be defined for the steel used in both steel containments and in the deformed bars used in reinforced concrete, which in both cases is the main over-pressure resisting element. However, high strength tendons used in prestressed concrete containments do not exhibit a well defined yield point. Instead, the allowable yield stress is specified as $85 \%$ of the minimum ultimate strength or $0.85^{*} \mathrm{f}_{\mathrm{pu}}$, which is what was used in this study.

Another reason for choosing the yield stress for comparison arises from the alternative deterministic criterion proposed for steel containments when subjected to a severe accident condition as stated in the Commission's safety goals in SECY-90-016:

The containment should maintain its role as a reliable leak tight barrier by ensuring that containment stresses do not exceed ASME Service Level $C$ limits for a minimum period of 24 hours following the onset of core damage and that following this 24 hour period the containment should continue to provide a barrier against the uncontrolled release of fission products.

For primary general membrane stresses in steel containment vessels, the ASME Service Level C allowable stresses are limited to $S_{y}$, which is equivalent to the minimum specified yield stress as given in Table Y-1, Section II, Part D of the ASME Boiler and Pressure Vessel Code [5-1]. At points of discontinuity, primary local membrane, Level $\mathrm{C}$ stresses are permitted to reach $1.5^{*} \mathrm{~S}_{\mathrm{y}}$. This local criterion rarely governs the design, but may require some local thickening of the steel in order to reduce stresses. In the case of the surrogate containments, the local membrane stresses never controlled the design. Therefore, the appropriate yield criteria would be to limit the stresses to the general primary membrane allowable of $S_{y}$ (minimum required yield stress as specified in Table Y-1 of the ASME Code and using Tresca yield stress criteria). The resulting review level pressures (in psig) are shown in Table 5.1 for the four steel surrogate containments, at ambient temperatures $\left(75^{\circ} \mathrm{F}\right)$ and assumed severe accident temperatures of $400^{\circ} \mathrm{F}$ and $600^{\circ} \mathrm{F}$.

As shown in Table 5.1, the review level pressures which result in membrane yielding of the steel shell, drop off significantly in the surrogate containments at increased temperatures. This is because the allowable stresses shown in Table Y-1 of the ASME Code show significant reductions at increased temperatures (approximately $15 \%$ at $400^{\circ} \mathrm{F}$ and $25 \%$ at $600^{\circ} \mathrm{F}$ ).

\subsubsection{Concrete Containment Surngates}

The review level pressures which result in yielding of the major structural resisting elements were also determined for both the reinforced and prestressed concrete surrogates. Yielding first occurred in the hoop steel at midheight of the cylinder wall using minimum required material properties $\mathrm{f}_{\mathrm{y}}=60 \mathrm{ksi}$ for the deformed steel and $\mathrm{f}_{\mathrm{py}}=0.85 * \mathrm{f}_{\mathrm{pu}}=204 \mathrm{ksi}$ for the tendons, with no capacity reduction factor $(\Phi=1.0)$. Initially, the strength of the diagonal steel and liner was not included 
in determining the review level pressure. Next, the strength of the liner was included using specified material properties at $400^{\circ} \mathrm{F}$ and $600^{\circ} \mathrm{F}$. Last, both the liner (at $400^{\circ} \mathrm{F}$ ) and diagonal reinforcement were included. Increased temperature effects were only considered in the yield strength of the liner and were assumed to not reduce the strength of the reinforcement. The review level pressures for each case are shown in Table 5.2.

These pressures for concrete containments are similar to the review level pressures calculated for the surrogate steel containments. In fact, when all strength resisting elements are included, the review level pressures are higher in the surrogate concrete containments than the steel containments at increased temperatures. The effect of higher temperatures on the concrete containments is very small because only the properties of the liner were affected by temperature, and since the liner only contributes about $10 \%$ to the overall strength, review level pressures changed very little.

\subsection{Ultimate Capacity Analysis}

As shown in chapter three of this report, determining the ultimate pressure capacity of any containment is a very complex process. Many different failure modes must be considered, and uncertainties, both systematic and random, must be included. As a result, it is very difficult to define a deterministic criteria for ultimate capacity. However, in this study, a deterministic ultimate capacity was needed in order to compare margins in steel and concrete containments.

In order to proceed, the Expert Review Panel for the Containment Performance Under Severe Accident Conditions program was asked to define a deterministic criteria that should be used to compute an ultimate pressure capacity. These criteria did not have to accurately represent some defined failure pressure (mean, median, 95\%, etc.) but rather display a comparable level of conservatism for all types of containments (steel, reinforced concrete and prestressed concrete). By assuring this, the margins to failure of all surrogate containments will be comparable.

It was first determined that a strain criteria be adopted that would result in a lower bound ultimate pressure for the surroggates but also be a reasonable estimate of actual containment capacities for both existing and future designs. Some previous studies on existing containments have used a failure strain of $2 \%$ in membrane and $5 \%$ in bending for steel containments. Similarly, the 1/6 scale model of a reinforced concrete containment tested at Sandia failed at a global hoop strain of about $2 \%$. For prestressed concrete containments, the panel wanted to limit the tendons to a strain of only $1 \%$, due to their less ductile behavior.

It was the final consensus that, for this study, an appropriate failure criteria would be to limit membrane strain to $2 \%$ in all steel containments, $2 \%$ strain in the reinforced concrete and $1 \%$ strain in the prestressed concrete containments. These criteria are a somewhat conservative estimate of the ultimate pressure capacity of actual containments (to reflect field installations) and are comparable for both steel and concrete containments. In addition, actual (or typical) material properties will be employed in determining the surrogate containment ultimate capacities.

\subsubsection{Steel Containment Surrogates}

The first step in determining the ultimate capacity of the steel containments is to define the material stressstrain behavior used in the analysis for both SA-516 Gr. 70 and SA-537 Cl.2 steels. After reviewing several reports and test results on the stress limits of both steels, nominal values for yield stress and ultimate stress were determined as shown in Table 5.3 along with the ASME specified minimum allowables. Next, the stress-strain behavior (at ambient temperature) was developed for each material, which came from individual tests on each of the two materials and is shown in Figure 5.1.

The next step was to determine how the two materials behaved at increased temperatures. Several studies of the effect of increased temperature on yield strength and ultimate strength for these or similar steels were reviewed and all showed similar results [5-2, 5-3]. The general trend was that the yield stress decreased about $10-15 \%$ at $400^{\circ} \mathrm{F}$ and about $20-30 \%$ at $600^{\circ} \mathrm{F}$. This is similar to the reductions from minimum stresses specified in Table Y-1 of the ASME Code [5-1] at increased temperatures. Ultimate stresses, on the other hand, typically increased at higher temperatures, about $20-30 \%$ at $400^{\circ} \mathrm{F}$ and about $10-20 \%$ at $600^{\circ} \mathrm{F}$. The Code conservatively assumes that the ultimate stresses of these materials do not change (increase or decrease) up to temperatures of about $800^{\circ} \mathrm{F}$ as shown in Table U-1 of the ASME Code [5-1]. For this study, the actual yield stress and ultimate stress values shown in Table 5.3 were ratioed by the same factors used in Tables $Y-1$ and $\mathrm{U}-1$ of the ASME Code for both steels at temperatures of $400^{\circ} \mathrm{F}$ and $600^{\circ} \mathrm{F}$ as shown in Table 5.4 .

The best stress-strain relationship which could be applied to these materials at increased temperatures was found in Reference [5-3] for SA-516 Gr.55 steel as 
shown in Figure 5.2. As can be seen, the yield stress did reduce significantly for the sample tested at $600^{\circ} \mathrm{F}$. However, strain hardening began much sooner in this sample and when the strain reached $1 \%$, the stress at both temperatures $\left(75^{\circ} \mathrm{F}\right.$ and $\left.600^{\circ} \mathrm{F}\right)$ was about the same. As the strains increased, the stress in the $600^{\circ} \mathrm{F}$ sample also increased up to an ultimate strength of about $20 \%$ higher than the $75^{\circ} \mathrm{F}$ sample.

The effect of increased temperatures on the yield and ultimate stresses shown in Figure 5.2 behaved in a similar fashion to the other results discussed previously. Therefore, the stress-strain curves shown in Figure 5.1 for both SA-516 Gr. 70 and SA-537 Cl. 2 steel were adjusted to the stress levels shown in Table 5.4 and fit to the behavior shown in Figure 5.2. It was assumed that at $600^{\circ} \mathrm{F}$ there was no yield plateau and at $400^{\circ} \mathrm{F}$ the plateau was ratioed by the yield stress between the length of the plateau at $75^{\circ} \mathrm{F}$ and no plateau at $600^{\circ} \mathrm{F}$. The shape of the curve beyond the yield plateau was matched to an exponential fit, which is adequate up to the ultimate strength, beyond which we were not concerned. The resulting stress-strain relations for the SA-516 Grade 70 at temperatures of $75^{\circ} \mathrm{F}, 400^{\circ} \mathrm{F}$ and $600^{\circ} \mathrm{F}$ are shown in Figure 5.3. Similarly, the stressstrain relations for SA-537 Class 2 are shown in Figure 5.4.

In order to determine the equivalent uniaxial stress when the global total hoop strain is $2 \%\left(\varepsilon_{\theta}=0.02\right)$, a relationship between them which accounts for biaxial effects was developed. Using von Mises equation, the equivalent stress is defined as:

$$
\sigma_{e}=\frac{1}{\sqrt{2}}\left[\left(\sigma_{r}-\sigma_{\theta}\right)^{2}+\left(\sigma_{\theta}-\sigma_{z}\right)^{2}+\left(\sigma_{z}-\sigma_{r}\right)^{2}\right]
$$

where;

$$
\begin{aligned}
& \sigma_{\theta}=\text { hoop stress, } \\
& \sigma_{r}=\text { radial stress, and } \\
& \sigma_{z}=\text { meridional stress. }
\end{aligned}
$$

In the case of a thin shell cylinder:

$$
\begin{aligned}
& \sigma_{z}=\frac{\sigma_{\theta}}{2} \text { and } \sigma_{r}=0 \\
& \therefore \sigma_{e}=\frac{\sqrt{3}}{2} \sigma_{\theta}
\end{aligned}
$$

The plastic strain increments are proportional to the deviatoric stresses and are given by the following Prandtl-Reuss flow rule:

$$
e_{\mathrm{\theta}}^{P}=1.5 \frac{\mathrm{e}^{P}}{\sigma_{e}} S_{\theta}
$$

where;

$$
\begin{aligned}
& \varepsilon_{\theta}^{P}=\text { plastic hoop strain } \\
& \varepsilon^{P}=\text { equivalent plastic strain } \\
& S_{\theta}=\text { deviatoric hoop stress }
\end{aligned}
$$

This is a radial loading problem, since stresses are proportional to pressure. Thus "deformation plasticity" theory is adequate and proceeding in an incremental fashion is not required. Hoop stress, $\sigma_{e}$, can be directly related to the total plastic strain, $\boldsymbol{\varepsilon}^{p}$, using the uniaxial experimental stress-strain curves developed previously. The assumed failure criteria is to limit membrane hoop strain to $2 \%\left(\varepsilon_{\theta}=0.02\right)$. This can be related to pressure via Hooke's Law,

$$
\begin{aligned}
\varepsilon_{\theta} & =\frac{1}{E}\left[\sigma_{\theta}-v \sigma_{z}\right]+\varepsilon_{\theta}^{P} \\
& =\frac{2-v}{\sqrt{3} E} \sigma_{e}+\frac{\sqrt{3}}{2} e^{P}
\end{aligned}
$$

where;

$$
\begin{aligned}
& E=\text { Young's Modulus } \\
& v=\text { Poisson's Ratio } \\
& \varepsilon_{\theta}=\text { hoop strain }
\end{aligned}
$$

Using the stress-strain curves developed in Figures 5.3 and 5.4, the value of $\sigma_{c}$ can be determined at a certain plastic strain value of $\varepsilon^{p}$ and entered into equation 5-3 in order to iteratively reach a hoop strain of $2 \%$ or $\varepsilon_{\theta}=0.02$. This final value of $\sigma_{e}$ can then be used to determine the failure pressure.

Similarly, for the case of a thin walled sphere, using 
von Mises stress criteria yields;

$$
\begin{aligned}
& \sigma_{z}=\sigma_{\theta} \text { and } \sigma_{r}=0 \\
& \therefore \sigma_{c}=\sigma_{\theta}
\end{aligned}
$$

The strain relationship then becomes:

$$
\begin{aligned}
\varepsilon_{\theta} & =\frac{1}{E}\left[\sigma_{\theta}-v \sigma_{z}\right]+\varepsilon_{\theta}^{P} \\
& =\frac{1-v}{E} \sigma_{e}+\frac{1}{2} e^{P}
\end{aligned}
$$

Which again can be solved for any particular stressstrain curve to get $\sigma_{e}$ and hence failure pressure.

Using the curves developed for both materials and shown in Figures 5.3 and 5.4, the equations 5-4 and 5-6 were used to solve for the effective stress when the hoop strain is $2 \%$ for both a cylinder or spherical shape. Knowing the relationship between effective stress and hoop stress (shown in equations 5-2 and 5-5), the actual hoop stress can then be computed. The effective strain $\left(\varepsilon_{e}\right)$, effective stress $\left(\sigma_{\partial}\right)$, and hoop stress $\left(\sigma_{\theta}\right)$ for both materials at temperatures of $75^{\circ} \mathrm{F}, 400^{\circ} \mathrm{F}$, and $600^{\circ} \mathrm{F}$ were computed for both a cylinder wall section and a sphere or dome shaped section and are shown in Table 5.5.

The hoop stresses shown in Table 5.5 were then used to compute the ultimate failure pressures of each of the surrogate containments. In the case of the cylindrical containments with a hemispherical dome, the stresses in the dome were always controlling. This can be seen in Table 5.5 where the hoop stress in the dome was always less than it was in the cylinder wall for each material and temperature case, although for SA-516 Gr. 70 it was very close. These hoop stresses are directly comparable because in the surrogate containments the dome thickness is always $1 / 2$ the cylinder thickness, which means the pressure to hoop stress ratio is equivalent. The resulting ultimate pressures for all the steel surrogates are shown in Table 5.6.

\subsubsection{Concrete Containment Surrogates}

The ultimate internal pressure capacities of the two surrogate containments designed for this study (reinforced concrete and prestressed concrete containment), were determined by Sargent and Lundy using the nonlinear structural analysis computer program ADINA. Prior to performing the nonlinear finite element analysis of the containments, the internal pressure capacity of each containment is first predicted using the simple procedure outlined in Reference [5-4].

For the purpose of this study, "failure" is defined as the attainment of the strain limits specified below:

\section{Reinforced Concrete Surrogate Containment Failure Criteria:}

a. Main reinforcing steel reaching a tensile strain of $0.02 \mathrm{in} / \mathrm{in}(2 \%)$.

b. Tensile yielding of the shear ties at a strain of $0.00231 \mathrm{in} /$ in signifying shear failure

c. Crushing of concrete signified by a concrete compressive strain of $0.002 \mathrm{in} / \mathrm{in}$

Prestressed Concrete Surrogate Containment Failure Criteria:

a. Post-tensioning tendon reaching a tensile strain of $0.01 \mathrm{in} / \mathrm{in}(1 \%)$.

b. Tensile yielding of shear ties at a strain of $0.00231 \mathrm{in} / \mathrm{in}$ signifying shear failure

c. Crushing of concrete signified by a concrete compressive strain of $0.002 \mathrm{in} / \mathrm{in}$

It should be noted that while the ultimate failure would occur at strains well past general yielding of the reinforcing steel/tendon in the critical section with attendant large displacements of the containment structure, the increase in internal pressure capacity past incipient yielding of steel would be very small when reinforcing steel/tendon with a negligible post-yield plastic modulus (flat stress-strain curve) is used.

\section{Capacity Using Simple Calculations}

Assuming that the hoop membrane section near the midheight of the containment is the most stressed section under internal pressure, the nonlinear response and the ultimate pressure capacity of this membrane section in each containment is predicted by simple calculations based on considerations of force equilibrium and strain compatibility as outlined in Reference [5-4]. The liner is assumed to be a strength element in these prediction calculations. The predicted internal capacity of the surrogate reinforced concrete containment is $131.6 \mathrm{psig}$. The predicted internal pressure capacity of the surrogate prestressed concrete containment is $129.7 \mathrm{psig}$. The simplified material properties assumed in the prediction calculations are listed below. 


\begin{tabular}{|c|c|c|}
\hline & Reinforced & Prestressed \\
\hline Area of concrete, $A_{c}$ & 648 sq. in $/ \mathrm{ft}$ & 480 sq. in $/ \mathrm{ft}$ \\
\hline Area of liner & 3.0 sq. in $/ \mathrm{ft}$ & 3.0 sq. in $/ \mathrm{ft}$ \\
\hline Area of reinforcing steel & $16.24 \mathrm{sq} . \mathrm{in} / \mathrm{ft}$ & 2.54 sq. in/ft \\
\hline Area of hoop tendon & N/A & $3.88 \mathrm{sq} . \mathrm{in} / \mathrm{ft}$ \\
\hline Concrete strength, $\mathrm{f}_{\mathrm{c}}^{\prime}$ & $4,000 \mathrm{psi}$ & $5,500 \mathrm{psi}$ \\
\hline $\begin{array}{l}\text { Concrete Young's } \\
\text { modulus }\end{array}$ & $3630 \mathrm{ksi}$ & $4227 \mathrm{ksi}$ \\
\hline Concrete cracking strain & $0.0001 \mathrm{in} / \mathrm{in}$ & $0.0001 \mathrm{in} / \mathrm{in}$ \\
\hline Steel Young's modulus & $29,000 \mathrm{ksi}$ & $29,000 \mathrm{ksi}$ \\
\hline Liner yield strength & $29 \mathrm{ksi}$ & $29 \mathrm{ksi}$ \\
\hline Rebar yield strength & $67 \mathrm{ksi}$ & $67 \mathrm{ksi}$ \\
\hline $\begin{array}{l}\text { Tendon yield strength } \\
\text { (@1\% strain) }\end{array}$ & N/A & $222 \mathrm{ksi}$ \\
\hline $\begin{array}{l}\text { Effective tendon stress } \\
\text { after losses }\end{array}$ & N/A & $139.34 \mathrm{ksi}$ \\
\hline
\end{tabular}

Bilinear stress-strain curves, linear elastic up to yield point and completely plastic beyond yield, are assumed for the steel liner, reinforcing steel, and the tendon. Figures 5.5 and 5.6 respectively show the predicted pressure versus radial displacement response of the hoop membrane section of the surrogate reinforced concrete containment and the surrogate prestressed concrete containment. These plots show an ultimate capacity of $131.6 \mathrm{psig}$ for the reinforced containment and 129.7 psig for the prestressed containment using simple calculation methods.

\section{Capacity Using Nonlinear Finite Element Analysis}

The global failure mode and the corresponding internal pressure capacity of the containments were also determined by using the ADINA nonlinear analysis computer program [5-5] to analyze a layered finite element model of each containment with nonlinear material stress-strain properties for concrete, liner plate, reinforcing steel, and prestressing tendon by incrementally increasing the internal pressure to "failure".

The finite element models of the surrogate containments used in the analysis are shown in Figures 5.7 and 5.8. The concrete shell and the basemat are modeled by axisymmetric solid elements. The liner is modeled by axisymmetric shell elements. Meridional reinforcement, meridional tangential shear reinforcement, shear ties, and vertical tendons in the cylinder are modeled by two-node truss elements. Hoop reinforcement, hoop tendons in the cylinder and dome, and hoop tangential shear reinforcement are modeled by one-node axisymmetric (ring) trusses. The model for the reinforced containment consists of 681 elements and 742 nodal points. The model for the prestressed containment consists of 631 elements and 775 nodal points.

The elements used to model the concrete containment shell are eight-node isoparametric elements with three by three (total of nine) integration points. The cylindrical wall and the dome are modeled by three elements across the thickness. Thus concrete stresses and strains are calculated at nine integration points across the wall thickness. Based on conversation with ADINA R\&D, Inc. and based on the good correlation between ADINA and experimental results reported in Reference [5-6] it was determined that this discretization is sufficiently fine to produce accurate stress distribution across the containment shell and to allow the positioning of reinforcing trusses as close as possible to the reinforcement position in the structure.

The attenuation length of the discontinuity bending moment of an axisymmetric cylindrical shell is approximately equal to $2(\mathrm{Rh})^{0.5}$, where ' $\mathrm{R}$ ' denotes the radius of the shell and ' $h$ ' denotes the thickness of the shell. Therefore, the lower $44 \mathrm{ft}$ of the shell is modeled with finer mesh, i.e. $3.3 \mathrm{ft}$ and $3.9 \mathrm{ft}$ element lengths, to capture the trend of moment gradient at the intersection between the cylinder and basemat. A finer mesh is also used below and above the springline, i.e. $2.5 \mathrm{ft}$ and $3.3 \mathrm{ft}$ element lengths, to determine any moment gradient effect due to variation in the thickness of the shell and the liner, and the amount of reinforcing due to the curtailment of tangential shear reinforcement in the dome near the springline. Elsewhere the element length does not exceed $5.7 \mathrm{ft}$.

The orthogonal inclined mesh of the seismic reinforcement is modeled by an equivalent orthogonal upright mesh. Meridional reinforcement, the shear ties in the lower cylinder, equivalent meridional tangential shear reinforcement, and meridional tendons are modeled by two-node trusses. The cross-section area of these trusses is referred to as one radian. Curtailment of meridional reinforcement in the lower portion of the cylinder and the tangential shear reinforcement in the dome near the spring line are simulated by varying the cross-sectional areas of the corresponding truss elements. Hoop reinforcement, hoop tendons, and equivalent hoop tangential reinforcement are modeled by one-node ring (axisymmetric) trusses. 
Meridional and hoop (ring) trusses are connected to nodal points of the concrete element mesh. This implies that there is no relative motion between meridional and hoop bars and that after the cracks formed the concrete pieces should follow the motion of the net of reinforcement bars. End trusses in the lower section of the cylinder are also connected to concrete mesh points on basemat top surface. The same is true for the meridional tangential reinforcement modeled by meridional trusses which terminate above the springline in the dome. This is an acceptable simplification [Reference 5-7].

The concrete basemat is modeled by five layers of eight-node isoparametric axisymmetric finite elements. The mesh is made finer with increasing radius and elevation. The basemat bottom surface is restrained to simulate the cylinder base fixity assumed in the design calculations and, therefore, since basemat bending was not of concern, the basemat concrete could be modeled as plain elastic concrete without any reinforcement.

Axisymmetric isoparametric shell elements are used to model the liner. These elements represent membrane, bending, and shear actions. These elements are defined by three nodes and contain three integration points along the length and three integration points through the thickness.

Liner nodal points are fixed to the nodal points of the inner concrete surface. This is a reasonable simplification because the liner is predominantly loaded by membrane stresses and any relative motion of stud ends anchored within the concrete layer and the ends welded to the liner shell can be neglected.

\section{Material Properties}

The ADINA concrete material model used for the concrete behavior is described in the ADINA Report ARD 92-8. It includes the following three basic features:

a. The model is based on the uniaxial stress-strain relation that is generalized to take biaxial and triaxial stress conditions into account

b. Tensile cracking and compression crushing are identified using failure surfaces

c. Strain-softening effects are included in the compression and the tensile regions
Cracking occurs if the largest principal stress is larger than the tensile failure stress. Perpendicular to the principal stress direction, a plane of failure develops and the normal and shear stiffnesses are reduced by user-provided factors, and the normal stress is released.

The concrete properties used in the reinforced concrete containment are as follows:

- initial (tangent) modulus at zero strain,

- Poisson's ratio, $E_{0}=3834.3 \mathrm{ksi}$

- uniaxial cut-off tensile stress,

- uniaxial maximum compressive stress,

- uniaxial compressive strain at maximum compressive stress,

- uniaxial ultimate compressive stress,

- uniaxial compressive strain at ultimate compressive stress,

- option for the triaxial failure curve,

$v=0.17$

$\sigma_{\mathrm{t}}=0.379 \mathrm{ksi}$

$\sigma_{c}=-4.0 \mathrm{ksi}$

$\varepsilon_{\mathrm{c}}=-0.002 \mathrm{in} / \mathrm{in}$

$\sigma_{\mathrm{u}}=3.403 \mathrm{ksi}$

$\varepsilon_{\mathrm{u}}=-0.004 \mathrm{in} / \mathrm{in}$

- normal stiffness reduction factor, $\eta_{\mathrm{n}}=0.0001$ (default)

- shear stiffness reduction factor, $\quad \eta_{0}=0.5$ (default)

The stress-strain behavior of the reinforcing steel is modeled using the elasto-plastic model in ADINA. The following actual typical properties of reinforcing steel are used [5-8]:

- modulus of elasticity,

- yield strength,

- yield strain,

- plastic modulus,

$$
\begin{aligned}
& E=29,000 \mathrm{ksi} \\
& \sigma_{\mathrm{y}}=67 \mathrm{ksi} \\
& \varepsilon_{\mathrm{y}}=0.00231 \mathrm{in} / \mathrm{in} \\
& E_{t}=0.0001 \mathrm{E}
\end{aligned}
$$

The behavior of the liner steel is modeled using the elasto-plastic model in ADINA. For the SA-516 Grade 60 liner plate, the following material properties are used [Ref. 5-1]:

- modulus of elasticity,

- poisson's ratio,

$E=28,700 \mathrm{ksi}$

- yield strength,

$v=0.3$

- plastic modulus,

$\sigma_{\mathrm{y}}=29.2 \mathrm{ksi}$

$E_{t}=0.0001 E$

The material behavior of the tendon steel is modeled using the elasto-plastic material of ADINA. The following material properties are used for the tendons [5-8]: 
- modulus of elasticity,

$\mathrm{E}=29,000 \mathrm{ksi}$

- elastic limit,

- yield strength,

- yield strain,

- plastic modulus, $\sigma_{1}=190 \mathrm{ksi}$

$\sigma_{\mathrm{y}}=222 \mathrm{ksi}$

$\varepsilon_{\mathrm{y}}=0.01 \mathrm{in} / \mathrm{in}$

$E_{t}=0.0001 E$

The stress-strain curve of the tendon material is modified in the analysis model to account for the pretension in the tendon. Figure 5.9 shows the idealized trilinear stress-strain curve specified for the hoop tendons. A similar trilinear curve is specified for the meridional tendons. The stress-strain relationships for the tendons are based on the calculations shown below.

- each tendon is made of 170 wires $1 / 4$ " dia., thus tendon area, $A_{t}=8.345 \mathrm{in}^{2}$

- hoop tendon area per unit length,

$$
A_{t \theta}=A_{t}^{*} 12 /(25.8)=3.88 \mathrm{in}^{2} / \mathrm{ft}
$$

- meridional tendon area per unit length, $A_{2 \phi}=A_{1}^{*} 12 /(45.4)=2.206 \mathrm{in}^{2} / \mathrm{ft}$

- cylinder average design prestress for hoop tendon, $\sigma_{t \theta}=139.34 \mathrm{ksi}$

- cylinder average design prestress for meridional tendon, $\sigma_{\mathrm{tp}}=135.14 \mathrm{ksi}$

Material properties of hoop tendons are represented by the following points on a trilinear stress-strain curve :

- Elastic limit

$$
\begin{aligned}
& \sigma_{1 \theta}=\sigma_{1}-\sigma_{\theta \theta}=50.76 \mathrm{ksi} ; \\
& \varepsilon_{1 \theta}=\sigma_{1 \theta} / E=0.00175 \mathrm{in} / \mathrm{in}
\end{aligned}
$$

- Yield point

$$
\begin{aligned}
& \sigma_{2 \theta}=\sigma_{y}-\sigma_{t \theta}=82.76 \mathrm{ksi} ; \\
& \varepsilon_{2 \theta}=\left(\varepsilon_{\mathrm{y}}-\sigma_{t \theta}\right) / \mathrm{E}=0.0052 \mathrm{in} / \mathrm{in}
\end{aligned}
$$

- Post-yield

$$
\begin{aligned}
& \sigma_{3 \theta}=83.05 \mathrm{ksi} ; \\
& \varepsilon_{3 \theta}=\left(\sigma_{3 \theta}-\sigma_{2 \theta}\right) / E_{\mathrm{t}}=0.1 \mathrm{in} / \mathrm{in}
\end{aligned}
$$

Material properties of meridional tendons are represented by the following points on a trilinear stressstrain curve:

- Elastic limit

$$
\begin{aligned}
& \sigma_{1 \phi}=\sigma_{1}-\sigma_{t \phi}=54.86 \mathrm{ksi} ; \\
& \varepsilon_{1 \phi}=\sigma_{1 \phi} / \mathrm{E}=0.00189 \mathrm{in} / \mathrm{in}
\end{aligned}
$$

- Yield point

$$
\begin{aligned}
& \sigma_{2 \phi}=\sigma_{y}-\sigma_{t \phi}=86.86 \mathrm{ksi} ; \\
& \varepsilon_{2 \phi}=\left(\varepsilon_{y}-\sigma_{t \phi}\right) / E=0.00534 \mathrm{in} / \mathrm{in}
\end{aligned}
$$

$$
\begin{aligned}
& \text { - Post-yield } \\
& \qquad \begin{array}{l}
\sigma_{3 \phi}=87.15 \mathrm{ksi} ; \\
\varepsilon_{3 \phi}=\left(\sigma_{3 \phi}-\sigma_{2 \phi}\right) / \mathrm{E}_{\mathrm{q}}=0.1 \mathrm{in} / \mathrm{in}
\end{array}
\end{aligned}
$$

Loads

The following loads are concurrently applied on the analysis model:

a. Self weight. This is specified as mass proportional vertical load. Only the weight of the modeled material is included as self weight.

b. Concrete prestress. This is simulated by external pressure load on dome and cylinder exterior face of outside concrete elements. The external pressure is calculated as follows:

- hoop external pressure

$$
p_{t \theta}=\left(\sigma_{t \theta} A_{t \theta} / R\right)^{*} 1000 / 144=57.808 \mathrm{psi}
$$

- meridional force at wall base

$$
P_{t \phi}=\left(\sigma_{t \phi} A_{t \phi} R\right) \quad=19005 \mathrm{k} / \mathrm{rad}
$$

- dome external pressure

$$
p_{t d}=\left(2 \sigma_{t \phi} A_{t \phi} / R\right)^{*} 1000 / 144=64.3 \mathrm{psi}
$$

c. Intemal pressure. This is specified over the interior face of the inside concrete elements of the containment shell and basemat. The magnitude of the internal pressure is incrementally increased with iterations of equilibrium and stiffness until the internal pressure capacity is attained.

For the reinforced containment, a load of 25 psig was first applied then increased in 1 psig increments up to an internal pressure of 132 psig. For the prestressed containment, the external pressures $p_{t \theta}$ on the cylinder and $P_{t d}$ on the dome and the meridional force $P_{t \phi}$, which together simulate the concrete prestress, are applied in the initial steps. This is then followed by the incremental internal pressure again up to 132 psig:

The pressure capacity of each containment model is determined by incrementally increasing the internal pressure to a level required to attain strain levels close to the designated failure criteria strains. At each incremental pressure step, equilibrium iterations are performed with the stiffness reformulated.

\section{$\underline{\text { Results }}$}

As anticipated, the hoop membrane section near the midheight of the cylinder was found to be the critical 
section in both containments. Concrete crushing or shear tie yielding did not precede the yielding of the hoop reinforcing/tendon at the critical section.

In the reinforced concrete containment, yielding of the hoop reinforcing bars near the midheight of the cylinder at a strain of $0.00231 \mathrm{in} /$ in occurred at an internal pressure of about $131 \mathrm{psig}$. A small pressure increment of only 1 psig resulted in a large rebar strain of 0.014 in/in. Owing to the very fine pressure increments required to target the specified rebar ultimate strain of $0.02 \mathrm{in} /$ in without commensurate increase in internal pressure, the ultimate internal pressure is considered as 132 psig. The maximum strains in the liner and rebar correspond to 132 psig internal pressure.

In the prestressed concrete containment, hoop tendons near the midheight of the cylinder reached $1 \%$ strain at an internal pressure of about 131 psig. These ultimate internal pressure capacity values obtained from the detailed finite element analysis are in good agreement with the simplified calculation predicted values of 131.6 psig and 129.7 psig for the reinforced and prestressed concrete containments, respectively.

Maximum hoop strain versus pressure curves are shown in Figures 5.10 and 5.11 for the reinforced and prestressed concrete containments respectively. Salient results of the analysis are summarized below:

\section{Reinforced Concrete Containment}

Ultimate Internal Pressure Capacity = 132 psig

Maximum strain in hoop rebar near midheight of cylinder $=$ $0.014 \mathrm{in} /$ in

No yielding of shear ties prior to yielding of rebars. No crushing of concrete prior to yielding of rebars.

\section{Prestressed Concrete Containment}

Ultimate Internal Pressure Capacity =

Maximum strain in the meridional clirection near base of cylinder $=$

131 psig

Maximum strain in hoop rebar near rnidheight of cylinder $=$

$0.015 \mathrm{in} / \mathrm{in}$

Maximum strain in hoop tendon near midheight of cylinder $=$ $0.015 \mathrm{in} / \mathrm{in}$

(Initial tensile strain $0.0048 \mathrm{in} / \mathrm{in}+$ Tensile strain due to pressure $0.014 \mathrm{in} / \mathrm{in}$ )

No yielding of shear ties prior to yielding of hoop tendon.

No crushing of concrete prior to yielding of hoop tendon.
After reviewing all the results of the concrete containment analysis, the following conclusions were made:

1. The hoop membrane section near midheight of the cylinder is found to be the critical section in the surrogate containments. Concrete crushing and shear failure do not occur prior to yielding of the hoop rebar/tendon at the critical section.

2. The ultimate internal pressure capacity of the surrogate containments corresponding to incipient yielding of the hoop rebar/tendon at the critical section is approximately 2.9 times the design pressure.

3. The pressure capacity at the critical membrane section obtained from the nonlinear finite element analysis is in good agreement with the value predicted by simple calculations.

4. Maximum strains in the liner obtained from the analysis indicate that global leak-tightness of the liner will not be impaired at an internal pressure of 2.9 times the design pressure.

\subsection{Margin Comparison}

The review level pressures $\left(P_{R L}\right)$ computed in Section 5.1 for the surrogate steel containments are summarized in Table 5.7. In addition, the ultimate pressures $\left(P_{\mathrm{ULT}}\right)$ determined using the strain failure criteria in Section 5.2 are also summarized in this Table. Below each computed pressure, the ratio to the design accident pressure $(\mathrm{Pa})$ is shown $\left(\mathrm{P}_{\mathrm{RL}} / \mathrm{Pa}\right.$ and $\left.\mathrm{P}_{\mathrm{ULT}} / \mathrm{Pa}\right)$.

Comparing these ratios, one can see that for increasing temperature the $\mathrm{P}_{\mathrm{RL}}$ ratios reduce significantly compared to the $P_{U L T}$ ratios at increasing temperatures. In addition, the margins are slightly higher in the spherical containments $(\sim 10 \%)$ due to the increased thickness from seismic requirements. In the last three columns of Table 5.7, the ratios of $P_{U L r}$ to $P_{R L}$ are shown. Here the ratios actually increase at higher temperatures because the review level pressures decrease faster than the ultimate pressures at increasing temperatures. Also, the ratios are slightly higher for the SA-516 steel than the SA-537 steel due the higher margin between yield and ultimate in SA-516 steel. The $\mathrm{P}_{\mathrm{ULT}} \mathrm{P}_{\mathrm{RL}}$ ratios for the cylinder and sphere are the same since both pressures are directly related to the actual steel wall thickness of 
the containment.

Similarly, Table 5.8 summarizes the review level and ultimate pressures for the surrogate concrete containments. For each pressure computed, three different cases were analyzed for the concrete surrogates:

1) no liner included and no diagonal reinforcement included,

2) liner included but no diagonal reinforcement included, and

3) both liner and diagonal reinforcement included.

In the surrogate prestressed concrete containment, no diagonal steel was required, therefore the last two cases resulted in the same pressures.

Below each computed pressure, the ratio of $\mathrm{P}_{\mathrm{RL}}$ to the design accident pressure $(\mathrm{Pa})$ is shown $\left(\mathrm{P}_{\mathrm{RL}} / \mathrm{Pa}\right.$ and $\mathrm{P}_{\text {ULT }}(\mathrm{Pa})$. The review level pressures and ratios in the prestressed containment are slightly higher due to tendon stress losses resulting in additional tendons required. However, the ultimate pressures and ratios are very similar for both types when all strength resisting elements are included. In the last five columns of Table 5.8, the ratios of $P_{U L T}$ to $P_{R L}$ are shown. The five cases represent all the combinations of $P_{U L T}$ to $P_{R L}$ of interest (i.e. strength of the liner was always included in $P_{\text {ULT }}$ ). Here the ratios do not differ very much among all the cases and for both containment types, ranging from 1.3 to 1.7 .

Comparing the steel containment ratios to the concrete containment ratios, many similarities and comparable margins exist. In the steel containments at a severe accident (SA) temperature of $400^{\circ} \mathrm{F}$, which is considered to be an upper bound temperature for most SA scenarios, the margin between design pressure and $P_{R L}$ is at least 1.7 for the mild steel (SA-516 Gr. 70) and at least 2.3 for the stronger steel (SA-537 Cl. 2). Similarly, the concrete containments inherently have a margin of at least 1.67 between design pressure and $P_{R L}$, even when the added strength of the liner and diagonal reinforcement is not considered. This is a result of the current design requirements, which require that for the load case $1.5 * \mathrm{~Pa}$ the stresses do not exceed $0.9 * \mathrm{~F}_{\mathrm{y}} . \mathrm{P}_{\mathrm{RL}}$ is the pressure when stresses in the reinforcement reach $F_{y}$, therefore the factor over design pressure is $1.5 / 0.9=1.67$. This would imply that since the alternative criteria for steel containments impose a margin of at least 1.7 and the concrete containments already posses a similar margin of 1.67 , no additional margin analysis of the concrete containments would be necessary.

Next, the design to ultimate pressure margins can be compared. In the concrete surrogates, the most applicable cases should always consider the strength of the liner both with or without the diagonal steel. These cases (number [5] and [6] in Table 5.8) yield $\mathrm{P}_{\mathrm{uLr}} \mathrm{Pa}$ ratios of between 2.6 and 2.9 for both concrete containment types. In the steel containments, case [5] in Table 5.7 representing a temperature of $400^{\circ} \mathrm{F}$, yields a slightly higher margin of at least 3.1 for all the surrogate steel containments. These is comparable to the probabilistic margins shown in Chapter 3 of this report (in Tables 3.3-3.5) in which the median controlling failure margin in reinforced concrete containments is 3.0 , for prestressed concrete is 2.7 , and for steel containments is approximately 3.4 .

The last set of margins to compare is the margin between the review level pressure and the ultimate pressure $\left(\mathrm{P}_{\mathrm{ULT}} / \mathrm{P}_{\mathrm{RL}}\right)$. For the concrete surrogates the last two columns in Table 5.8 are the most applicable ([6]/[1] and [5]/[1]). For both these cases the $\mathrm{P}_{\mathrm{RL}}$ does not include the liner or the diagonal steel, and the $\mathrm{P}_{\mathrm{ULT}}$ includes the liner strength and considers the strength both with and without the diagonal steel. The margins computed for both concrete containment types are between 1.4 and 1.7. In the steel surrogates, the [5]/[2] case represents the margin between $P_{U L T}$ and $P_{R L}$, again at a temperature of $400^{\circ} \mathrm{F}$. This margin is similar to the concrete and is between 1.6 and 1.8 for both steel containment geometries and both material types.

\subsection{References}

5-1. The American Society of Mechanical Engineers, 1995 ASME Boiler and Pressure Vessel Code, 1995.

5-2. Lou, S. and Northwood, D. O., "Elevated Temperature Mechanical Properties and Dynamic Strain Aging in Pressure Vessel Quality Steel Plate," Canadian Metallurgical Quarterly, Vol. 31, No. 3, pp 225-229, 1992. 
5. Deterministic Pressure Capacities for Surrogate Containments

5-3. Gowda, B. C., "Tensile properties of SA 516 (Grade 55) steel in the temperature range of $75^{\circ} \mathrm{F}$ to $1700^{\circ} \mathrm{F}$ and strain rate range of $10^{-4}$ to $10^{-1} \mathrm{sec}^{-1}, "$ Westinghouse Electric Corporation - Advanced Reactors Division, Madison, PA, WARD-D-0189, July 1977.

5-4. Krishnaswamy, C. N., et. al., "Ultimate Internal Pressure Capacity of Concrete Containment Structure", 7th SMiRT Conference, August 1983.

5-5. S\&L Program ADINA No. 03731510 and ADINA-IN Users Manual (Report ARD 90-4), ADINA-PLOT Users Manual (Report ARD 925 ) and Theory and Modeling Guide (Report ARD 92-8).

5-6. Bathe, K. J., et. al., "Nonlinear Analysis of Concrete Structures", Computer and Structures, Vol. 32, pp. 563-590, 1989.

5-7. Clauss, D. B., Round-Robin Pretest Analyses of a 1:6-Scale Reinforced Concrete Containment Model Subject to Static Internal Pressurization, NUREG/CR-4913, SAND87-0891, May 1987.

5-8. Carter, J. C., et. al., Technical Report 10.1 Containment Structural Capability of Light Water Nuclear Power Plants, IDCOR Program Report, Technology for Energy Corporation, July 1983. 
5. Deterministic Pressure Capacities for Surrogate Containments

Table 5.1 Minimum Review Level Pressures for Surrogate Steel Containments (in psig)

\begin{tabular}{|c|c|c|c|}
\hline Material & $\begin{array}{c}\mathrm{P}_{\mathrm{RL}} \\
\left(75^{\circ} \mathrm{F}\right)\end{array}$ & $\begin{array}{c}\mathrm{P}_{\mathrm{RL}} \\
\left(400^{\circ} \mathrm{F}\right)\end{array}$ & $\begin{array}{c}\mathrm{P}_{\mathrm{RL}} \\
\left(600^{\circ} \mathrm{F}\right)\end{array}$ \\
\hline Cylinder & \multicolumn{3}{|l|}{} \\
\hline SA-516 Gr. 70 & 89.3 & 76.6 & 66.0 \\
\hline SA-537 Cl. 2 & 125.8 & 104.9 & 96.5 \\
\hline Sphere & & & 72.1 \\
\hline SA-516 Gr. 70 & 97.5 & 83.6 & 112.1 \\
\hline SA-537 Cl. 2 & 146.2 & 121.8 & \\
\hline
\end{tabular}

$\mathrm{Pa}=45$ psig

Table 5.2 Minimum Review Level Pressures for Surrogate Concrete Containments (in psig)

\begin{tabular}{||l|c|c|c|c|}
\hline $\begin{array}{c}\text { Construction } \\
\text { Type }\end{array}$ & $\begin{array}{c}\mathrm{P}_{\mathrm{RL}} \text { (liner \& } \\
\text { diagonal } \\
\text { reinforcement } \\
\text { not included) }\end{array}$ & $\begin{array}{c}\mathrm{P}_{\mathrm{RL}} \text { (liner } \\
\text { included @ } 400^{\circ} \mathrm{F} \\
\text { \&iagonal not } \\
\text { included) }\end{array}$ & $\begin{array}{c}\mathrm{P}_{\mathrm{RL}} \text { (liner } \\
\text { included @600 } \\
\text { \& diagonal not } \\
\text { included) }\end{array}$ & $\begin{array}{c}\mathrm{P}_{\mathrm{RL}} \text { (liner } \\
\text { included } \\
\text { @400\% \& } \\
\text { diagonal } \\
\text { included) }\end{array}$ \\
\hline Reinforced & 77.7 & 86.6 & 85.6 & 97.5 \\
\hline Prestressed & 93.8 & 102.8 & 101.6 & 102.8 \\
\hline
\end{tabular}

$\mathrm{Pa}=45 \mathrm{psig}$ 
5. Deterministic Pressure Capacities for Surrogate Containments

Table 5.3 Comparison of Typical Steel Material Properties to Code Specified Minimums

\begin{tabular}{|l|c|c|c|c|}
\hline \multirow{2}{*}{ Material } & \multicolumn{2}{|c|}{$\begin{array}{c}\text { ASME Code Specified } \\
\text { Minimum Allowables }\end{array}$} & \multicolumn{2}{c|}{ Typical Values } \\
\cline { 2 - 5 } & Sy (ksi) & Su (ksi) & Fy (ksi) & Fu(ksi) \\
\hline \hline SA-516 Gr. 70 & 38.0 & 70.0 & 53.0 & 74.2 \\
\hline SA-537 Cl. 2 & 60.0 & 80.0 & 71.7 & 89.3 \\
\hline
\end{tabular}

Table 5.4 Stress Values used in Steel Material Model

\begin{tabular}{||l|c|c|c|c|c|c||}
\hline \multirow{2}{*}{ Material } & \multicolumn{3}{|c|}{ Yield Stress (ksi) } & \multicolumn{3}{c||}{ Ultimate Stress (ksi) } \\
\cline { 2 - 7 } & $75^{\circ} \mathrm{F}$ & $400^{\circ} \mathrm{F}$ & $600^{\circ} \mathrm{F}$ & $75^{\circ} \mathrm{F}$ & $400^{\circ} \mathrm{F}$ & $600^{\circ} \mathrm{F}$ \\
\hline \hline SA-516 Gr. 70 & 53.0 & 45.5 & 39.2 & 74.7 & 74.7 & 74.7 \\
\hline SA-537 Cl. 2 & 71.7 & 59.7 & 55.0 & 89.3 & 89.3 & 89.3 \\
\hline
\end{tabular}


5. Deterministic Pressure Capacities for Surrogate Containments

Table 5.5 Material Behavior when Hoop Strain equals $2 \%\left(\varepsilon_{\theta}=0.02\right)$

\begin{tabular}{||c|c|c|c|c|c|c|c||}
\hline \hline Material & \multicolumn{3}{|c|}{ Cylinder Wall } & \multicolumn{3}{c|}{ Sphere or Dome } \\
\hline Temp. & $\begin{array}{c}\text { Effective } \\
\text { Strain } \\
\varepsilon_{e} \\
(\mathrm{in} / \mathrm{in})\end{array}$ & $\begin{array}{c}\text { Effective } \\
\text { Stress } \\
\sigma_{\mathrm{e}} \\
(\mathrm{ksi})\end{array}$ & $\begin{array}{c}\text { Hoop } \\
\text { Stress } \\
\sigma_{\theta} \\
(\mathrm{ksi})\end{array}$ & $\begin{array}{c}\text { Effective } \\
\text { Strain } \\
\varepsilon_{e} \\
(\mathrm{in} / \mathrm{in})\end{array}$ & $\begin{array}{c}\text { Effective } \\
\text { Stress } \\
\sigma_{\mathrm{e}} \\
(\mathrm{ksi})\end{array}$ & $\begin{array}{c}\text { Hoop } \\
\text { Stress } \\
\sigma_{\theta} \\
(\mathrm{ksi})\end{array}$ \\
\hline SA-516 Grade 70 & 0.0228 & 54.8 & 63.2 & 0.0391 & 62.4 & 62.4 \\
\hline $75^{\circ} \mathrm{F}$ & 0.0229 & 53.0 & 61.2 & 0.0392 & 59.8 & 59.8 \\
\hline $400^{\circ} \mathrm{F}$ & 0.0229 & 51.3 & 59.3 & 0.0392 & 57.7 & 57.7 \\
\hline $600^{\circ} \mathrm{F}$ & & & & & & \\
\hline SA-537 Class 2 & 0.0227 & 79.2 & 91.4 & 0.0388 & 84.0 & 84.0 \\
\hline $75^{\circ} \mathrm{F}$ & 0.0228 & 75.1 & 86.7 & 0.0389 & 81.8 & 81.8 \\
\hline $400^{\circ} \mathrm{F}$ & 0.0228 & 72.7 & 83.9 & 0.0389 & 79.8 & 79.8 \\
\hline $600^{\circ} \mathrm{F}$ &
\end{tabular}

Table 5.6 Ultimate Pressures for Steel Surrogate Containments (in psig)

\begin{tabular}{|c|c|c|c||}
\hline Material & $\begin{array}{c}\mathrm{P}_{\mathrm{ULT}} \\
\left(75^{\circ} \mathrm{F}\right)\end{array}$ & $\begin{array}{c}\mathrm{P}_{\mathrm{ULT}} \\
\left(400^{\circ} \mathrm{F}\right)\end{array}$ & $\begin{array}{c}\mathrm{P}_{\mathrm{ULT}} \\
\left(600^{\circ} \mathrm{F}\right)\end{array}$ \\
\hline Cylindrical Containment \\
\hline SA-516 Gr. 70 & 146.7 & 140.5 & 135.6 \\
\hline SA-537 Cl. 2 & 176.4 & 171.7 & 167.6 \\
\hline Spherical Containment & \multicolumn{5}{|l}{} \\
\hline SA-516 Gr. 70 & 159.9 & 153.2 & 147.9 \\
\hline SA-537 Cl. 2 & 204.6 & 199.2 & 194.4 \\
\hline
\end{tabular}

$\mathrm{Pa}=45$ psig 
sisd $s t=e_{d}$

\begin{tabular}{|c|c|c|c|c|c|c|c|c|c|c|c|}
\hline 61 & $t \cdot I$ & $\varepsilon \cdot I$ & $\varepsilon$ & $\varepsilon \cdot I$ & $\begin{array}{l}(6 \cdot \tau) \\
I \varepsilon I\end{array}$ & $\begin{array}{l}(6 \cdot \tau) \\
I \varepsilon I\end{array}$ & $\begin{array}{l}(L Z) \\
0 Z I\end{array}$ & $\begin{array}{l}(\varepsilon \tau) \\
\varepsilon 0 \mathrm{I}\end{array}$ & $\begin{array}{l}(\varepsilon \tau) \\
\varepsilon 0 \mathrm{I}\end{array}$ & $\begin{array}{c}(\mathrm{I} z) \\
t 6\end{array}$ & passənsəId \\
\hline$\varsigma \mathrm{I}$ & $L^{\prime} I$ & $S I$ & $t \cdot I$ & $t \cdot I$ & $\begin{array}{l}(6 \cdot z) \\
z \varepsilon I\end{array}$ & $\begin{array}{l}(9 \cdot \tau) \\
\text { LII }\end{array}$ & $\begin{array}{l}\left(\varepsilon^{\prime} Z\right) \\
\text { SOI }\end{array}$ & $\begin{array}{c}(z ' z) \\
86\end{array}$ & $\begin{array}{c}(6.1) \\
\angle 8\end{array}$ & $\begin{array}{l}(L I) \\
8 L\end{array}$ & pәэголитәу \\
\hline$\frac{\mathrm{ON}}{\mathrm{ON}}$ & $\frac{\mathrm{oN}}{\mathrm{sod}}$ & $\frac{\mathrm{oN}}{\operatorname{sa} \lambda}$ & $\frac{o_{N}}{o_{N}}$ & $\frac{s \partial \lambda}{s \partial \lambda}$ & $\operatorname{so} \alpha$ & $\mathrm{O}_{\mathrm{N}}$ & ON & $\operatorname{se} \alpha$ & oN $_{\mathbf{N}}$ & ON & 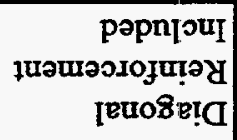 \\
\hline$\frac{O_{N}}{\operatorname{son}}$ & $\frac{o N}{s \partial X}$ & $\frac{\operatorname{son}}{\operatorname{so} \lambda}$ & $\frac{s \partial A}{s \partial \lambda}$ & $\frac{s \theta \lambda}{s \theta \lambda}$ & $\operatorname{se}_{\alpha}$ & so $X$ & oN & sod & sa $x$ & $\mathrm{o}_{\mathrm{N}}$ & $\begin{array}{r}\text { popnjouI } \\
\text { Iәu! }\end{array}$ \\
\hline$\frac{[\mathrm{I}]}{[\mathrm{S}]}$ & $\frac{[1]}{[9]}$ & $\frac{[z]}{[9]}$ & $\frac{[z]}{[s]}$ & $\frac{[\varepsilon]}{[9]}$ & [9] & [S] & [t] & [ع] & [Z] & [I] & [əseo] \\
\hline & & $\frac{{ }^{T d} d}{I^{2} n_{d}}$ & & & arnssa & $\begin{array}{l}\text { ed } \\
\text { gitsd } \\
\text { giteum! }\end{array}$ & ${ }^{17 n_{d}}$ & & 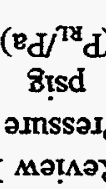 & & อңaIotios \\
\hline
\end{tabular}

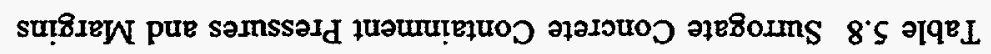

$8 t s d s t=e_{d}$

\begin{tabular}{|c|c|c|c|c|c|c|c|c|c|c|}
\hline$L I$ & $9^{\circ} I$ & $t I$ & $\begin{array}{l}(\varepsilon t) \\
t 6 I\end{array}$ & $\begin{array}{l}(t \cdot t) \\
66 I\end{array}$ & $\begin{array}{l}\left(\varsigma^{\prime} t\right) \\
\varsigma 0 \tau\end{array}$ & $\begin{array}{l}\left(\varsigma^{\prime} \tau\right) \\
\tau I I\end{array}$ & $\begin{array}{l}(L \tau) \\
\tau z I\end{array}$ & $\begin{array}{l}(\tau \cdot \varepsilon) \\
9 \forall[\end{array}$ & $\begin{array}{l}\tau \text { ssEID } \\
\text { LES-VS }\end{array}$ & \\
\hline$I \cdot z$ & $8 I$ & $9 I$ & $\begin{array}{l}(\varepsilon \cdot \varepsilon) \\
8+I\end{array}$ & $\begin{array}{l}\left(t^{\circ} \varepsilon\right) \\
\varepsilon S I\end{array}$ & $\begin{array}{l}\left(9^{\circ} \varepsilon\right) \\
09 \mathrm{I}\end{array}$ & $\begin{array}{c}(9 \cdot 1) \\
\tau L\end{array}$ & $\begin{array}{c}(6.1) \\
t 8\end{array}$ & $\begin{array}{c}(z \cdot \tau) \\
L 6\end{array}$ & $\begin{array}{r}\text { OL әреID } \\
91 S-\forall S\end{array}$ & әrəџฺds \\
\hline$L I I$ & $9 \cdot 1$ & $t \cdot I$ & $\begin{array}{l}\left(L^{\circ} \varepsilon\right) \\
89 L\end{array}$ & $\begin{array}{l}\left(8^{\circ} \varepsilon\right) \\
\tau L I\end{array}$ & $\begin{array}{l}(6 \cdot \varepsilon) \\
9 \angle I\end{array}$ & $\begin{array}{l}\left(I^{\prime} Z\right) \\
96\end{array}$ & $\begin{array}{l}(\varepsilon \cdot \tau) \\
\text { sol }\end{array}$ & $\begin{array}{l}(8 \cdot \tau) \\
9 Z I\end{array}$ & $\begin{array}{l}Z \text { SSEID } \\
\angle E S-\forall S\end{array}$ & \\
\hline$I z$ & $8 \cdot I$ & 91 & $\begin{array}{l}\left(0^{\circ} \varepsilon\right) \\
9 \varepsilon I\end{array}$ & $\begin{array}{c}(I \cdot \varepsilon) \\
I+I\end{array}$ & $\begin{array}{l}(\varepsilon \varepsilon) \\
L t I\end{array}$ & $\begin{array}{c}(\varsigma 1) \\
99\end{array}$ & $\begin{array}{c}(L \cdot L) \\
L L\end{array}$ & $\begin{array}{c}\left(0^{\circ} 2\right) \\
68\end{array}$ & $\begin{array}{r}0 L \text { apero } \\
9 I S-\forall S\end{array}$ & 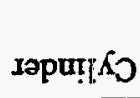 \\
\hline H. 009 & do $00 t$ & $H_{0} \subseteq L$ & d. 009 & d. $00 t$ & Jo $S L$ & Ho 009 & H. 00t & $I_{0} S L$ & & jeIadure L \\
\hline$\frac{[\varepsilon]}{[9]}$ & $\frac{[z]}{[s]}$ & $\frac{[\mathrm{I}]}{[\mathrm{t}]}$ & [9] & [s] & {$[t]$} & [ع] & [z] & [1] & & [aseo] \\
\hline \multicolumn{3}{|c|}{$\frac{{ }^{T d} d}{12 n_{d}}$} & \multicolumn{3}{|c|}{$\left(\mathrm{E}_{\mathrm{d}} J^{I T \Omega} \mathrm{d}\right)$} & \multicolumn{3}{|c|}{ 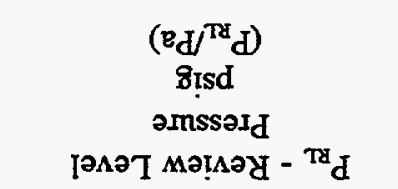 } & & \\
\hline
\end{tabular}

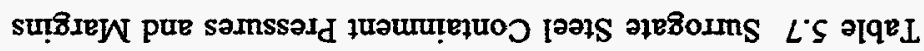


5. Deterministic Pressure Capacities for Surrogate Containments

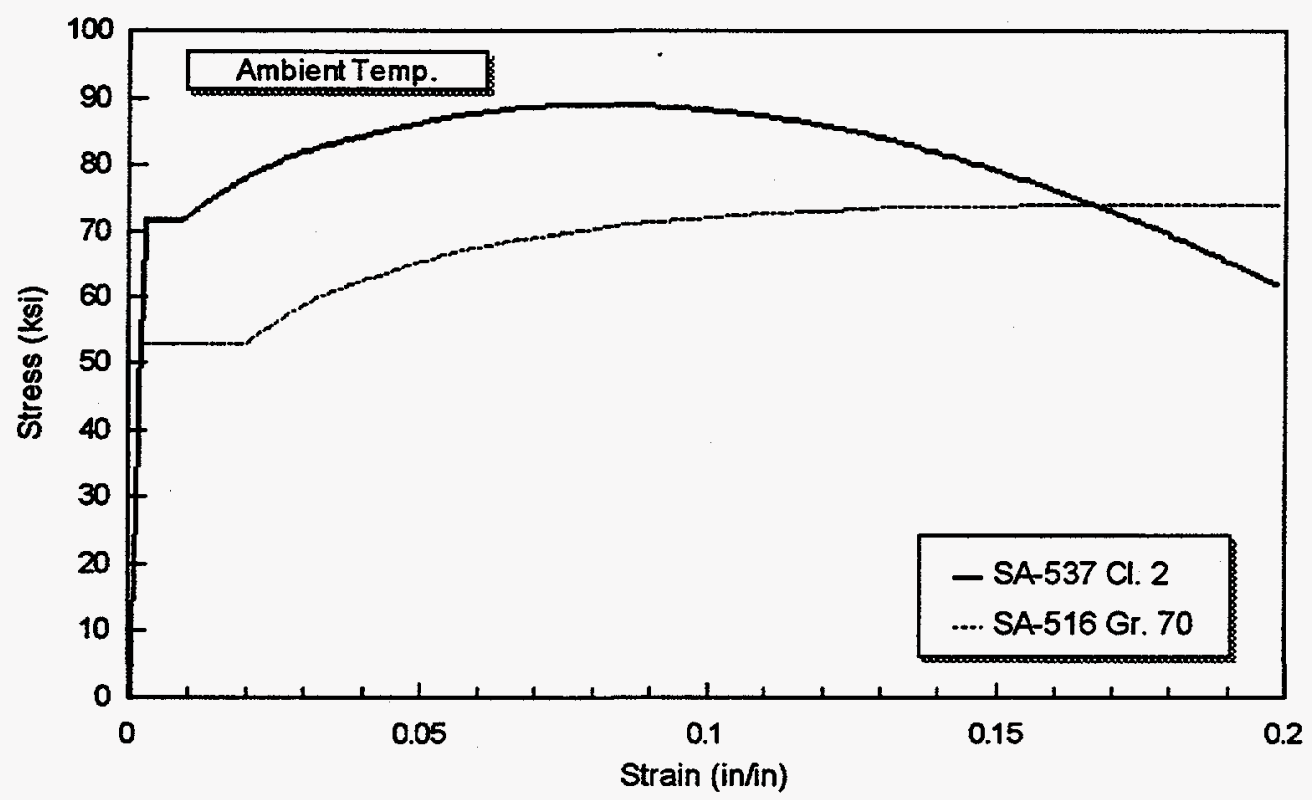

Figure 5.1 Typical Stress-Strain Behavior of Surrogate Steel Containment Materials

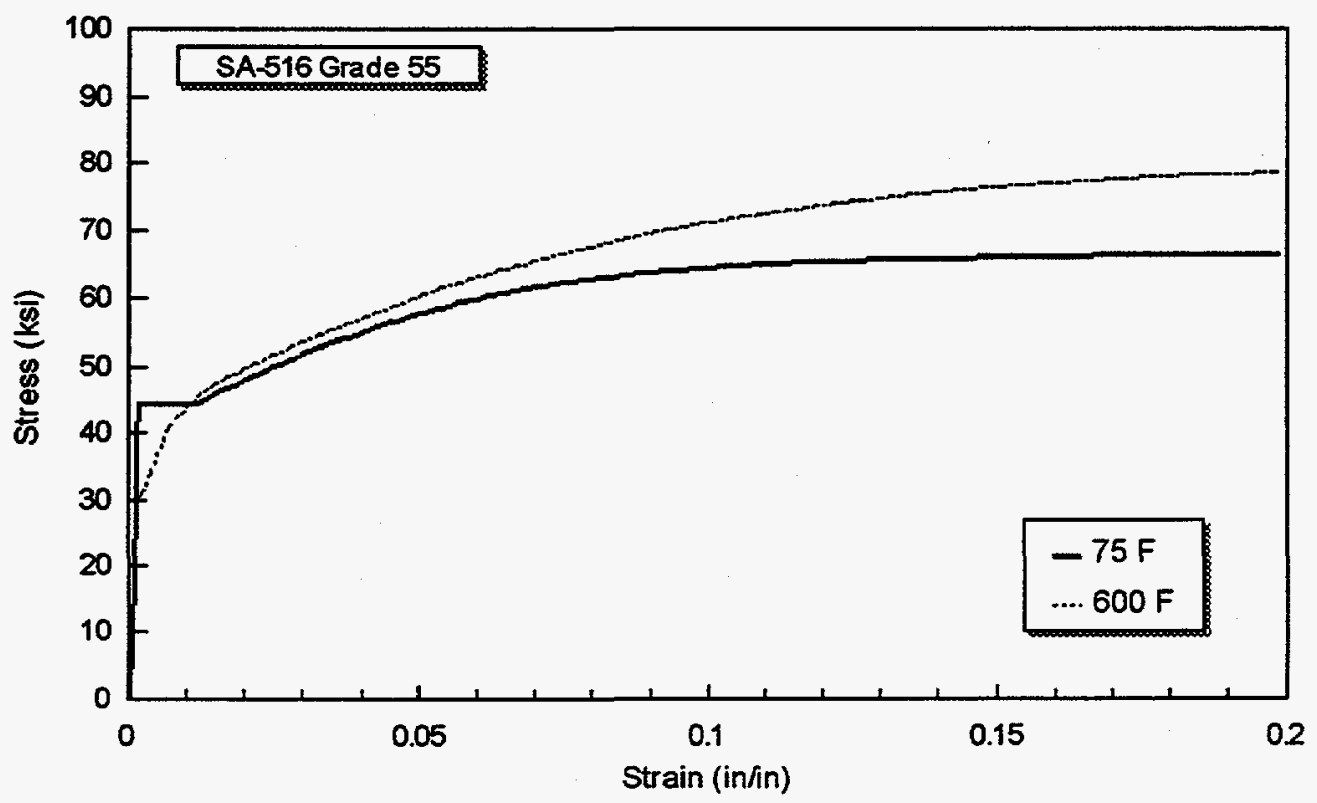

Figure 5.2 Example of Temperature Effects on the Stress-Strain Behavior of Steel 
5. Deterninistic Pressure Capacities for Surrogate Containments

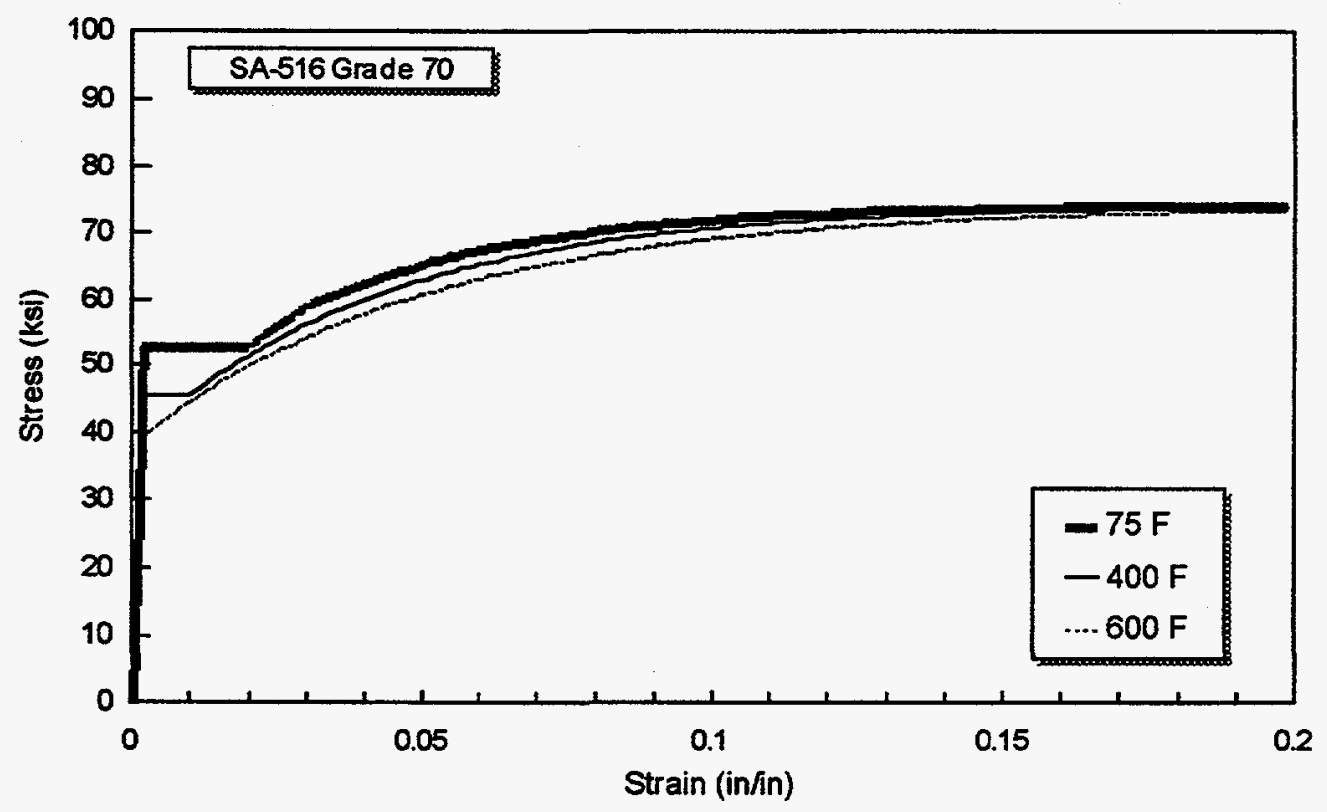

Figure 5.3 Stress-Strain Model used for SA-516 Grade 70 Steel

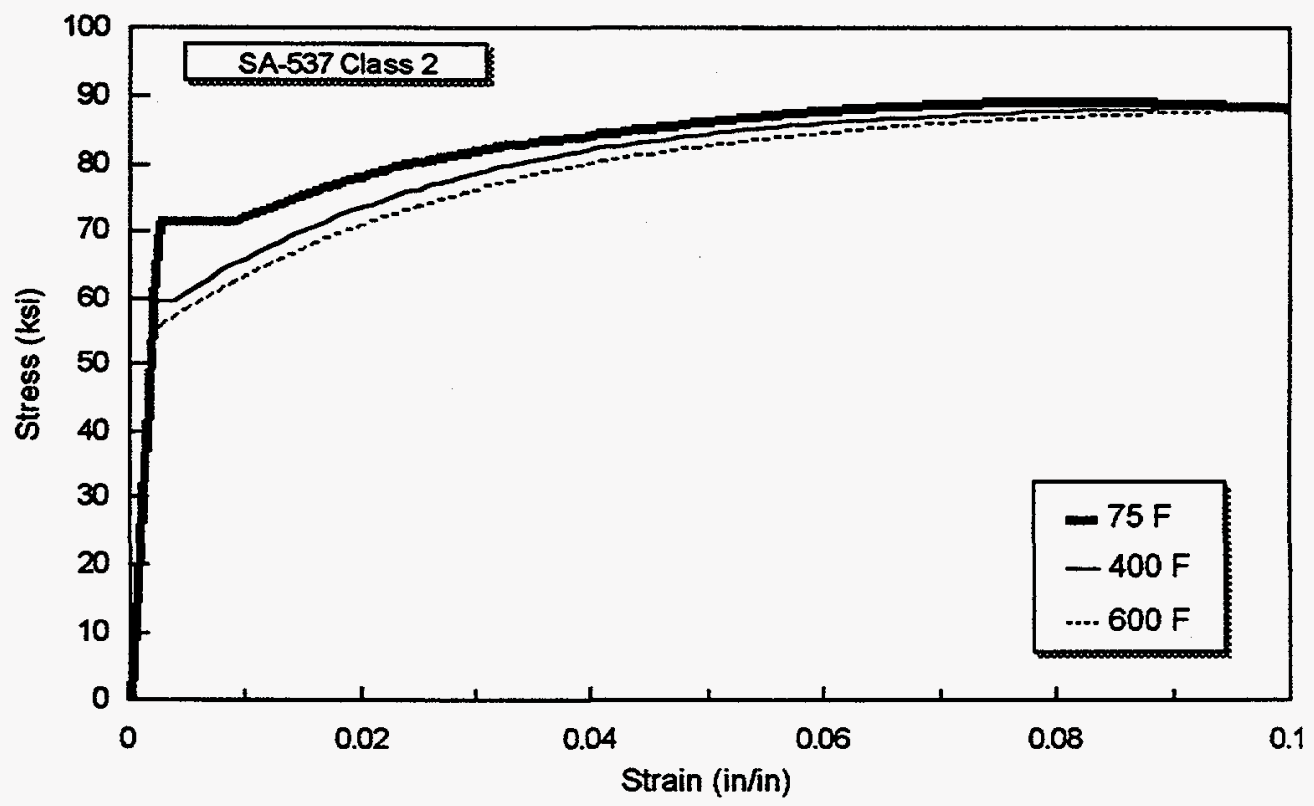

Figure 5.4 Stress-Strain Model used for SA-537 Class 2 Steel 
5. Deterministic Pressure Capacities for Surrogate Containments

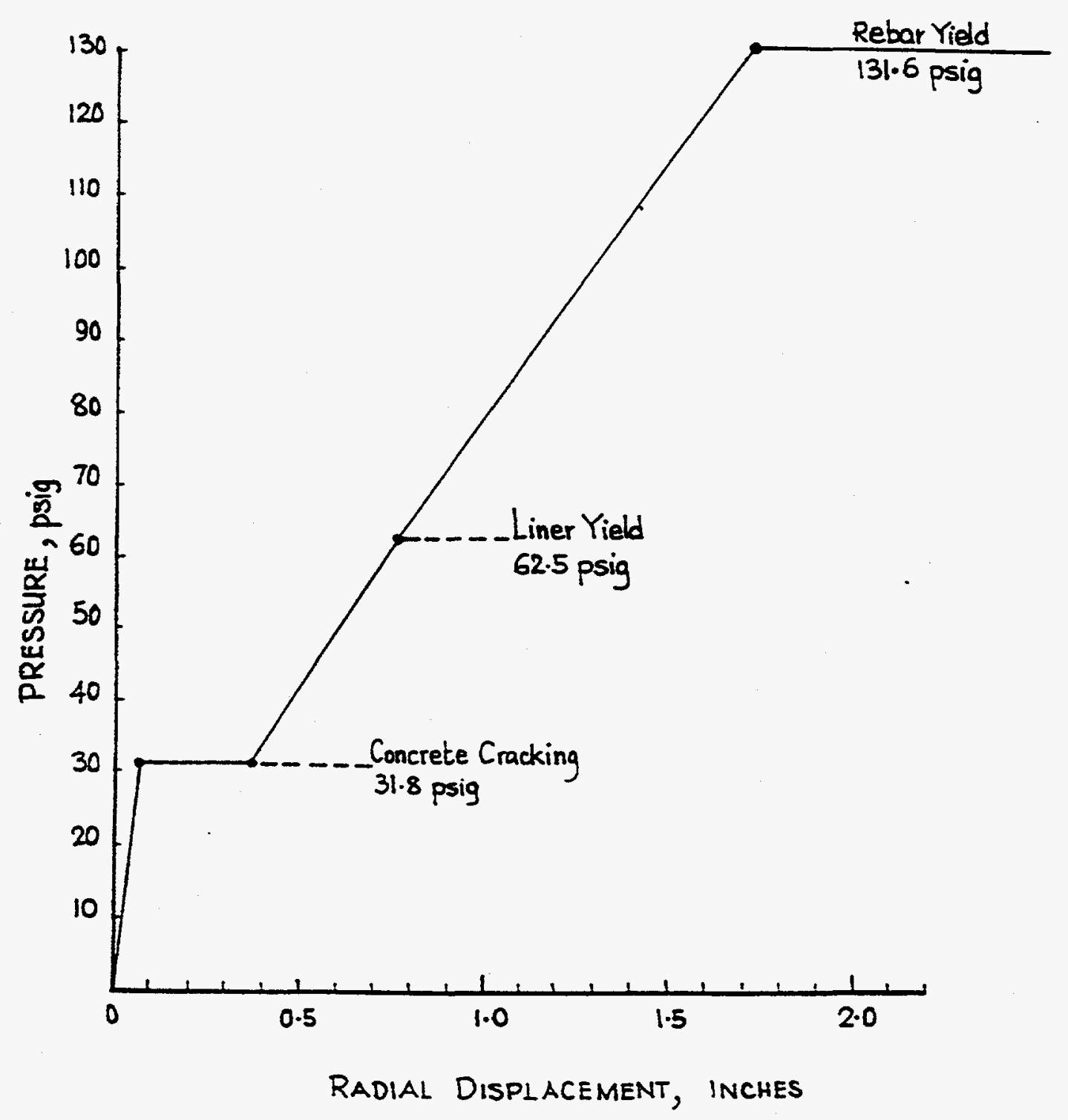

Figure 5.5 Reinforced Concrete Containment Pressure vs. Radial Displacement (Membrane Hoop Section Near Midheight of Containment) 
5. Deterrninistic Pressure Capacities for Surrogate Containments

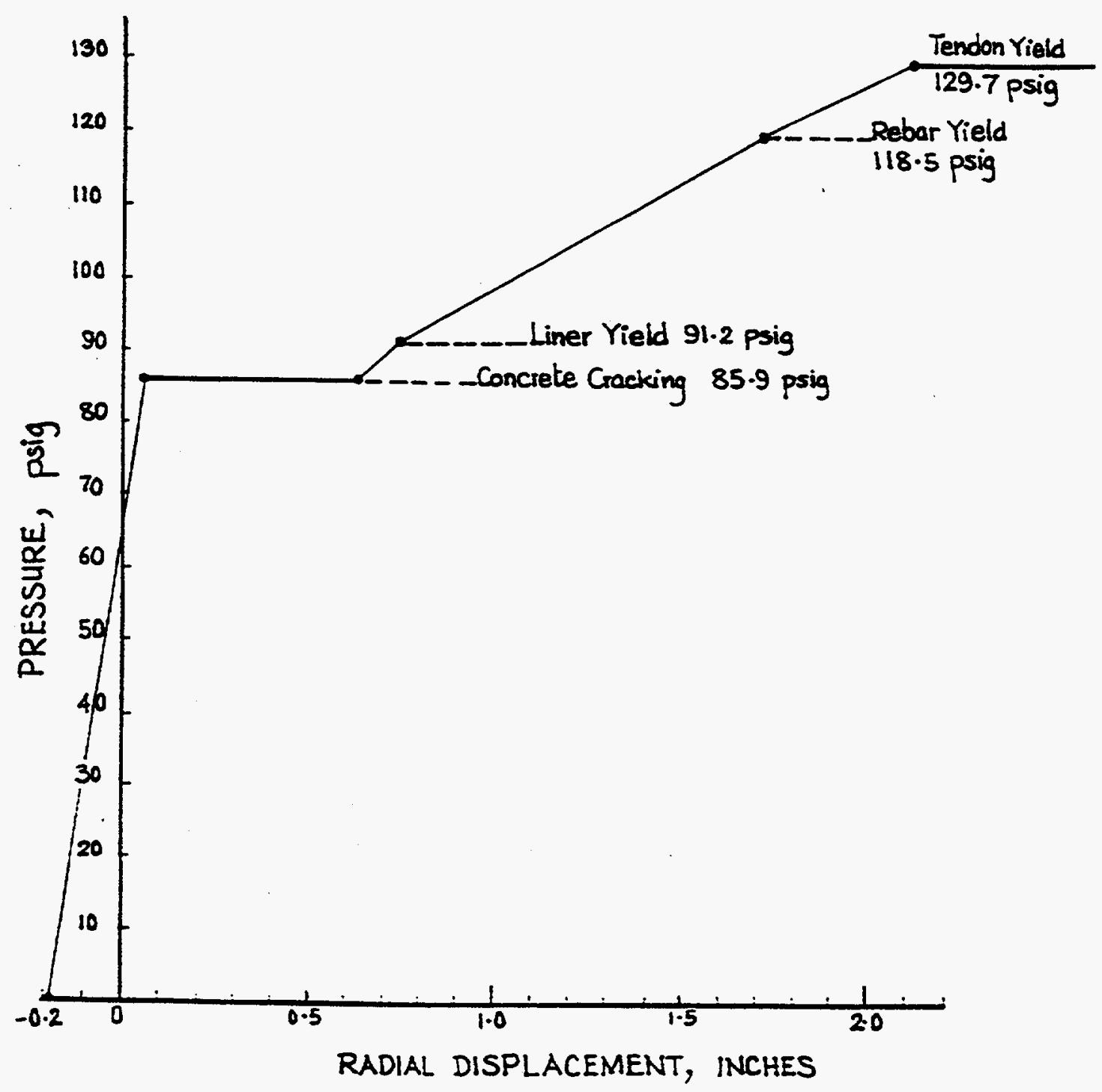

Figure 5.6 Prestressed Concrete Containment Pressure vs. Radial Displacement (Membrane Hoop Section Near Methought of Containment) 


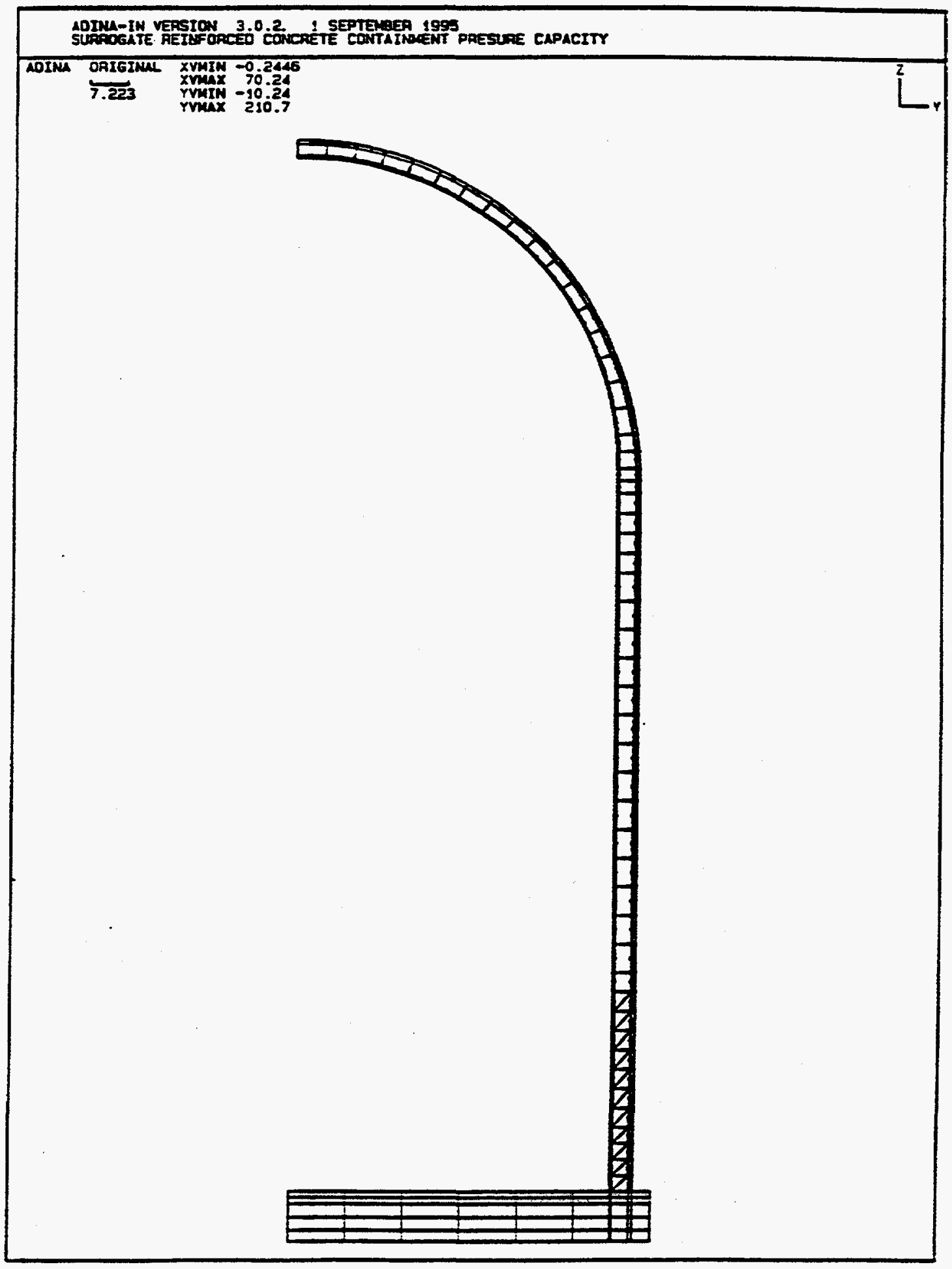

Figure 5.7 Reinforced Concrete Containment Finite Element Model 
5. Deterministic Pressure Capacities for Surrogate Containments

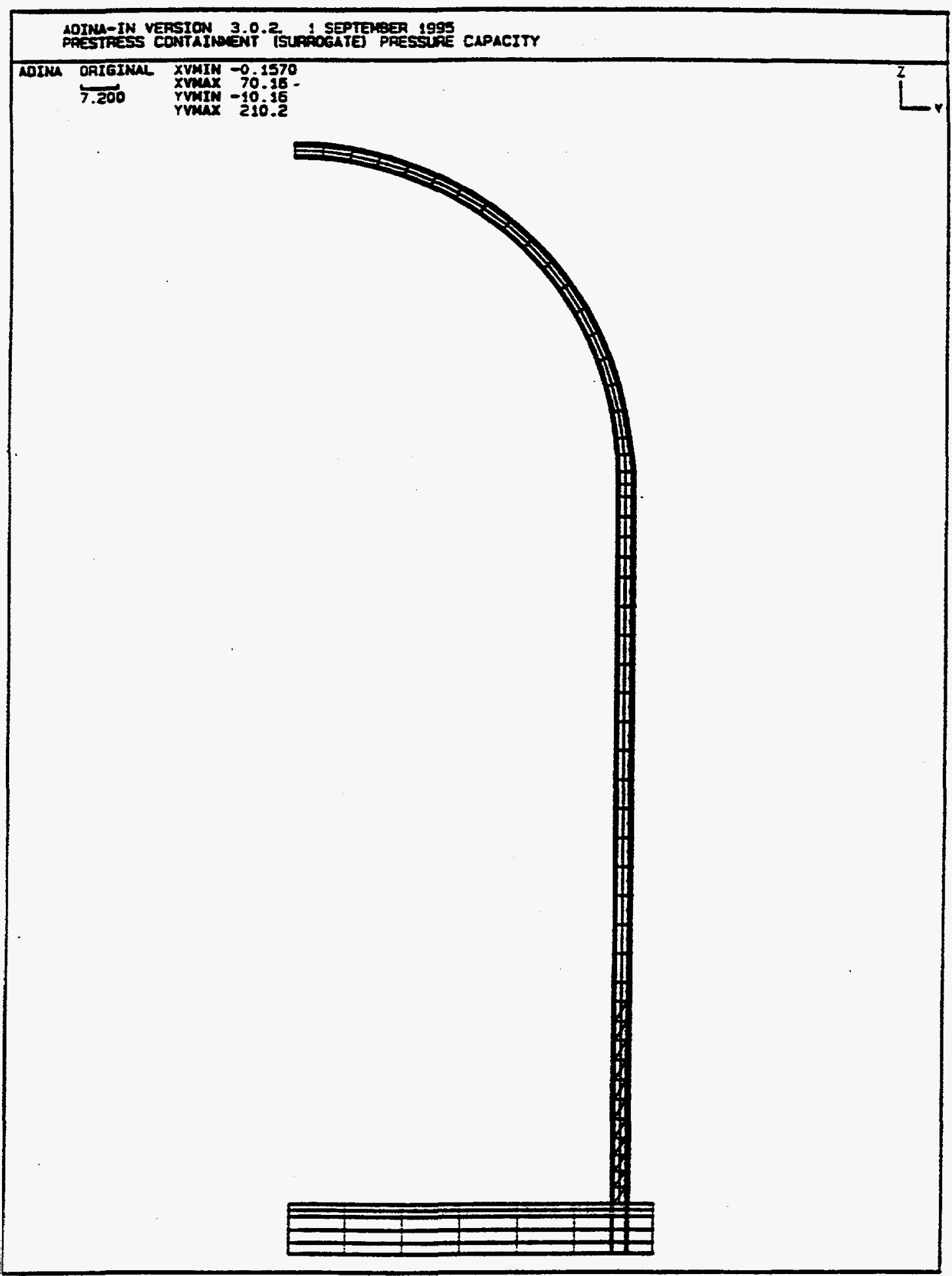

Figure 5.8 Prestressed Concrete Containment Finite Element Model 


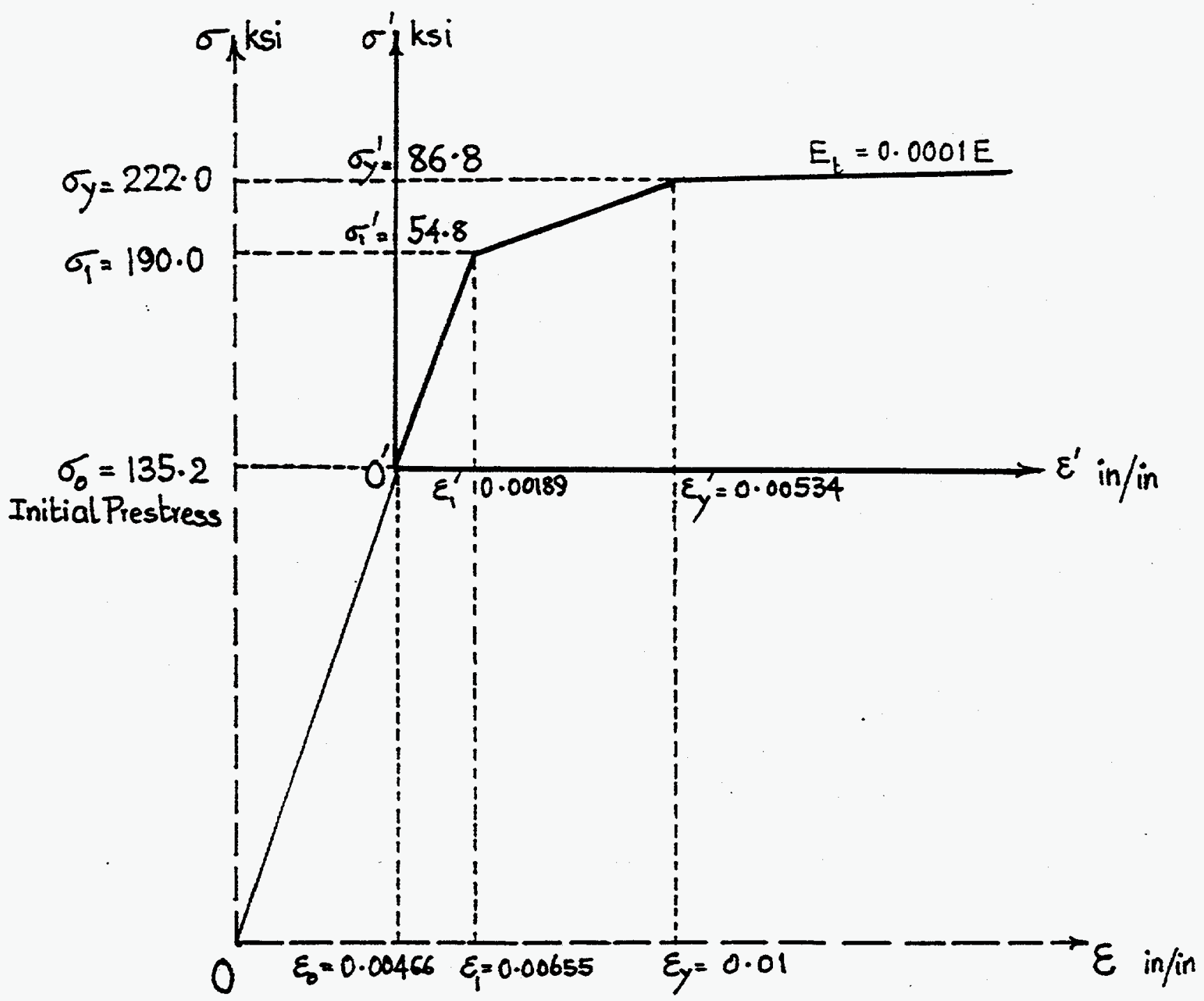

Figure 5.9 Hoop Tendon Stress-Strain Curve 
5. Deternainistic Pressure Capacities for Surrogate Containments

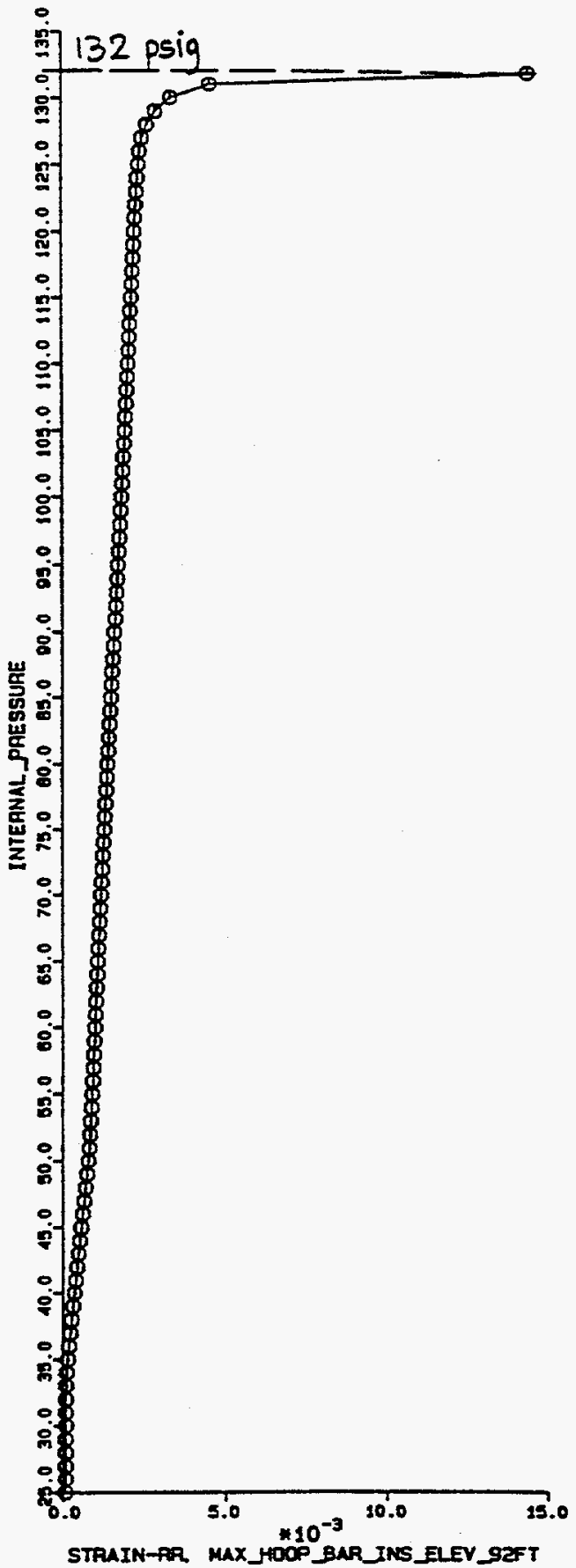

Figure 5.10 Maximum Hoop Reinforcement Strain vs. Internal Pressure Reinforced Concrete Containment @ El. 92' 0" 
5. Deterministic Pressure Capacities for Surrogate Containments

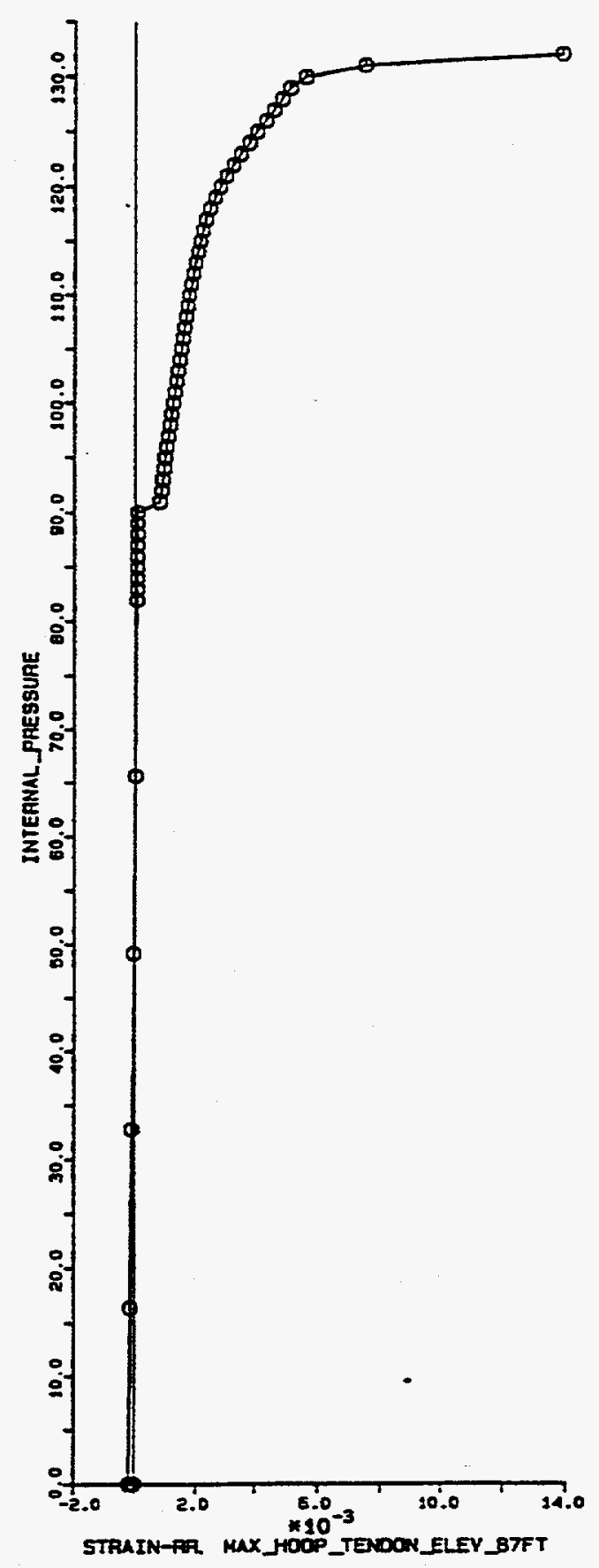

Figure 5.11 Maximum Hoop Tendon Strain vs. Internal Pressure Prestressed Concrete Containment @ El. 87' 0" 


\section{PROBABILISTIC FRAGILITIES FOR SURROGATE CONTAINMENTS}

Deterministic models of each of the surrogate containments shown in Chapter 4 and 5 were embedded in a multiple simulation calculational procedure along with a description of the random and systematic uncertainties in the parameters involved in the models. A Monte Carlo analysis was performed which computed the containment membrane hoop strains as a function of pressure, and compared them to the appropriate surrogate containment hoop strain failure criteria, resulting in probabilistic fragility curves for each of the surrogate containments.

\subsection{Monte Carlo Procedure}

In computing the free-field membrane hoop strain in the reinforced and prestressed concrete containment walls, the composite nature of the wall involving the inner liner, the concrete, the reinforcing steel, and the tendons must be considered. The maximum membrane strains in the containment wall occur in the cylindrical portion of the containment. Similarly, the free-field membrane hoop strain calculation in the steel containments must consider both biaxiality and temperature effects on the specific material.

A simple deterministic model for computing the membrane strains in the containment was developed. This model includes the nonlinear behavior of all the constituents of the composite membrane (rebar, liner, and tendons or steel shell). Properties for these materials used in this analysis were taken from actual material tests. Details of the deterministic membrane hoop strain model are presented in Section 6.2. By use of this model, the free-field membrane hoop strain in the containment wall can be computed as a function of containment pressure. The membrane hoop strain experienced by the containment is the strain which must be compared with the strain failure criteria to determine failure.

Each deterministic model was embedded in a Monte Carlo calculational procedure which varies both the random and systematic uncertainties. The calculations were performed in two steps. In the first step, a Monte Carlo analysis was performed which computed the membrane containment hoop strains as a function of pressure. A flow chart of this first procedure is shown in Figure 6.1. At each input pressure, cumulative distribution functions for these strains are computed. Distributions of all random variables are input on a separate file. The code then selects random samples of all variables. These are then input to the deterministic model for free-field hoop strain. From this calculation a single value of free-field hoop strain results. These are then stored. The code then loops back and selects new samples of all the random variables and computes new values of free-field hoop strain. This process is repeated for the specified number of Monte Carlo trials. For the results presented herein, 1001 Monte Carlo trials were specified. Sensitivity studies showed that this was an adequate number of Monte Carlo trials. After all Monte Carlo trials have been completed, the code computes the statistics on the free-field strains to get the distribution of these strains, at a given constant pressure. The code then returns, reads a new pressure and repeats the process.

As described above, the output for the initial Monte Carlo analysis consists of the distributions of free-field hoop strain as a function of pressure. For input to the second Monte Carlo analysis, these distributions are characterized as being $\log$ normal with a median and $\beta_{x}$ as a function of pressure. These numerical values are input along with pressure into the second step of the process in which containment failure probabilities are computed. A flow chart of the second step is shown in Figure 6.2. The process is very much the same. The code first selects samples of all random variables except in this second Monte Carlo loop, only the systematic random variables are modified. The code then computes the containment failure probability (at a given pressure) by using the free-field hoop strain distributions (in terms of median and $\beta_{5}$ ) and the corresponding failure criteria. Since free-field strains are taken as log normal random variables, the probability of failure of each particular containment mode is computed as shown below:

$$
\mathrm{P}_{\text {Fail }}=\Phi\left[\frac{\ln \left(\varepsilon / \varepsilon_{\mathrm{f}}\right)}{\sqrt{\beta_{\varepsilon}^{2}+\beta_{\varepsilon_{\mathrm{f}}}^{2}}}\right]
$$

where

$$
\begin{aligned}
& \Phi[]=\text { the standard normal distribution } \\
& \varepsilon=\text { the median computed strain (at a given } \\
& \text { pressure) } \\
& \varepsilon_{\mathrm{f}}=\text { the failure strain for the containment } \\
& \text { being considered }
\end{aligned}
$$




\author{
$\beta_{e}, \beta_{c_{t}}=$ the logarithmic standard \\ deviations for the computed hoop strain \\ and failure strain of the failure mode \\ being considered.
}

Thus for each set of random samples of the random variables involved, a single value of total containment failure probability is computed. This is stored in an array and the Monte Carlo trials are repeated for the number of trials specified. After all trials have been completed and the results stored, the statistics on the containment failure probability (at a given pressure) are computed from the accumulated samples. Following this, the code reads a new set of pressures and input strains and the process is repeated. The result is a family of overpressure fragility curves for the specific containment chosen.

\subsection{Deterministic Models of Surrogate Containments}

\subsubsection{Concrete Containments}

In concrete cylindrical containments the first membrane yield is expected to occur in the hoop direction in the cylinder wall. The basemat is thick and heavily weighted by the walls and does not experience excessive stress. Therefore, only the plastic behavior in the hoop direction of the cylinder was modeled. The total force in the hoop direction will be determined by summing the forces in the hoop and any diagonal reinforcing bars, the hoop tendons and the liner plate. A simple 1-D subroutine was prepared to model the response in the hoop direction in the free-field wall containment. (This approach ignores the 2-D effects of the liner plate. These effects provice only small perturbations to the carrying capacity of the liner, and coupled to the fact that the liner contributes only about $10 \%$ of the total hoop load carrying capacity, the resulting errors in hoop strain are not large.)

The 1-D code that was developed for this analysis performs a non-linear stress analysis by determining a containment pressure for a given hoop strain. The hoop strains for each structural element are considered to be equal and locked together by the concrete. The hoop strains are varied between the values of 0.0 and 0.10 $(10 \%)$ in order to obtain the free field hoop strain as a function of pressure. For any given hoop strain, a corresponding stress is determined for each structural element present in the composite containment wall using bi-linear representations of the material uniaxial stress-strain relationships.

This 1-D code can analyze a number of typical concrete containment load carrying systems. For example, if diagonal reinforcing steel is used, the stress calculations must take into account the angle for determining strain in the steel. The stresses in the hoop tendons must include prestressing that is present in the tendons; the appropriate initial prestress strain is added to the hoop strain being used in the calculation. A slight error exists in this method, however, due to the slight initial compressive strains in the reinforcing steel and due to ignoring the liner plate. These strains are small because the concrete carries most of these compressive loads. The steel experiences only small loads, and consequently, small strains. The absence of 2-D effects in the formulation also results in small error. Because the hoop stresses are about twice the vertical stresses, the 2-D effects are not significant until yielding has occurred after which neglecting the axial stress provides a very slight conservatism. Thus the $2-D$ effects have little impact on the results for the strains considered here.

The forces in the hoop direction in the liner plate can be calculated from the following simple equation:

Liner Hoop Force/Unit Wall Height $=$ Liner Hoop Stress $\bullet$ Liner Thickness

A similar procedure is used to determine the forces from the hoop reinforcing steel. The cross-sectional area of the steel per unit height of the wall is used in place of the wall thickness in the above equation. The diagonal reinforcing steel equation must account for the angle of the steel when determining the equivalent cross-sectional area. Finally, the hoop tendons are treated the same way as the hoop reinforcing steel by using the equivalent cross-sectional area of the hoop tendon per unit wall height.

The pressure at a specific strain is calculated by the following equation:

$$
\begin{aligned}
\text { Pressure } & =[\Sigma \text { hoop forces }] / \text { Containment Radius } \\
& =\left(A_{R} \sigma_{R}+A_{P} \sigma_{P}+A_{T} \sigma_{T}\right) / R
\end{aligned}
$$


where

$$
\begin{aligned}
& A_{R}, A_{P}, A_{T,}=\text { cross-sectional area (per unit height) } \\
& \text { of the rebar, liner plate and tendons }
\end{aligned}
$$

The stresses are related to the hoop strain through the uniaxial stress strain curves for each of the components. By determining the pressures at many different strains, the curves defining the hoop strain versus pressure can be developed.

In order to verify the assumptions used in this 1-D analysis, the 1:6 scale containment model tested at Sandia [6-1] was modeled using the 1-D code described above. The model was a reinforced concrete containment without any tendons. The hoop and diagonal reinforcing steel and the liner plate properties were specified in the code input. The actual material properties for both the liner and reinforcing steel were available and were used for this analysis. The material properties were input as a series of linear segments. The code interpolates along these line segments to determine the correct stress for any given strain. The 1-D model showed very good agreement with the 1:6 scale model as shown in Figure 6.3.

The fact that very good information for the material properties used in the 1:6 scale model was available contributed to the good agreement with the data. In general, actual properties (and not minimum properties) should be used where available. Minimum properties are often very conservative and should be avoided unless absolutely necessary. Using minimum values or even minimum values plus $10 \%$ more for yield strengths may be very conservative. For the analysis presented in this report, actual material properties were used.

\subsubsection{Steel Containments}

The deterministic model used to relate internal pressure to free-field hoop strain in the surrogate steel containments was very similar to the one shown above for the concrete containments. However, instead of developing a composite membrane using three different nonlinear materials (rebar, liner, and tendons) only the single nonlinear material behavior of the steel was modeled.
The concrete model used the uniaxial behavior of each material in relating the effective hoop stress to hoop strain. In the steel containments this is no longer valid due to the significant biaxiality effects. Using von Mises equation, the equivalent stress is defined as:

$$
\sigma_{e}=\frac{1}{\sqrt{2}}\left[\left(\sigma_{r}-\sigma_{\theta}\right)^{2}+\left(\sigma_{\theta}-\sigma_{z}\right)^{2}+\left(\sigma_{z}-\sigma_{r}\right)^{2}\right]
$$

where;

$$
\begin{aligned}
& \sigma_{\theta}=\text { hoop stress, } \\
& \sigma_{r}=\text { radial stress, and } \\
& \sigma_{z}=\text { meridional stress. }
\end{aligned}
$$

In addition to modifying the effective stress, for this non-linear model, the effective plastic strain must also be determined. This deterministic steel model used the same procedure shown in Section 5.2.1 of this report for determining the ultimate pressures. The material properties modeled in the Monte Carlo analysis were the same as the stress-strain curves shown in Figures 5.3 and 5.4 .

\subsection{Probabilistic Results}

\subsubsection{Concrete Containments}

For the surrogate reinforced concrete containment design shown in Chapter 4, a probabilistic overpressure fragility was determined. Using the first Monte Carlo procedure described in Section 6.1 and the deterministic model described in Section 6.2, a distribution of freefield hoop strains were determined as a function of pressure. Uncertainties specified for material properties were based on typical material behavior and were $\beta=0.10$ for the steel reinforcement and $\beta=0.05$ for the steel liner. The resulting mean, median, $5 \%$ and $95 \%$ percentile curves are shown in Figure 6.4. As shown in this plot, the median strains do not begin to grow significantly until a pressure of about 115-120 psig. This corresponds to the pressure at which yielding of the reinforcing bars occurs. The strains reach $0.02(2 \%)$ at a pressure of about 130 psig.

When these strains are input into the second Monte Carlo program and a failure strain of $2 \%$ is specified, a probability of failure distribution as a function of pressure is determined. The mean, median, $5 \%$ and $95 \%$ percentile overpressure fragility curves are shown 
in Figure 6.5. As expected, the median probability of failure is $130 \mathrm{psig}$. This corresponds to the pressure at which the median strains reached $2 \%$ and is also similar to the deterministic ultimate pressure capacity determined in Section 5.2.2 (131.6 psig). As shown in this plot the probability of failure is essentially zero for pressures below 115 psig. This is because there is almost no yielding of the reinforcement at $115 \mathrm{psig}$ and strains are only about $0.2 \%$ or $1 / 10$ the failure criteria strain.

For the surrogate prestressed concrete containment design shown in Chapter 4, a probabilistic overpressure fragility was determined in similar fashion as for the reinforced concrete surrogate. Uncertainties specified for material properties were $\beta=0.08$ for the tendons, $\beta=0.10$ for the steel reinforcement, and $\beta=0.05$ for the steel liner. The resulting mean, median, $5 \%$ and 95\% percentile hoop strain curves are shown in Figure 6.6. As shown in this plot, the median strains grow gradually at first, then increase more dramatically at strains above $2 \%$. This is due to the less ductile behavior of the tendon steel. The strains reach 0.01 (1\%) at a pressure of about $130 \mathrm{psig}$.

When these strains are input into the second Monte Carlo program and a failure strain of $1 \%$ is specified, a probability of failure distribution as a function of pressure is determined. The mean, median, $5 \%$ and 95\% percentile overpressure fragility curves are shown in Figure 6.7. As expected, the median probability of failure is $131 \mathrm{psig}$. This corresponds to the pressure at which the median strains reached $1 \%$ and is also similar to the ultimate pressure capacity determined in Section 5.2 .2 (129.7 psig). As shown in this plot the probability of failure is essentially zero for pressures below 120 psig. Again, this is because the amount of free-field hoop strain drops off significantly between pressures of essentially 130 psig to 120 psig.

\subsubsection{Steel Containments}

For the cylindrical surrogate steel containment designs shown in Chapter 4, a probabilistic overpressure fragility was similarly determined. (Fragilities were not computed for the spherical containments because the cylindrical containments will always govern. This is due to the increased thickness of the spherical shell to satisfy seismic requirements as shown in Chapter 4.) In addition, only one material temperature was considered. The $400^{\circ} \mathrm{F}$ Case was considered to be a realistic representation of a severe accident temperature of the temperature cases analyzed in the deterministic analysis in Chapter 5.

Using the first Monte Carlo procedure described in Section 6.1 and the deterministic model for steel containment stresses described in Section 6.2, the distribution of effective free-field hoop strain was determined as a function of pressure. The mean, median, $5 \%$ and $95 \%$ percentile curves are shown in Figure 6.8 for SA-516 Grade 70 steel. As shown in this plot, the median strains begin to grow very gradually starting at a pressure of about 100 to 105 psig. This corresponds to the pressure as which first yielding of the steel occurs. The strains reach $0.02(2 \%)$ at a pressure of about 140 psig.

When these strains are input into the second Monte Carlo program and a failure strain of $2 \%$ is specified, a probability of failure distribution as a function of pressure is determined. The mean, median, $5 \%$ and $95 \%$ percentile overpressure fragility curves are shown in Figure 6.9. As expected, the median probability of failure is 140 psig. This corresponds to the pressure at which the median strains reached $2 \%$ and is also similar to the deterministic ultimate pressure capacity found in Section 5.2.1 for the 516 steel at $400^{\circ} \mathrm{F}(140.5$ psig). As shown in this plot the probability of failure is essentially zero for pressures below 105 psig. This is because there is only a small amount of yielding at 105 psig and strains are only about $0.2 \%$ or $1 / 10$ the strain failure criteria.

Similarly, the cylindrical steel surrogate using SA-537 Class 2 steel was analyzed. The mean, median, $5 \%$ and $95 \%$ percentile curves are shown in Figure 6.10. As shown in this plot, the median strains begin to grow very gradually starting at a pressure of about 120 psig. This corresponds to the pressure as which first yielding of the steel occurs. The strains reach $0.02(2 \%)$ at a pressure of about $170 \mathrm{psig}$.

When these strains are input into the second Monte Carlo program and a failure strain of $2 \%$ is specified, a probability of failure distribution as a function of pressure is determined. The mean, median, $5 \%$ and 95\% percentile overpressure fragility curves are shown in Figure 6.11. As expected, the median probability of failure at $50 \%$ is 170 psig. This corresponds to the pressure at which the median strains reached $2 \%$ and is also similar to the deterministic ultimate pressure capacity determined in Section 5.2 .1 for the 537 steel at $400^{\circ} \mathrm{F}$ (171.7 psig). As shown in this plot the 
probability of failure is essentially zero for pressures below 130 psig.

The steel containments have a more significant low probability 'tail' than the concrete containments due to the fact that the effective strain in the steel at failure is about $4 \%$, due to biaxial effects, which is well into the strain hardening regime. The concrete containments are assumed to fail at a uniaxial strain of $2 \%$ in the reinforced concrete containment and $1 \%$ in the prestressed concrete containment, which are essentially on the yield plateau. Therefore, when pressures are reduced slightly, the strain and resulting failure probability drop much more rapidly, resulting in steeper low probability 'tails'. These low probability tails are important when combining them with the severe accident loads and computing a conditional containment failure probability (CCFP) as shown in the next Chapter.

\subsection{References}

6-1 Horschel, D. S., Experimental Results From Pressure Testing a 1:6-Scale Nuclear Power Plant Containment, NUREG/CR-5121, SAND88-0906, Sandia National Laboratories, January, 1992. 


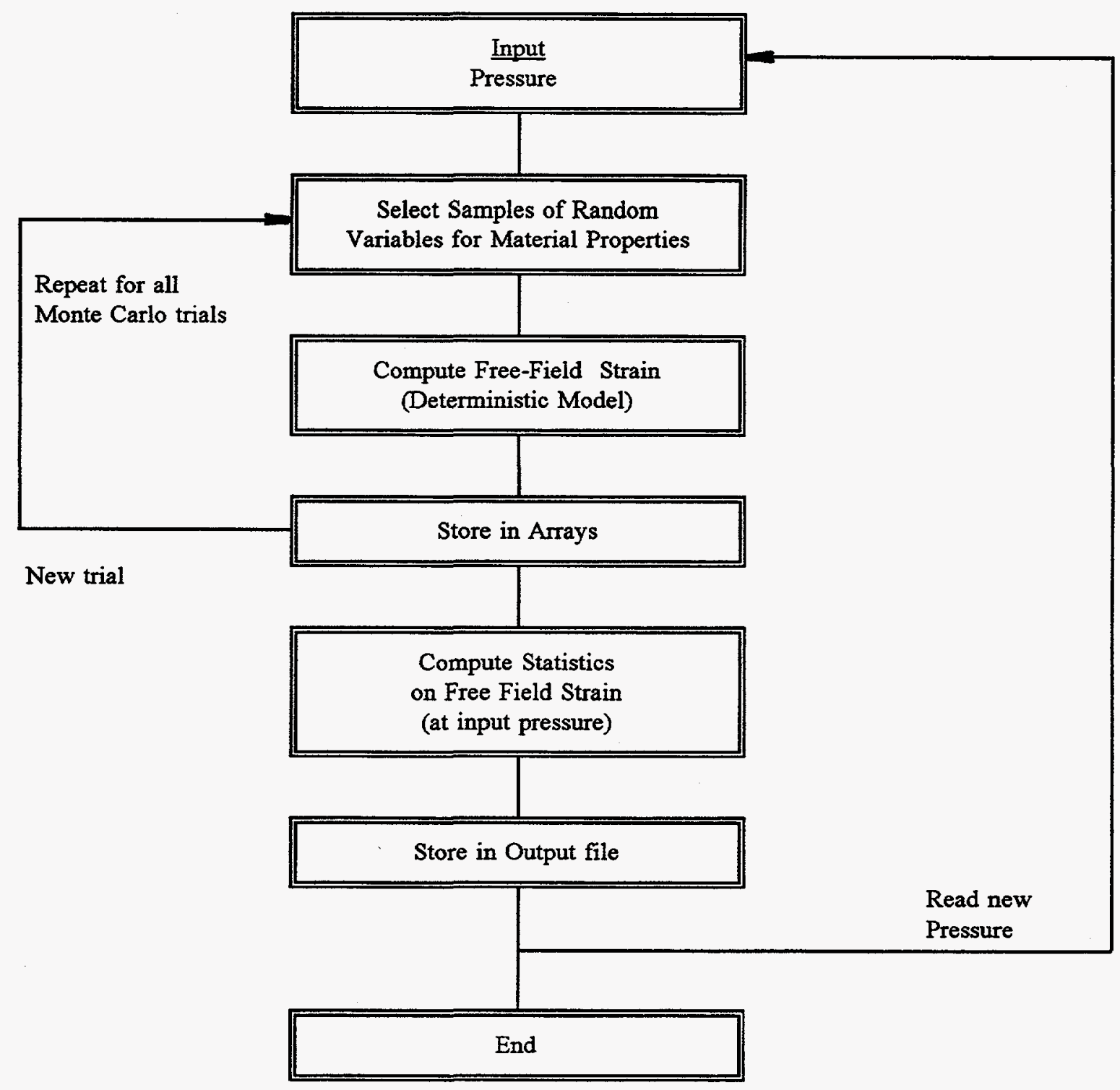

Figure 6.1 Flow Chart of Monte Carlo Analysis of Strains 


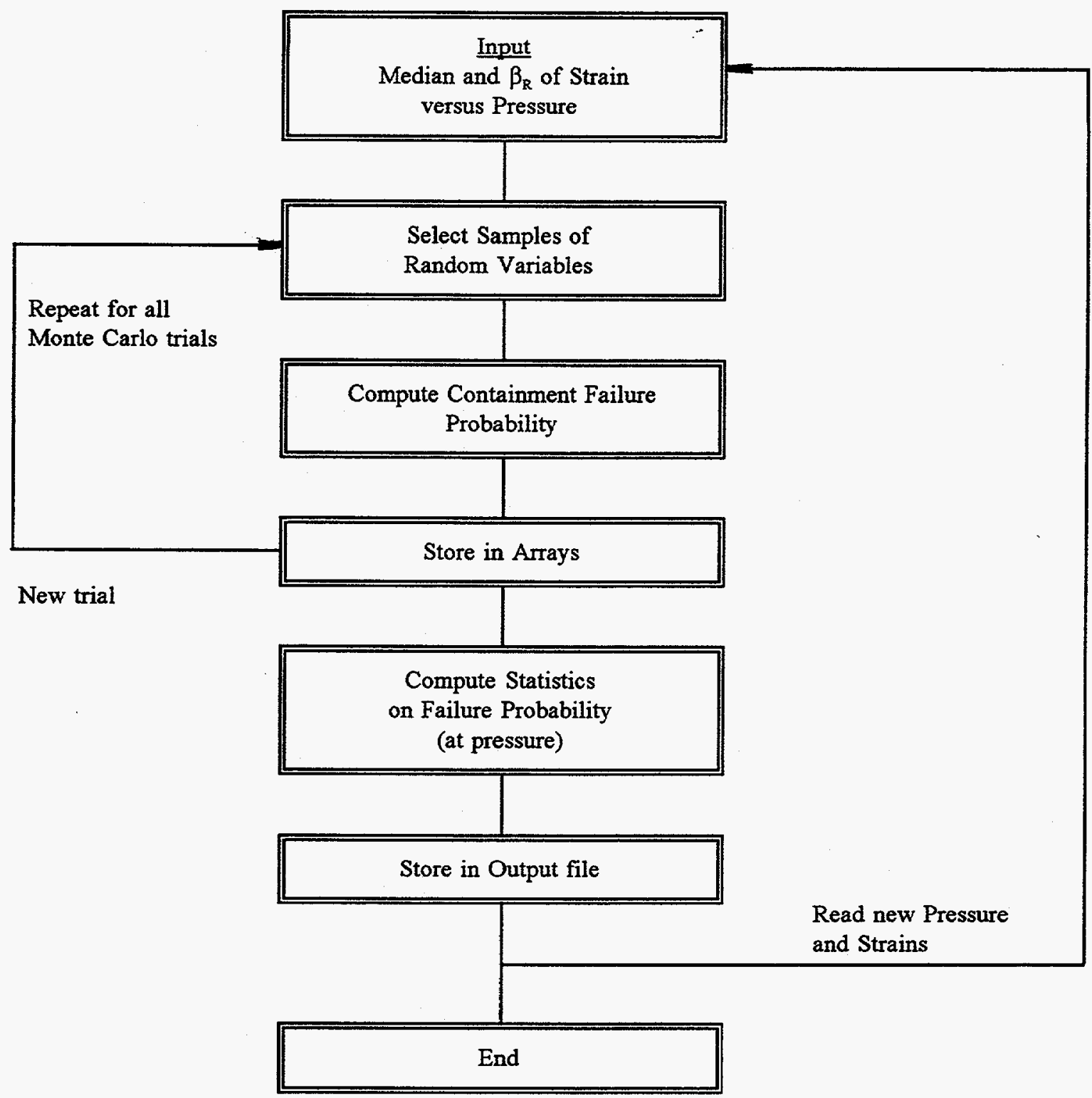

Figure 6.2 Flow Chart of Containment Failure Probability Analysis 
6. Probabilistic Fragilities for Surrogate Containments

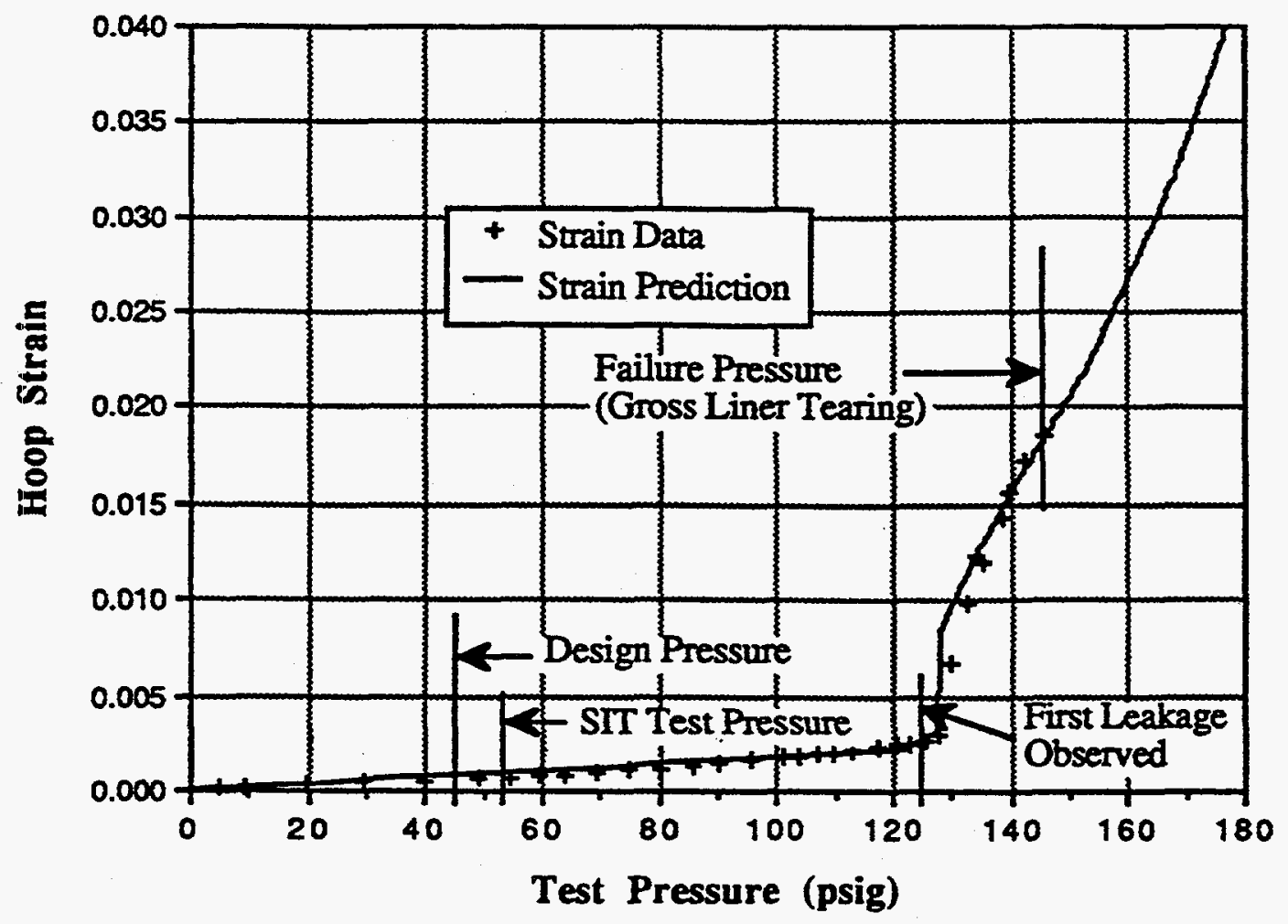

Figure 6.3 Predicted Hoop Strain and Actual Strain Response Versus Containment Pressure for the 1:6 Scale Containment Model 


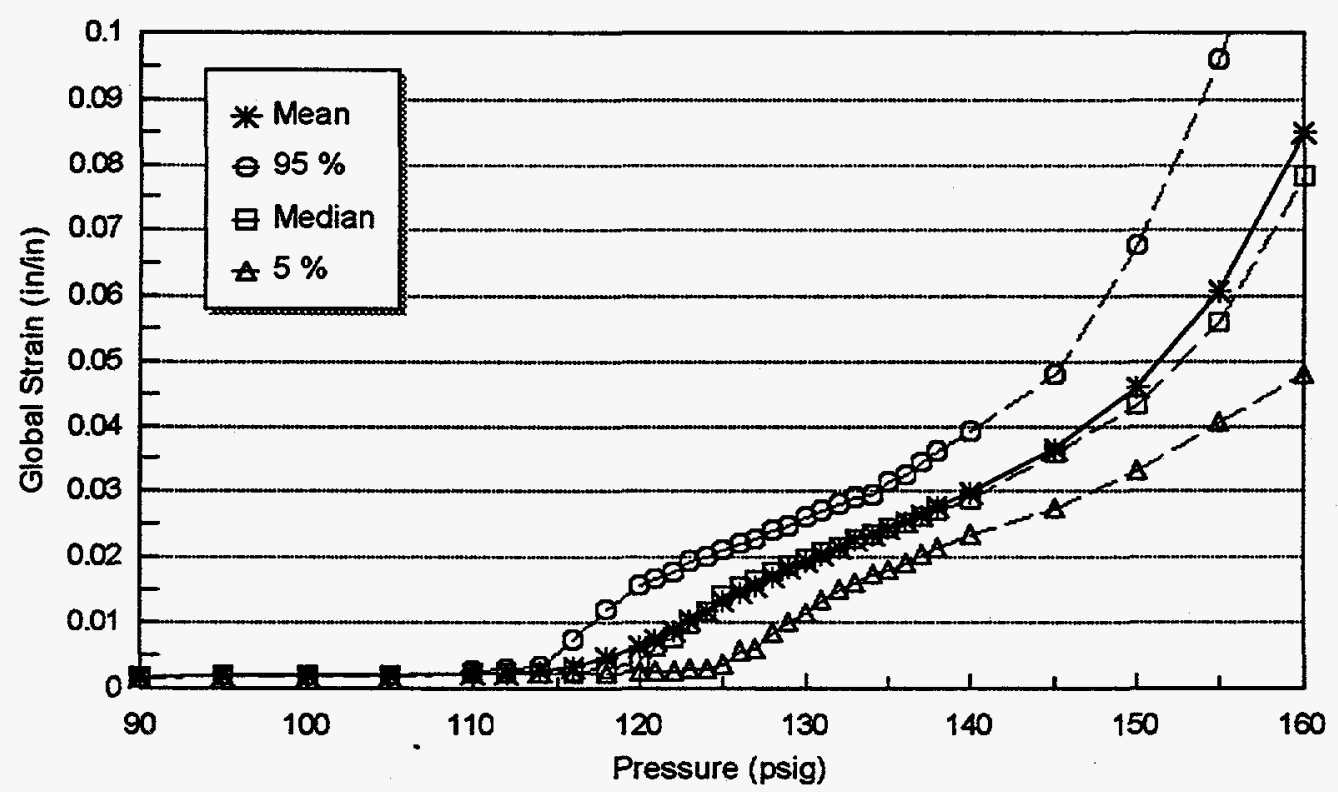

Figure 6.4 Reinforced Concrete Surrogate Free-Field Hoop Strain vs. Pressure

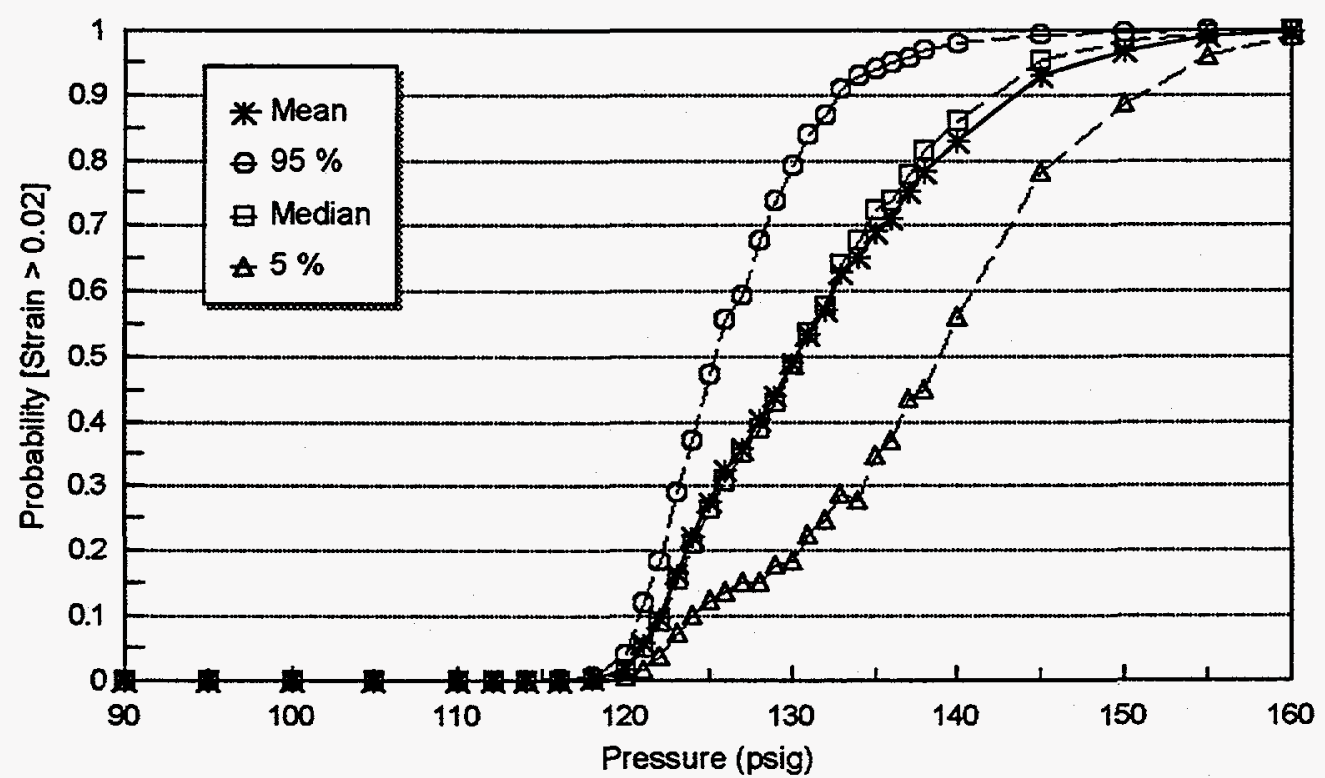

Figure 6.5 Reinforced Concrete Surrogate Overpressure Fragility Curves 
6. Probabilistic Fragilities for Surrogate Containments

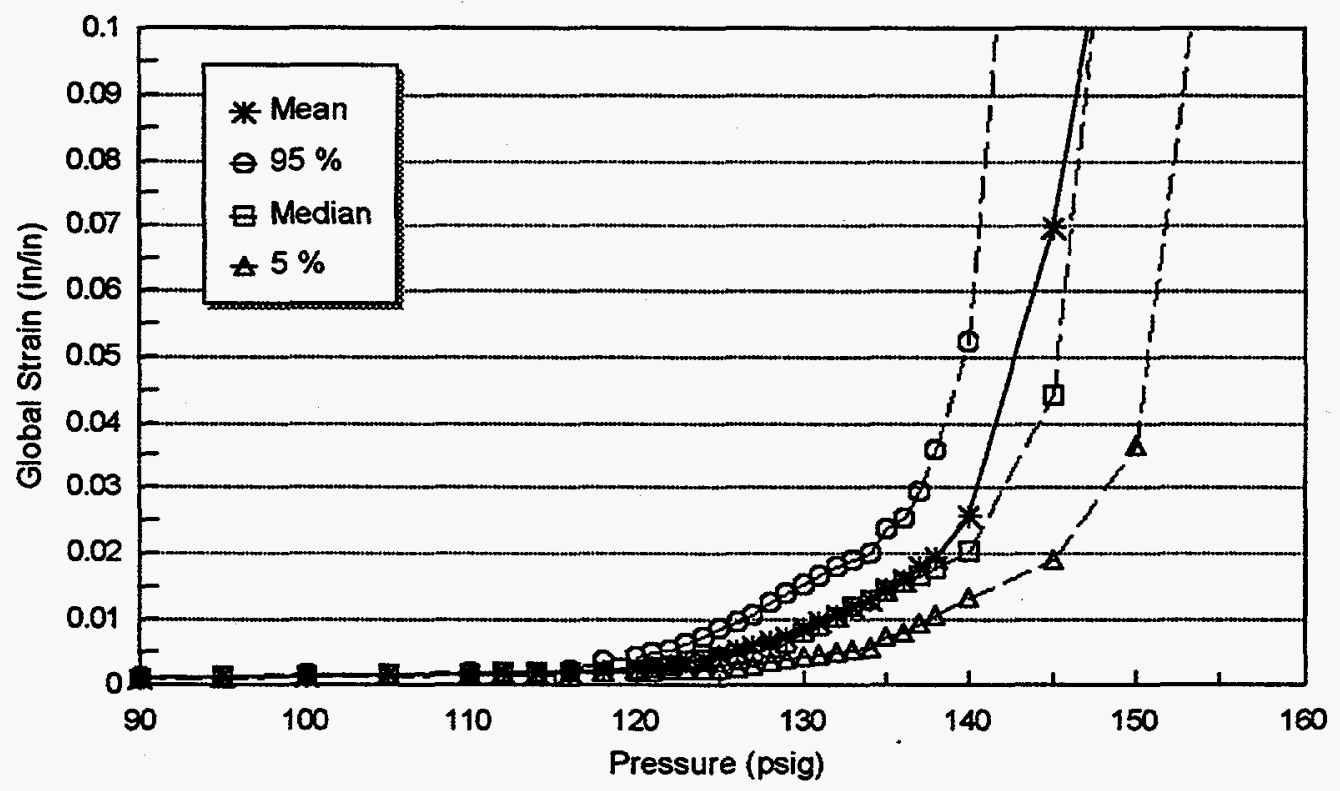

Figure 6.6 Prestressed Concrete Surrogate Free-Field Hoop Strain vs. Pressure

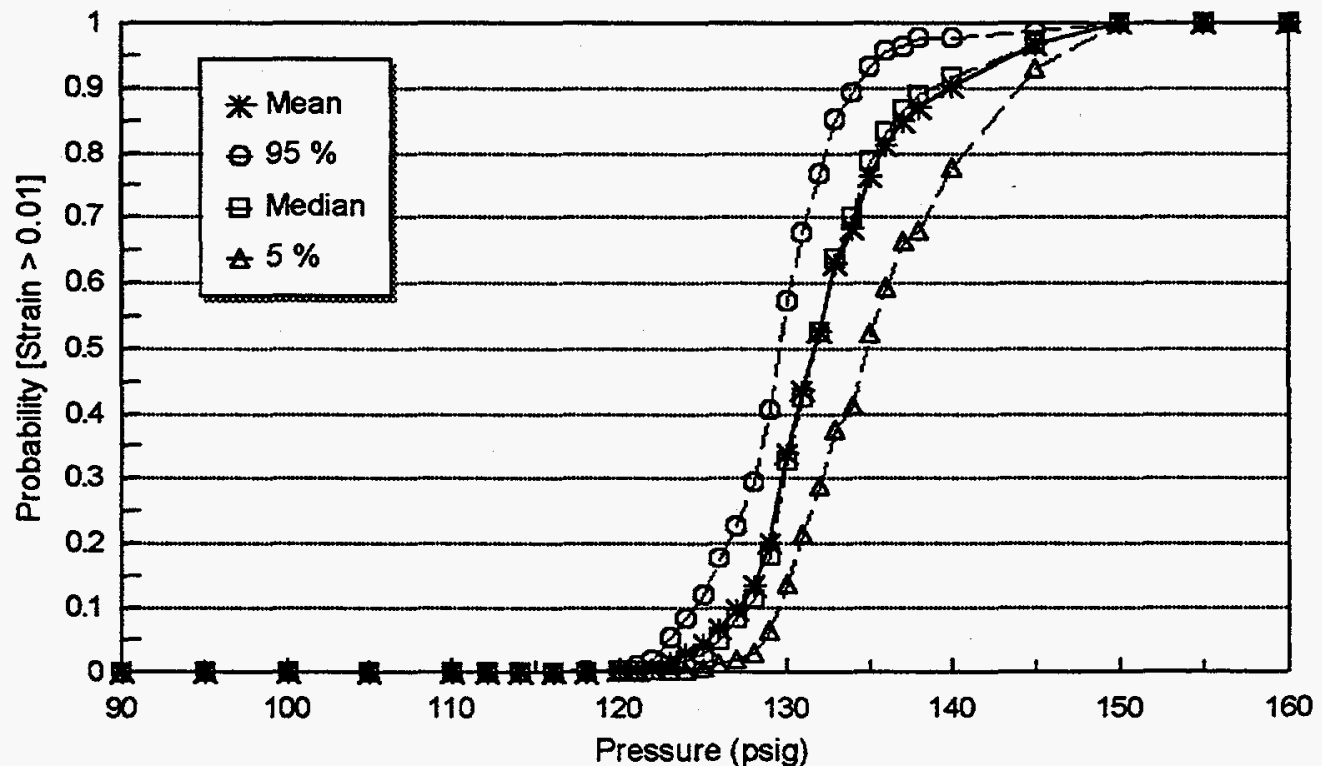

Figure 6.7 Prestressed Concrete Surrogate Overpressure Fragility Curves 
6. Probabilistic Fragilities for Surrogate Containments

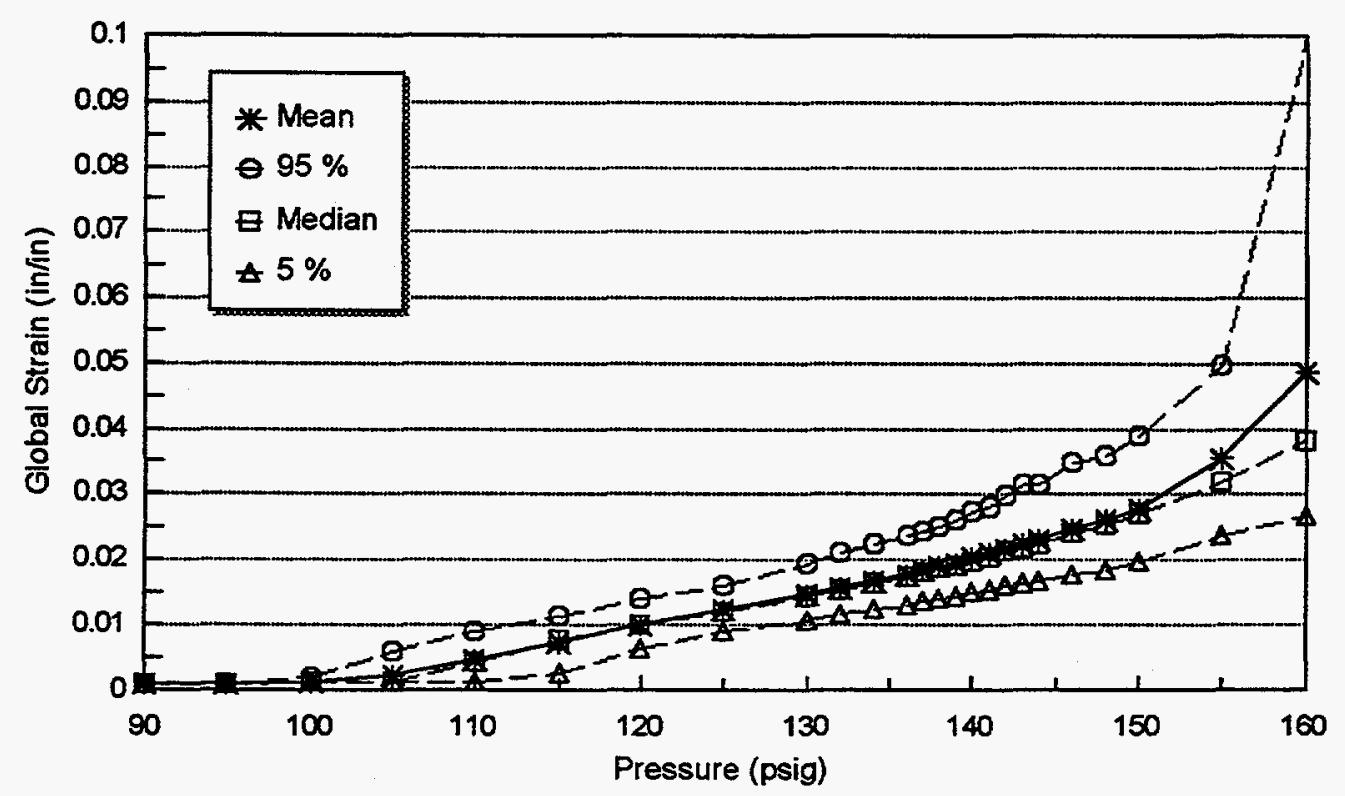

Figure 6.8 Cylindrical Steel Surrogate Free-Field Hoop Strain vs. Pressure SA-516 Grade $70 @ 400^{\circ} \mathrm{F}$

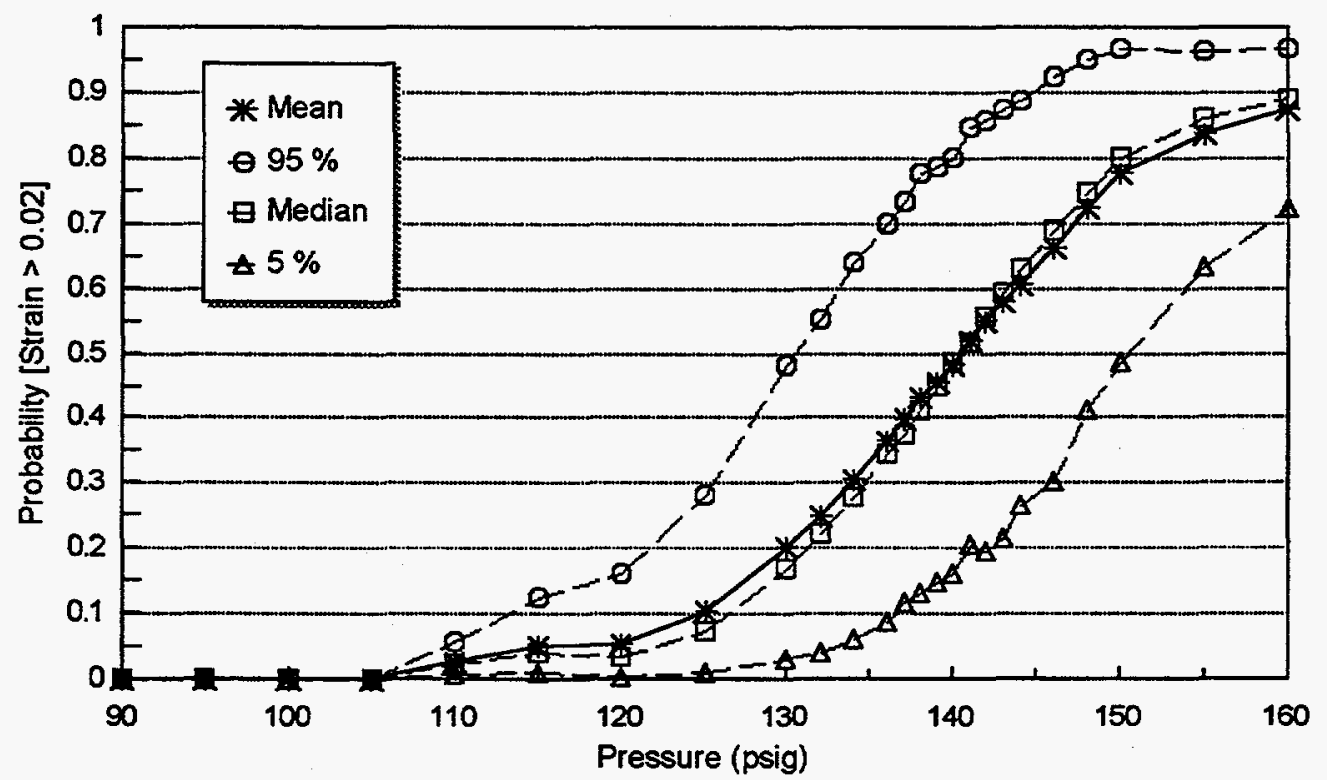

Figure 6.9 Cylindrical Steel Surrogate Overpressure Fragility Curves SA-516 Grade70@400F 
6. Probabilistic Fragilities for Surrogate Containments

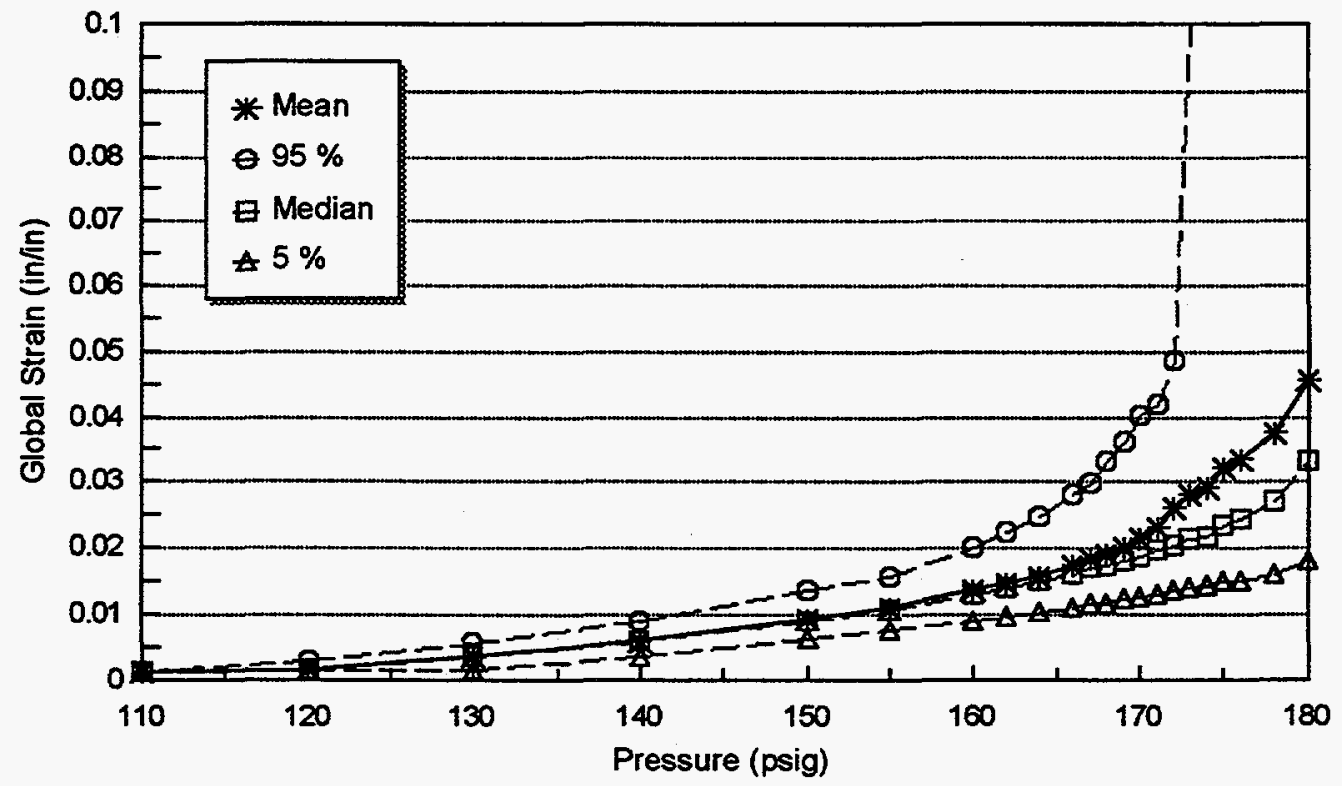

Figure 6.10 Cylindrical Steel Surrogate Free-Field Hoop Strain vs. Pressure SA-537 Class $2 @ 400^{\circ} \mathrm{F}$

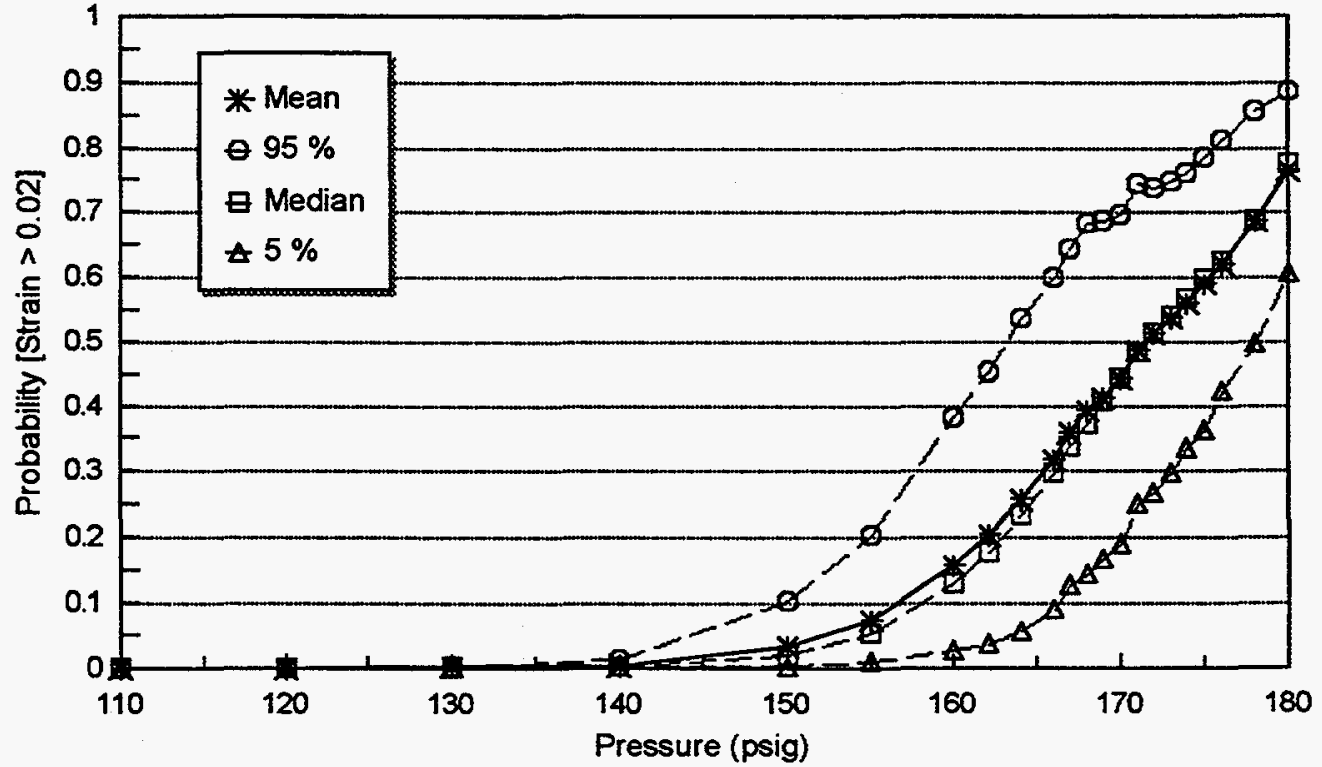

Figure 6.11 Cylindrical Steel Surrogate Overpressure Fragility Curves SA-537 Class $2 @ 400^{\circ} \mathrm{F}$ 


\section{CONDITIONAL CONTAINMENT FAILURE PROBABILITIES}

As described in Chapter 1, the U. S. NRC's Severe Accident Safety Goal is to have the conditional containment failure probability (CCFP) (given a severe accident) be 0.1 or less. If the distribution of severe accident pressures (at a given temperature) is known, then the conditional containment failure probability is computed from:

$$
C C F P=\int_{0}^{\infty} F_{\text {fal }}(p) f_{\text {Pres }}(p) d p
$$

where

$$
\begin{aligned}
& C C F P= \begin{array}{l}
\text { Conditional containment failure } \\
\text { probability }
\end{array} \\
& F_{\text {fari }}(p)=\begin{array}{l}
\text { Cumulative distribution of containment } \\
\text { failure pressure (i.e., the containment } \\
\text { overpressure fragility) }
\end{array} \\
& f_{\text {Prass }}(p)=\begin{array}{l}
\text { Probability density function of severe } \\
\text { accident pressure }
\end{array}
\end{aligned}
$$

The containment overpressure fragilities for the surrogate containments considered in this report were presented in Chapter 6.

The severe accident policy is not specific as to what severe accidents are to be included (and at what level of likelihood). There are, of course, a wide range of severe accident scenarios which could potentially result in abnormal pressures inside containment (i.e., station blackouts, LOCAs due to pipe failures, ATWS events, etc.).). Overpressurization can be enhanced by direct containment heating $(\mathrm{DCH})$, core-concrete interactions, and hydrogen deflagration or detonation.

Within the scope of this project, it was not possible to attempt to characterize the anticipated pressure distributions for severe accident scenarios specific to individual reactor types. However, it was felt desirable to put the containment overpressure fragility curves (derived in Chapter 6) into perspective. To this end, the results of an NRC-sponsored program at Sandia National Laboratories (whose goal was to develop a methodology to resolve the $\mathrm{DCH}$ issue for pressurized water reactors) were utilized. In this program, detailed evaluations of pressures resulting from a variety of DCH scenarios were made for the Surry and Zion nuclear power plants (as reported in references 7-1 and 7-2). The methodology was then used to extrapolate the DCH pressure loads to 28 Westinghouse PWRs (both large dry and subatmospheric containments) as reported in NUREG/CR-6338 [Ref. 7-3].

Tables 7.6, 7.7, and 7.8 of NUREG/CR-6338 present the mean and standard deviations of the containment pressures resulting from the most severe $\mathrm{DCH}$ scenarios out of the wide variety of scenarios considered (scenarios VI and VIa.) The twenty-four highest pressure distributions from the 41 plants considered are reproduced in Figure 7.1 of this report. As can be seen, there is a fair degree of consistency between them. The highest median pressure is about $71 \mathrm{psig}$, and the majority of the curves have a logarithmic standard deviation of about 0.1. Only two of these have logarithmic standard deviations approaching 0.3. Also shown on this figure is a bounding pressure distribution (the heavy solid line). This bounding curve has a median equal to the largest median in the set of curves, and a logarithmic standard deviation of 0.3 . Using this bounding pressure distribution with any of the surrogate containment fragility curves will give an upper bound the CCFP which would be obtained if any of the individual (plant-specific) pressure distributions were used.

Of course, this is very much a bounding analysis, for the plant specific DCH pressure distributions depend very much on the containment type, free volume and other plant specific details. However, as will be seen, useful generalizations will result.

The "bounding curve" pressure distribution shown in Figure 7.1 was taken as a lognormal probability distribution characterized with a median of $71 \mathrm{psig}$ and logarithmic standard deviation $\left(\beta_{c}\right)$ of 0.3 . This pressure distribution was convolved with the overpressure fragility curves for the four surrogate containment designs using equation 7-1. The results are shown in Table 7.1. As can be seen, the mean conditional containment failure probabilities for the reinforced concrete cylinder, the prestressed concrete cylinder and the SA-516 Grade 70 steel cylinder containments are all on the order of 0.01-0.02. That is, they are all a factor of 5-7 smaller than the safety goal of 0.1. In addition, the mean CCFP for the SA-537 steel cylinder containment is 0.0017 , or about a factor of 50 smaller. Thus, when using a bounding pressure distribution derived for 28 Westinghouse PWRs, the surrogate containment designs all result in capacities which give conditional containment failure probabilities 
well below the NRC's severe accident safety goal of 0.1 given a severe accident.

Another perspective can be obtained using the $\mathrm{DCH}$ pressure distributions. In this case, the pressure distribution uncertainty was varied between 0.1 and 0.3 (the range from the DCH curves) and the median pressure was increased until, for each of the four surrogate containments, a CCFP of 0.1 was obtained. The results of this sensitivity study are shown on Table 7.2. As can be seen, for both concrete containment types, the median pressure to cause a CCFP of 0.1 varied between 93 and 115 psig, depending on the particular value of pressure distribution uncertainty assumed. The corresponding pressure range for the SA516 steel containment was about the same. However, the pressure range for the SA-537 steel containment was significantly higher (134-147 psig). Again, this is due to the increased strength of the SA-537 steel.

The implications of this study are two-fold. First, even when a conservative bounding pressure load distribution is used in conjunction with the overpressurization fragility curves for the four surrogate containment designs, the computed CCFP is significantly below the 0.1 safety goal. Second, the median pressure causing a CCFP $=0.1$ is at last twice the design pressure for the four containment designs. Thus a deterministic margin of about 1.7 to pressure causing first yield (as described in Chapter 5) has translated into a margin of 2 or more to the pressure at which the CCFP is 0.1 or less.

\subsection{References}

7-1. Pilch, M. M., et. al., The Probability of Containment Failure by Direct Containment Heating in Zion," NUREG/CR-6075, SAND931535, Sandia National Laboratories, 1994.

7-2. Pilch, M. M., et. al., The Probability of Containment Failure by Direct Containment Heating in Surry," NUREG/CR-6109, SAND93-2078, Sandia National Laboratories, 1995.

7-3. Pilch, M. M., et. al., Resolution of the Direct Containment Heating Issue for all Westinghouse Plants with Large Dry Containments or Subatmospheric Containments, NUREG/CR-6338, Sandia National Laboratories, 1995. 
Table 7.1 Conditional Containment Failure Probabilities for Four Surrogate Containments using a Bounding DCH Severe Accident Load Case

\begin{tabular}{|l|c|c|c|}
\hline $\begin{array}{l}\text { Surrogate } \\
\text { Type }\end{array}$ & $\begin{array}{c}\text { Median Accident } \\
\text { Pressure } \\
\text { (psig) }\end{array}$ & $\begin{array}{c}\text { Uncertainty } \\
\left(\beta_{\mathrm{C}}\right)\end{array}$ & $\begin{array}{c}\text { Conditional Containment } \\
\text { Failure Probability } \\
\text { (CCFP) }\end{array}$ \\
\hline Reinforced Concrete Cylinder & 71 & 0.3 & 0.019 \\
\hline Prestressed Concrete Cylinder & 71 & 0.3 & 0.017 \\
\hline SA-516 Grade 70 Steel Cylinder & 71 & 0.3 & 0.013 \\
\hline SA-537 Class 2 Steel Cylinder & 71 & 0.3 & 0.0017 \\
\hline
\end{tabular}

Table 7.2 Median Severe Accident Pressures Yielding a CCFP of $10 \%$ for Four Surrogate Containments

\begin{tabular}{|c|c|c|c|}
\hline $\begin{array}{l}\text { Surrogate } \\
\text { Type }\end{array}$ & $\begin{array}{l}\text { Conditional Containment } \\
\text { Failure Probability } \\
\text { (CCFP) }\end{array}$ & $\begin{array}{l}\text { Uncertainty } \\
\left(\beta_{c}\right)\end{array}$ & $\begin{array}{c}\text { Median Accident } \\
\text { Pressure } \\
\text { (psig) }\end{array}$ \\
\hline \multirow{3}{*}{$\begin{array}{l}\text { Reinforced } \\
\text { Concrete Cylinder }\end{array}$} & 0.10 & 0.1 & 113 \\
\hline & 0.10 & 0.2 & 102 \\
\hline & 0.10 & 0.3 & 93 \\
\hline \multirow{3}{*}{$\begin{array}{l}\text { Prestressed } \\
\text { Concrete Cylinder }\end{array}$} & 0.10 & 0.1 & 115 \\
\hline & 0.10 & 0.2 & 103 \\
\hline & 0.10 & 0.3 & 95 \\
\hline \multirow{3}{*}{$\begin{array}{l}\text { SA-516 Grade } 70 \\
\text { Steel Cylinder }\end{array}$} & 0.10 & 0.1 & 117 \\
\hline & 0.10 & 0.2 & 108 \\
\hline & 0.10 & 0.3 & 103 \\
\hline \multirow{3}{*}{$\begin{array}{l}\text { SA-537 Class } 2 \\
\text { Steel Cylinder }\end{array}$} & 0.10 & 0.1 & 147 \\
\hline & 0.10 & 0.2 & 136 \\
\hline & 0.10 & 0.3 & 134 \\
\hline
\end{tabular}


7. Conditional Containment Failure Probabilities

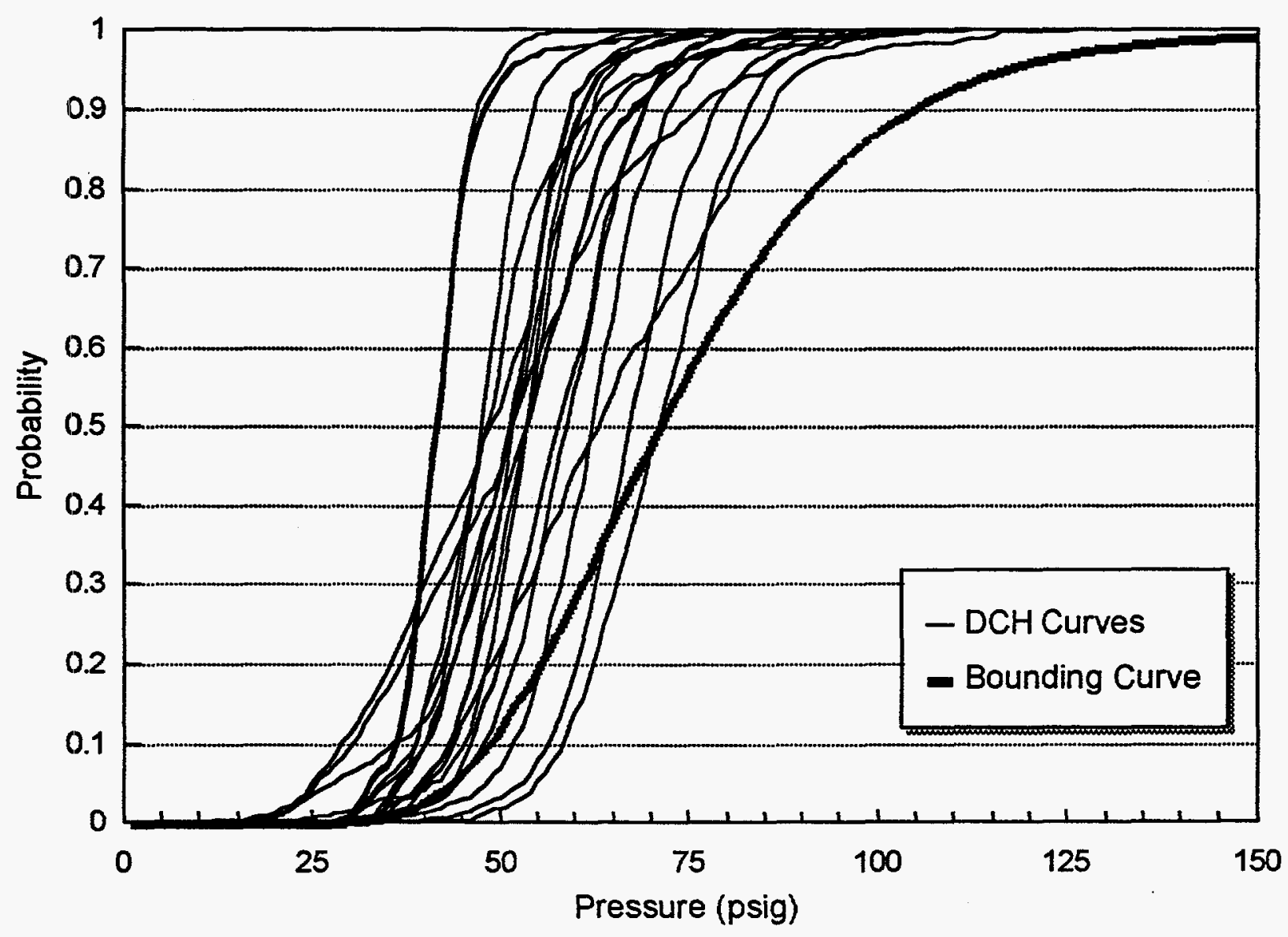

Figure 7.1 DCH Pressure Curves and Bounding Curve using Maximum Median Pressure and Maximum Uncertainty 


\subsection{CONCLUSIONS}

This report has examined the issues of containment design, margin to first yield, and probabilistic failure capacity. The original motivation for the program was to examine the relation between the NRC's safety goal of a conditional containment failure probability (CCFP) of 0.1 and the alternative acceptance criteria allowed for steel containments, which specifies that it is sufficient that the stresses should satisfy the ASME Level C allowables for severe accident pressures and temperatures. The underlying question of interest was whether or not a similar criterion could or should be developed for concrete containment designs which would provide the same level of margin as the alternative steel containment criterion.

In order to examine these questions, a prototypical set of steel and concrete containments (having the same design pressure and free volume) were defined, designed according to the applicable ASME codes and current design practice, and were deterministically analyzed - both for pressure to first yield and then pressure to failure. In addition, best estimate probabilistic overpressure failure distributions (fragilities) were developed for each design. Based on these analyses, a number of insights and conclusions with regard to the original questions driving the program can be reached.

First and foremost, the current ASME design practices and requirements for concrete containments are based on yield criteria. Similarly, although the design of steel containments are usually governed by some fraction of the ultimate allowable stress, the ASME Level C allowables are, in fact, based on (code specified) yield. Thus it was found that there is a commonality between the basic concrete design requirements in place today and the alternative Safety Goal criteria based on the Level $\mathrm{C}$ allowables for steel containments. In fact, as shown in Table 5.2 of this report, the margin to yield is approximately 1.7 above the design pressure for both concrete and steel containments. Thus there would seem to be no need for an additional alternative criteria for concrete containments in order to provide a similar level of margin to yield as that provided by the alternative Level $\mathrm{C}$ allowable criteria currently in place for steel containments.

The margin to failure was also examined both deterministically and probabilistically. It was found for the concrete surrogates that the margin to failure was about 2.9 times the design pressure. Similarly, for the cylindrical SA-516 Grade 70 steel containment, the margin to failure (for accident temperatures between $400^{\circ} \mathrm{F}$ and $600^{\circ} \mathrm{F}$ ) was about 3.0 to 3.1. Thus, again, it is seen that there is a high degree of consistency between the deterministic margins. When a cylindrical containment surrogate was designed with SA-537 Class 2 steel (which has significantly higher strength than the SA-516 Grade 70 steel) a somewhat higher margin to failure results. Note that the definition of failure was based on a global membrane hoop strain of $2 \%$ for the reinforced concrete containments and the steel containments, and a $1 \%$ hoop strain for the prestressed concrete containments. These failure definitions were based both on model test failure strains and reflect the presence of strain concentrations.

Although a strain failure criteria of $2 \%$ membrane hoop strain was specified (for steel and reinforced concrete containments), in reality, these types of containments might fail in general membrane (assuming no strain concentrations) at about $8 \%$. This would imply a strain concentration factor of about 4 was assumed for these studies which is probably appropriate for most localized areas in a containment were strain concentrations might occur. However, in some plant specific cases, it is possible to have higher strain concentration factors which could lower the global membrane failure strain and these would have to be addressed on a plant specific basis. On the other hand, the ratio between design pressure and median failure pressure determined for most of the surrogates ( 2.9 to 3.1 ) is comparable to the average median ratio for controlling failure modes computed for several IPE containment fragilities (2.7 to 3.4). In this study all plausible failure modes were considered as well as any strain concentration factors which might exist for each specific containment examined.

Finally, the question of the conditional containment failure probability (CCFP) associated with the surrogate containment designs could be addressed. In order to do this, a set of severe accident pressure loading distributions had to be identified and these were taken from an ongoing NRC study on direct containment heating (DCH). When these pressure distributions were convolved with the probabilistic overpressure failure distributions, it was found that the CCFP values were at least a factor of 5 under the stated NRC safety goal of 0.1. This shows that, for the global failure mechanisms assumed strain concentration factors implicit in the ultimate strain criteria used, containments designed 
8. Conclusions

according to current ASME rules for concrete containments and for steel containments would have CCFP values significantly less than the NRC's safety goal. Alternatively, it was found that, for pressure load distributions having a logarithmic standard deviation variation in the 0.1 to 0.3 range (which probably is typical for most severe accident scenarios) the median pressure distribution required to cause a CCFP value of 0.1 is at least twice the design pressure. That is, any pressure distribution (with the stated uncertainty range) having a median value less than twice the design pressure would be expected to have a CCFP value less than 0.1 and hence meet the NRC safety goal. Median pressures to failure $(\mathrm{CCFP}=0.50$ ) were just below a factor of 3 times the design pressure for containments designed according to the current requirements.

Thus it can be seen that, for the global failure modes and strain concentration factors considered in this study, the current design criteria for concrete containments are consistent with the alternative safety goal criteria for steel containments and both provide probabilistic containment failure probabilities less than 0.1 by a significant margin. Thus it is concluded that no additional criteria need be developed for concrete containments designed according to the current ASME requirements. 


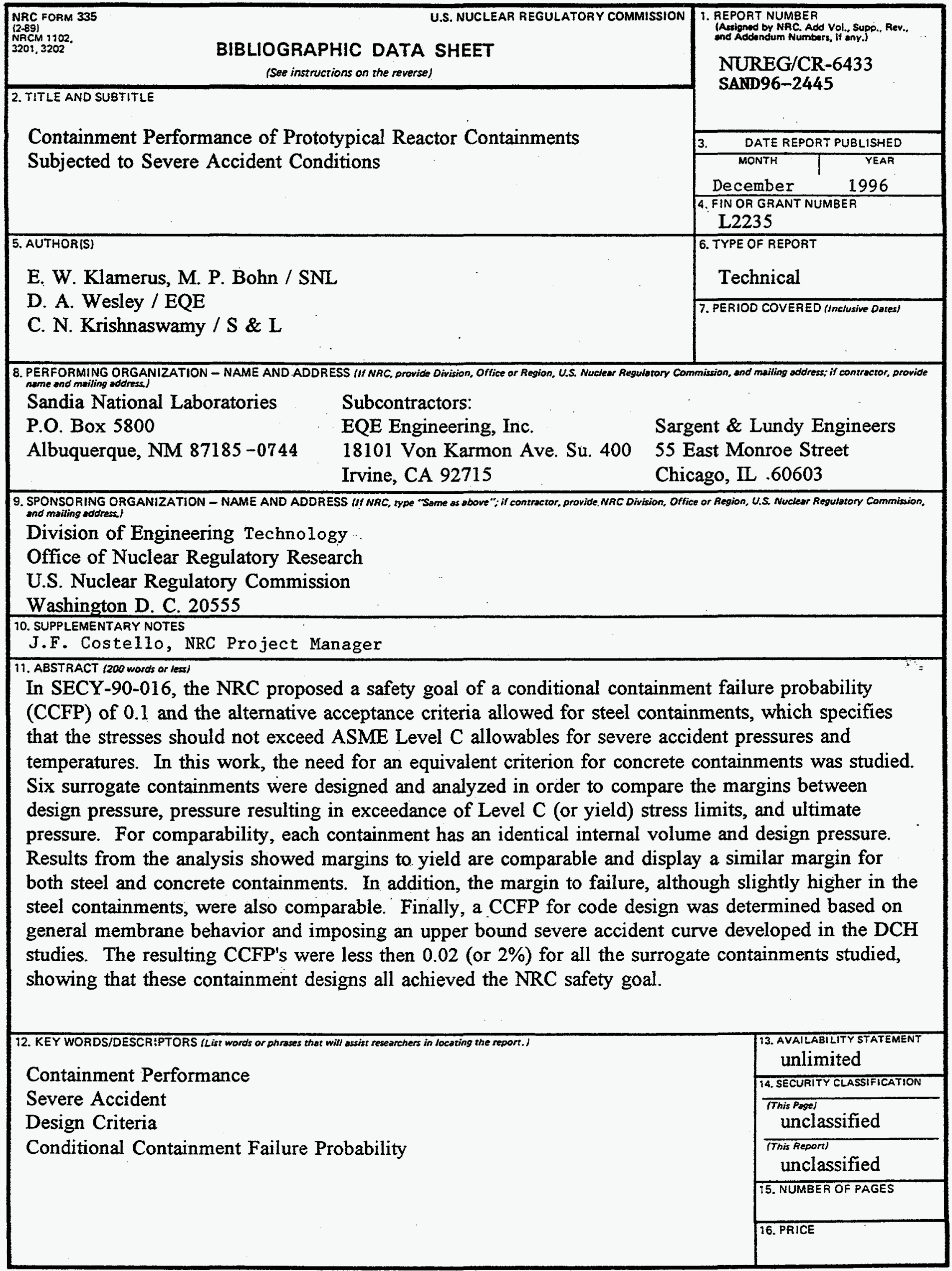

